\title{
CONTRIBUIÇÃO AO ESTUDO DA \\ INSTABILIDADE LATERAL DE VIGAS PRÉ-MOLDADAS
}

Maria CRISTINA ViDigal DE Lima

Tese apresentada à Escola de Engenharia de São Carlos da Universidade de São Paulo como parte dos requisitos para obtenção do título de Doutor em Engenharia de Estruturas.

ORIENTADOR: MOUNIR KHALIL EL DEBS 
Ficha catalográfica preparada pela seção de Tratamento

da Informação do Serviço de Biblioteca EESC/USP

$\mathrm{L} 732 \mathrm{C}$

Lima, Maria Cristina Vidigal de Contribuição ao estudo da instabilidade lateral de vigas pré-moldadas / Maria Cristina Vidigal de Lima. - São Carlos, 2002.

Tese (Doutorado) -- Escola de Engenharia de São Carlos-Universidade de São Paulo, 2002.

Área: Engenharia de Estruturas.

Orientador: Prof. Dr. Mounir Khalil El Debs.

1. Instabilidade lateral. 2. Torção. 3. Vigas prémoldadas. 4. Concreto armado. 5. Concreto protendido. I. Título. 
Ao meu pai e à minha mãe, é claro.

"Pai e mãe, ouro de mina, coração..."

Ao Francisco, com amor.

"Antes, e com tal zelo, e sempre e tanto." 


\section{A GRADECIMENTOS}

Ao meu orientador Prof. Mounir Khalil El Debs, por aceitar o desafio de um trabalho de doutorado, pela amizade, pelo apoio e pelos ensinamentos.

Ao Prof. Irineu da Silva do Departamento de Transportes, pelo grande apoio técnico na realização de nosso programa experimental. À Wild Comercial Ltda, pelo empréstimo das Estações Totais. Com muita gratidão, ao doutorando Artur Pantoja Marques e ao técnico Paulo Sérgio Batista (Paulinho), pela eficiência das leituras dos deslocamentos com as Estações Totais, pela gentileza e por cederem seu tempo em favor deste trabalho.

Ao meu marido Prof. Francisco, em especial, pelos incontáveis acompanhamentos técnicos. Acima de tudo, pela paciência generosa e querida, compreensão e ternura.

Ao Ismael Cadamuro Jr., pelo desprendimento em me oferecer o programa fonte, base da implementação numérica.

À todos os funcionários do Laboratório de Estruturas, pela paciência, pela amizade, pela colaboração, pela força física e moral. À Rosi e à Nadir, acima de tudo, pela amizade.

À CAPES, pelo apoio financeiro e programa sanduíche PDEE na Universidade de Toronto.

À todas as minhas queridas amigas e amigos, pela mão extendida e pela convivência feliz. Estou certa de que vocês sabem o quanto é terno e grato meu sentimento por cada um. Aline, teu apoio incondicional nestes 4 anos e nossa grande amizade são para mim uma benção. Ana Elisabete, Ana Rita, Crés, Felício, Lari, Regina, Rejane e Suzana, em especial, pelo trabalho extra que dei a vocês. A amizade de vocês foi o prêmio mais valioso.

Aos meus queridos irmãos Rod e Edu, minhas doces irmãs Dri e Cecé, porque existir sem vocês não seria tão maravilhoso. É isto! Indi e Pri, não os esqueceria.

À minha tia Neusa e à vovó Universa, lógico, vocês sabem muito bem porque. Amor e fé, todos os dias, longe mas sempre perto, não é pra qualquer um.

Meu pai e minha mãe, meu eterno e querido porto seguro, onde o amor tem mais de quatro dimensões e qualquer palavra diz pouco.

Acima de tudo, à Deus, pela vida, pelas oportunidades, pelo amor. E ao Espiritismo, por nortear com ternura e vigor meu espírito, por sustentar-me na fé, em todos os momentos de minha vida. 


\section{SUMÁRIO}

CAṔ́tULO 1 INTRODUÇÃO

1.1 CONSIDERAÇÕES INICIAIS

1.2 OBJETIVOS 3

1.2.1 Objetivo Geral 3

1.2.2 Objetivos Específicos 3

1.3 JUSTIFICATIVA 3

1.4 METOdOLOGIA 4

1.5 APRESENTAÇÃO DO TRABALHO 5

CAṔ́tulo 2 ESTADO da ARTE SObRE INSTABILIDAdE LATERAL EM Vigas DE 7 CONCRETO

2.1 CONSIDERAÇÕES INICIAIS

2.2 ESTUDOS ANTERIORES SOBRE INSTABILIDADE LATERAL EM
ELEMENTOS PRÉ-MOLDADOS DE CONCRETO ARMADO

Caṕttulo 3 Torção em Vigas de Concreto Armado 21

3.1 GENERALIDADES 21

3.2 CONSIDERAÇÕES SOBRE A TEORIA CLÁSSICA DE TORÇ̃̃o EM
ELEMENTOS HOMOGÊNEOS

3.3 Introdução aos Modelos de TRELIÇA Espacial Para TORÇÃO 23

3.4 TEORIAS DOS CAMPOS COMPRIMIDOS 27

3.4.1 Teoria dos Campos Comprimidos - CFT - $1973 \quad 27$

3.4.2 Teoria Diagonal dos Campos Comprimidos - DCFT - $1974 \quad 29$

3.4.3 Teoria Modificada dos Campos Comprimidos - MCFT $1986 \quad 32$

3.4.4 Breve Descrição do Modelo Teórico MCFT 33

3.5 TORÇÃO EM AÇÃO CONJUNTA COM FLEXÃO E FORÇA AXIAL 37

3.6 RigideZ À TORÇÃO EM ELEMENTOS DE CONCRETO ARMADO FISSURADOS POR FLEXÃO 38

Capítulo 4 Modelos Teóricos do Comportamento de Vigas DE 44 CONCRETO ARMADO SOB TORÇÃo, FleXão E ForÇa AXIAL

4.1 CONSIDERAÇÕES INICIAIS 44 4.2 MOdelo Estrutural de AÇões Combinadas SEgundo
COCCHI \& VOLPI (1996) 
4.2.1 Fundamentos da Análise Inelástica $\quad 45$

4.2.1.1 Hipóteses Básicas 46

4.2.2 O Modelo Estrutural 47

4.2.2.1 Deformação nos Elementos da Seção Transversal 47

4.2.2.2 Equações de Equilibrio e Esforços Resistentes 48

4.2.2.3 Equações de Compatibilidade $\quad 51$

4.2.2.4 Determinação da Espessura do Elemento 51

4.2.2.5 Leis Constitutivas $\quad 52$

4.2.2.6 Algoritmo com Sistema Não-Linear $\quad 55$

4.2.3 Cobrimento e Parcela Central da Seção Transversal 56

4.2.4 Resultados Numéricos e Experimentais 58

4.2.4.1 Modelagem com o Programa ANSYS 58

4.2.4.2 Resultados Obtidos 59

4.3 Rigidez À TORÇÃo SEgundo HANNACHI \& FOURÉ (1996) 63

4.3.1 Contribuição das Armaduras 65

4.3.2 Contribuição do Concreto $\quad 67$

4.3.3 Expressão do Módulo G 67

4.3.4 Expressão da Rigidez $\left(\mathrm{GJ}_{\mathrm{t}}\right)_{\mathrm{b}}$

4.3.5 Simplificações Complementares 68

4.4 Rigidez À TORÇÃO E POSIÇÃO DO CENTRO DE TORÇÃO
SEgUNDO FOURÉ \& HANNACHI (1999)

4.4.1 Cálculo das características à torção apenas do concreto na seção da fissura e da posição do centro de torção $\quad 78$

4.4.1.1 Caso em que a seção comprimida é um retângulo 78

4.4.1.2 Caso da seção duplo T

Caṕtulo 5 Programa Computacional Tritor Para Análise 80 NÃO-LINEAR DE ESTRUTURAS

5.1 CONSIDERAÇÕES INICIAIS 80

5.2 RECURSOS DisPonívEIS NO PROGRAMA TRITOR 81

5.3 CÁlCUlo do ESTAdo DE DEFormaÇÃo do ElEMENTO 82

5.4 CÁlCULO DOS ESFORÇOS RESISTENTES 84

5.5 LEIS CONSTITUTIVAS DOS MATERIAIS 84

5.5.1 Concreto à Compressão 84

5.5.2 Concreto à Tração e Zona de Enrijecimento 85

5.5.3 Armaduras Longitudinais 86

5.6 ESFORÇOS NODAIS NAS COORDENADAS LOCAIS DO
ELEMENTO FINITO

5.7 RIgIDEZ À TORÇÃO APROXIMADA POR DIAGRAMA BI-LINEAR 87

5.8 PARÂMETROS NECESSÁRIOS AO CÁLCULO DA RIGIDEZ À
TORÇÃO SEGUNDO HANNACHI \& FOURÉ (1996)

5.9 CONTRIBUiÇÃO DO NúClEO NÃO-FISSURADO NO MODELO
ESTRUTURAL DE COCCHI \& VOLPI (1996)

5.10 FluXograma Geral do Programa 90

CAṔtTLLO 6 Programa EXPERIMENTAL 92

6.1 CONSIDERAÇÕES INICIAIS 92

6.2 MOTIVAÇÃO DO ENSAIO 92

6.3 CARACTERÍSTICAS GEOMÉTRICAS E DETALHAMENTO 95

6.4 EXECUÇÃO E DOSAGEM DO CONCRETO DE GRANULOMETRIA
FINA 
6.4.1 Instrumentação dos Modelos $\quad 98$

6.5 APARELHO DE APOIO ESFÉRICO 100

6.6 PROCEDIMENTOS DO ENSAIO 103

6.6.1 Ilustração de Algumas Etapas de Giro imposto 106

6.7 RESPOSTAS EXPERIMENTAIS 111

6.7.1 Extensômetros no Concreto 111

6.7.2 Extensômetros nas Armaduras 112

6.7.3 Estações Totais 114

6.8 SimUlaÇÃO NUMÉRICA DAS VIGAS V1 E V2 ENSAIADAS 117

6.8.1 Comparação entre Resultados Numéricos e Experimentais 118

6.8.1.1 Deslocamentos Laterais e Verticais 118

6.8.1.2 Deformação no Concreto 120

6.8.1.3 Deformação nas Armaduras 122

6.8.2 Momentos de Inércia Vertical e Lateral 123

6.8.3 Quadro de Fissuração - Respostas Numéricas das Vigas V1 e V2 123

6.8.4 Quadro de Escoamento das Armaduras - Resposta Numérica 125

6.8.5 Rigidez à Torção - Resposta Numérica 126

6.9 CONSIDERAÇÕES FINAIS 126

CAṔ́tULO 7 ANÁlISE DE Resultados EXPERIMENTAIS E 127 EXEMPLOS DE APLICAÇÕES

7.1 CONSIDERAÇÕES INICIAIS 127

7.2 GRELHA ENSAIADA POR COLLINS \& LAMPERT (1973) 127

7.3 Viga ENSAIADA POR ONSONGO (1978) - TORÇÃO

7.4 Viga Submetida À Flexão lateral e Vertical com TORÇÃO 135

7.5 Viga PROTENDIDA ENSAIADA POR MAST (1994) 139

7.5.1 Simulação numérica da Fase de Içamento com Apoios
Deformáveis

7.5.1.1 Suspensão sem balanços 146

7.5.1.2 Suspensão com balanços 147

7.5.2 Fatores de Segurança Segundo Mast (1993) 149

7.6 TESOURA PROTENDIDA 152

7.6.1 Considerações da Modelagem Numérica 153

7.6.2 Simulação numérica da Fase de Içamento com Apoios
Deformáveis

7.6.2.1 Consideraçoes Finais do Içamento da Tesoura Protendida 157

7.6.3 Içamento com Cabos Inclinados 158

CAṔTULO 8 CONSIDERAÇÕES FINAIS E CONCLUSÕES 161

8.1 SíNTESE DO TRABALHO E CONCLUSÕES 161

8.2 SUgESTÕES PARA TRABALHOS FutUROS 164

CAPITULO 9 REFERÊNCIAS BIBLIOGRÁFICAS E BiBLIOGRAFIA CONSULTADA 165 


\section{RESUMO}

Lima, M. C. V. (2002). Contribuição ao estudo da instabilidade lateral de vigas pré-moldadas. São Carlos. 170p. Tese (Doutorado) - Escola de Engenharia de São Carlos, Universidade de São Paulo, Brasil.

A verificação da estabilidade lateral de vigas pré-moldadas merece maior atenção em vigas longas e delgadas, especialmente durante as fases transitórias, como o içamento e o transporte, e também quando se leva em conta a deformabilidade das ligações temporárias.

Apresenta-se nesta tese, um estado da arte sobre o problema da instabilidade lateral em vigas pré-moldadas, a fim de situar este trabalho no contexto técnico atual, bem como estudos anteriores relacionados à torção pura e quando associada a outras solicitações.

Alguns modelos numéricos foram implementados computacionalmente a fim de simular o comportamento não-linear físico de vigas de concreto armado e protendido sob ação conjunta de torção, flexão bi-lateral e força axial.

O modelo adequado a situações onde a torção é predominante sobre a flexão baseia-se na analogia ao comportamento de treliça espacial e na extensão da teoria dos campos diagonais comprimidos. Os resultados numéricos obtidos foram satisfatoriamente comparados aos experimentais disponíveis na literatura técnica.

Nos casos onde a flexão é predominate, utilizou-se um modelo numérico que permite calcular a rigidez à torção após a fissuração por flexão da viga, sendo este o recomendado para as análises das fases transitórias de içamento por cabos. Duas vigas longas e esbeltas de concreto armado, sob tombamento lateral gradual e ação única do peso-próprio, foram moldadas e ensaiadas no laboratório. Os resultados experimentais obtidos serviram para validar o modelo numérico. No ensaio, a utilização de Estações Totais para medidas de deslocamentos mostrou ser uma boa alternativa, comparando-se bem aos resultados numéricos calculados. As medidas experimentais das deformações no concreto e nas armaduras concordaram satisfatoriamente com as respostas numéricas.

$\mathrm{Na}$ aplicação à elementos estruturais com protensão, o comportamento numérico obtido para uma viga protendida de ponte de seção I, sob tombamento lateral gradual, comparou-se satisfatoriamente com a resposta experimental. Enfim, a medida da segurança do içamento de uma viga protendida de ponte e de uma tesoura protendida de cobertura foi calculada numericamente, considerando apoios deformáveis à torção. Os resultados numéricos mostram a importância de se escolher adequadamente o comprimento dos balanços, bem como a inclinação dos cabos de suspensão, garantindo a estabilidade da viga.

Palavras-chave: instabilidade lateral, torção, vigas pré-moldadas, concreto armado, concreto protendido. 


\section{A B STRACT}

Lima, M. C. V. (2002). On the lateral stability of precast concrete beams. São Carlos. 170p. Ph.D. Dissertation - Escola de Engenharia de São Carlos, Universidade de São Paulo, Brazil.

The lateral stability of long and slender precast concrete beams requires great attention. In particular, it is important to ensure the stability of these members during transitory phases like tilting and transport, and also when the deformability of temporary supports is taken into account.

The state of the art of the problem of lateral stability in precast concrete beams is presented in order to place this work in the current technical context. Previous studies of the problem of pure torsion and combined loading are reviewed.

Numerical models considering the physical non-linear behavior of reinforced and prestressed concrete beams subjected to combined torsion, bi-axial bending and axial loads were implemented.

The appropriate model when torsion dominates over bending is based on the space truss model and an extension of the diagonal compression field theory. The numerical results obtained compared satisfactorily with the experimental ones available in the technical literature.

In bending dominated cases, a numerical model that evaluates the torsional stiffness in a cracked state due to bending is recommended for the analyses of temporary phases such as tilting. Two slender reinforced concrete beam models were built and tested under controlled gradual tilting conditions and self-weight action. These experimental results were used to validate the numerical model. Experimental results obtained using Total Stations for measuring displacements showed to be a good alternative, comparing well with those provided by the numerical model. The experimental measures of deformations in concrete and steel agreed well with the numerical calculations.

Good agreement between numerical and experimental results was obtained for a prestressed concrete I-beam gradually tilted. Finally, a numerical analysis considering the flexibility of the supports of a prestressed concrete I-beam and a prestressed concrete truss with variable cross-section was carried out. The numerical results showed the importance of choosing the appropriate overhang length as well as the inclination of the suspension cables, in order to ensure the stability of the beam.

Keywords: lateral stability, torsion, precast beams, reinforced concrete, prestressed concrete. 


\section{Capítulo}

\subsection{CONSIDERAÇÕES INICIAIS}

No projeto das estruturas pré-moldadas é necessário considerar todas as etapas que compõem a produção do elemento até a sua disposição final na estrutura. Em geral, estas fases podem ser divididas em fase de serviço e fases transitórias, sendo estas últimas, referentes a todas as situações provisórias, como é o caso do transporte e do manuseio para montagem.

Dois tipos de problemas críticos com relação à instabilidade lateral podem ser analisados nas situações provisórias. Um deles é o caso das vigas de pontes, normalmente longas e delgadas, e geralmente protendidas, durante a fase de içamento por meio de cabos e guindastes. O outro é o caso de vigas convencionais de edifícios durante a fase de montagem, quando as ligações dos apoios são ainda precárias e muitas vezes insuficientes até para impedir perda de equilíbrio como corpo rígido, o que pode ser visualizado na Figura 1.1.

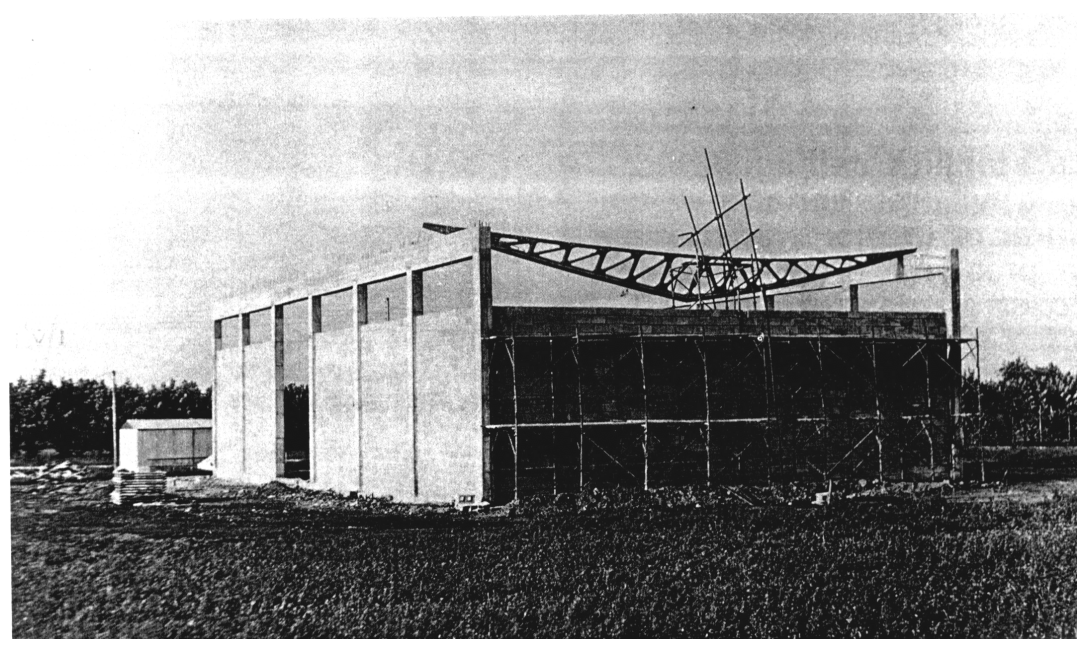

Figura 1.1 - Perda de equilíbrio como corpo rígido de uma viga pré-moldada. Catania \& Coccbi (1976).

Elementos estruturais com seções delgadas e de grande comprimento são mais susceptíveis a apresentarem perda de estabilidade lateral. Por este motivo, os elementos pré-moldados sujeitos ao colapso por instabilidade lateral devem apresentar rigidez lateral suficiente para evitar a redução da capacidade resistente, por excesso de deformação ou fissuração.

Por outro lado, a maioria dos problemas de instabilidade lateral em vigas longas e esbeltas ocorre quando os apoios apresentam liberdade ao giro por flexão e torção. Estes vínculos podem ser, no caso de elementos de pontes, ligações provisórias como 
mostra a Figura 1.2, comuns na fase de suspensão ou transporte, ou ainda, ligações finais da estrutura no período de utilização. Considerar a deformabilidade das ligações consiste em uma análise mais real com relação à fase de serviço.

Além dos graus de liberdade apresentados pelos vínculos, é importante considerar, para efeito do estudo da instabilidade, as inevitáveis imperfeições construtivas e os desvios de montagem.

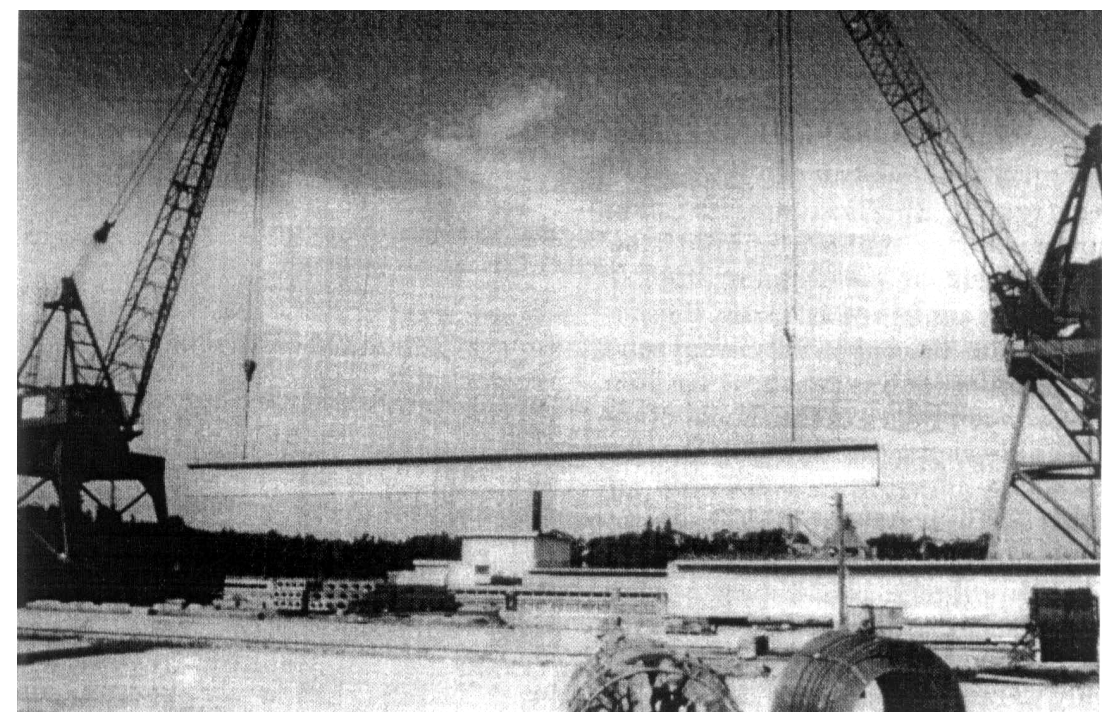

Figura 1.2 - Transporte de uma viga pré-moldada de concreto com cabos. Imper \& Laszlo (1987).

As imperfeições geradas na fase construtiva do elemento pré-moldado são basicamente provocadas pelo controle ineficaz do posicionamento das armaduras, pela não homogeneidade da peça moldada, pelos erros de posicionamento das fontes de calor na cura acelerada ou gradientes térmicos, pela retração diferenciada entre as faces laterais do elementos, pela má execução da protensão, apresentando perdas excessivas e não controladas. Tais variações causam curvatura horizontal no elemento durante a sua fabricação.

O posicionamento dos pontos de suspensão feito de forma imprevista, por exemplo, o içamento com balanços sem prévia consideração de projeto, pode acarretar uma série de inconvenientes ao elemento, resultando no aparecimento de tensões de tração em pontos onde estas tensões não eram esperadas, podendo ocorrer fissuração de algumas seções, o que altera a rigidez da peça.

Durante o transporte das vigas longas, os efeitos dinâmicos variam em intensidade conforme as condições da pista de rolamento, a elasticidade do sistema de amortecimento do meio e dos vínculos, a elasticidade do elemento estrutural, dentre outros fatores. O aparecimento das fissuras nas seções das vigas pode ser provocado pelas excessivas solicitações causadas por um incorreto ou mal posicionamento do elemento na carreta. Também ocorrem, durante a passagem do veículo sobre as curvas e superelevações, cujos desníveis, não sendo compensados pelo sistema hidráulico do aparelho de apoio, resultam em esforços de torção ao longo do comprimento da viga. Estes fatores contribuem de forma singular com a instabilidade do elemento. 


\subsection{OBjETIVOS}

\subsubsection{OBJETIVO GERAL}

Contribuir no estudo da estabilidade lateral de vigas pré-moldadas durante as fases transitórias, as quais constituem o período crítico no tratamento de problemas de instabilidade. Estas fases transitórias serão consideradas para análise de peças longas e delgadas de concreto pré-moldado, especialmente durante o manuseio por cabos para içamento da peça, bem como durante o período de montagem do elemento na posição definitiva, enquanto as ligações são ainda provisórias.

\subsubsection{OBjeTIVOS ESPECífICOS}

1. Contribuir no estudo do comportamento das peças de concreto armado e protendido submetidas à ação conjunta de torção, flexão e força axial.

2. Desenvolver procedimentos para a verificação da estabilidade de vigas de concreto pré-moldado nas fases provisórias de montagem, incluindo a fase de içamento, tendo em vista a segurança contra a instabilidade lateral.

\subsection{JUSTIFICATIVA}

Segundo Elliott (1997), 3/4 dos problemas relacionados à utilização do concreto prémoldado estão relacionados com as fases transitórias, principalmente a montagem. Por isto, acredita-se ser de fato necessária a verificação da estabilidade para a fase temporária, como parte integrante dos procedimentos de projeto em geral. Acrescentase ainda que, a seqüência de montagem deve ditar as considerações de projeto.

Twelmeier \& Brandmann (1985), dentre outros, observaram que os riscos de instabilidade lateral aumentaram consideravelmente devido à esbeltez das vigas pré-fabricadas de concreto armado com grandes vãos. Mas, ao contrário das estruturas de aço, uma solução matemática para este problema em vigas de concreto armado é muito difícil, uma vez que a rigidez à flexão e à torção dependem da intensidade do carregamento e da propagação da fissuração, que é variável ao longo do eixo longitudinal da viga.

O estudo apresentado por Lima (1995) permite, como uma primeira aproximação, o cálculo da carga crítica de instabilidade lateral resultante do limite de instabilidade elástica, a partir do qual, ocorre mudança de equilíbrio em teoria de segunda ordem. Conhecida a carga crítica, pode-se escrever expressões aproximadas para a rigidez reduzida. Porém, estas não correspondem às reais condições de forma satisfatória, uma vez que o problema da instabilidade lateral deve ser tratado levando-se em conta as deformações da viga.

A rigidez à flexão pode ser calculada de forma satisfatória apenas se não houver torção, ou quando esta é pequena, uma vez que a variação da efetiva rigidez à torção não é ainda bem conhecida.

Vale lembrar ainda que o carregamento da viga nas fases transitórias resume-se ao pesopróprio do elemento estrutural, podendo existir eventuais solicitações laterais devido ao vento. Porém, as fases temporárias de montagem podem não apresentar vinculações adequadas para limitar os efeitos de instabilidade, que pode ser desencadeada pelas inevitáveis imperfeições construtivas da peça. 
Enfim, em peças de concreto armado e protendido, a deformação do elemento acarreta a fissuração da peça, reduzindo a rigidez da seção transversal, por efeitos combinados de torção e flexão. Considerar esta redução no decorrer na deformação, bem como a sua interação com o tipo de vinculação da fase de montagem ou pré-serviço, depende de um razoável conhecimento do comportamento estrutural da peça de concreto.

Desta forma, justifica-se um estudo adequado para conhecer o comportamento de peças estruturais de concreto armado em condições temporárias, de forma mais realista, onde as leis constitutivas dos materiais são consideradas, bem como o estudo do equilíbrio levando em conta a mudança de geometria do elemento estrutural.

Além destes fatores agravantes do colapso por instabilidade lateral, tem-se a influência da deformabilidade das ligações provisórias, típicas das fases de montagem, intensificando os riscos de perda de estabilidade.

\subsection{Metodologia}

O problema da instabilidade lateral em vigas de concreto armado depende, em primeiro lugar, da diminuição da rigidez à flexão e à torção nas vigas devido à fissuração da mesma. $\mathrm{Na}$ instabilidade lateral, a flexão principal é acompanhada por pequenos momentos laterais e torção.

Uma vez que a rigidez à flexão varia em função da intensidade do carregamento e das leis constitutivas dos materiais, observa-se que a resistência à torção altera-se em peças fletidas fissuradas. Neste trabalho, serão utilizados alguns algoritmos disponíveis na literatura técnica a fim de descrever o comportamento de peças solicitadas por ação conjunta de flexão vertical e lateral, torção e força axial. Estes modelos numéricos estruturais são: o modelo proposto por Leung \& Schnobrich (1987), reformulado por Cocchi \& Volpi (1993,1996), e o método apresentado por Hannachi \& Fouré (1996) e Fouré \& Hannachi (1999).

Em linhas gerais, existe uma diferença básica entre os dois modelos acima definidos, referente à predominância ou não da torção sobre a flexão na seção transversal em análise. O modelo utilizado por Cocchi \& Volpi (1996) estuda o mecanismo estrutural por meio do modelo de treliça espacial, onde a porção central da seção transversal da viga é desprezada. A seção transversal é discretizada em elementos retangulares ao longo das paredes da seção. Calculam-se, para cada elemento, a espessura, o ângulo de inclinação das bielas comprimidas de concreto, verificando-se, para toda a seção, o fluxo de cisalhamento que satisfaz as condições de equilíbrio e compatibilidade, levando-se em conta as leis constitutivas dos materiais. Assim, a fim de verificar a convergência numérica, deve-se ter que a solicitação predominante da seção é o momento de torção. Além disto, o algoritmo descreve apenas o comportamento do trecho fissurado por torção.

Embora o modelo estudado por Cocchi \& Volpi (1996) descreva o comportamento estrutural para ações combinadas de torção e flexão, o mesmo não é adequado ao tratamento de problemas de instabilidade lateral, quando a flexão é solicitação predominante. Entretanto, a literatura técnica encontra-se muito limitada com relação ao conhecimento da variação da rigidez à torção. Estudos de torção pura em peças de concreto armado tem sido utilizados nos casos de flexão combinada com torção, por meio de procedimentos simplificados. Lampert (1973) apresenta um trabalho onde estuda a rigidez à torção de vigas fissuradas de concreto armado sob ação conjunta de 
torção e flexão. Nesse trabalho, Lampert (1973) apresenta expressões teóricas simplificadas para o cálculo da rigidez após a fissuração. Para as situações onde a torção não é predominante sobre a flexão, Lampert (1973) recomenda adotar a mesma expressão para rigidez à torção após a fissuração, como se a solicitação fosse de torção pura. Isto se deve ao fato da contribuição da zona comprimida não fissurada na rigidez à torção da seção ser desconhecida, e também, porque a inclinação das bielas comprimidas na face tracionada não pode mais ser adotada igual à $45^{\circ}$, à medida em que se aproxima da flexão pura.

Enfim, a formulação utilizada por Cocchi \& Volpi (1996) serve, neste trabalho, como uma ferramenta numérica para melhor conhecimento da influência da torção na definição do mecanismo estrutural de fissuração e ruína, tanto como ação isolada, como quando em ação conjunta com flexão vertical e lateral e força axial, desde que seja solicitação predominante.

O modelo descrito por Hannachi \& Fouré (1996) destina-se aos casos onde a flexão é a solicitação predominante. Hannachi \& Fouré (1996) apresentam um método para o cálculo da rigidez à torção de vigas de concreto armado, fissuradas por flexão e submetidas a pequenos momentos de torção. Neste modelo, os citados autores consideram a influência da forma da seção transversal, do estado de fissuração e do efeito de pino gerado pelas armaduras longitudinais.

$\mathrm{Na}$ tarefa de estudar a instabilidade lateral de vigas pré-moldadas, foi implementado numericamente os algoritmos anteriormente citados em um programa de pórtico tridimensional, considerando que a resposta da estrutura para um estado de carregamento não é linear. Esta resposta não-linear está associada às características do comportamento mecânico dos materiais constituintes da estrutura, caracterizando a não-linearidade física. Tem-se enfim, um procedimento incremental-iterativo, resultante da aplicação de etapas de carregamento até a verificação do equilíbrio estrutural.

Foram ensaiadas duas vigas longas e esbeltas de concreto armado submetidas a um tombamento lateral gradual, a fim de validar o programa numérico desenvolvido, bem como avaliar o efeito da torção sobre a flexão e vice-versa, no comportamento geral da peça.

As ligações foram representadas, no programa computacional desenvolvido, por meio de elementos de molas, os quais permitem a consideração de nós semi-rígidos. O programa ANSYS também foi utilizado neste trabalho como ferramenta numérica, na tarefa de modelar vigas de concreto armado através de elementos finitos tridimensionais sólidos, e portanto, com malhas transversais e longitudinais, e elementos de barra espaciais, no tratamento via método dos elementos finitos.

\subsection{APRESENTAÇÃO DO TRABALHO}

O Capitulo 2 apresenta uma breve introdução ao estudo da instabilidade lateral, dentro do contexto atual.

Um histórico resumido do estudo da torção em vigas de concreto armado encontra-se descrito no Capitulo 3, a fim de esclarecer o tipo de mecanismo estrutural que melhor representa as solicitações atuantes. O modelo teórico de treliça espacial aplicada à torção é discutido em linhas gerais neste capítulo juntamente com as teorias dos campos 
comprimidos e algumas propostas disponíveis na literatura técnica para o cálculo da rigidez à torção pós-fissuração.

No Capitulo 4 apresenta-se a teoria dos modelos numéricos implementados neste trabalho, seus fundamentos, hipóteses e aplicações. Estes modelos contemplam os casos onde a torção é predominante na definição do mecanismo estrutural de ruína e aqueles onde a flexão é solicitação dominante, com redução da rigidez à torção da peça.

O programa computacional implementado e apresentado no Capitulo 5 consiste em um programa de pórticos tri-dimensionais cujo comportamento não-linear dos materiais pode ser considerado pelos modelos numéricos implementados.

O programa experimental desenvolvido no laboratório do Departamento de Estruturas é apresentado no Capitulo 6. Neste, foram ensaiadas duas vigas de concreto armado sob tombamento lateral gradual, as quais foram também modeladas numericamente. A comparação entre as respostas numéricas e experimentais serviu, no capítulo em questão, para calibrar o programa computacional.

No Capitulo 7 são apresentados os resultados numéricos obtidos para várias análises, utilizando-se os recursos disponíveis no programa computacional implementado, tendo sido comparadas as respostas numéricas com as experimentais disponíveis na literatura técnica.

As conclusões obtidas do tratamento numérico e experimental encontram-se no Capitulo 8 , juntamente com algumas sugestões para investigações futuras.

Finalmente, a relação da bibliografia consultada e das referências bibliográficas citadas e utilizadas nesta tese encontram-se reunidas no Capitulo 9. 


\title{
Capítulo
}

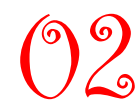

\author{
ESTADO DA ARTE DA INSTABILIDADE \\ LATERAL EM VIGAS DE CONCRETO
}

\subsection{CONSIDERAÇÕES INICIAIS}

Será apresentada neste capítulo uma revisão bibliográfica sobre o problema da instabilidade lateral em vigas pré-moldadas de concreto, no período de 1966 à 2000, a fim de situar o tema deste trabalho no contexto técnico atual.

\subsection{ESTUDOS ANTERIORES SOBRE A INSTABILIDADE LATERAL EM ELEMENTOS PrÉ-MOLDADOS DE CONCRETO ARMADO}

O estudo da instabilidade lateral de vigas pré-moldadas apresenta-se na literatura de forma restrita, com poucos trabalhos desenvolvidos neste assunto, bem como insuficientes especificações de projeto em normas técnicas.

As vigas de pontes, usualmente pré-moldadas e protendidas, geralmente apresentam grande altura a fim de garantirem a resistência à flexão em torno do seu eixo de maior inércia. Porém, para viabilizar o seu transporte e manuseio, seu peso-próprio deve ser mantido o mínimo possível, o que tem sido alcançado, diminuindo-se a largura da mesa inferior, sendo a mesa superior, muitas vezes moldada no local. Assim, observa-se uma rigidez em torno do eixo de menor inércia ou rigidez à flexão lateral muito baixa. Tudo isto contribui de forma significativa para aumentar os riscos de colapso por instabilidade lateral.

As imperfeições construtivas resultantes da moldagem do elemento pré-moldado e as inevitáveis diferenças nas forças dos cabos de protensão também contribuem para a perda de estabilidade lateral de vigas longas e delgadas. A estabilidade de uma viga perfeita ou com uma excentricidade lateral inicial decorrente das possíveis imperfeições, pode ser observada na Figura 2.1, ilustrando os tipos de equilíbrio estável e indiferente.

Com relação à fase transitória de suspensão, alguns trabalhos importantes foram desenvolvidos, seja por meio do estudo do equilíbrio em teoria de segunda ordem, utilizando métodos numéricos para a solução do sistema de equações diferenciais, seja pela aplicação do método dos elementos finitos.

De acordo com Swann \& Godden (1966), o fenômeno da instabilidade quando vigas longas e esbeltas estão em sua posição final de projeto não é geralmente crítico. Porém, quando encontram-se em fase de suspensão, uma situação instável pode ocorrer, resultando em uma carga de colapso com valor inferior à correspondente situação em serviço. Uma situação extrema pode ocorrer na fase de içamento devido à instabilidade por giro total como corpo rígido e flexão lateral, sem torção ao longo do comprimento.

Swann \& Godden (1966) sugerem como uma pesquisa ideal, encontrar um procedimento capaz de tratar adequadamente o grande número de parâmetros que influenciam a 
estabilidade estrutural. Dentre estes parâmetros, tem-se: seção transversal variável, carregamento variável, cargas fora do centro de cisalhamento, carga axial, restrição ao empenamento da seção, posição dos pontos de içamento, curvatura inicial da viga em seu próprio plano e altura dos pontos de içamento acima do centro de cisalhamento.

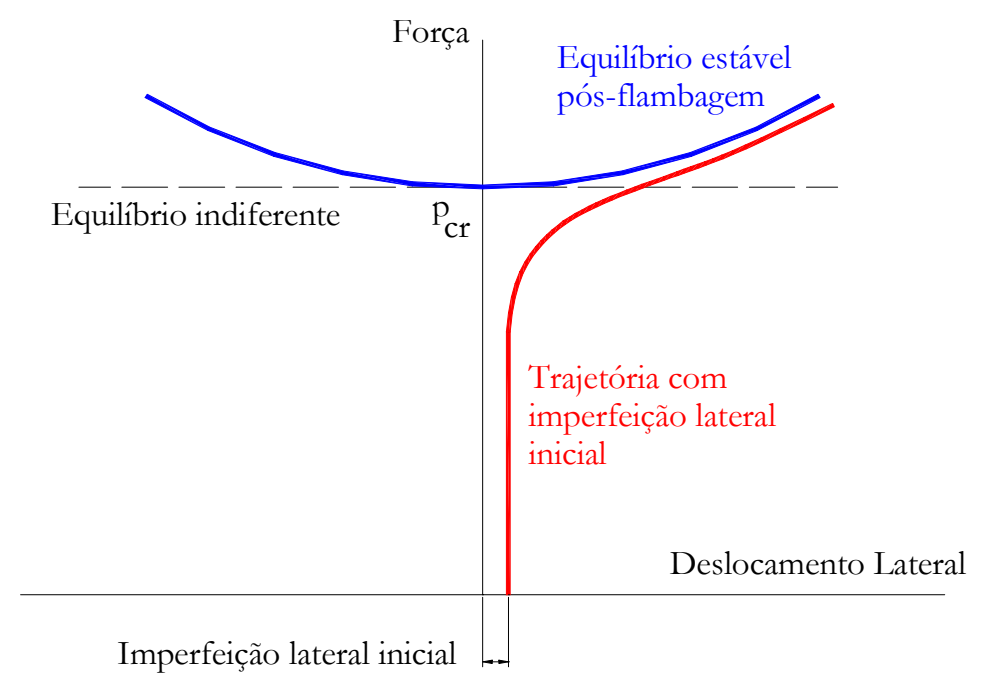

Figura 2.1 - Tipos de equilíbrio.

No entanto, Swann \& Godden (1966) trataram do problema da instabilidade lateral de vigas de concreto suspensas por cabos, basicamente considerando diferentes carregamentos e condições de apoio, através de um procedimento numérico que consiste em dividir a viga curva em um conjunto de trechos retos. Neste sistema equivalente, calcula-se analiticamente a carga crítica ou a excentricidade lateral crítica. Para isto, assume-se uma configuração inicial de rotação por torção de acordo com o tipo de vinculação, imitando um modo de flambagem. Do momento de torção gerado pelo carregamento e pela rotação adotada na configuração inicial, obtém-se uma nova configuração, que deve corresponder à adotada, dentro de uma certa tolerância. Tem-se então, um procedimento de tentativa e erro até a convergência. Além do desenvolvimento numérico, foram apresentados por Swann \& Godden (1966) os resultados de duas séries de testes realizados em vigas suspensas por cabos.

Segundo Park \& Paulay (1975), a instabilidade e consequente ruptura de vigas esbeltas podem ocorrer, antes de ser atingida a resistência à flexão. $O$ colapso por instabilidade lateral ocorre por flexão lateral acompanhada de torção. Tal fenômeno pode ser importante em vigas com restrição lateral deficiente, se a rigidez à flexão no plano for muito maior do que a rigidez lateral. Mas, situações críticas podem ocorrer durante o içamento de elementos de concreto pré-moldado antes que sejam colocadas as restrições laterais adequadas. Entretanto, o tratamento analítico do problema torna-se ainda mais complexo quando se procura considerar as propriedades do comportamento do concreto armado de forma realista.

Park \& Paulay (1975), baseados no código britânico de 1972, recomendam adotar os seguintes limites, a fim de prevenir a ocorrência de instabilidade lateral:

- Para vigas simplesmente apoiadas ou contínuas, o vão livre L entre as restrições laterais deve ser tal que: 


$$
\frac{\mathrm{L}}{\mathrm{b}}<60 \text { e } \frac{\mathrm{Ld}}{\mathrm{b}^{2}}<250
$$

onde b é a largura da seção transversal e d é a altura.

- Para vigas em balanço com restrições laterais apenas nos apoios, os valores devem ser:

$$
\frac{\mathrm{L}}{\mathrm{b}}<25 \text { e } \frac{\mathrm{Ld}}{\mathrm{b}^{2}}<100
$$

O trabalho de Catania \& Cocchi (1985) constitui uma das mais completas bibliografias sobre este tema. O estudo da instabilidade lateral para algumas seções típicas de concreto encontra-se desenvolvido para a fase de serviço e também durante o içamento, para várias disposições dos cabos de suspensão.

No estudo da estabilidade em campo pós-crítico e regime anelástico, Catania \& Cocchi (1985) apresentam procedimentos analíticos e numéricos, para tratar de problemas considerando os efeitos da não-linearidade geométrica da estrutura e da não-linearidade física do concreto, admitindo a fissuração, os efeitos dinâmicos do carregamento e os deslocamentos elevados com relação à configuração inicial, levando-se em conta as imperfeições construtivas. Mostram também que, junto às tensões e deformações elásticas geradas pelo carregamento, surgem tensões e deformações anelásticas devido ao aparecimento da fissuração e da redução da zona comprimida de concreto.

Catania \& Cocchi (1985) sugerem a utilização de métodos numéricos, como por exemplo, o método dos elementos finitos, para análise de tensões e deformações de cada ponto da estrutura, na configuração inicial e deformada, de modo a levar em conta a fissuração e a plastificação, distinguindo a parcela elástica da parcela plástica, na definição da expressão do trabalho interno. Algumas tentativas de se obter uma aproximação da rigidez à torção e à flexão na fase fissurada também foram desenvolvidas.

Twelmeier \& Brandmann (1985) realizaram um programa experimental piloto a fim de investigar o fenômeno da instabilidade lateral na Technical University of Braunschweig. $\mathrm{O}$ programa tinha o objetivo de cobrir os dois seguintes temas:

- Investigar experimentalmente a variação das rigidezes de flexão lateral e vertical e da rigidez à torção, em função do momento fletor vertical até a ruptura. Os citados autores utilizaram vigas pré-moldadas de seção retangular e de seção I. O principal parâmetro variável foi a taxa de armadura. Partindo da flexão pura, o efeito de pequenos momentos de flexão lateral e de torção, atuando ao mesmo tempo, permitiram simular a influência das imperfeições geométricas em estruturas reais.

- Observar o modo de ruptura e o progresso da instabilidade lateral em ensaios de vigas com escala reduzida.

Os resultados dos ensaios piloto de Twelmeier \& Brandmann (1985) mostraram que, quando não existe torção, as curvas de rigidez à flexão consistem de dois patamares praticamente horizontais descrevendo as fases não fissurada e totalmente fissurada, conforme ilustra a Figura 2.2. O comprimento do patamar horizontal inicial depende da magnitude da resistência à tração. A inclinação da curva que define o final da fase nãofissurada até o início do patamar de fissuração mostra o efeito de tension-stiffening ou enrijecimento observado nas armaduras em virtude da presença de trechos de concreto 
não-fissurado entre fissuras. Nas curvas relativas à rigidez à torção a inclinação da curva devido à fissuração é mais inclinada, o que permite observar o efeito de engrenamento dos agregados e o efeito de pino das armaduras na região fissurada. Esses efeitos resultam em valores finais para a rigidez à torção superiores aos previstos por expressões teóricas da literatura técnica.
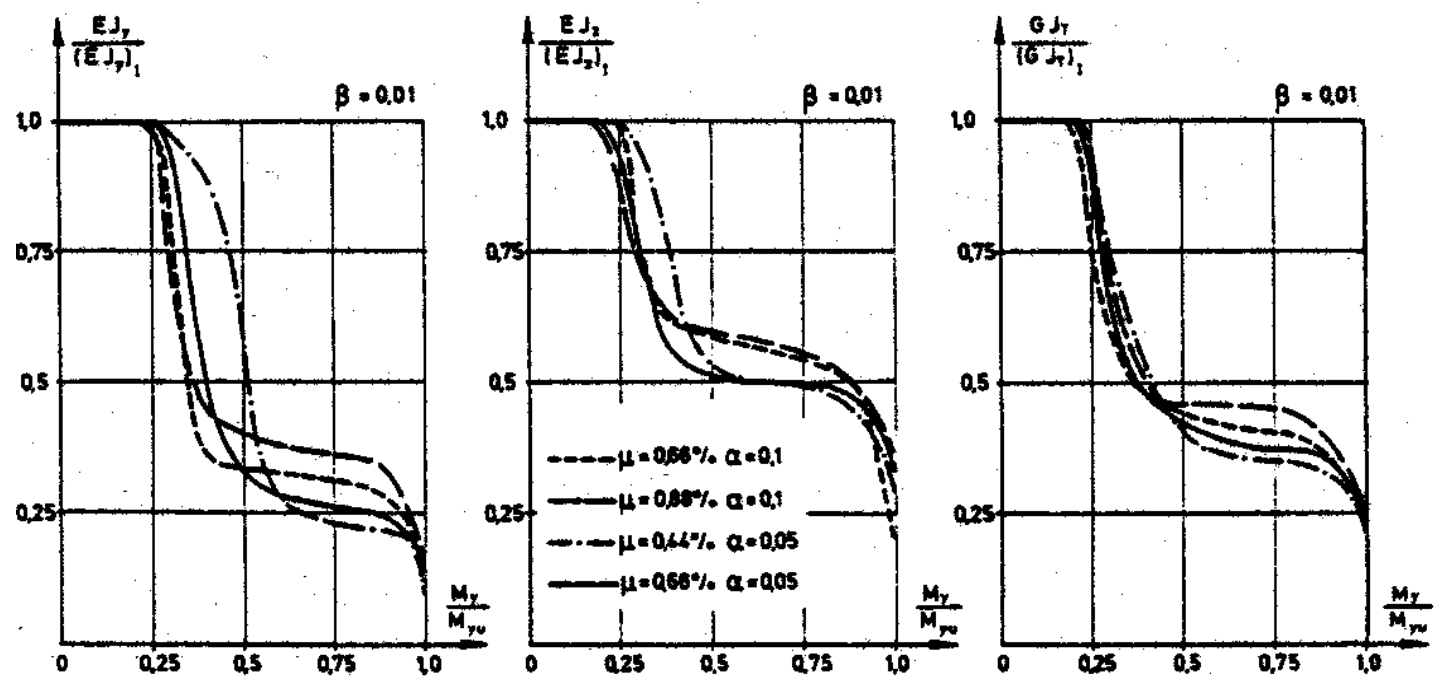

$$
\begin{aligned}
& \mu=A_{s \ell} / A_{c}: \text { taxa de armadura longitudinal } \\
& \alpha=M_{z} / M_{y}: \text { relação entre momento fletor lateral } M_{z} \text { e vertical } M_{y} \\
& \beta=T / M_{y}: \text { relação entre momento de torção } T \text { e fletor vertical } M_{y}
\end{aligned}
$$
(a) flexão vertical
(b) flexão lateral
(c) torção

Figura 2.2 - Variação da rigidez à (a) flexão vertical, (b) flexão lateral e (c) torção. Twelmeier \& Brandmann (1985).

Imper \& Las‡lo (1987), nas análises da instabilidade durante o manuseio de longas vigas de pontes, fornecem um procedimento empírico para a avaliação da segurança durante a fase transitória. Observam também a influência do posicionamento dos pontos de apoio nas duas etapas consideradas da fase transitória - o transporte e o içamento - em benefício da estabilidade da viga. A suspensão com balanços pode aumentar significativamente o valor da carga crítica de instabilidade lateral. Os citados autores observam que para um balanço equivalente a $6 \%$ do vão, a flecha máxima diminui para $58,8 \%$ da flecha para a mesma viga apoiada nas extremidades, podendo com isto, duplicar o fator de segurança.

Porém, é difícil, em alguns casos, mover os pontos de suspensão a partir da extremidade, sem aumentar significativamente as tensões na seção do meio do vão, o que ocorre sistematicamente em vigas protendidas. Isto, porque o momento fletor na seção central devido ao peso-próprio é menor que no içamento pelas extremidades. Logo, as tensões finais são maiores, já que o alívio de tensões devido ao peso-próprio frente à protensão é menor.

Imper \& Lasz̧o (1987) também consideram que os efeitos de deformação lenta e impacto são preferencialmente importantes durante o transporte em veículo, especialmente quando o mesmo passa sobre uma superelevação da via em baixa velocidade. Porém, a 
suspensão e as superelevações constituem etapas passageiras para que se preocupe com os problemas de fluência. Enfim, acrescentam que deve-se ter a preocupação de não manter a viga em posição inclinada por um tempo suficientemente capaz de tornar os efeitos de deformação lenta significativos. Alguns sistemas de contraventamento usuais são discutidos no citado trabalho.

O estudo desenvolvido por Mast (1989) avalia a estabilidade lateral de vigas protendidas de seção duplo T, quando suspensas por cabos de elevação, através da definição de um fator de segurança. Este fator depende da altura do eixo de giro, da excentricidade lateral inicial, da rigidez lateral e da máxima inclinação permissível para a viga. $O$ fator de segurança a ser adotado deve ser o menor entre os valores obtidos nas expressões (2.3) e (2.4).

$$
\begin{aligned}
& \mathrm{FS}=\frac{\mathrm{y}_{\mathrm{r}}}{\mathrm{z}_{\mathrm{o}}}\left(1-\frac{\phi_{\mathrm{i}}}{\phi_{\text {máx }}}\right) \\
& \mathrm{FS}=\frac{\phi_{\text {máx }}}{\phi_{\mathrm{i}}}\left(1-\frac{\mathrm{z}_{\mathrm{o}}}{\mathrm{y}_{\mathrm{r}}}\right)
\end{aligned}
$$

onde $\mathrm{y}_{\mathrm{r}}$ é a distância do CG da seção transversal referente à suspensão até a face superior da viga, $z_{\mathrm{o}}$ é um valor fictício de deslocamento referente ao deslocamento lateral do CG para todo o peso próprio aplicado lateralmente, $\phi_{\mathrm{i}}$ é rotação inicial devido às imperfeições construtivas e $\phi_{\text {máx }}$ a rotação máxima relativa à fissuração, conforme ilustra a Figura 2.3.

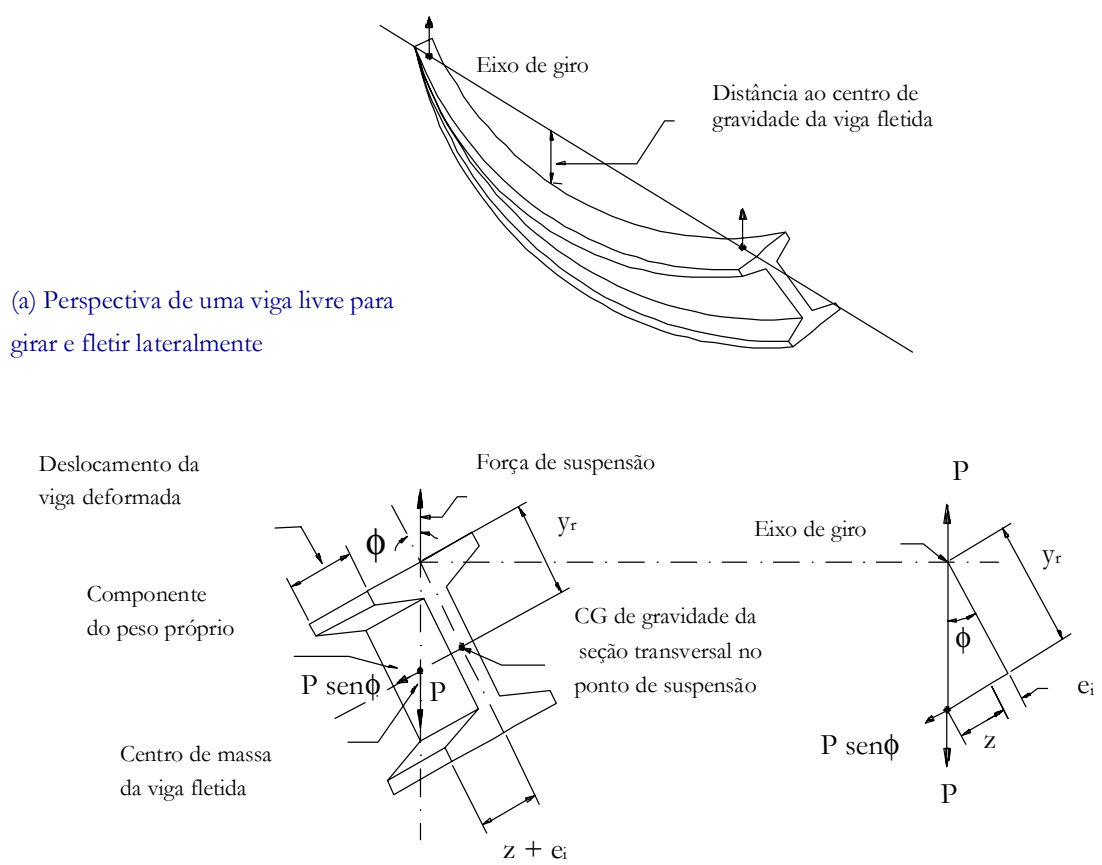
(b) Vista em corte
(c) Diagrama de equilíbrio

Figura 2.3 - Equilíbrio da viga durante a suspensão. Mast (1989). 
Inicialmente, os estudos desenvolvidos em Mast (1989) limitavam-se aos problemas de instabilidade antes da viga começar a fissurar, e o máximo ângulo de giro era limitado pela máxima tensão de tração das fibras superiores da seção.

Ensaios experimentais apresentados por Mast (1993) confirmaram que as vigas suportam ângulos maiores que o ângulo limite de fissuração, devendo a rigidez à flexão ser reduzida. Assim, Mast (1993) amplia as análises da estabilidade lateral para casos mais gerais de vigas, cujo suporte seja provido de restrições elásticas ao giro.

Mast (1993) inclui vigas apoiadas em almofadas de elastômero e em caminhões, durante o transporte em via de tráfego. A superelevação da via é considerada e procedimentos simples são descritos para sua determinação.

Para a fase de suspensão, os fatores de segurança alcançaram maior amplitude, e o estudo realizado anteriormente por Mast (1993) foi reformulado pela avaliação da fissuração e do colapso da viga, com comprovação experimental por ensaios em escala real.

As equações (2.5) e (2.6) fornecem o fator de segurança contra fissuração e contra a ruptura, respectivamente.

$$
\begin{gathered}
\mathrm{FS}_{\text {fiss }}=\frac{1}{\mathrm{z}_{\mathrm{o}} / \mathrm{y}_{\mathrm{r}}+\phi_{\mathrm{i}} / \phi_{\text {máx }}} \\
\mathrm{FS}_{\text {rupt }}=\frac{\mathrm{y}_{\mathrm{r}} \phi_{\text {máx }}^{\text {rupt }}}{\mathrm{z}_{\mathrm{o}}^{\text {rupt }} \phi_{\text {máx }}^{\text {rupt }}+\mathrm{e}_{\mathrm{i}}}
\end{gathered}
$$

onde $\mathrm{e}_{\mathrm{i}}$ é a excentricidade inicial admitida.

Mast (1994) apresenta um ensaio de uma viga de concreto protendido de 45,4 $\mathrm{m}$ de comprimento à flexão lateral até a ruptura, tendo sido esta gradualmente inclinada sob condições controladas. Os objetivos do teste foram investigar o comportamento das seções fissuradas de vigas I sujeitas a cargas laterais e verificar a eficiência dos sistemas de contraventamento comumente usados no transporte de vigas longas de concreto protendido. Os testes demonstraram que as vigas apresentaram carga referente à fissuração consideravelmente superior à carga teórica prevista, e que para esta carga, ainda não apresentavam nenhum sinal visível de danificação após a retirada da carga lateral. Além disso, também o ângulo de inclinação lateral observado até a ruptura foi muito superior ao valor previsto em projeto.

Kraus \& Ebret (1990) consideram que os problemas de instabilidade lateral são geralmente críticos em vigas altamente rígidas à flexão vertical e com baixa rigidez à flexão lateral e torção. No trabalho em referência, apresentam as equações diferenciais que regem o problema, bem como os métodos de solução para material de comportamento linear e não-linear.

Em casos de não-linearidade física do material, Kraus \& Ehret (1990) consideram necessário utilizar métodos de solução iterativa como, por exemplo, o método da carga incremental, onde a carga é aplicada em incrementos, sendo a rigidez em cada um destes passos, igual ao módulo tangente, conforme mostra a Figura 2.4 (a). A carga crítica é encontrada quando o módulo tangente tende a zero. O método da iteração direta 
ilustrado na Figura 2.4 (b) permite obter a carga limite por iteração direta. A rigidez é determinada em cada passo da iteração pelo valor do módulo secante.

Kraus \& Ebret (1990), com relação à não-linearidade geométrica, recomendam utilizar o método dos elementos finitos, considerando além da matriz de rigidez elástica, outra parcela, somada a esta, que considera a contribuição geométrica não-linear, em teoria de segunda ordem. Em problemas com bifurcação de equilíbrio, a carga crítica é obtida resolvendo o problema de auto-valor.

Segundo Kraus \& Ehret (1990), uma vez que as vigas longas de concreto são geralmente pré-fabricadas, a dificuldade de se desenvolver um estudo mais realista do comportamento destes elementos com relação à instabilidade está no cálculo da rigidez efetiva à flexão lateral e à torção, que dependem das tensões atuantes na seção transversal em análise.
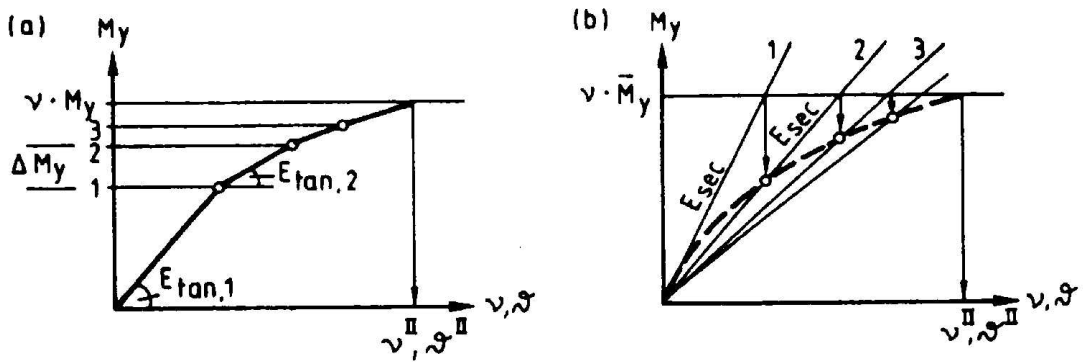

Figura 2.4 - (a) Rigidez Tangente e (b) Rigidez Secante. Kraus \& Ehret (1990).

A análise de tensões no trabalho de Kraus \& Ehret (1990) foi feita para a seção fissurada e não fissurada, conforme a Figura 2.5, para obtenção da rigidez à flexão lateral. Kraus \& Ehret (1990) consideram uma distribuição parabólica de rigidez entre duas fissuras, resultando nas expressões (2.7) e (2.8) para a rigidez lateral média efetiva e para a rigidez à torção, respectivamente.

$$
\begin{aligned}
& \mathrm{EI}_{\mathrm{y}}=\frac{1}{3}\left[2\left(\mathrm{EI}_{\mathrm{y}}\right)_{\text {real }}+\left(\mathrm{EI}_{\mathrm{y}}\right)_{\text {fiss }}\right] \\
& \mathrm{GI}_{\mathrm{t}}=\frac{1}{3}\left[2\left(\mathrm{GI}_{\mathrm{t}}\right)_{\text {real }}+\left(\mathrm{GI}_{\mathrm{t}}\right)_{\text {fiss }}\right]
\end{aligned}
$$

As rigidezes antes e após a fissuração são calculadas a partir da curvatura resultante na seção antes e após a fissuração.

O trabalho de Lima (1995) aborda o estudo da instabilidade lateral das vigas prémoldadas durante o regime de serviço e a fase transitória. A fase de serviço inclui os casos de apoio indeformáveis e deformáveis à torção. Para a fase transitória, o cálculo da carga crítica é desenvolvido para as diversas disposições dos cabos de içamento. $\mathrm{O}$ estudo do equilíbrio no espaço é realizado a partir da resolução das equações diferenciais regentes da instabilidade elástica. A resolução do sistema diferencial composto pelas equações acopladas da flexão lateral e da torção é realizada por vários métodos, incluindo o desenvolvimento e automatização do método numérico de RungeKutta, para algumas seções típicas. 
Segundo Lima (1995), estudos baseados nas hipóteses de regime elástico-linear nos fornecem, como uma primeira aproximação, o cálculo da carga crítica de instabilidade lateral. No entanto, uma análise mais realista consiste em considerar o comportamento não-linear dos materiais bem como sua relação com o surgimento de fissuras, o que requer o estudo e desenvolvimento de uma forma de se obter a rigidez efetiva à torção e flexão lateral, uma vez que dependem da distribuição das tensões na seção transversal em análise.

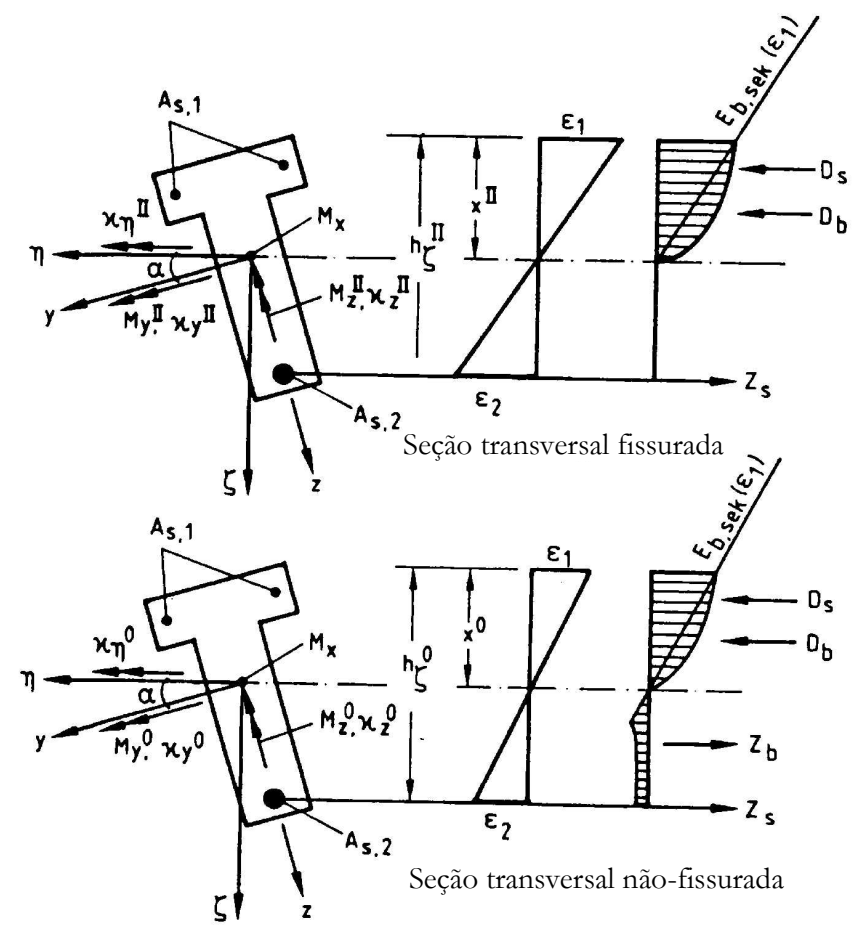

Figura 2.5 - Tensões e deformações na seção transversal sob flexão oblíqua. Kraus \& Ehret (1990).

Zilch et al. (1997) apresentam uma investigação comparativa entre 3 métodos da literatura técnica para a determinação da estabilidade lateral de vigas de concreto armado e protendido, considerando a variação da rigidez à flexão lateral e à torção, após a fissuração, em teoria de segunda ordem. A Figura 2.6 ilustra a distribuição da rigidez à flexão lateral e à torção para vigas simplemente apoiadas com carregamento uniforme, segundo Zilch et al. (1997).

A expressão (2.9) refere-se a rigidez à torção substituta, após a fissuração, $G J_{t_{\text {sub }}}$ apresentada por Zilch et al. (1997), a partir das rigidezes calculadas antes da fissuração $\mathrm{GJ}_{\mathrm{t}, \mathrm{A}}$, e após a fissuração, $\mathrm{GJ} \mathrm{J}_{t, \mathrm{~B}}$.

$$
\mathrm{GJ}_{\mathrm{t}_{\text {subs }}}=\left[\frac{1}{\mathrm{GJ}_{\mathrm{t}, \mathrm{B}}}+\operatorname{sen}\left(\frac{\pi \mathrm{z}_{\mathrm{r}}}{\mathrm{L}}\right)\left(\frac{1}{0,8 \mathrm{GJ} \mathrm{t}_{\mathrm{t}, \mathrm{A}}}-\frac{1}{\mathrm{GJ}_{\mathrm{t}, \mathrm{B}}}\right)\right]^{-1}
$$

onde $z_{\mathrm{r}}$ é o trecho da viga sem fissuração e L é o vão da viga.

Aydin \& Kiraç (1998) apresentam um estudo sobre instabilidade lateral em vigas de concreto armado sem restrições laterais. $\mathrm{Na}$ verificação da estabilidade da viga, Aydin \& Kiraş (1998) consideram a variação da rigidez à flexão e à torção devido à formação de 
fissuras, dividindo a viga em um número finito de segmentos, para os quais calculam-se a rigidez e o momento fletor, assumidos constantes em cada trecho. A análise de estabilidade é aproximada, utilizando-se os valores médios em cada trecho.
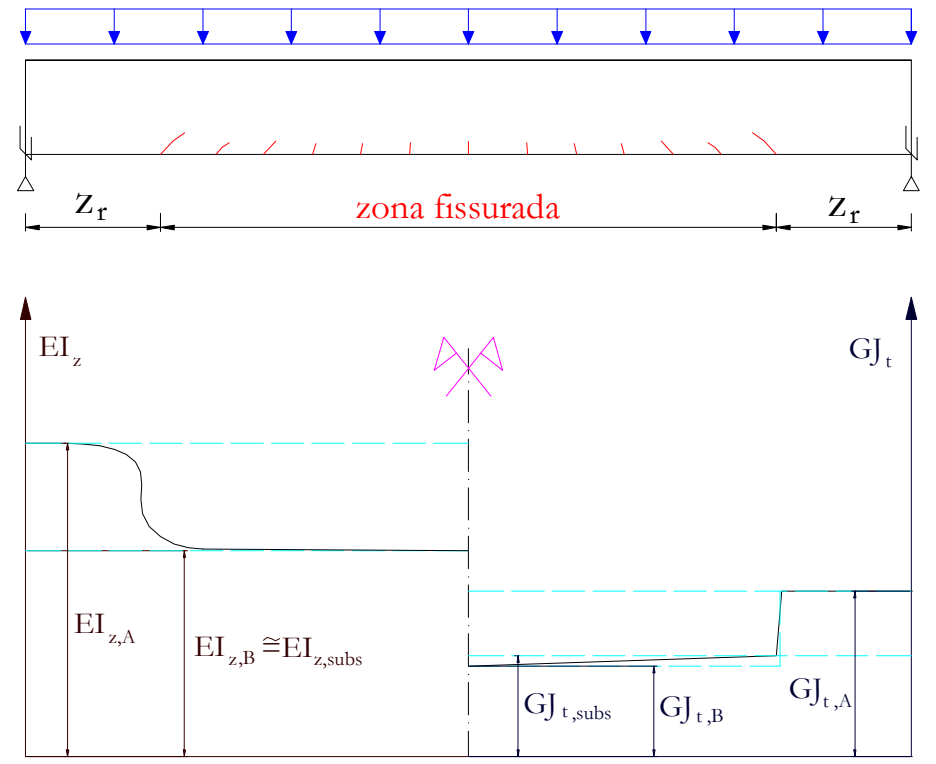

Figura 2.6 - Distribuição da rigidez à flexão lateral e à torção segundo Zilch et al (1997).

Aydin \& Kiraç (1998) definem uma relação de esbeltez crítica $\lambda_{\text {cr }}$ dada por $\mathrm{Lh} / \mathrm{b}_{\mathrm{w}}^{2}$, para a qual pode-se checar ou estimar a segurança à instabilidade lateral da viga. Esta verificação é feita através de um procedimento de tentativa e erro, para o qual, em cada trecho da viga dividida, calcula-se a taxa de giro por torção, função das condições de contorno do trecho, do momento fletor vertical, da rigidez à flexão lateral e da rigidez à torção. Tem-se então que o valor da relação $\lambda$ que verifica o sistema de equações é o valor da esbeltez crítica $\lambda_{\text {cr }}$. Compara-se a esbeltez $\lambda_{\text {cr }}$ então obtida com o valor real da relação $\lambda=\mathrm{Lh} / \mathrm{b}_{\mathrm{w}}^{2}$, que satisfaz o sistema de equações. Assim, tem-se:

$$
\gamma=\frac{\lambda_{\mathrm{cr}}}{\lambda}
$$

Desta forma, se $\gamma<1$, Aydin \& Kiraç (1998) consideram que a viga não verifica as condições de segurança com relação à instabilidade lateral. Com relação à recomendação de verificação de estabilidade para relações de esbeltez $\mathrm{Lh} / \mathrm{b}_{\mathrm{w}}^{2}$ superiores a 125 , os autores observam que, no caso de vigas, este limite deve ser menor.

Segundo Sexsmith (1998), existem muitos casos de pontes cujos elementos atingem o colapso durante a fase de montagem. Para tratar deste período considerado vulnerável, apresenta um estudo sobre confiabilidade, mostrando a escolha de níveis de confiabilidade em termos de fatores de carga para situações típicas de montagem. Cita que o nível de confiabilidade depende do tempo de exposição às cargas temporárias, dos custos dos escoramentos e travamentos utilizados, e também, das conseqüências do colapso. Embora os critérios de projeto apresentados nas normas técnicas baseiem-se geralmente em princípios de confiabilidade, isto ainda não se verifica para 
carregamentos e condições temporárias de vinculações relativas à estrutura em montagem. Por aproximação, Sexsmith (1998) acredita que o conhecimento e a otimização de custos probabilísticos é razoável para a escolha do nível de confiabilidade necessário para a fase de montagem dos elementos de pontes.

Boer \& Schaafsma (1998) apresentam um estudo sobre a capacidade de rotação de uma viga protendida de concreto durante a fase de içamento. A pesquisa desenvolvida no Ministério dos Transportes da Holanda resultou de um acidente no canteiro de obras durante a suspensão de uma viga de $57,5 \mathrm{~m}$ de comprimento, $3,15 \mathrm{~m}$ de altura, de seção transversal I com pequena mesa superior e uma mesa inferior com $1,2 \mathrm{~m}$ de largura. Os pontos de içamento foram posicionados à $35 \mathrm{~cm}$ das extremidades. Os autores em questão desenvolveram duas análises, a primeira discretizando a viga em elementos de barra, e na segunda, em elementos de placa, os quais apresentaram resultados muito próximos. As análises numéricas foram realizadas no programa DIANA versão 6.2. Os resultados das análises visaram obter um melhor entendimento das relações entre critérios de tensões e de estabilidade. O ângulo máximo de rotação alcançado numericamente foi de $6^{\circ}$. Boer \& Schaafsma (1998) observam a necessidade de um estudo do comportamento pós-flambagem, para que se possa descrever numericamente a perda de estabilidade da mesa superior.

Stratford et al. (1999) apresentam algumas equações simplificadas que permitem aos projetistas estruturais verificarem a estabilidade de vigas pré-moldadas de concreto na fase de serviço, durante o transporte, suspensas por cabos e apoiadas sobre almofadas de elastômero. Indicam algumas expressões para o cálculo da carga crítica de instabilidade lateral e como estimar tanto os efeitos de imperfeições construtivas da viga, quanto o nivelamento dos apoios. Mostram ainda como as tensões que são induzidas por efeitos de segunda ordem em vigas imperfeitas podem ser determinadas.

De acordo com Stratford et al. (1999), os riscos de instabilidade lateral são acentuados à medida em que aumentam-se os vãos das vigas e a esbeltez. Algumas situações devem ser observadas, como:

- Vigas na posição final submetidas apenas ao peso-próprio - fase pré-serviço são menos susceptíveis à instabilidade lateral. Entretanto, deve-se tomar cuidado para garantir o nivelamento dos apoios.

- Durante o transporte de vigas perfeitamente retas, a instabilidade não é um fenômeno esperado, porém, devido ao carregamento lateral resultante da superelevação da via de tráfego, forças de vento e efeitos dinâmicos podem causar tensões significativas no concreto e levar à ruptura.

- A fase transitória de suspensão é a mais crítica com relação à instabilidade lateral. A presença de imperfeições iniciais na viga pode causar grandes tensões no concreto.

Com relação à fase de suspensão, Stratford et al. (1999) recomendam minimizar os riscos de ruptura, baseado nas seguintes observações:

- Os cabos de suspensão devem ser posicionados o mais vertical possível. Isto pode ser conseguido utilizando uma viga de distribuição (balancim), embora o peso adicional desta deva ser considerado na escolha adequada dos guindastes. 
- A posição ótima dos cabos de içamento deve situar-se próxima dos quartos do vão, exceto no caso de vigas protendidas, onde deve aproximar-se das extremidades da viga.

- Deve-se preocupar em manter mínimas as imperfeições laterais. Uma pequena curvatura lateral irá sempre existir em virtude do processo de manufatura. Entretanto, um posicionamento com excentricidade dos cabos de suspensão podem introduzir tensões significantes.

Stratford \& Burgoyne (1999) observam a importância do estudo da instabilidade lateral em vigas pré-moldadas uma vez que, nos tempos atuais, a indústria da construção préfabricada busca aliar melhor comportamento mecânico com menor peso-próprio e máximo vão. Para máximo comprimento longitudinal e menor peso, tem-se reduzido a largura das mesas, resultando em seções com menor rigidez à torção e menor rigidez à flexão lateral. Os autores mostram que a verificação da estabilidade lateral pode passar a ser uma prática no projeto de longas vigas pré-moldadas, acima de $40 \mathrm{~m}$. Este fenômeno era incomum em vigas de concreto armado, ao contrário das vigas metálicas. Vale lembrar que as verificações da estabilidade em vigas de aço são imprescindíveis e extensivamente estudadas na literatura das estruturas metálicas. Porém, no caso do concreto, o peso-próprio é muito mais significativo, além da rigidez à torção também ser muito superior.

No trabalho de Stratford \& Burgoyne (1999), os parâmetros necessários para análises de estabilidade através do cálculo da carga crítica são o comprimento da viga, as propriedades físicas dos materiais e mecânicas da seção transversal, a posição dos apoios e a inclinação dos cabos de suspensão. As análises de estabilidade foram desenvolvidas para 3 tipos de apoios, dentre eles: viga simplesmente apoiada, viga suspensa por cabos e viga durante o transporte. Para estas condições, admite-se que a ruína irá ocorrer por instabilidade elástica sob solicitação única do peso-próprio. Assim, a carga crítica corresponde ao carregamento uniformemente distribuído que causaria instabilidade lateral em uma viga perfeita. Este valor é então comparado com o peso-próprio real da viga. Este procedimento também foi utilizado por Lima (1995) para vigas retangulares e de seção I, suspensas por cabos retos e inclinados, tendo sido a carga crítica obtida dos resultados da implementação numérica do método de Runge-Kutta para solução do sistema de equações diferenciais.

Stratford \& Burgoyne (1999) utilizaram duas análises com elementos finitos. Primeiramente, calcula-se a carga crítica de instabilidade e o modo de flambagem, considerando o comportamento de um problema de auto-valor. Posteriormente, os citados autores desenvolveram uma análise não-linear geométrica, introduzindo uma pequena excentricidade inicial. Assim, pode-se conhecer a resposta completa da curva força-deslocamento da viga. Neste caso, a carga crítica não pode mais ser calculada, uma vez que não se tem um problema de mudança de equilíbrio.

É importante observar que em todas as análises numéricas desenvolvidas por Stratford \& Burgoyne (1999), o material é considerado com comportamento elástico-linear, sem levar em conta os efeitos de fissuração.

Stratford \& Burgoyne (1999) observaram que nas vigas metálicas a componente de torção que colabora na instabilidade lateral é consideravelmente mais importante do que nas vigas de concreto. Baseados nestas observações, os citados autores descrevem o problema da instabilidade de vigas suspensas por cabos através da rotação de corpo- 
rígido em torno do ponto de fixação dos cabos e da flexão em torno do eixo de menor inércia. Este tipo de comportamento aproximado é definido por Stratford \& Burgoyne (1999) pelo termo toppling. Desta forma, o problema da viga suspensa é analisado pelos autores como instabilidade por flexão lateral.

Stratford \& Burgoyne (1999) indicaram ainda algumas expressões simplificadas para a estimativa da imperfeição inicial ou curvatura lateral resultante da protensão, que faz com que a viga tenha um pequeno deslocamento para um dos lados.

- Para uma viga simplesmente apoiada ou apoiada durante o transporte, e neste último caso, sob apoios que permitem rotação, a máxima curvatura lateral $\mathrm{k}_{\mathrm{ms}} \mathrm{da}$ viga irá ocorrer no meio do vão e pode ser dada por:

$$
\mathrm{k}_{\mathrm{ms}}=\frac{\mathrm{wL}^{2} \operatorname{sen} \delta \theta}{8 \mathrm{EI}}
$$

onde w é o peso-próprio da viga, $\mathrm{L}$ é o comprimento, $\mathrm{EI}_{\mathrm{y}}$ é a rigidez à flexão lateral e $\delta \theta$ é o giro em torno do eixo da viga.

- Para um viga em suspensão, assumindo uma imperfeição inicial descrita por uma senóide, tem-se então que o deslocamento lateral $\mathrm{v}_{\mathrm{ms}}$ pode ser escrito por:

$$
\mathrm{v}_{\mathrm{ms}}=\frac{\delta_{\mathrm{o}}\left(1-\operatorname{sen}\left(\pi_{\mathrm{a}} / \mathrm{L}\right)\right.}{\left(1-\mathrm{w} / \mathrm{w}_{\mathrm{cr}}\right)}
$$

onde a é o comprimento dos balanços no içamento, $\delta_{o}$ é o valor da excentricidade inicial lateral e $\mathrm{w}_{\mathrm{cr}}$ é o valor do peso-próprio que causaria instabilidade lateral.

Para o caso onde existe uma rotação inicial dos apoios $\eta$ em torno do eixo da viga e com relação à horizontal, rotação esta decorrente do desnível destes pontos, Stratford \& Burgoyne (1999) recomendam verificar se a máxima curvatura lateral $\mathrm{k}_{\mathrm{ms}}$ não provocará ruptura na viga por gerar excessivas tensões no concreto. Neste caso, $\mathrm{k}_{\mathrm{ms}}$ pode ser estimado por:

$$
\mathrm{k}_{\mathrm{ms}}=\frac{\mathrm{wL}^{2} \operatorname{sen} \eta}{8 \mathrm{EI}_{\mathrm{y}}}
$$

Stratford \& Burgoyne (2000) apresentam um estudo sobre a estabilidade de vigas suspensas por cabos, considerando que o comportamento de vigas grandes e pesadas podem ser idealizadas através da rotação de corpo-rígido acrescidas do efeito dos deslocamentos em relação ao eixo de menor inércia. Esta simplificação permite tratar o problema de forma analítica, para o caso de vigas suspensas por cabos inclinados, verticais, com barras rígidas verticais ou inclinadas, com cargas laterais como o efeito do vento, bem como vigas com imperfeições iniciais.

Em Stratford \& Burgoyne (1999), utilizando técnicas de elementos finitos, os autores observaram que o caso de vigas suspensas por cabos constitui a situação mais crítica, devido à ausência de restrições à rotação. Apresentando alta rigidez à torção, a viga tende a girar como corpo-rígido, com pequena variação de giro ao longo do comprimento. Assim, o modo de flambagem de uma viga suspensa pode ser tratado 
como um problema de flexão lateral em torno do eixo de menor inércia combinado com uma rotação de corpo-rígido em torno de pontos fixos nos cabos de suporte.

O problema completo da instabilidade lateral com torção de uma viga suspensa por cabos apresenta solução analítica complexa. Stratford \& Burgoyne (2000) admitem, entretanto, que a viga não gira por torção, assumindo uma rigidez infinita à torção, simplificando o problema, e tornando possível uma solução analítica, embora tenham utilizado também solução numérica no conjunto final de equações.

Stratford \& Burgoyne (2000) analisaram algumas vigas de comprimento L suspensas por cabos retos ou inclinados, com balanços. Os cabos são presos a barras rígidas fixas na viga acima do eixo do CG. O carregamento se resume ao peso-próprio, atuando na linha do centróide, e a uma carga $p$ distribuída lateralmente ao longo do comprimento da viga, representando o carregamento do vento e efeitos dinâmicos.

As seguintes hipóteses foram assumidas por Stratford \& Burgoyne (2000):

- A viga não apresenta flexão em torno do eixo de maior inércia nem torção. Entretanto, é livre para fletir em torno do eixo de menor inércia bem como apresentar giro de corpo-rígido.

- Barras rígidas são fixas nas vigas. As partes superiores destas barras são presas nos cabos de suspensão que estão inclinados com relação à horizontal. Os cabos apenas suportam forças de tração.

- A viga apresenta imperfeições iniciais que variam segundo a metade de uma onda de senóide ao longo do comprimento da viga, porém desfasadas de tal forma que o deslocamento é nulo nos pontos onde as barras rígidas estão fixas.

- A viga é submetida a um carregamento lateral aplicado a uma dada distância abaixo do ponto de fixação das barras rígidas, sendo este carregamento paralelo à direção do eixo de maior inércia da viga enquanto esta gira.

- Considera-se o carregamento devido ao peso-próprio ao longo do CG.

- Os deslocamentos relativos ao eixo de menor inércia são assumidos pequenos em comparação com o eixo da viga.

- A viga permanece no regime elástico-linear em toda a análise, sendo invariáveis as propriedades das seções.

Stratford \& Burgoyne (2000) consideraram a rigidez do elemento estrutural constante. Isto significa que a análise não pode ser desenvolvida a partir do instante em que a viga começa a fissurar-se, uma vez que a fissuração reduz a rigidez da viga. Esta simplificação é justificada pelos citados autores pelo fato de que se a instabilidade é eminente antes da fissuração, ela certamente irá ocorrer após a fissuração, o que seria catastrófico.

Uma vez escritas as equações de equilíbrio para o trecho central entre os cabos de içamento e o trecho dos balanços, Stratford \& Burgoyne (2000) observaram que não existe solução analítica, porém, a tarefa passa a ser encontrar o valor da rotação de corporígido $\theta$ em torno do eixo da viga que satisfaça as condições de compatibilidade, segundo as condições de contorno. Segundo os autores, o procedimento é repetitivo, porém, essencialmente simples.

As análises simplificadas desenvolvidas por Stratford \& Burgoyne (2000) mostraram o comportamento de vigas suspensas em gráficos plotando a relação da carga crítica com 
o comprimento dos balanços, considerando ou não excentricidade inicial lateral como imperfeição inicial. Também encontram-se comparadas a influência da inclinação dos cabos de suspensão observando-se ainda os modos de flambagem resultantes.

Com relação à consideração inicial de que a viga gira como corpo-rígido, Stratford \& Burgoyne (2000) observaram que a taxa de giro por torção é pequena comparada com o giro de corpo-rígido, verificando que a simplificação é razoável.

Enfim, entende-se que os problemas de instabilidade lateral de vigas podem ser críticos quando as ligações ainda são provisórias, uma vez que a montagem ainda não foi concluída. Estas ligações são geralmente insuficientes para impedir giros e deslocamentos, e uma vez que a deformabilidade das ligações é considerada, esta contribui para a perda de estabilidade.

No caso das ligações referentes à fase de montagem, em linhas gerais, três tipos de situações de ruína podem ocorrer: a ruína do elemento, a do apoio ou a perda de equilíbrio do elemento como corpo rígido.

Com relação às ligações, tem sido cada vez mais pesquisado o estudo da deformabilidade, uma vez que sua consideração torna a análise estrutural mais próxima e coerente com o comportamento real da estrutura. Isto certamente resultará em valores mais adequados para o dimensionamento e para o estudo da estabilidade estrutural.

Porém, o comportamento real de uma ligação é não-linear, o que torna ainda mais complexo o seu estudo. É necessário então distinguir em que situações é razoável considerar a relação momento-rotação por meio de uma aproximação linear. 


\section{Capítullo}

$$
\text { O马 TORÇÃO EM VIGAS DE CONCRETO ARMADO }
$$

\subsection{GenERALiDADES}

No estudo do comportamento de vigas pré-moldadas de concreto durante as fases transitórias e temporárias, onde a estabilidade lateral deve ser cuidadosamente verificada, a presença de solicitações combinadas e seus efeitos na rigidez do elemento são importantes na análise estrutural.

A fim de desenvolver um estudo do comportamento de peças de concreto armado e protendido sob ação conjunta de torção, flexão e força axial, faz-se necessário conhecer melhor os efeitos da torção no concreto, quando ação isolada e quando associada a outras solicitações.

A torção é normalmente considerada uma solicitação secundária na maioria das estruturas de concreto armado. No entanto, o efeito da torção em vigas curvas, em vigas que constituem um sistema monolítico de grelhas e na maioria das vigas de pontes, devido ao carregamento excêntrico, merece cuidadosa atenção. Bhatti (1996) considera a torção um efeito primário nestas situações.

Segundo Leung \& Schnobrich (1987), o refinamento dos métodos de cálculo diminuindo os fatores de segurança utilizados em projetos resultam em elementos estruturais mais esbeltos, onde os efeitos secundários da torção não podem mais serem ignorados.

A complexidade de problemas que envolvem torção é um fator que inibe o desenvolvimento de modelos eficientes que representem o comportamento à torção. Por exemplo, elementos como pilares, cuja solicitação dominante é a força axial, podem ser reduzidos à análise de tensões uniaxiais. Elementos onde o cisalhamento e a flexão são predominantes, podem ser analisados segundo o estado plano de tensões. Mas aqueles elementos estruturais onde a torção é significativa exigem modelos tridimensionais para análise de tensões. Assim, uma análise cuidadosa torna-se mais importante, uma vez que as peças já começam a apresentar um início no quadro de fissuração, ainda em estágios relativamente precoces de carregamento.

Quando um elemento de concreto armado está solicitado por torção, o comportamento estrutural observado é especialmente influenciado pela presença de fissuração. Normalmente, admite-se que o concreto antes de fissurar-se, sob torção, comporta-se em regime elástico-linear. Porém, após a fissuração, o comportamento de um elemento de concreto é fortemente influenciado pela inclinação das fissuras, que depende das características da seção transversal, bem como da quantidade de armadura, dentre vários outros fatores. Nesta fase, a torção de Saint-Venant não pode mais ser considerada, uma vez que o material não é mais um meio contínuo. 
De acordo com Leung \& Schnobrich (1987), dependendo do nível do carregamento, a presença da torção influencia consideravelmente o comportamento da peça, chegando a ser o efeito dominante na definição do mecanismo estrutural.

O modelo apresentado por Leung (1982) e posteriormente utilizado por Cocchi \& Volpi (1996), bem como neste trabalho, para análise inelástica de vigas de concreto sujeitas a torção combinada com flexão e força axial, baseia-se no modelo de treliça espacial com ângulo de inclinação variável.

O modelo de treliça espacial aplicado a elementos sob torção constitui-se de banzos e montantes tracionados de aço, representando as armaduras longitudinais e transversais, e de diagonais comprimidas de concreto que distribuem-se ao longo da viga, em espiral.

Este capítulo apresenta um breve histórico da evolução da teoria de torção em termos do modelo de treliça espacial, dedicando-se também a introduzir uma das teorias da literatura técnica sobre torção e cisalhamento em peças estruturais de concreto armado. Esta teoria proposta por Vecchio \& Collins (1986), conhecida atualmente como Modified Compression Field Theory - MCFT ou Teoria Modificada dos Campos Comprimidos, foi utilizada neste trabalho na definição do comportamento estrutural do concreto armado sob torção, assim como em Cocchi \& Volpi (1996). O desenvolvimento, o estudo e a aplicação desta teoria iniciou-se na Universidade de Toronto na década de 70, sendo um dos modelos teóricos recomendados pela Norma Canadense CSA A23.3-94 (1994), para o cálculo e análise de estruturas solicitadas por torção e cisalhamento.

Cronologicamente, observa-se um pico de trabalhos publicados nos anos 60 referentes a elementos estruturais solicitados por torção pura, em virtude dos recursos computacionais disponíveis, embora as pesquisas relativas ao estudo do comportamento de elementos de concreto armado sob torção datem do início do século XX.

\subsection{Considerações SOBRe a TeOria Clássica de TORÇão eM ELEMENTOS HOMOGÊNEOS}

Os estudos sobre torção em elementos circulares iniciaram-se em 1784 quando Coulomb, investigando as propriedades de cargas elétricas, observou a proporcionalidade entre momento de torção e taxa de giro por torção.

No entanto, mais de 40 anos depois, em 1826, Navier apresenta um estudo teórico sobre resistência dos materiais, com uma fundamentada formulação satisfazendo as condições de equilíbrio, de compatilibidade e as relações tensão-deformação. Para descrever o comportamento de seções circulares de material homogêneo, Navier define 2 hipóteses básicas de compatilibilidade:

- A forma da seção transversal permanece indeformada após o giro por torção;

- Seções planas permanecem planas após o giro por torção, sem empenamento.

Saint-Venant, a partir de 1855, dedicou-se ao estudo da torção em elementos homogêneos, buscando obter expressões para o momento polar de inércia para outras seções transversais. Saint-Venant observa que as hipóteses assumidas por Navier realmente se verificam para seção circular. No entanto, a segunda hipótese referente à 
ausência de empenamento não é válida para seções não circulares. Assim, Saint-Venant mantém a primeira hipótese de Navier, mas considera que o empenamento da seção transversal é idêntico ao longo de todo o comprimento do elemento não circular.

Vale a pena observar que a teoria de Saint-Venant demorou 30 anos para ser desenvolvida, aguardando os avanços da Teoria da Elasticidade e as necessárias ferramentas matemáticas, como a Série de Fourier.

Saint-Venant define uma função de tensão que satisfaz as condições de contorno, a fim de obter as tensões em uma seção retangular. Escrevendo a função de tensão em termos da série de Fourier, bem como o empenamento, Saint-Venant obtém os valores para a constante de torção C, conhecida da Resistência dos Materiais, função das dimensões da seção retangular, e que representa o parâmetro geométrico de sua expressão clássica.

\subsection{InTRODUÇão aOS MODELOS DE TReliça Espacial Para TORÇÃO}

Os primeiros estudos sobre cisalhamento em elementos de concreto armado baseiam-se na analogia ao conceito de treliça, desenvolvidos no final do século XIX e início do século XX, por Ritter e Mörsch.

O modelo teórico adotado para o concreto armado era descrito por dois tipos de elementos lineares: bielas comprimidas de concreto e tirantes tracionados de aço. Embora as bielas e os tirantes fossem idealizados como elementos de barra, e portanto, sem dimensões transversais, as forças nestes elementos deveriam satisfazer as condições de equilíbrio nos pontos nodais.

Esta teoria admitia que o elemento fissurado de concreto armado comportava-se como uma treliça com banzos paralelos constituídos pelas barras longitudinais sob tração, diagonais constituídas pelo concreto comprimido e os montantes tracionados representados pelos estribos. Nessa época, desprezava-se a resistência do concreto à tração.

Considerava-se então, o cisalhamento resistido pela componente vertical da força de compressão das diagonais comprimidas de concreto. A componente horizontal equilibrava-se com a força de tração da armadura longitudinal.

Mörsch apud Collins \& Mitchell (1980), em 1922, considerava absolutamente impossível determinar matematicamente o ângulo de inclinação das fissuras secundárias, o que dificultava o cálculo da área necessária de estribos. Para fins práticos, no cálculo usual da armadura transversal Mörsch recomendava assumir $\theta=45^{\circ}$, ângulo este referente às fissuras iniciais, uma vez que entendia que estas realmente deveriam apresentar esta inclinação.

As pesquisas sobre torção em elementos de concreto armado iniciaram-se em $1929 \mathrm{com}$ os trabalhos de Rausch, que estendeu o conceito proposto para o cisalhamento, considerando então, o comportamento à torção representado por uma treliça espacial. 
Conforme assumido para o cisalhamento, Rausch admitia que após a fissuração o concreto não era capaz de absorver esforços de tração.

O modelo de Rausch considera a seção como um tubo vazado, sendo o momento de torção resistido pelo fluxo circulatório de cisalhamento nas paredes da seção. Assim, a componente da diagonal comprimida na direção do eixo da peça deve equilibrar-se com as forças resultantes da armadura longitudinal tracionada. Admitiu-se ainda que a trajetória do fluxo de cisalhamento coincidia com a linha central dos estribos.

Rausch, assim como Mörsch, adotou $\theta=45^{\circ}$. Este é considerado um dos motivos pelo qual a teoria proposta por Rausch superestima significativamente a real capacidade da seção resistente do elemento sob torção.

Porém, o ângulo de inclinação das bielas de concreto não é em geral $45^{\circ}$. O código modelo CEB permite variações para o ângulo $\theta$ entre $3 / 5<\tan \theta<5 / 3$, ou seja, entre $30,96^{\circ}$ e $59,04^{\circ}$. Estes valores baseiam-se na modificação dos limites empíricos apresentados por Lampert \& Thürlimann (1971) apud Collins \& Mitchell (1980), para vigas sob torção.

Até então, os modelos definidos com elementos lineares para cisalhamento e torção frequentemente superestimavam a resistência atribuída à peça estrutural sob estas solicitações. Entretanto, de acordo com Hsu (1998), em regiões de perturbação da inclinação das diagonais comprimidas, a teoria com elementos lineares continua sendo uma ferramenta utilizada.

Em 1960, um novo conceito foi aplicado para representar a ação da torção e do cisalhamento no concreto armado. Considerava-se que o elemento estrutural de concreto armado era composto por elementos bidimensionais ao invés de elementos lineares.

Para implementar o conceito de material contínuo em elementos bi-dimensionais de placa, o modelo de treliça pôde fundamentar-se no conceito de fissuração distribuída ou smeared cracks. Neste contexto, as leis constitutivas do concreto armado fissurado consideram as tensões e deformações através de seus valores médios. Isto significa que um valor médio de tensão equivale ao valor médio obtido entre a tensão na fissura e a tensão entre duas fissuras; um valor médio de deformação é igual ao valor obtido a partir de um deslocamento que atravessa várias fissuras, incluindo as descontinuidades dadas pelo valor da abertura das fissuras. Enfim, as leis constitutivas que definem as relações médias para tensão-deformação do concreto e das armaduras devem ser estabelecidas diretamente dos testes em painéis de concreto armado.

Considerando válidos os princípios de Navier referente à mecânica dos materiais em elementos bi-dimensionais, o modelo de treliça espacial adquire maior consistência e fundamentação teórica. Alguns avanços podem ser observados na formulação dos modelos de treliça com elementos bi-dimensionais, à medida em que são considerados alguns conceitos nas análises e nos modelos teóricos.

O primeiro princípio baseado no equilíbrio de forças, representa o tratamento angular da inclinação das bielas comprimidas de concreto, através dos conceitos de plasticidade. Ou seja, definem-se as equações de equilíbrio no plano, e admitem-se que as tensões nas 
armaduras atingem o valor de escoamento na ruptura, enquanto a tensão de tração no concreto é desprezada. Assim, tem-se uma relação entre o ângulo de inclinação $\alpha$ das bielas comprimidas em função das taxas de armaduras transversal $\rho_{\mathrm{t}}$ e longitudinal $\rho_{\ell}$, e das tensões de escoamento $f_{\text {ty }}$ e $f_{l y}$, conforme ilustra a equação (3.1). Uma vez que a equação (3.1) depende diretamente dos valores de escoamento da armadura, a mesma deve ser utilizada apenas no estado limite último.

$$
\tan \theta=\sqrt{\frac{\rho_{\mathrm{t}_{\mathrm{ty}}}}{\rho_{\ell} \mathrm{f}_{\ell \mathrm{y}}}}
$$

O segundo princípio refere-se às condições de compatibilidade, onde o ângulo de inclinação das diagonais comprimidas encontra-se definido através das condições de compatibilidade de deformações, sendo limitado pelo primeiro princípio. Nestas considerações, tem-se a teoria linear de flexão, desprezando-se a resistência à tração do concreto. Admite-se válida a lei de Hooke para o concreto à compressão e para as armaduras. Este modelo teórico de análise linear é válido apenas no estado de utilização.

No terceiro princípio, relativo às leis constitutivas dos materiais, admite-se o efeito de amolecimento ou softening do concreto à compressão, devido à existência de tensões de tração na direção perpendicular à direção principal de compressão. $O$ trabalho de Robinson \& Demorieux (1972) apud Hsu (1996) abriu as portas às investigações do comportamento do concreto considerando o efeito do amolecimento.

Até 1972, a concepção do modelo de treliça para esforço cortante e torção ainda apresentava controvérsias, uma vez que até então os resultados teóricos superestimavam a resistência da peça sob estes esforços. Nessa época, a tensão de ruptura do concreto era considerada igual ao valor obtido em corpos-de-prova cilíndricos sob compressão uniaxial.

No entanto, as observações de Robinson \& Demorieux (1972) apud Hsu (1996) mostravam que um elemento de concreto submetido ao cisalhamento comportava-se segundo um estado plano de tensões. Então, a tensão efetiva do concreto passou a ser considerada como a resultante obtida levando-se em conta que a tensão principal de compressão é alterada pela presença da tensão principal de tração, ortogonal à direção da primeira.

No trabalho de Hsu (1985a) observa-se a grande preocupação em considerar o amolecimento ou efeito de softening no concreto, no cálculo da resistência à torção de elementos de concreto armado baseado no modelo de treliça espacial. Segundo Hsu (1985a), o efeito de amolecimento nas bielas de concreto explica porque a equação proposta por Rausch, em 1929, superestima a resistência à torção de elementos de concreto armado.

De acordo com Hsu (1985a), as tentativas utilizadas para reduzir o valor do momento de torção resistente da peça estrutural como admitir que a armadura é parcialmente eficiente, reduzir a área considerando que a linha central por onde passa o fluxo de cisalhamento coincide com as linhas que unem os centro das barras longitudinais nas quinas da seção, e desprezar o cobrimento de concreto externo à linha central do estribo, são desnecessárias, frente à consideração do efeito de softening do concreto. Mesmo porque, segundo Hsu (1985a), o comportamento à torção de uma peça estrutural 
depende do ângulo de inclinação das bielas, da deformação das armaduras e da deformação do concreto ao longo da história do carregamento.

O trabalho experimental desenvolvido por Hsu (1968) para investigação do comportamento do concreto armado sob torção pura, destaca-se por sua abrangência, e por ter-se tornado referência para comparação com os modelos estruturais teóricos desenvolvidos posteriormente. Para este fim, foi projetado um equipamento capaz de aplicar um momento de torção de até $113 \mathrm{kNm}$, em vigas com dimensões limites de $38,1 \times 50,8 \mathrm{~cm}$. Três tipos de testes foram realizados: em elementos de concreto simples, em elementos de concreto armado e em vigas de seção vazada de concreto simples e armado.

Nesses ensaios Hsu (1968) considerou importante a observação de oito variáveis, sendo elas: a porcentagem de armadura, a comparação do comportamento de vigas sólidas e correspondentes de seção vazada, a relação volume de armadura longitudinal e transversal, a resistência do concreto, o efeito de escala, a relação entre as dimensões da seção transversal retangular, o espaçamento entre as barras longitudinais e entre os estribos.

Nas análises desenvolvidas a partir dos resultados experimentais obtidos por Hsu (1968), o autor apresenta algumas conclusões importantes, tais como:

- O comportamento de uma viga submetida à torção é completamente diferente antes e após a fissuração. O momento de fissuração é pouco superior ao momento de ruptura apresentado por uma viga equivalente de concreto simples.

- Antes da fissuração, o comportamento de uma viga de concreto armado é semelhante ao de uma viga de concreto simples com as mesmas dimensões, sem sofrer influência da presença da armadura.

- Após a fissuração, o comportamento da viga não segue mais o proposto por Saint-Venant, nem mesmo com relação à distribuição de tensões das armaduras. A deformação de compressão é muito maior que a prevista teoricamente.

- O comprimento da viga aumenta com o aumento do momento de torção, devido ao alongamento das armaduras longitudinais.

- As vigas de concreto subarmadas podem ser previstas a partir de uma expressão empírica, que define a máxima taxa de armadura para a qual existirá escoamento da mesma, antes do esmagamento do concreto.

- A relação entre volume de armadura longitudinal e volume de estribos, que garante que ambas as armaduras irão escoar na ruptura não é sempre igual a 1. Outras relações irão resultar em vigas parcialmente super-armadas, para as quais as barras longitudinais ou os estribos não irão escoar na ruptura.

- O concreto interno desprezado quando se define a seção vazada não contribui para a capacidade resistente última da viga sólida de concreto.

A seguir serão apresentadas as Teorias de Campos Comprimidos, proposta inicialmente 
por Collins em 1973 e denominada Compression Field Theory, depois aplicada e avaliada experimentalmente por Mitchell (1974), quando passou a ser chamada de Diagonal Compression Field Theory. Até então a teoria desprezava a resistência à tração do concreto. Vecchio \& Collins (1986) apresentam um estudo do comportamento de elementos de concreto armado solicitados por cisalhamento baseado na análise experimental de 30 painéis de concreto armado, onde buscavam também, reformular as relações constitutivas do concreto fissurado. Com as novas relações constitutivas apresentadas para o concreto, a teoria passa a ser designada por Modified Compression Field Theory.

\subsection{TEORIAS DOS CAMPOS COMPRIMIDOS}

\subsubsection{TEORIA DOS CAMPOS COMPRIMIDOS - CFT - 1973}

Para avaliar os esforços resultantes decorrentes do cisalhamento e da torção, a partir das equações de equilíbrio da analogia de treliça, é necessário conhecer a inclinação das tensões de compressão nas bielas de concreto.

Em 1931, Wagner apud Mitchell (1974) tratou de um problema análogo estudando a resistência ao cisalhamento em vigas esbeltas de aço no regime pós-flambagem. Wagner admitiu que após a flambagem as paredes delgadas não eram mais capazes de resistir à compressão e que o cisalhamento seria suportado por um campo de diagonais tracionadas. Para determinar o ângulo de inclinação das diagonais sob tração, Wagner considerou que o ângulo de inclinação das tensões nas diagonais tracionadas coincidia com o ângulo de inclinação das deformações principais de tração. Esta aproximação tornou-se conhecida como Tension Field Theory ou Teoria dos Campos Tracionados.

Aplicando a aproximação de Wagner para o concreto armado, e admitindo que o concreto após fissurar-se não absorve esforços de tração, sendo o cisalhamento suportado pelas diagonais comprimidas, pode-se definir a expressão (3.2), escrita em termos do ângulo de inclinação $\theta$ das tensões na biela comprimida:

$$
\tan ^{2} \theta=\frac{\varepsilon_{\ell}-\varepsilon_{\mathrm{d}}}{\varepsilon_{\mathrm{t}}-\varepsilon_{\mathrm{d}}}
$$

onde $\varepsilon_{\ell}$ representa a deformação longitudinal da armadura (positiva para tração), $\varepsilon_{\mathrm{t}}$ é a deformação transversal (positiva para tração) e $\varepsilon_{\mathrm{d}}$ a deformação principal média de compressão do concreto (negativa para compressão).

A equação (3.2) pode ser obtida a partir do círculo de Mohr, descrito para as deformações, sendo também idêntica à obtida por Wagner, a partir de considerações de minimização da energia de deformação. Além disto, a equação (3.2) pode ser definida como uma relação de compatilibidade entre as deformações observadas no concreto e nas armaduras.

O significado físico da expressão (3.2), análoga à de Wagner, pode ser avaliado segundo as inclinações das fissuras. Para fissuras com baixa inclinação, a armadura transversal será altamente solicitada, enquanto que para fissuras com grande inclinação, o mesmo 
ocorrerá na armadura longitudinal.

Segundo Mitchell (1974), o ângulo de inclinação das tensões de compressão nas diagonais não corresponde necessariamente com o ângulo de inclinação das fissuras. Porém, teoricamente são admitidos equivalentes.

Da condição de compatibilidade definida pela expressão (3.2), das equações de equilíbrio da analogia de treliça e das relações constitutivas dos materiais envolvidos, pode-se conhecer teoricamente o comportamento de elementos de concreto armado sob cisalhamento e torção. Esta aproximação foi denominada por Collins, em 1973, por analogia ao trabalho de Wagner, de Compression Field Theory ou Teoria dos Campos Comprimidos, uma vez que inclui a consideração de que no regime pós-fissuração o concreto não resiste à tração e a torção é resistida pelas diagonais comprimidas de concreto.

Assim, admitindo-se um valor inicial para o ângulo de inclinação das diagonais comprimidas, pode-se calcular as tensões de tração nas armaduras longitudinal e transversal, bem como a tensão de compressão nas diagonais, através das relações de equilíbrio. Uma vez que as relações constitutivas do aço e do concreto são conhecidas, pode-se calcular então, as respectivas deformações. Com as deformações, verifica-se com a expressão de compatibilidade (3.2) se o ângulo encontrado é igual ao adotado inicialmente. Caso não sejam iguais dentro de uma certa tolerância, deve-se reiniciar o processo, até a sua convergência. Deste modo, esta teoria permite calcular o ângulo de inclinação das bielas comprimidas de concreto.

Em uma viga deformada submetida à torção pura, observa-se que as paredes não permanecem planas. Devido à curvatura das paredes, a deformação das diagonais comprimidas deve ser no máximo igual a $\varepsilon_{\mathrm{ds}}$ na superfície, e irá diminuir linearmente, segundo o modelo, ao longo da espessura efetiva $t_{d}$.

As tensões nas diagonais de concreto irão variar ao longo da espessura efetiva de concreto da seção, de zero, no interior, até o valor $\mathrm{f}_{\mathrm{ds}}$ correspondente à deformação $\varepsilon_{\mathrm{ds}}$, na superfície efetiva externa.

Como na flexão, pode-se substituir a real distribuição de tensões por uma equivalente uniformemente distribuída, sendo os parâmetros para esta equivalência função da forma da curva tensão-deformação do concreto e do valor da deformação de compressão do concreto na superfície da peça.

De acordo com Collins \& Mitchell (1980), a teoria Compression Field Theory para elementos sob torção requer atenção para alguns aspectos. Na resistência à torção, nem todo concreto auxilia nas tensões de compressão da diagonal. Nos elementos das quinas, por exemplo, nota-se que a compressão tende a separar o cobrimento do concreto, enquanto a tração nos estribos, tende a segurar o concreto interno ao estribo, como ilustra a Figura 3.1.

Considerando a fragilidade do concreto à tração, para torção elevada, a camada de concreto fora da armadura se descola. Por este motivo, Collins \& Mitchell (1980) sugerem que a superfície externa efetiva do concreto deve ser considerada até a linha central da armadura transversal. 

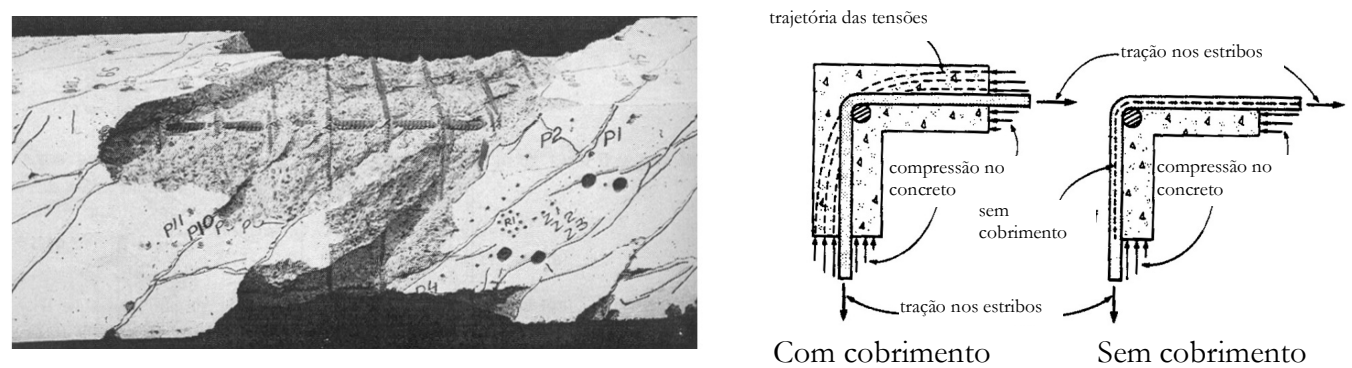

Figura 3.1 - Destacamento da camada de cobrimento. Collins \& Mitchell (1980).

Entretanto, segundo McMullen \& El-Degny (1985) apud Hsu (1996), o destacamento do cobrimento não pode ser justificado segundo os ensaios disponíveis na literatura técnica, e definem a teoria de Collins como modelo de treliça sem cobrimento.

De acordo com Collins \& Mitchell (1980), estudos considerando a analogia de treliça com $45^{\circ}$ de inclinação para as bielas comprimidas têm-se revelado conservativos, particularmente com relação ao caso de vigas com baixas taxas de armadura. Para menores ângulos de inclinação das diagonais comprimidas, será necessária uma taxa de armadura transversal menor, porém, maior taxa de armadura longitudinal.

À medida que a relação momento de torção/momento de flexão diminui, ou seja, a flexão passa a ser predominante sobre a torção, o ângulo de inclinação da diagonal comprimida aumenta. Os valores previstos para o ângulo das bielas comprimidas de concreto variam de $24^{\circ}$, na torção pura, a $90^{\circ}$ na flexão pura, tendo sido estes valores obtidos experimentalmente, conforme apresentados em Collins \& Mitchell (1980).

\subsubsection{TeORIA DOS CAMPOS DiAGONAIS COMPRIMIDOS - DCFT - 1974}

Em 1974, Mitchell (1974) apresenta em sua tese de doutorado um modelo teórico baseado na Teoria dos Campos Comprimidos para elementos de concreto submetidos à torção pura, chamado Diagonal Compression Field Theory ou Teoria dos Campos Diagonais Comprimidos. O modelo é capaz de prever o comportamento pós-fissuração de elementos simetricamente armados de concreto. Uma vez conhecida a curva que define a resposta do modelo, pode-se determinar a deformação dos estribos, da armadura longitudinal, a distribuição da deformação do concreto e a taxa de giro de um elemento para um dado nível de carregamento de momento de torção. Mitchell (1974) desprezava a resistência à tração do concreto.

O objetivo de Mitchell (1974) era o de apresentar um modelo teórico para concreto estrutural sob torção pura, o qual pudesse ser analisado de forma análoga à teoria de flexão, considerando as propriedades do aço e do concreto através de suas leis constitutivas, e que descrevesse o comportamento pós-fissuração.

Para este fim, Mitchell (1974) apresenta um procedimento, baseado em equações de equilibrio e compatibilidade de deslocamentos, considerando conhecidas as leis constitutivas dos materiais envolvidos, que consiste em adotar um valor para a deformação do concreto na superfície da seção, e a partir de então calcular a 
deformação da armadura longitudinal e transversal. Para isto, deve-se adotar um valor inicial para a espessura da seção onde percorre o fluxo de cisalhamento, e depois verificá-la segundo as equações que definem o comportamento do modelo. Uma vez encontrada a convergência para o valor adotado, calcula-se o fluxo de cisalhamento, a taxa de giro por torção da viga, bem como o momento de torção correspondente. Repetindo-se o procedimento citado para vários valores da deformação do concreto, obtem-se uma curva que define a resposta completa da seção solicitada por torção pura.

Com relação ao destacamento da camada de cobrimento do concreto sob altas solicitações de torção, Mitchell (1974) mostra que se o equilíbrio de um elemento de quina for analisado em uma viga sob torção, pode-se observar que o concreto tende a ser destacado da quina da seção, enquanto a tração nos estribos tende a conter o concreto que encontra-se interno à armadura transversal. Uma vez que os estribos não podem impedir a perda de concreto nas quinas sem gerar altas tensões de tração nos mesmos, Mitchell (1974) considera que para altas solicitações, o cobrimento deverá soltar-se.

Em seu trabalho, a fim de investigar os efeitos da perda da camada de cobrimento, Mitchell (1974) analisa duas vigas idênticas com relação às armaduras e com concretos de resistências similares. A única diferença entre as duas vigas ensaiadas por Mitchell (1974) é a espessura da camada de cobrimento. A viga denominada PT5 apresentava 0,16 cm de cobrimento, ou seja, praticamente cobrimento nulo, e a viga PT6, 3,97 cm. As dimensões das duas vigas, internas à linha central dos estribos era a mesma, porém, externamente a viga PT5 apresentava 35,56 x 35,56cm e a viga PT6, 43,18 x 43,18cm.

Mitchell (1974) conclui, a partir dos resultados experimentais, que a carga de ruptura das vigas foi praticamente a mesma, ou seja, o cobrimento da viga PT6 não colaborou para aumentar a capacidade resistente da mesma. No entanto, verifica também que o concreto fora dos estribos contribui significativamente para aumentar a carga que representa o início da fissuração da viga, onde o diagrama momento-curvatura passa a ser não-linear. Os resultados mostram que o momento de fissuração da viga PT6 foi praticamente o dobro do verificado para a viga PT5, mesmo porque nesta fase, o efeito das dimensões da seção é dominante. A influência da rigidez da viga considerando as dimensões reais contribui para enrijecer toda a resposta do comportamento observado na viga PT6.

Com relação ao controle da abertura de fissuras, Mitchell (1974) observa que como a armadura da viga PT5 está mais próxima da superfície, ela é portanto, mais eficiente. A diferença entre a abertura de fissuras observada por Mitchell (1974), nas análises experimentais, torna-se significativa após o escoamento da armadura transversal. Com relação à espessura do cobrimento, Mitchell (1974) conclui que à medida que a espessura da camada de cobrimento aumenta, as fissuras tornam-se maiores.

Uma aplicação dada ao trabalho de Mitchell (1974) foi desenvolvida por Onsongo (1978), em sua tese de doutorado. Onsongo (1978) apresentou um modelo teórico capaz de prever a resposta de vigas de concreto armado submetidas à torção combinada com flexão e força axial, no período pós-fissuração. O modelo teórico foi comparado com os resultados experimentais de 14 vigas de concreto superarmadas submetidas à torção combinada com flexão. 
Neste modelo, onde utiliza a Teoria dos Campos Diagonais Comprimidos apresentada por Mitchell (1974), Onsongo (1978) admite as seguintes hipóteses básicas: seções planas permanecem planas, a direção das tensões principais são admitidas coincidentes com a direção das deformações principais, e o concreto fissurado não resiste a tensões de tração, assumindo ainda no regime pós-fissuração que o cobrimento de concreto se descola a partir da linha central do estribo.

Assim como Mitchell (1974), Onsongo (1978) considera que o fluxo de cisalhamento gerado pela torção é suportado pelas tensões de compressão nas bielas, e portanto, o modelo não é válido onde prevalece a flexo-torção.

Segundo Onsongo (1978), as análises dos resultados experimentais mostraram que a torção induz o descolamento do cobrimento. Em vigas submetidas à flexão pura, não ocorreu nenhum sinal de destacamento da camada de cobrimento. No entanto, nas vigas de concreto ensaiadas sob solicitação de flexão e torção, observou-se que quanto maior a relação torção/flexão, mais significativo é o efeito da perda do cobrimento. Nestes casos, observou-se experimentalmente que o descolamento do cobrimento ocorreu para carga próximas à de ruptura. Quando a torção não era muito superior à flexão, observou-se nos ensaios que apenas as quinas da seção apresentaram destacamento.

Onsongo (1978) observou que desprezando a resistência do concreto à tração, era consistente assumir que a perda da camada de cobrimento deveria iniciar-se nas quinas, e propagar-se em todo o contorno da seção, até que a seção ativa de concreto se resumisse à interna a linha central que define o perímetro do estribo. Ou seja, o cobrimento deveria ser considerado incapaz de absorver o carregamento aplicado.

No entanto, ignorar a resistência à tração do concreto também significava desconsiderar o enrijecimento nas barras da armadura, proporcionados pelo trecho delimitado entre duas fissuras, constituído pelo concreto não-fissurado. Este efeito de tension-stiffening, segundo Onsongo (1978), deveria ser significativo nos primeiros níveis de carregamento após a formação das fissuras.

Assim, admitindo a resistência à tração do concreto igual a zero e desprezando a camada de cobrimento na definição da seção transversal, Onsongo (1978) conscientemente obteve deformações teóricas superiores às obtidas experimentalmente. Uma das considerações de Mitchell (1974), a fim de aproximar-se dos resultados experimentais, consistia em utilizar a média das deformações obtidas utilizando a seção real e a seção desprezando o cobrimento. Mesmo assim, Onsongo (1978) recomenda utilizar a seção sem o cobrimento por estar a favor da segurança e por fornecer melhores resultados sob altas solicitações de torção.

Com relação à inclinação das fissuras observadas experimentalmente, Onsongo (1978) relata que em qualquer nível de carregamento, apesar da inclinação das fissuras não indicar necessariamente a direção da tensão principal de compressão, o padrão da mudança de inclinação das fissuras dá uma indicação da variação da direção das tensões principais de compressão no concreto.

A consideração de seção sem cobrimento no caso da flexão pura evidentemente subestima a capacidade da mesma à flexão. No entanto, a seção em sua forma real 
torna-se contra a segurança quando existe também solicitação de torção. Segundo Onsongo (1978), a capacidade de uma viga sob ação conjunta de torção e flexão é melhor prevista considerando a seção sem o cobrimento. Da avaliação experimental, Onsongo (1978) conclui que para os valores últimos da relação torcão/flexão superior a 0,6, temse bons resultados considerando-se a seção sem a camada de cobrimento.

\subsubsection{TEORIA MODIFICADA DOS CAMPOS COMPRIMIDOS - MCFT - 1986}

Em 1981, Vecchio \& Collins apud Hsu (1996) apresentaram a primeira proposta de uma curva tensão-deformação para o concreto à compressão incluindo o efeito de amolecimento, após ensaios experimentais de cisalhamento em painéis de concreto. Esta curva incorpora um coeficiente de amolecimento definido por $\lambda$, sendo este parâmetro, função da deformação principal de tração.

O comportamento do concreto admitindo o amolecimento foi então considerado juntamente com as relações de tensão e deformação dadas pelo círculo de Mohr, para prever a resposta de elementos sob esforços de cisalhamento e torção.

Até então, a teoria dos campos comprimidos desprezava a resistência à tração do concreto. Em Vecchio \& Collins (1986), a teoria é modificada para elementos de concreto armado sob torção e cisalhamento. O concreto fissurado é tratado como um novo material, com características próprias para as relações tensão-deformação.

As relações de equilíbrio, de compatibilidade e as leis constitutivas são formuladas através dos valores médios das tensões e das deformações, conforme comentado anteriormente, com relação à teoria de fissuração distribuída.

O modelo analítico proposto por Vecchio \& Collins (1986) é capaz de prever o comportamento de elementos de concreto armado submetidos a um estado plano de tensões normais e cisalhantes. As relações tensão-deformação foram medidas em laboratório, em ensaios de 30 painéis de concreto armado, tendo sido utilizadas várias situações de tensões bi-axiais uniformes, incluindo torção pura.

Vecchio \& Collins (1986) verificaram a partir dos resultados dos ensaios experimentais, que o concreto fissurado submetido a altas deformações de tração na direção normal à de compressão é mais frágil na resistência à compressão, comparando com os resultados obtidos nos testes para cálculo da resistência do material, em corpos-de-prova padrão das normas técnicas. Além disto, tensões de tração significativas foram verificadas no concreto entre as fissuras, mesmo para altos valores médios da deformação de tração.

As hipóteses básicas admitidas por Vecchio \& Collins (1986) foram:

- Para cada estado de deformação existe um único estado correspondente de tensão; a influência da história do carregamento não é considerada, mesmo sendo significativa.

- As tensões e deformações devem ser consideradas em termos de seus valores médios, de forma que as áreas e distâncias sejam suficientes para incluir várias fissuras. 
- A aderência concreto-armadura é perfeita.

- As armaduras longitudinal e transversal são uniformemente distribuídas no elemento.

Com respeito à transmissão de esforços entre as fissuras, a formulação desenvolvida por Vecchio \& Collins (1986) encontra-se descrita através dos valores médios, não apresentando informações sobre as variações de tensões e deformações em pontos discretos.

Assim, em uma fissura, as tensões de tração na armadura atingem valores superiores ao valor médio, enquanto no ponto médio entre as fissuras, apresenta valor menor que o médio. Por outro lado, a tensão de tração no concreto é zero na fissura e atinge valor superior ao médio no ponto central entre duas fissuras. Estas variações locais são importantes porque a capacidade última de um elemento solicitado no plano é governada pela capacidade da armadura transmitir esforço de tração entre as fissuras.

No trabalho desenvolvido por Vecchio \& Collins (1986) encontram-se resultados avaliados experimentalmente referente às relações constitutivas do concreto fissurado, sendo estas relações incorporadas na resposta tensão-deformação principal de compressão, bem como no comportamento verificado na relação tensão-deformação principal de tração. As leis constitutivas são influenciadas pelos efeitos de softening ou amolecimento do concreto e tension-stiffening ou enrijecimento verificado na armadura, em virtude da presença de trechos de concreto não-fissurado, nos espaços entre as fissuras.

\subsubsection{BREVE DesCrição do MODELO Té́rico MCFT}

A Teoria Modificada dos Campos Comprimidos apresentada por Vecchio e Collins (1986) conhecida como Modified Compression Field Theory - MCFT consiste em um modelo analítico para elementos de membrana de concreto armado, baseado na aproximação da teoria de fissuração distribuída ou smeared crack model, no qual o concreto fissurado é tratado como um novo material com características próprias referentes à relação tensãodeformação. A Figura 3.2 apresenta um resumo das relações básicas utilizadas na teoria MCFT.

Em um elemento de membrana de concreto ortogonalmente armado será a seguir descrita, em linhas gerais, a teoria MCFT. A Figura 3.3 ilustra um elemento de concreto armado com armadura londitudinal na direção x e transversal na direção y distribuída em toda a membrana.

As taxas de armadura encontram-se representadas respectivamente por $\rho_{\mathrm{x}}$ e $\rho_{\mathrm{y}}$, bem como as tensões de escoamento por $\mathrm{f}_{\mathrm{yx}}$ e $\mathrm{f}_{\mathrm{yy}}$. A resistência do concreto à compressão é dada pelo valor obtido em ensaio de corpo-de-prova cilíndrico, e então definida por $f_{c}$, sendo $\varepsilon_{o}$ a deformação na tensão de pico e $f_{\text {cr a }}$ tensão de fissuração à tração. $O$ carregamento aplicado nas bordas do elemento plano consiste em tensões normais uniformes definidas por $f_{x}$ e $f_{y}$ e tensão uniforme de cisalhamento $v_{x y}$. Admite-se que as bordas do elemento de membrana permanecem retas e paralelas após a deformação. 


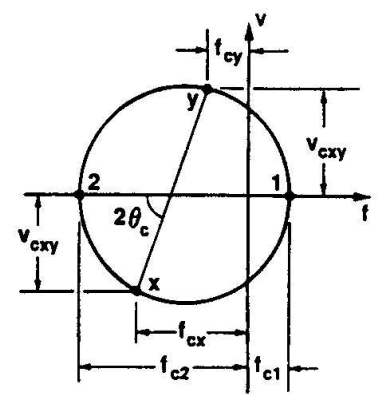

(a) Relações de Equilíbrio: Tensões no Concreto

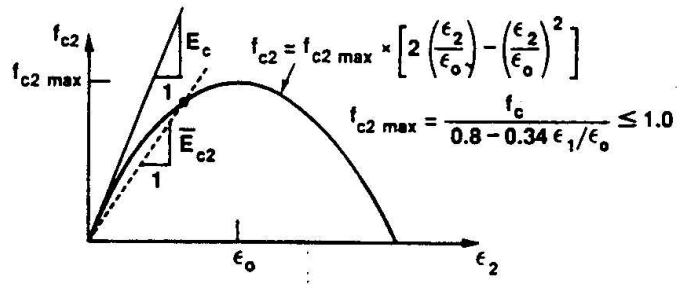

(c) Relação tensão-deformação do concreto fissurado - Direção principal de compressão.

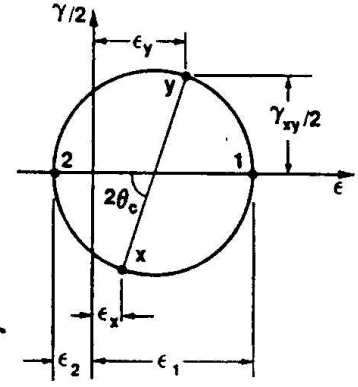

(b) Relações de Compatibilidade: Deformações no Concreto

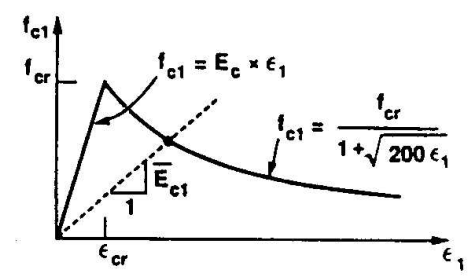

(d) Relação tensão-deformação do concreto fissurado - Direção principal de tração.

Figura 3.2 - Teoria Modificada dos Campos Comprimidos. Vecchio (1989).

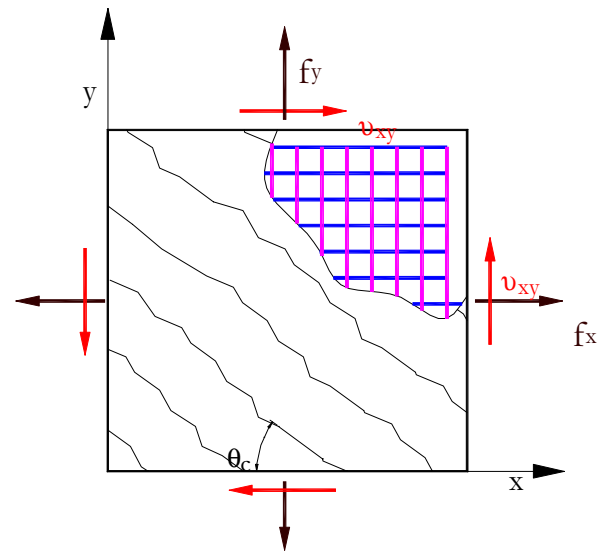

Figura 3.3 - Elemento de membrana de concreto armado fissurado.

Com auxílio do círculo de Mohr para as deformações médias ilustrado na Figura 3.2 (b), para o carregamento aplicado, e chamando $\varepsilon_{1}$ de deformação principal de tração, $\varepsilon_{2}$ de deformação principal de compressão e sendo $\theta_{c}$ a direção principal, tem-se:

$$
\begin{gathered}
\varepsilon_{1}=1 / 2\left(\varepsilon_{\mathrm{y}}+\varepsilon_{\mathrm{x}}\right)+1 / 2\left[\left(\varepsilon_{\mathrm{y}}-\varepsilon_{\mathrm{x}}\right)^{2}+\gamma_{\mathrm{yx}}{ }^{2}\right]^{\frac{1}{2}} \\
\varepsilon_{2}=1 / 2\left(\varepsilon_{\mathrm{y}}+\varepsilon_{\mathrm{x}}\right)-1 / 2\left[\left(\varepsilon_{\mathrm{y}}-\varepsilon_{\mathrm{x}}\right)^{2}+\gamma_{\mathrm{yx}}{ }^{2}\right]^{\frac{1}{2}} \\
\theta_{\mathrm{c}}=1 / 2 \tan ^{-1}\left[\gamma_{\mathrm{yx}} /\left(\varepsilon_{\mathrm{y}}-\varepsilon_{\mathrm{x}}\right)\right]
\end{gathered}
$$

Admite-se que a inclinação das deformações principais é igual à inclinação das tensões 
principais, ou seja, as direções principais para tensões equivalem à das deformações.

As tensões no concreto e na armadura podem ser determinadas a partir das deformações através das relações constitutivas dos materiais. Estas relações foram definidas para serem utilizadas na teoria MCFT conforme mostra a Figura 3.2 (c).

$$
\begin{aligned}
& \mathrm{f}_{\mathrm{c} 2}=\mathrm{f}_{\mathrm{c} 2 \max }\left[2\left(\frac{\varepsilon_{2}}{\varepsilon_{\mathrm{o}}}\right)-\left(\frac{\varepsilon_{2}}{\varepsilon_{\mathrm{o}}}\right)^{2}\right] \\
& \text { onde } \mathrm{f}_{\mathrm{c} 2 \max }=\frac{-\mathrm{f}_{\mathrm{c}}}{0,8-0,34\left(\frac{\varepsilon_{1}}{\varepsilon_{\mathrm{o}}}\right)}
\end{aligned}
$$

onde $\mathrm{f}_{\mathrm{c} 2}$ é a tensão principal média de compressão.

Segundo ilustra a Figura 3.2 (c) com relação à lei constitutiva do concreto à compressão, a formulação considera o efeito de amolecimento ou strain softening do concreto fissurado sob compressão.

Com relação ao concreto tracionado, antes de fissurar-se, a teoria considera comportamento elástico-linear, conforme mostra a Figura 3.2 (d). Assim sendo, tem-se:

$$
\mathrm{f}_{\mathrm{c} 1}=\mathrm{E}_{\mathrm{c}} \varepsilon_{1} \text { para } \varepsilon_{1} \leq \varepsilon_{\mathrm{cr}}
$$

onde $\varepsilon_{\text {cr }}$ é a deformação correspondente ao início de fissuração e $\mathrm{E}_{\mathrm{c}}$ é o módulo de elasticidade tangente inicial do concreto, obtido por $\mathrm{E}_{\mathrm{c}}=2 \mathrm{f}_{\mathrm{c}} / \varepsilon_{\mathrm{o}}$.

Após a fissuração, sugere-se a seguinte relação que leva em conta o efeito do enrijecimento dado pela presença da armadura entre fissuras ou tension stiffening:

$$
\mathrm{f}_{\mathrm{c} 1}=\frac{\mathrm{f}_{\mathrm{cr}}}{1+\sqrt{200 \varepsilon_{1}}}
$$

sendo $\mathrm{f}_{\mathrm{c} 1}$ a tensão principal média de tração e $\mathrm{f}_{\mathrm{cr}}$ é a resistência do concreto à tração.

Para garantir que as tensões médias de tração no concreto possam ser transmitidas entre as fissuras, $\mathrm{f}_{\mathrm{c} 1}$ deve ser verificado com relação ao seu limite superior, e portanto, levando em conta as tensões atuantes nas armaduras e o limite de escoamento. Assim:

$$
f_{c 1} \leq \rho_{x}\left(f_{y x}-f_{s x}\right) \operatorname{sen}^{2} \theta_{c}+\rho_{y}\left(f_{y y}-f_{s y}\right) \cdot \cos ^{2} \theta_{c}
$$

onde $f_{\text {sx }}$ e $f_{\text {sy }}$ são as tensões nas armaduras.

As tensões nas armaduras são determinadas através das relações elasto-plástico perfeitas. Desta forma, tem-se: 


$$
\mathrm{f}_{\mathrm{sx}}=\mathrm{E}_{\mathrm{s}} \varepsilon_{\mathrm{x}} \leq \mathrm{f}_{\mathrm{yx}} \quad \text { e } \quad \mathrm{f}_{\mathrm{sy}}=\mathrm{E}_{\mathrm{s}} \varepsilon_{\mathrm{y}} \leq \mathrm{f}_{\mathrm{yy}}
$$

onde $\mathrm{E}_{\mathrm{s}}$ é o módulo de elasticidade da armadura.

As tensões principais médias no concreto e a aproximação através do círculo de Mohr foram utilizadas a fim de determinar as tensões no concreto nas direções x e y, ou seja, $f_{c x}$ e $f_{c y}$ respectivamente, bem como a tensão de cisalhamento $v_{c x y}$. Assim sendo, resulta:

$$
\begin{gathered}
f_{c x}=1 / 2\left(f_{c 1}+f_{c 2}\right)-1 / 2\left(f_{c 1}-f_{c 2}\right) \cos 2 \theta_{c} \\
f_{c y}=1 / 2\left(f_{c 1}+f_{c 2}\right)+1 / 2\left(f_{c 1}-f_{c 2}\right) \cos 2 \theta_{c} \\
v_{c x y}=1 / 2\left(f_{c 1}-f_{c 2}\right) \operatorname{sen} 2 \theta_{c}
\end{gathered}
$$

Da condição de equilíbrio vertical e horizontal, tem-se que:

$$
\begin{gathered}
f_{c x}+\rho_{x} f_{s x}=f_{x} \\
f_{c y}+\rho_{y} f_{s y}=f_{y} \\
v_{c x y}=v_{x y}
\end{gathered}
$$

Uma vez não verificadas as condições de equilíbrio expressas nas equações (3.15), (3.16) e (3.17), deve-se rever o estado de deformações assumido para $\varepsilon_{\mathrm{x}}, \varepsilon_{\mathrm{y}}$ e $\gamma_{\mathrm{xy}}$ de forma a satisfazer o equilíbrio do elemento.

$\mathrm{Na}$ análise em elementos finitos, esta verificação de equilíbrio não é desenvolvida diretamente. Dadas as tensões e deformações compatíveis, o módulo secante pode ser definido para o concreto e para a armadura. Assim sendo, tem-se:

$$
\begin{aligned}
& \overline{\mathrm{E}}_{\mathrm{c} 1}=\mathrm{f}_{\mathrm{c} 1} / \varepsilon_{1} \\
& \overline{\mathrm{E}}_{\mathrm{c} 2}=\mathrm{f}_{\mathrm{c} 2} / \varepsilon_{2} \\
& \overline{\mathrm{E}}_{\mathrm{sx}}=\mathrm{f}_{\mathrm{sx}} / \varepsilon_{\mathrm{x}} \\
& \overline{\mathrm{E}}_{\mathrm{sy}}=\mathrm{f}_{\mathrm{sy}} / \varepsilon_{\mathrm{y}}
\end{aligned}
$$

onde $\overline{\mathrm{E}}_{\mathrm{c} 1}$ e $\overline{\mathrm{E}}_{\mathrm{c} 2}$ referem-se ao comportamento tensão-deformação do concreto nas direções principais; $\overline{\mathrm{E}}_{\mathrm{sx}}$ e $\overline{\mathrm{E}}_{\mathrm{sy}}$ referem-se às armaduras nas duas direções ortogonais.

\subsection{TORÇÃo EM AÇÃo CONJUNTA COM FLEXÃO E FORÇA AXIAL}

O estudo do comportamento das vigas de concreto armado quando submetidas à ação conjunta de torção, flexão lateral e vertical, bem como força axial, será neste trabalho desenvolvido, a fim de integrar-se ao objetivo fundamental desta pequisa, que é o estudo 
da instabilidade lateral das vigas pré-moldadas em serviço e durante a fase transitória.

Entretanto, poucos trabalhos podem ser encontrados na literatura técnica sobre a consideração combinada de tais esforços. Conforme descrito neste capítulo, a maioria das publicações sobre torção em concreto armado, limitam-se à torção pura. Alguns trabalhos que consideram o efeito combinado da torção com a flexão, aplicam o conceito básico do comportamento análogo a uma treliça espacial.

Leung (1982) apresenta em sua tese de doutorado uma aplicação do modelo de treliça espacial em estruturas de concreto armado submetidas a torção, flexão bi-lateral e força axial. As respostas geradas pelo modelo referem-se às relações força axial $x$ deformação axial, momento fletor $\mathrm{x}$ curvatura e torção $\mathrm{x}$ taxa de giro.

O modelo apresentado por Leung (1982) baseia-se nos trabalhos de Mitchell (1974), Onsongo (1978) e de Collins \& Mitchell (1980).

Leung (1982) consideram que uma seção de concreto quando fissurada sob torção comporta-se como uma seção vazada, podendo então, cada uma das paredes que formam a seção, ser discretizada em vários elementos. É então definido um sistema nãolinear formado por equações relacionadas ao equilíbrio, às condições de compatibilidade e às leis constitutivas do material, para o qual obtém-se as forças internas correspondentes às deformações apresentadas em cada seção.

Algumas disparidades observadas entre o modelo teórico e os resultados experimentais, Leung (1982) justifica no fato do modelo desprezar a resistência à tração do concreto, ao progressivo descolamento do cobrimento à medida que a solicitação por torção aumenta na seção e devido à contribuição da seção central não fissurada enrijecer o elemento, nos primeiros estágios do carregamento.

Leung (1982) conclui que o modelo de treliça espacial comporta-se adequadamente quando aplicado a problemas de seções retangulares submetidas a torção e flexão uniaxial. Comporta-se, no entanto, de maneira menos satisfatória quanto à resposta momento de torção $x$ taxa de giro, quando o esforço de flexão é dominante sobre o de torção na peça. Também a relação momento fletor-curvatura obtida com o modelo não é completamente satisfatória quando o esforço de torção é predominante da análise.

Porém, segundo Leung (1982), apesar destas discrepâncias existirem, elas não são em geral significativas, justificando que em situações onde o momento fletor é predominante, a resposta momento fletor $\mathrm{x}$ curvatura é naturalmente de maior interesse na análise do comportamento geral da peça estrutural. Ressalta ainda que as propriedades de rigidez obtidas no modelo teórico são satisfatórias.

Enfim, Leung (1982) considera que o modelo de treliça espacial é realmente um modelo geral para ações combinadas, uma vez que pode reproduzir a resposta das solicitações em separado, como é o caso de tração, compressão ou flexão simples, o que confirma a consistência teórica do mesmo. Observa ainda, que na análise de elementos sob torção, a presença da solicitação de torção afeta significativamente a resistência da peça.

Cocchi \& Volpi (1996), seguindo os mesmos conceitos considerados na formulação de Leung (1982) e Leung \& Schnobrich (1987), apresentaram uma metodologia para análise 
não-linear de elementos de concreto armado submetidos à esforços combinados de torção, flexão e força axial. Cocchi \& Volpi (1996) utilizam a Teoria Modificada dos Campos Comprimidos, e portanto, consideram a contribuição do concreto à tração, o efeito de softening ou amolecimento e tension stiffening ou enrijecimento na armadura tracionada.

A formulação utilizada por Cocchi \& Volpi (1996) será apresentada neste trabalho no Capítulo 4, por constituir uma das ferramentas utilizadas para avaliação do comportamento das vigas pré-moldadas de concreto, quando considerado o efeito combinado das solicitações de torção, flexão e força axial.

Em Hsu $(1985$ c, 1988, 1991), observa-se a preocupação em tratar problemas de peças sob torção pura admitindo o comportamento não-linear dos materiais, bem como incluir os efeitos da protensão. Nestes trabalhos, Hsu $(1985 c, 1988,1991)$ observa ainda que, quando a armadura de protensão é admitida perfeitamente ancorada nas extremidades da peça, a distribuição dos cabos não interfere no comportamento à torção da peça. Entretanto, faltam dados experimentais para maiores conclusões.

\subsection{RigideZ À TORÇÃo EM ElEMENTOS DE CONCRETO ARMADO FISSURADOS POR FLEXÃO}

A variação da rigidez à torção em vigas de concreto armado também submetidas à flexão é ainda uma questão que merece cuidadosas pesquisas tanto analíticas quanto experimentais.

Vários estudos têm sido realizados com relação à variação da rigidez em elementos sob torção pura. Conforme apresentado anteriormente, sabe-se que a rigidez à torção no concreto armado varia segundo o estado de fissuração da peça. Normalmente considerase que antes de fissurar-se, o elemento de concreto armado comporta-se sob torção como uma peça homogênea, ou seja, a colaboração do concreto e da armadura ocorre de forma homogênea. Entretanto, após a fissuração, o elemento sob torção não trabalha mais como em um meio contínuo, havendo contribuições distintas para o concreto e para a armadura.

Alguns modelos teóricos podem ser encontrados na literatura técnica para representar o comportamento de um elemento fissurado de concreto armado sob torção. Os métodos mais difundidos são a teoria das superfícies de ruptura ou skew bending theory e o já citado modelo teórico de treliça espacial ou space truss model.

A teoria das superfícies de ruptura, proposta inicialmente por Lessig em 1958, trata basicamente da idealização de dois modos de ruptura. O primeiro modo de ruptura tem a zona comprimida perto da face superior da viga, enquanto o segundo modo tem a zona comprimida ao longo da face lateral. No primeiro modo de ruptura, prevalece a flexão sobre a torção, enquanto no segundo modo, a torção é predominante sobre a flexão. Para cada um dos modos, escrevem-se duas condições de equilíbrio. Uma equação de equilíbrio de momentos em relação à linha neutra e outra de equilíbrio de forças com relação à normal a zona comprimida. Para determinar o ângulo de inclinação das fissuras helicoidais que iniciam-se na superfície de ruptura, minimiza-se a resistência do elemento, obtendo-se a terceira equação. Desta forma, tem-se três equações de 
equilíbrio para a análilse de cada modo de ruptura, as quais podem ser resolvidas por um procedimento de tentativa e erro.

Em geral, segundo Hsu (1984), a maioria das teorias baseadas em superfícies de ruptura inclinadas consistem em aproximações conservativas.

O modelo de treliça espacial representando o comportamento de elementos de concreto armado sob torção permite conhecer as deformações da peça ao longo da história do carregamento. Esta é uma clara vantagem sobre a teoria das superfícies de ruptura inclinadas, que é unicamente aplicável na situação de ruptura. A representação através de mecanismo estrutural de treliça espacial consiste em uma aproximação resultante da comparação do comportamento de tubos de paredes finas sob torção. Assim, desprezase a contribuição do núcleo em seções sólidas.

Poucos trabalhos podem ser encontrados na literatura técnica quanto à variação da rigidez à torção de peças de concreto armado quando também solicitadas por flexão, em especial, no caso onde a flexão é solicitação predominante. Esta situação é particularmente de grande interesse neste trabalho, uma vez que representa a maioria dos casos de vigas pré-moldadas nas fases transitórias.

Sendo poucos os trabalhos analíticos e experimentais disponíveis, ainda mais escassos encontram-se os textos técnicos quando se deseja conhecer a variação da rigidez à torção em vigas fletidas de seção não-retangular, como as vigas de pontes de seção I, típicas de elementos pré-fabricados.

Alguns trabalhos destacam-se no tratamento dado ao cálculo da rigidez considerando a ação conjunta da torção com a flexão.

Ojha (1974) propõe expressões teóricas para o cálculo da rigidez à torção e à flexão após a fissuração utilizando o modelo de treliça espacial, em vigas de seção retangular, baseadas no equilíbrio de forças e na energia de deformação. A rigidez pós-fissuração é definida via relação tensão-deformação por unidade de comprimento no instante do escoamento da armadura ou na ruptura, o que acontecer primeiro. Ohja (1974) considera apenas a torção de Saint-Venant e comportamento elástico-linear para o concreto e para a armadura.

Nesse trabalho, Ojha (1974) observa que a rigidez à torção na seção fissurada é apenas uma pequena parcela da rigidez antes da fissuração, em torno de 10 a $15 \%$ desta última. Verifica também que as formulações baseadas na analogia de treliça fornecem melhores resultados. A relação entre torção e flexão é considerada de forma que quando a torção predomina, admitem-se que as fissuras envolvem as 4 faces da viga retangular, e no caso da flexão prevalecer sobre a torção, considera-se que a face superior da viga não se fissura.

Baseado em resultados experimentais, Ohja (1974) observa que até um momento de torção equivalente a $20 \%$ do seu valor último, a rigidez é praticamente igual à rigidez no estado pré-fissuração. Quando a torção aplicada corresponde a aproximadamente $80 \%$ do valor de ruptura, a rigidez tem seu valor mínimo, devendo ser considerada igual à rigidez da seção fissurada. Na situação intermediária entre 20 a $80 \%$ do valor último, a rigidez pode ser considerada variando parabolicamente entre estes dois limites, como 
ilustra a Figura 3.4.

As expressões apresentadas por Ojha (1974) tanto para a rigidez à torção como para a flexão, dependem das propriedades elásticas dos materiais, das dimensões da seção, da inclinação média das bielas de concreto, da relação torção/flexão, das áreas de armaduras, do espaçamento entre os estribos e da espessura teórica da parede da seção correspondente vazada.

Segundo Hsu (1973), a drástica perda de rigidez à torção após a fissuração, estimada na ordem de $10 \%$ do valor pré-fissuração afeta seriamente a redistribuição de momentos em estruturas estaticamente indeterminadas.

Baseado no modelo teórico de treliça espacial com bielas comprimidas a $45^{\circ}$, desprezando a resistência ao cisalhamento das mesmas e admitindo que as armaduras apenas suportam tração, desconsiderando o efeito de pino das mesmas, Hsu (1984) propõe a expressão (3.22) para o cálculo da rigidez à torção pós-fissuração de vigas com seções quaisquer, sob torção pura.

$$
\left(G J_{t}\right)_{\text {fiss }}=\frac{4 E_{a} A_{1}^{2} A_{c}}{u^{2}\left(\frac{4 n A_{c}}{u h}+\frac{1}{\rho_{\ell}}+\frac{1}{\rho_{h}}\right)} \text { sendo } n=\frac{E_{a}}{E_{c}}
$$

onde $\mathrm{E}_{\mathrm{a}}$ é o módulo de elasticidade da armadura, $\mathrm{E}_{\mathrm{c}}$ é o módulo de elasticidade do concreto, $\mathrm{A}_{1}$ é a área da seção transversal limitada pela linha central da parede da seção vazada correspondente ou área interna à linha central dos estribos, $A_{c}$ é a área real da seção transversal sólida, u é o perímetro da linha central do estribo, h é a espessura da parede vazada da seção correspondente e $\rho_{\ell}$ e $\rho_{\mathrm{h}}$ são a taxa de armadura transversal e longitudinal, respectivamente.

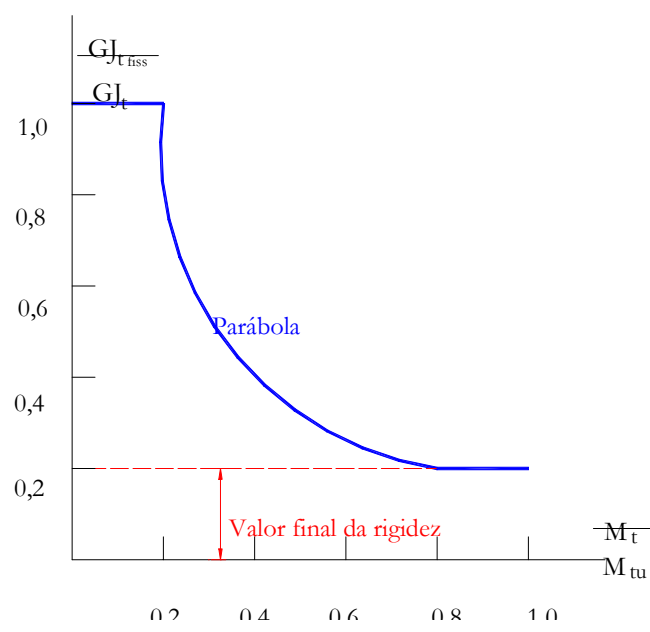

(a) Parábola recomendada por Ojha (1974).

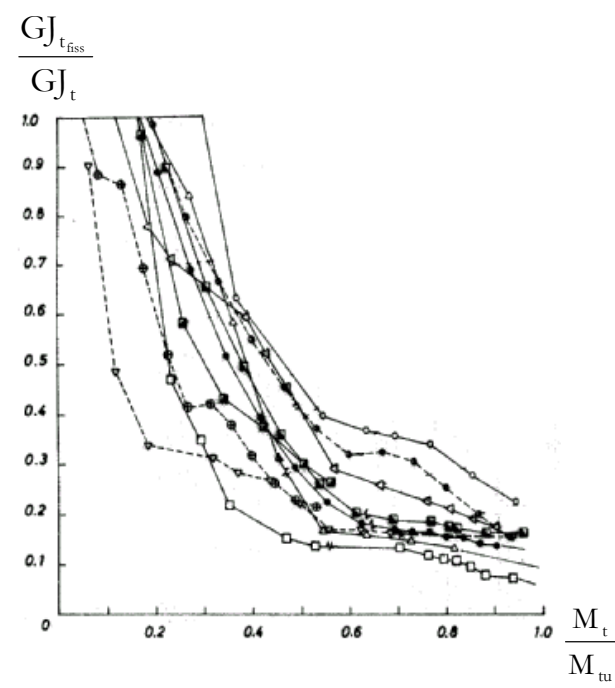

(b) Resultados de ensaio. Technical University of Braunschweig.

Figura 3.4 - Rigidez à torção. Ojha (1974).

Nestes termos, Hsu (1984) sugere que após a fissuração o comportamento possa ser 
representado como ilustra a Figura 3.5. Nesta, tem-se que $M_{t c}$ é a contribuição do concreto na resistência à torção, $\eta$ é um coeficiente empírico que aumenta com o aumento da espessura da parede, podendo ser calculado por $\eta=0,57+2,86 \mathrm{~h} / \mathrm{x}$, sendo x a menor dimensão no caso da seção retangular e para seções arbitrárias, é a menor distância entre duas linhas paralelas tangentes ao perímetro da seção transversal, $\mathrm{M}_{\mathrm{t}_{\text {fiss }}}$ é o momento de torção de fissuração e $\mathrm{M}_{\mathrm{t}_{\mathrm{u}}}$ é o valor da torção última.

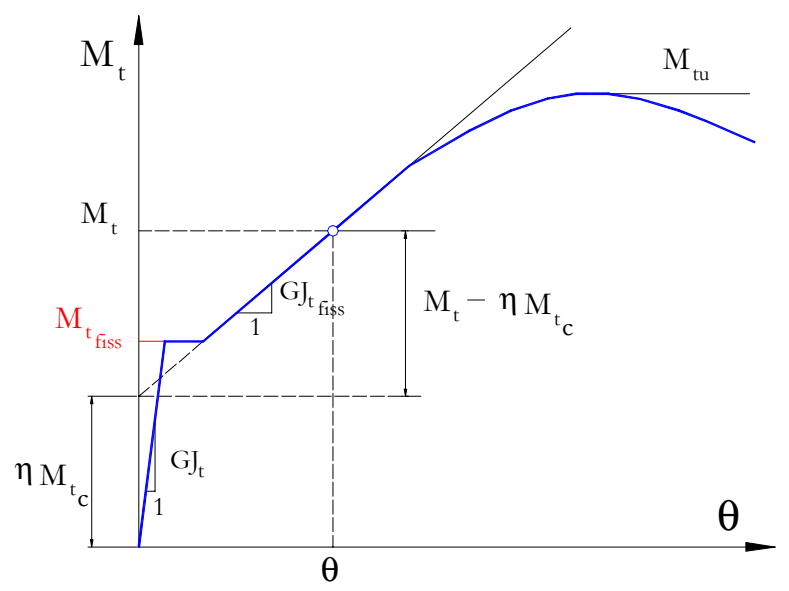

Figura 3.5 - Curva típica torção-taxa de giro de vigas de concreto armado. Hsu (1984).

Bishara et al (1979) realizaram uma série de ensaios a fim de quantificar a capacidade de rotação nas regiões de máximo momento fletor de vigas de concreto armado de seção L e seção retangular, submetidas a iguais momentos de torção nas extremidades. A única variável nos ensaios foi a relação momento fletor/momento de torção, que variou entre 0,02 a 0,3 , incluindo também flexão pura e torção pura.

Segundo Bishara et al (1979), os ensaios mostraram um comportamento praticamente linear na flexão antes do aparecimento das primeiras fissuras, seguido por outro trecho linear com redução de rigidez antes da ruptura. $O$ que essencialmente varia é o comprimento do patamar antes da ruptura. Quanto maior a relação torção/flexão, maior é a redução da rigidez à flexão após a primeira fissura. A porcentagem desta redução é muito pequena. Entretanto, esta redução é maior nas vigas de seção L do que nas vigas de seção retangular, tendo sido observado experimentalmente uma redução máxima de $20 \%$ na rigidez à flexão. Vale ressaltar que, um exame dos resultados dos ensaios mostra que a máxima abertura de fissura na viga sob torção e flexão é maior do que quando submetida apenas à flexão pura, para o mesmo valor do momento fletor. Enfim, conclui-se que a presença da torção reduz a rigidez à flexão da viga, proporcionalmente à relação torção/flexão.

Lampert (1973) propõe expressões teóricas simplificadas para o cálculo da rigidez à torção e à flexão pós-fissuração em vigas retangulares de concreto armado baseadas no modelo de treliça espacial. Segundo Lampert (1973), a perda de rigidez à torção na torção pura, após a fissuração, é geralmente muito maior do que a perda da rigidez à flexão na flexão pura. $\mathrm{O}$ citado autor observa também que a rigidez à torção pós-fissuração não é 
fortemente influenciada pela flexão, embora a rigidez à flexão pós-fissuração dependa de forma mais acentuada do valor do momento de torção.

Lampert (1973) define uma relação $\mathrm{k}$ limite entre os dois intervalos de cálculo por ele propostos. Este dois intervalos são limitados pelo valor da relação momento de torção/momento de flexão, ou seja, $\mathrm{k}=\mathrm{M}_{\mathrm{t}} / \mathrm{M}$. O valor $\mathrm{k}$ limite é definido por $\overline{\mathrm{k}}=2 /\left(1+\mathrm{h}_{\mathrm{o}} / \mathrm{b}_{\mathrm{o}}\right)$, caracterizado pela condição de tensão longitudinal nula nas armaduras superiores, de forma que:

\begin{tabular}{|c|c|c|}
\hline Intervalo I & Flexão dominante & $\mathrm{k}<\overline{\mathrm{k}}$ \\
\hline Intervalo II & Torção dominante & $\mathrm{k}>\overline{\mathrm{k}}$ \\
\hline
\end{tabular}

onde $h_{0}$ é a altura entre os eixos das barras longitudinais nas quinas e $b_{o}$ é a largura entre as barras longitudinais nas quinas da seção retangular.

As expressões teóricas propostas por Lampert (1973) para as rigidezes à torção e à flexão encontram-se resumidas na Tabela 3.1. As curvaturas de flexão e de torção podem ser expressas pela equações (3.23) e (3.24), respectivamente.

$$
\begin{aligned}
\text { Curvatura à flexão: } & \frac{\mathrm{d} \theta}{\mathrm{dx}}=\frac{\mathrm{M}}{\mathrm{K}_{\mathrm{M}, \mathrm{M}}}+\frac{\mathrm{M}_{\mathrm{t}}}{\mathrm{K}_{\mathrm{M}, \mathrm{T}}} \\
\text { Taxa de giro por torção: } & \frac{\mathrm{d} \psi}{\mathrm{dx}}=\frac{\mathrm{M}_{\mathrm{t}}}{\mathrm{GJ}_{\mathrm{tfiss}}}
\end{aligned}
$$

\begin{tabular}{|c|c|c|}
\hline & Rigidez à flexão & Rigidez à Torção \\
\hline \multirow[b]{2}{*}{$\begin{array}{c}\text { Flexão } \\
\text { Dominante }\end{array}$} & $\mathrm{K}_{\mathrm{M}, \mathrm{M}}=\mathrm{EI}_{\text {fiss }} \rightarrow$ rigidez na flexão pura & \multirow[b]{2}{*}{$\mathrm{GJ}_{\mathrm{t} \text { fiss }}=\frac{\mathrm{E}_{\mathrm{a}}\left(\mathrm{b}_{\mathrm{o}} \mathrm{h}_{\mathrm{o}}\right) \mathrm{A}_{\mathrm{h}}}{\mathrm{u} . \mathrm{s}}(1+\mathrm{m})$} \\
\hline & $\mathrm{K}_{\mathrm{M}, \mathrm{M}_{\mathrm{t}}}=\frac{\mathrm{EI}_{\text {fiss }} \overline{\mathrm{k}}}{\frac{\mathrm{EI}_{\text {fiss }}}{\overline{\mathrm{R}}_{\mathrm{M}}}-1}$ onde $\overline{\mathrm{R}}_{\mathrm{M}}=\mathrm{E}_{\mathrm{a}} \mathrm{h}_{\mathrm{o}}^{2} \mathrm{~A}_{\mathrm{s}} / 2$ & \\
\hline \multirow{2}{*}{$\begin{array}{c}\text { Torção } \\
\text { Dominante }\end{array}$} & $K_{M, M}=\bar{R}_{M}\left(\frac{2 r}{1+r}\right)$ onde $r=\frac{A_{s}^{\prime}}{A_{s}}$ & \multirow{2}{*}{$G J_{\text {tfiss }}=\frac{E_{a}\left(b_{o} h_{o}\right) A_{h}}{u . s}(1+m)$} \\
\hline & $\mathrm{K}_{\mathrm{M}, \mathrm{M}_{\mathrm{t}}}=-\overline{\mathrm{R}}_{\mathrm{M}}\left(\frac{2 \mathrm{r} \overline{\mathrm{k}}}{1-\mathrm{r}}\right)$ & \\
\hline
\end{tabular}

Tabela 3.1 - Sumário das rigidezes pós-fissuração propostas por Lampert (1973) para seções retangulares.

onde $\mathrm{m}$ é a relação entre a porcentagem de armadura longitudinal e transversal, $\mathrm{A}_{\mathrm{h}}$ é a área de estribo, $A_{s}^{\prime}$ é a área de armadura longitudinal superior, $A_{s}$ é a área de armadura longitudinal inferior, u é o perímetro da área $\mathrm{b}_{\mathrm{o}} \mathrm{xh}_{\mathrm{o}}$, s é o espaçamento dos estribos e $\mathrm{E}_{\mathrm{a}}$ é o módulo de elasticidade do aço.

Observa-se que para as duas situações de solicitação dominante, Lampert (1973) sugere utilizar a mesma expressão para o cálculo da rigidez à torção na fase pós-fissuração, por reconhecer a dificuldade em se estabelecer um mecanismo estrutural adequado neste período. 
Hannachi \& Fouré (1996) apresentam um método para calcular a rigidez à torção de vigas de concreto armado com seção qualquer, fissuradas por flexão e submetidas a pequenos momentos de torção. Resulta assim, o estudo de um problema de estabilidade de forma. Consideram a influência de alguns parâmetros como a forma da seção transversal, o estado de fissuração da viga e a armadura longitudinal. Alguns resultados experimentais em vigas de seção vazada, maciça e seção I delgada, permitem determinar alguns parâmetros de forma semi-empírica.

As longas vigas pré-moldadas de pontes, com seção de melhor comportamento mecânico e normalmente delgadas com relação ao comprimento, devem ser tratadas levando-se em conta os efeitos da torção no estudo da estabilidade do conjunto. Segundo Hannachi \& Fouré (1996), deve-se considerar especialmente o efeito da rotação por torção, mesmo se as tensões correspondentes forem pequenas.

A fissuração por flexão reduz de modo importante a rigidez ao empenamento. No entanto, tem efeito distintamente menor sobre a rigidez à torção pura, conforme observado por Hannachi \& Fouré (1996), para pequenos valores do momento de torção. Observam ainda que a rigidez ao empenamento não depende muito da abertura de fissuras, mas a rigidez à torção pura depende da abertura de fissuras, diminuindo à medida em que o momento de torção torna-se suficientemente elevado.

O comportamento à torção de vigas de seção transversal de paredes finas, abertas e fissuradas por flexão, pode ser interpretado considerando comportamento elástico nãolinear. Para isto é necessário determinar a posição do centro de torção, a área setorial, a inércia setorial e a rigidez ao empenamento. Nesta abordagem, é necessário levar em conta a contribuição do concreto na zona fissurada. Entretanto, nenhum método encontra-se disponível para um cálculo direto. Hannachi \& Fouré (1996) sugerem calcular um módulo fictício de deformação transversal G que permita alterar o comportamento médio do concreto armado fissurado.

Enfim, será apresentado no próximo capítulo a teoria e as hipóteses básicas para a aplicação dos modelos propostos por Cocchi \& Volpi (1996) e Hannachi \& Fouré (1996), tendo sido implementados computacionalmente neste trabalho, constituindo-se as ferramentas utilizadas para análise não-linear de elementos estruturais sob ação conjunta de flexão e torção. 


\title{
Capítullo
}

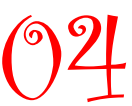

\author{
MODELOS TEÓRICOS DO COMPORTAMENTO \\ DE VIGAS DE CONCRETO ARMADO SOB \\ TORÇÃO, FLEXÃo E FORÇA AXIAL
}

\subsection{CONSIDERAÇÕES INICIAIS}

Neste capítulo será apresentado um modelo teórico para análise inelástica de vigas de concreto armado submetidas à ação combinada de torção, flexão lateral e vertical e força axial, baseado no modelo estrutural de treliça espacial apresentado por Cocchi \& Volpi (1996). Neste modelo teórico, após a fissuração por torção, o elemento de concreto armado comporta-se como uma seção vazada. No entanto, esta formulação aplica-se aos casos onde a torção é solicitação predominante sobre a flexão. Também será descrita a proposta de Hannachi \& Fouré (1996) e de Fouré \& Hannachi (1999) para aplicações quando a torção não é solicitação dominante na definição do mecanismo estrutural.

Onsongo (1978), utilizando a Teoria dos Campos Diagonais Comprimidos ou Diagonal Compression Field Theory - DCFT, desenvolve o equacionamento de equilíbrio e compatibilidade, considerando a seção vazada de concreto armado. A partir do estado de deformações da seção transversal, Onsongo (1978) calcula as deformações nas armaduras longitudinais e, segundo as leis constitutivas do aço, obtém as tensões nas mesmas. A resultante de força nas armaduras longitudinais é obtida pelo somatório das forças em cada barra individual. Para a seção transversal vazada, Onsongo (1978) integra as tensões no concreto e calcula a força resultante. Para as paredes verticais, as tensões são obtidas em 5 pontos igualmente espaçados, e o somatório é feito através da integração de Simpson. Os resultados obtidos por Onsongo (1978) são apresentados para a seção transversal real e para a seção sem o cobrimento, ambas apenas para a fase fissurada.

Leung (1982) permite considerar a variação da espessura e do ângulo de inclinação das bielas comprimidas em cada um dos elementos das paredes discretizadas da seção vazada resultante. Além da análise do comportamento das seções sob ações combinadas, Leung (1982) desenvolve um elemento de barra com grau de liberdade à torção, utilizando as propriedades das seções obtidas através do modelo de treliça espacial. Os trabalhos de Onsongo (1978) e Leung (1982) desprezam a resistência do concreto à tração.

Cocchi \& Volpi (1996) consideram a seção vazada resultante discretizada em elementos, da mesma forma que Leung (1982), porém, as relações de equilíbrio e compatibilidade são escritas para cada elemento, considerado composto por concreto e armadura.

Será a seguir descrito, o método de análise não-linear apresentado por Coccbi \& Volpi (1996), baseado nos trabalhos de Mitchell (1974), Onsongo (1978) e Leung (1982) para a análise do comportamento de seções submetidas às ações conjuntas de torção, flexão bilateral e força axial, observando a superioridade da torção sobre os demais esforços. E 
para o cálculo da rigidez à torção de peças fissuradas por flexão, a proposta de Hannachi \& Fouré (1996) e Fouré \& Hannachi (1999).

\subsection{Modelo Estrutural de Ações Combinadas Segundo COCCHI \& VOLPI (1996)}

No caso de elementos estruturais submetidos à ação conjunta de torção e flexão, em virtude da variação da deformação longitudinal em pontos diferentes da seção transversal, a deformação de compressão nas bielas de concreto na superfície das paredes varia também de ponto a ponto. Isto também altera a inclinação das diagonais comprimidas, a deformação dos estribos e a espessura das zonas comprimidas, ao longo de pontos nas paredes da seção.

A teoria proposta por Leung \& Schnobrich (1987) considera que a variação dos itens acima definidos ocorrem de forma discreta, e portanto, podem ser admitidos constantes em cada elemento das paredes de uma seção transversal discretizada.

Um exame da resposta do modelo desenvolvido e avaliado por Leung \& Schnobrich (1987) indica que o mesmo une as teorias de torção pura e flexão pura.

Baseado no trabalho de Leung \& Schnobrich (1987), Cocchi \& Volpi (1996) consideram que uma seção de concreto quando fissurada sob torção comporta-se como uma seção vazada, podendo então, cada uma das paredes que formam a seção, serem discretizadas em vários elementos. É então definido um sistema não-linear formado por equações de equilíbrio, de compatibilidade e expressões que caracterizam as leis constitutivas dos materiais envolvidos, obtendo-se deste sistema, os esforços internos correspondentes às deformações apresentadas nos diversos pontos de cada seção.

\subsubsection{FUNDAMENTOS DA ANÁLISE INELÁSTICA}

As vigas de concreto armado, quando ainda não fissuradas e submetidas a esforços de torção, comportam-se segundo um material homogêneo e isótropo. Hsu (1968), baseado em resultados experimentais, observou que o momento de fissuração por torção de uma viga de concreto armado é em torno de 1 a 1,3 vez o valor do momento de torção de ruptura de vigas correspondentes de concreto simples. Para estes valores, observou que as tensões verificadas nas armaduras eram muito pequenas. Além disso, verificou que os resultados encontrados entre a viga armada e a viga de concreto simples, com relação a rigidez à torção e as deformações no concreto, foram também muito próximos, no período pré-fissuração.

Após a fissuração, forma-se um novo mecanismo resistente, sendo então a rigidez à torção da peça, fortemente influenciada pela presença da armadura.

O trabalho de Cocchi \& Volpi (1996) estuda este mecanismo considerando-o por meio de um modelo de treliça espacial onde a porção central da seção transversal da viga é desprezada, resultando para uma seção inicialmente maciça, o comportamento representado por uma seção vazada, o que pode ser observado na Figura 4.1. 
O comportamento inelástico do concreto será considerado segundo Hsu (1991) e através da teoria modificada dos campos comprimidos ou MCFT, proposta por Vecchio \& Collins (1986).

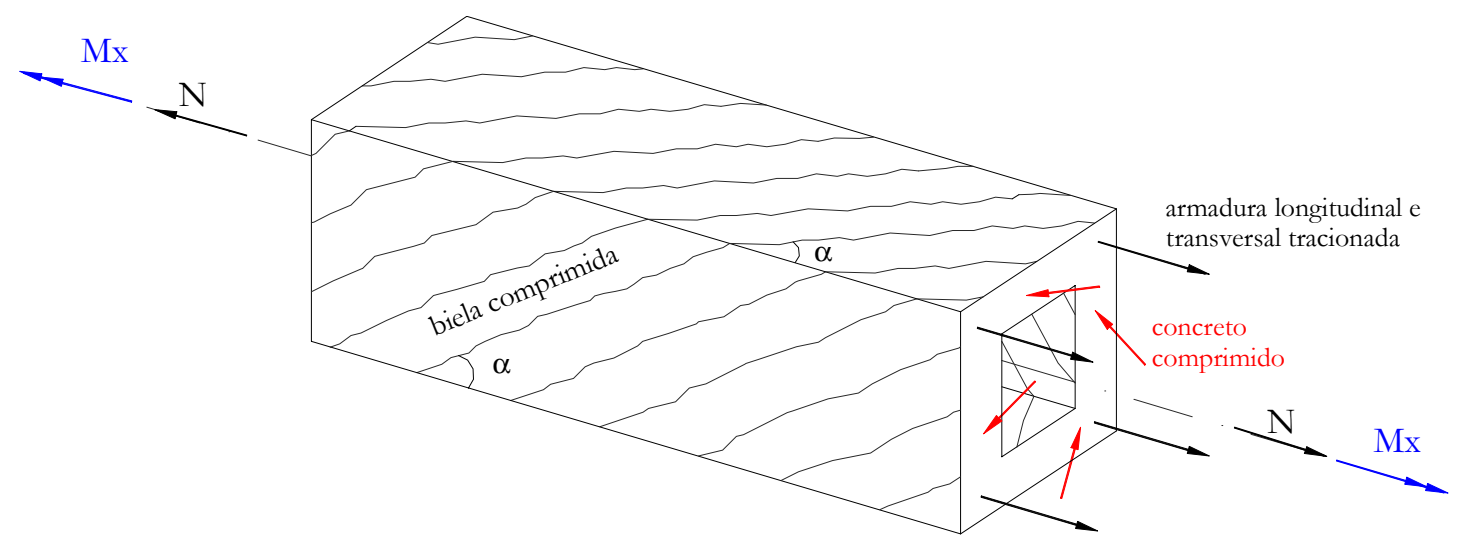

Figura 4.1 - Modelo estrutural de treliça espacial em elemento retangular submetido à torção e força axial.

\subsubsection{HIPÓTESES BÁSICAS}

Para o estudo de peças submetidas à ação conjunta de torção, flexão e força axial, foram adotadas as seguintes hipóteses:

- As seções planas permanecem planas, embora as deformações longitudinais tenham sido admitidas variando linearmente em cada elemento da seção discretizada.

- Assume-se a compatibilidade das deformações.

- As direções principais para tensões e deformações são admitidas coincidentes, ou seja, para um material isotrópo, a direção principal das tensões coincide com direção principal das deformações.

- Não existem vínculos que impedem o empenamento da seção, e por isto, apenas a torção livre ou de Saint-Venant é considerada.

- Admitem-se pequenas deformações.

O modelo teórico de fissuração utilizado na formulação da Teoria Modificada dos Campos Comprimidos MCFT é o modelo de fissuração distribuída ou smeared-cracking model. Nesta aproximação, segundo Chen (1982), o concreto fissurado é ainda considerado como um meio contínuo. Admite-se que o concreto passa a comportar-se como um material ortotrópico ou transversalmente isotrópico, depois do aparecimento da primeira fissura. Esta formulação permite tanto uma diminuição gradual ou súbita da resistência do material na direção das tensões de tração. No modelo de fissuração distribuída, como a fissura não é discreta, significa que um número infinito de fissuras paralelas atravessam o elemento considerado. 


\subsubsection{O MODELO ESTRUTURAL}

\subsubsection{DeFormação nos ElemEntos da SEÇão TransVERsal}

No modelo proposto por Leung (1982) e Cocchi \& Volpi (1996), a seção transversal é discretizada em um número suficiente de elementos retangulares ao longo das paredes da seção, conforme ilustra a Figura 4.2.

Cada um destes elementos deve apresentar largura suficiente para garantir que a espessura e o ângulo de inclinação das diagonais comprimidas de concreto sejam constantes nos mesmos.

Para cada elemento retangular $i$ da seção transversal é possível determinar a deformação longitudinal $\varepsilon_{\ell}(\mathrm{i})$ no CG do mesmo, em função das curvaturas de flexão $\chi_{\mathrm{y}}$ e $\chi_{\mathrm{z}}$ e da deformação axial $\eta$ da seção transversal. Assim:

$$
\varepsilon_{\ell}(i)=\eta-\chi_{z} \cdot y_{c}(i)-\chi_{\mathrm{y}} \cdot z_{c}(i)
$$

onde, $\mathrm{y}_{\mathrm{C}}(\mathrm{i})$ e $\mathrm{z}_{\mathrm{C}}$ (i) são as coordenadas do CG do elemento $i$, que podem ser obtidas, uma vez conhecida a espessura $t_{d}(i)$ do elemento $i$, já que as coordenadas $y_{A}(i)$ e $z_{A}(i)$ no ponto central na face externa do elemento são conhecidas, e x, y e $z$ são os eixos principais.

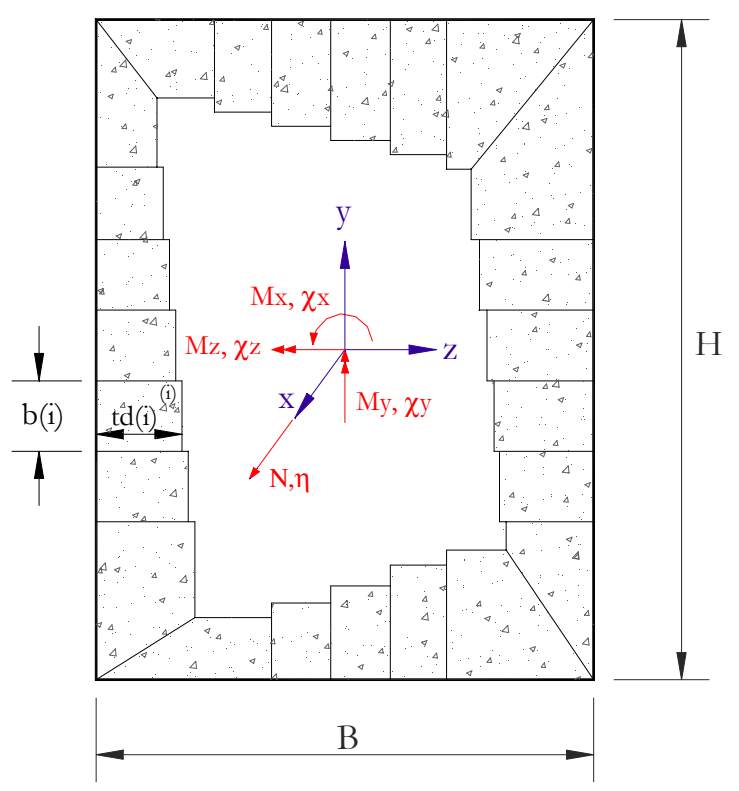

Figura 4.2 - Modelo para seção retangular submetida à torção, flexão e força axial.

Da geometria do elemento $i$, de acordo com a Figura 4.3, pode-se escrever:

$$
\begin{aligned}
& \mathrm{y}_{\mathrm{C}}(\mathrm{i})=\mathrm{y}_{\mathrm{A}}(\mathrm{i})-\Delta \mathrm{y}(\mathrm{i}) \\
& \mathrm{z}_{\mathrm{C}}(\mathrm{i})=\mathrm{z}_{\mathrm{A}}(\mathrm{i})+\Delta \mathrm{z}(\mathrm{i})
\end{aligned}
$$

sendo, 


$$
\begin{aligned}
& \Delta y(i)=\frac{t_{d}(i)}{2} \cos \omega(i) \\
& \Delta z(i)=\frac{t_{d}(i)}{2} \operatorname{sen} \omega(i)
\end{aligned}
$$

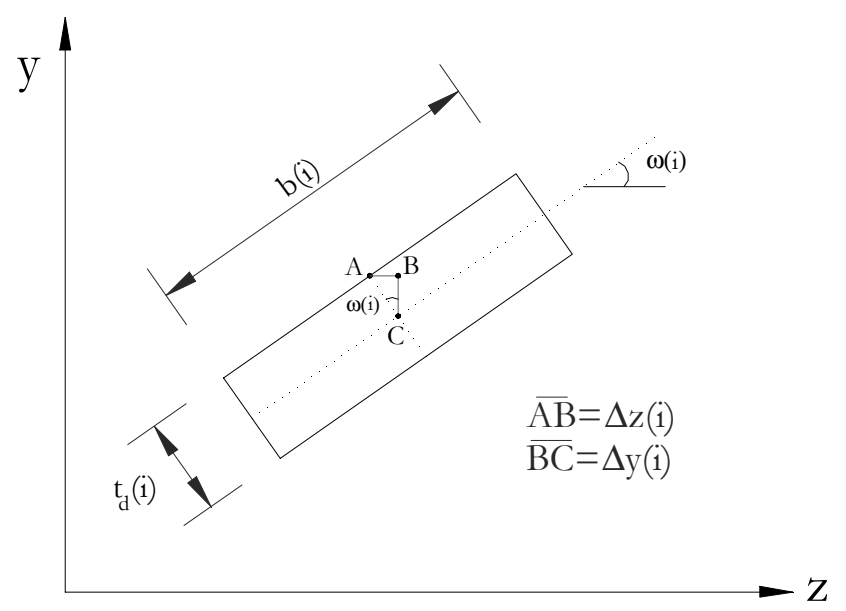

Figura 4.3 - Características geométricas do elemento ' $i$ ‘.

Substituindo-se (4.2) em (4.1), resulta:

$$
\varepsilon_{\ell}(i)=\eta-\chi_{z} \cdot y_{A}(i)-\chi_{y} \cdot z_{A}(i)+t_{d}(i)\left[\frac{\chi_{z} \cos \omega(i)}{2}-\frac{\chi_{y} \operatorname{sen} \omega(i)}{2}\right]
$$

onde o ângulo $\omega$ representa a inclinação da parede, e chamando,

$$
\mathrm{A}(\mathrm{i})=\left[\frac{\chi_{\mathrm{z}} \cos \omega(\mathrm{i})}{2}-\frac{\chi_{\mathrm{y}} \operatorname{sen} \omega(\mathrm{i})}{2}\right]
$$

tem-se, enfim:

$$
\varepsilon_{\ell}(i)=\eta-\chi_{z} \cdot y_{A}(i)-\chi_{y} \cdot z_{A}(i)+t_{d}(i) \cdot A(i)
$$

Desta forma, a deformação axial no CG do elemento $i$ está escrita em função das curvaturas de flexão da seção e das coordenadas no ponto $\mathrm{A}$, sendo estes parâmetros conhecidos, e em função da espessura $t_{d}(i)$, que até então, é uma incógnita do problema.

\subsubsection{EQUAÇÕES DE EQUILÍBRIO E ESFORÇOS RESISTENTES}

Considerando o estado plano de tensões de um elemento da viga de concreto fissurada, e estando o plano deste elemento no plano do fluxo de cisalhamento, ou seja, na face externa da viga, da Teoria da Elasticidade, pode-se escrever:

$$
\begin{aligned}
& \sigma_{\mathrm{c} \ell}=\sigma_{\mathrm{d}} \cos ^{2} \alpha+\sigma_{\mathrm{r}} \operatorname{sen}^{2} \alpha \\
& \sigma_{\mathrm{ct}}=\sigma_{\mathrm{d}} \operatorname{sen}^{2} \alpha+\sigma_{\mathrm{r}} \cos ^{2} \alpha \\
& \tau_{\ell \mathrm{t}}=\left(\sigma_{\mathrm{r}}-\sigma_{\mathrm{d}}\right) \operatorname{sen} \alpha \cos \alpha
\end{aligned}
$$


onde, $\sigma_{\mathrm{c} \ell}$ e $\sigma_{\mathrm{ct}}$ representam as tensões de compressão no elemento de concreto nas direções longitudinal e transversal, respectivamente; $\sigma_{d}$ e $\sigma_{\mathrm{r}}$ referem-se às tensões principais de compressão e tração, respectivamente; $\tau_{\ell t}$ é a tensão tangencial e $\alpha$ é o ângulo de inclinação das diagonais comprimidas.

Nas expressões definidas em (4.7a), (4.7b) e (4.7c) o índice $\ell$ refere-se à direção longitudinal e o índice $t$, à direção transversal. As direções principais para tensões e deformações foram admitidas coincidentes e apresentam-se representadas pelos índices $d$ e $r$, sendo $d$ relativo à direção principal de compressão e $r$, à de tração.

Outra condição de equilíbrio pode ser escrita, uma vez que o fluxo de cisalhamento é constante na seção. Assim, para i variando de 1 até n-1, podem ser escritas n-1 equações de equilíbrio. Sendo n o número de elementos na seção transversal, tem-se:

$$
\tau_{\ell \mathrm{t}}(\mathrm{i}) . \mathrm{t}_{\mathrm{d}}(\mathrm{i})=\tau_{\ell \mathrm{t}}(\mathrm{i}+1) . \mathrm{t}_{\mathrm{d}}(\mathrm{i}+1)
$$

Do equilíbrio transversal e longitudinal das forças atuantes no modelo de treliça considerado, resultam as equações (4.9) e (4.10), para as quais deve-se considerar a tensão principal de compressão $\sigma_{\mathrm{d}}$ negativa e a de tração $\sigma_{\mathrm{r}}$ positiva, ao utilizarem-se as mesmas nesta formulação.

$$
\begin{aligned}
& \frac{\rho_{\ell}}{t_{d}} f_{s \ell}=\sigma_{\ell}-\sigma_{d} \cos ^{2} \alpha-\sigma_{r} \operatorname{sen}^{2} \alpha \\
& \frac{\rho_{t}}{t_{d}} f_{s t}=-\sigma_{d} \operatorname{sen}^{2} \alpha-\sigma_{r} \cos ^{2} \alpha
\end{aligned}
$$

onde, $\mathrm{f}_{\mathrm{s} \ell}$ e $\mathrm{f}_{\mathrm{st}}$ são as tensões longitudinais e transversais na armadura, $\rho_{\ell}$ e $\rho_{\mathrm{t}}$ são as taxas de armaduras longitudinais e transversais, respectivamente. Sendo $A_{s}$ a área da armadura longitudinal, a expressão da taxa de armadura pode ser escrita por:

$$
\rho(i)=\frac{\sum_{j} A_{s}(j)}{b(i)}
$$

Os esforços resultantes na seção transversal resultam da contribuição de cada um dos elementos que compõem a seção transversal discretizada.

Assim, a força normal absorvida na seção transversal considerada da viga, calculada segundo o modelo em análise, é:

$$
\mathrm{N}=\sum_{\mathrm{i}=1}^{\mathrm{n}} \sigma_{\ell}(\mathrm{i}) \cdot \mathrm{b}(\mathrm{i}) \cdot \mathrm{t}_{\mathrm{d}}(\mathrm{i})
$$

Substituindo-se o valor da tensão normal longitudinal $\sigma_{\ell}$ obtida na equação (4.9), na expressão (4.12), resulta:

$$
\mathrm{N}=\sum_{\mathrm{i}=1}^{\mathrm{n}}\left[\sigma_{\mathrm{d}}(\mathrm{i}) \cos ^{2} \alpha(\mathrm{i})+\sigma_{\mathrm{r}}(\mathrm{i}) \operatorname{sen}^{2} \alpha(\mathrm{i})+\frac{\rho_{\ell}(\mathrm{i})}{\mathrm{t}_{\mathrm{d}}(\mathrm{i})} \mathrm{f}_{\mathrm{s} \ell}(\mathrm{i})\right] \mathrm{b}(\mathrm{i}) \cdot \mathrm{t}_{\mathrm{d}}(\mathrm{i})
$$




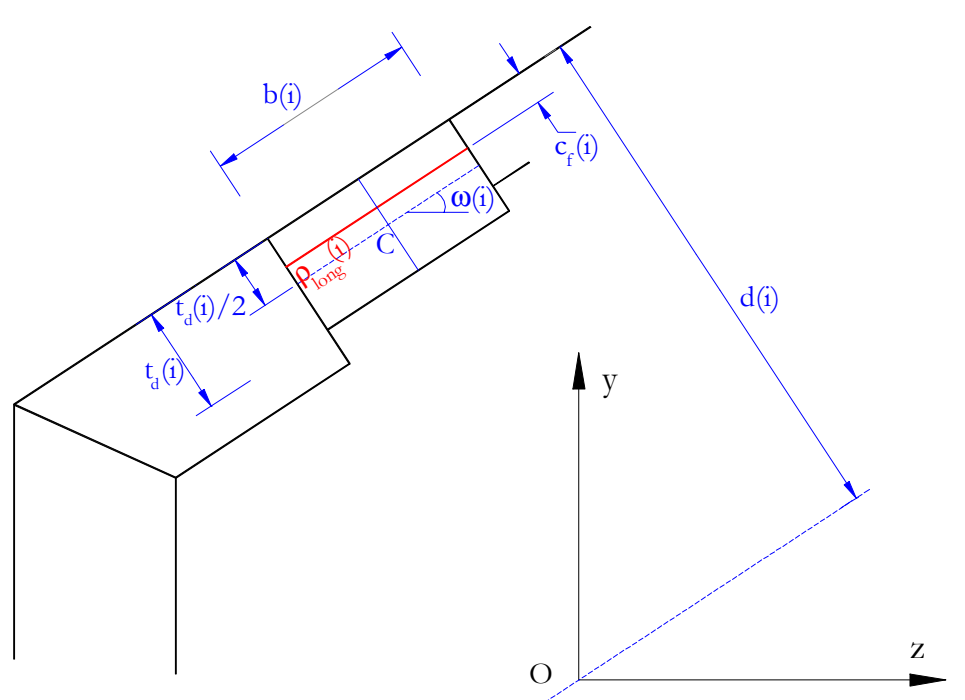

Figura 4.4 - Distribuição da armadura longitudinal no elemento ' $i$ '

Admitindo-se que em cada elemento, a força tangencial resultante $\mathrm{T}(\mathrm{i})$, obtida multiplicando a tensão tangencial pela área do mesmo, encontra-se aplicada no centro do elemento, então, o momento de torção $M_{x}$ resistente da seção pode ser expresso segundo a equação (4.15).

$$
\begin{aligned}
& \mathrm{T}(\mathrm{i})=\tau_{\ell t}(\mathrm{i}) \cdot \mathrm{b}(\mathrm{i}) \cdot \mathrm{t}_{\mathrm{d}}(\mathrm{i}) \\
& \mathrm{M}_{\mathrm{x}}=\sum_{\mathrm{i}=1}^{\mathrm{n}} \mathrm{T}(\mathrm{i})\left[\mathrm{d}(\mathrm{i})-0,5 \mathrm{t}_{\mathrm{d}}(\mathrm{i})\right]=\sum_{\mathrm{i}=1}^{\mathrm{n}} \tau_{\ell t}(\mathrm{i}) \mathrm{b}(\mathrm{i}) \mathrm{t}_{\mathrm{d}}(\mathrm{i})\left[\mathrm{d}(\mathrm{i})-0,5 \mathrm{t}_{\mathrm{d}}(\mathrm{i})\right]
\end{aligned}
$$

sendo, d(i) a distância dada pelo braço de alavanca a partir da face externa do elemento até o CG da peça, como mostra a Figura 4.4.

$$
d(i)=\left|y_{A}(i) \cdot \operatorname{sen} \omega(i)\right|+\left|z_{A}(i) \cdot \cos \omega(i)\right|
$$

Substituindo a expressão (4.7c) na equação (4.15) do momento de torção, resulta então:

$$
M_{x}=\sum_{i=1}^{n}\left[\sigma_{r}(i)-\sigma_{d}(i)\right] \cdot \operatorname{sen} \alpha(i) \cdot \cos \alpha(i) \cdot b(i) \cdot t_{d}(i) \cdot\left[d(i)-0,5 t_{d}(i)\right]
$$

As expressões para os momentos fletores em y e z, obtidas por equilíbrio, são:

$$
\begin{array}{r}
M_{z}=\sum_{i=1}^{n}\left[\sigma_{d}(i) \cos ^{2} \alpha(i)+\sigma_{r}(i) \operatorname{sen}^{2} \alpha(i)\right] b(i) \cdot t_{d}(i) \cdot\left[y_{A}(i)-k_{2}(i) \cdot t_{d}(i) \cdot \cos \omega(i)\right]+ \\
-\rho_{\ell}(i) \cdot b(i) \cdot f_{s \ell}(i) \cdot\left[y_{A}(i)-c_{f}(i) \cos \omega(i)\right] \\
M_{y}=\sum_{i=1}^{n}\left[\sigma_{d}(i) \cos ^{2} \alpha(i)+\sigma_{r}(i) \operatorname{sen}^{2} \alpha(i)\right] b(i) \cdot t_{d}(i) \cdot\left[z_{A}(i)-k_{2}(i) \cdot t_{d}(i) \cdot \operatorname{sen} \omega(i)\right]+ \\
+\rho_{\ell}(i) \cdot b(i) \cdot f_{s}(i) \cdot\left[z_{A}(i)-c_{f}(i) \operatorname{sen} \omega(i)\right]
\end{array}
$$

onde $k_{2}(i) \cdot t_{d}(i)$ é a distância da força resultante devido às tensões de compressão até a fibra extrema. O coeficiente $k_{2}$ será definido juntamente com as leis constitutivas dos 
materiais e $c_{f}$ é a distância da face externa da seção até o CG da armadura longitudinal no elemento $i$ considerado. A armadura longitudinal é admitida distribuída em linha à uma distância $c_{f}$ das fibras externas, conforme a Figura 4.4.

\subsubsection{EQUAÇÕES DE COMPATIBILIDADE}

A fim de obedecer à hipótese de compatibilidade de deformações, e uma vez que a presença de fissuras no elemento faz com que o mesmo apresente descontinuidade, as deformações utilizadas na formulação do modelo apresentado por Cocchi \& Volpi (1996) são apresentadas através de seus valores médios.

Das relações obtidas do círculo de Mohr para as deformações, pode-se escrever:

$$
\begin{gathered}
\varepsilon_{\mathrm{r}}+\varepsilon_{\mathrm{d}}=\varepsilon_{\ell}+\varepsilon_{\mathrm{t}} \\
\operatorname{tg}^{2} \alpha=\frac{\varepsilon_{\ell}-\varepsilon_{\mathrm{d}}}{\varepsilon_{\mathrm{t}}-\varepsilon_{\mathrm{d}}} \\
\gamma_{\ell \mathrm{t}}=2 .\left(\varepsilon_{\mathrm{t}}-\varepsilon_{\mathrm{d}}\right) \cdot \operatorname{tg} \alpha
\end{gathered}
$$

onde, $\varepsilon_{\ell}$ e $\varepsilon_{\mathrm{t}}$ são as deformações médias nas direções longitudinais e transversais do concreto fissurado, respectivamente; e onde $\varepsilon_{\mathrm{d}}$ e $\varepsilon_{\mathrm{r}}$ são as deformações médias principais de compressão e de tração, respectivamente, $\gamma_{\ell t}$ a distorção média, lembrando que $\alpha$ é a inclinação da bielas comprimidas.

Em um elemento na parede externa da viga, de dimensões $\operatorname{cotg} \alpha(\mathrm{i}) \times 1$, a distorção angular total $\bar{\gamma}$ devido à $\varepsilon_{\ell}, \varepsilon_{\mathrm{t}}$ e $\varepsilon_{\mathrm{d}}$, equivale a:

$$
\bar{\gamma}(i)=\left[\varepsilon_{\ell}(i)+\varepsilon_{d}(i)\right] \cot g \alpha(i)+\left[\varepsilon_{t}(i)+\varepsilon_{d}(i)\right] \operatorname{tg} \alpha(i)
$$

A equação de compatibilidade que relaciona a taxa de giro de torção com o ângulo total de distorção em cada elemento da parede, pode ser apresentada conforme a equação (4.25), segundo o Princípio dos Trabalhos Virtuais. Assim, em uma seção $x$ qualquer:

$$
\mathrm{M}_{\mathrm{x}}(\mathrm{x}) \cdot \chi_{\mathrm{x}}(\mathrm{x})=\sum_{\mathrm{i}=1}^{\mathrm{n}} \mathrm{T}_{\mathrm{i}}(\mathrm{x}) \cdot \bar{\gamma}_{\mathrm{i}}(\mathrm{x})
$$

então:

$$
\chi_{x}=\frac{\sum_{i=1}^{n}\left[\varepsilon_{\ell}(i) \cdot \cot g \alpha(i)+\varepsilon_{t}(i) \operatorname{tg} \alpha(i)-\frac{\varepsilon_{d}(i)}{\operatorname{sen} \alpha(i) \cdot \cos \alpha(i)}\right]}{\sum_{i=1}^{n}\left[d(i)-0,5 \cdot t_{d}(i)\right]}
$$

tendo sido definida na equação (4.14), a força resultante do fluxo de cisalhamento em cada elemento $i$.

\subsubsection{DeterminaçÃo da EsPESSURA dO ELEMENTO}

Para calcular a curvatura na direção da diagonal comprimida, Leung (1982) considera cada elemento da parede como um elemento de placa submetido a componentes de 
deformação por torção e flexão. Assim, assumindo a teoria das pequenas deformações, pode-se admitir que as paredes não apresentam curvatura na direção transversal, sendo a taxa de giro por torção a mesma para todos os elementos.

A curvatura na direção da diagonal $\alpha$ comprimida do elemento é:

$$
\chi_{\mathrm{n}}(\mathrm{i})=\chi_{\mathrm{s}}(\mathrm{i}) \cos ^{2} \alpha(\mathrm{i})+\chi_{\mathrm{x}} \operatorname{sen}(2 \alpha(\mathrm{i}))
$$

onde,

$$
\chi_{\mathrm{s}}(\mathrm{i})=-\chi_{\mathrm{y}}(\mathrm{i}) \operatorname{sen} \omega(\mathrm{i})+\chi_{z}(\mathrm{i}) \cos \omega(\mathrm{i})
$$

sendo, $\chi_{\mathrm{y}}$ e $\chi_{\mathrm{z}}$ as curvaturas de flexão da seção, e $\chi_{\mathrm{x}}$ a taxa de giro por torção, para os valores positivos apresentados na Figura 4.2.

Segundo Leung \& Schnobrich (1987), resultados experimentais permitem considerar uma variação linear para a deformação de compressão no concreto, nos elementos que constituem a seção transversal. Desta consideração, pode-se escrever:

$$
\mathrm{t}_{\mathrm{d}}(\mathrm{i})=-\frac{\varepsilon_{\mathrm{ds}}(\mathrm{i})}{\chi_{\mathrm{n}}(\mathrm{i})}
$$

onde,

$$
\varepsilon_{\mathrm{ds}}(\mathrm{i})=2 . \varepsilon_{\mathrm{d}}(\mathrm{i})
$$

sendo, $\varepsilon_{\mathrm{d}}$ (i) a deformação principal média de compressão do concreto fissurado na direção $d$, e $\varepsilon_{\mathrm{ds}}(\mathrm{i})$ a deformação de compressão na superfície externa da biela de concreto.

\subsubsection{LEIS CONSTITUTIVAS}

Vecchio \& Collins (1986) introduziram algumas modificações na Teoria da Diagonal Comprimida - DCFT, uma vez que a teoria original ignora a resistência à tração do concreto fissurado. Assim, consideram a ocorrência de strain softening ou amolecimento do concreto à compressão em virtude da ação de deformações de tração transversais, bem como, o efeito tension stiffening ou aumento da rigidez da armadura devido à presença contínua de tensões de tração no concreto entre as fissuras.

A partir de resultados experimentais, Vecchio \& Collins (1986) observaram que as direções principais de deformação diferem das direções principais verificadas para as tensões no concreto. Entretanto, ainda indicam como razoável a simplificação de considerar as direções principais para tensões e deformações coincidentes.

Verificaram ainda que, a tensão principal de compressão no concreto é função não apenas da deformação principal de compressão, mas também da deformação principal de tração. Isto significa que peças de concreto altamente fissuradas são menos resistentes à compressão quando comparadas aos resultados obtidos nos corpos-deprova cilíndricos, através de testes padronizados para avaliação da resistência do material comprimido. Destas análises, tem-se proposta a seguinte equação: 


$$
\frac{\sigma_{\text {cmáx }}}{\mathrm{f}_{\mathrm{c}}}=\frac{1}{\lambda}=\frac{1}{0,8-0,34 \cdot \frac{\varepsilon_{\mathrm{r}}}{\varepsilon_{\mathrm{o}}}} \leq 1
$$

onde $f_{c}$ é a resistência à compressão do concreto obtida em corpos-de-prova cilíndricos, $\varepsilon_{0}$ é a deformação para máxima tensão de compressão, sendo usualmente igual a $-0,002$. Sendo $\varepsilon_{0}$ um número negativo, acréscimos na deformação de tração reduz a relação $1 / \lambda$, resultando em uma diminuição no valor da resistência à compressão do concreto. A relação 1/ $\lambda$ é apresentada em Cocchi \& Volpi (1996) como coeficiente de amolecimento.

Segundo Hsu (1991), a relação tensão-deformação para o concreto à compressão pode ser expressa da seguinte forma:

$$
\sigma_{\mathrm{d}}=\frac{1}{\lambda} \cdot \mathrm{k}_{1} \cdot \mathrm{f}_{\mathrm{c}}
$$

onde $k_{1}$ é a relação entre a tensão média e a tensão pico de compressão em um elemento na diagonal de concreto, devendo ser obtido através da integração da curva tensãodeformação do concreto considerando o amolecimento, conforme apresentada por Vecchio \& Collins (1986), e ilustrada na Figura 4.5.

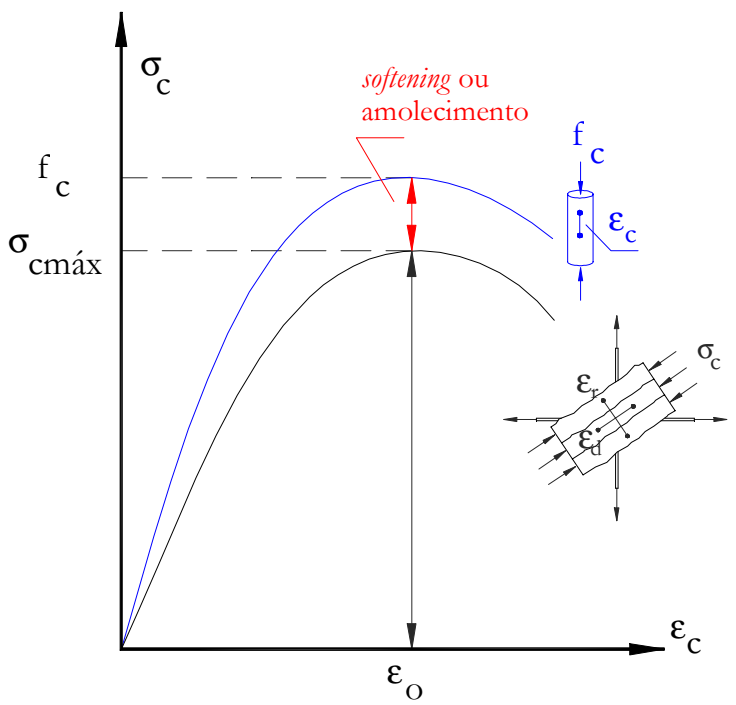

Figura 4.5 - Diagrama tensão-deformação de compressão para o concreto.

Nestes termos, a expressão de $k_{1}$, segundo Cocchi \& Volpi (1996) é:

$$
\mathrm{k}_{1}=\frac{\varepsilon_{\mathrm{ds}}}{\varepsilon_{\mathrm{o}}}\left[1-\left(\frac{1}{3}\right)\left(\frac{\varepsilon_{\mathrm{ds}}}{\varepsilon_{\mathrm{o}}}\right)\right]
$$

e de $k_{2}$, com relação ao braço de alavanca conforme ilustra a Figura 4.6, 


$$
\mathrm{k}_{2}=\frac{1}{4}\left[\frac{4-\varepsilon_{\mathrm{ds}} / \varepsilon_{\mathrm{o}}}{3-\varepsilon_{\mathrm{ds}} / \varepsilon_{\mathrm{o}}}\right]
$$

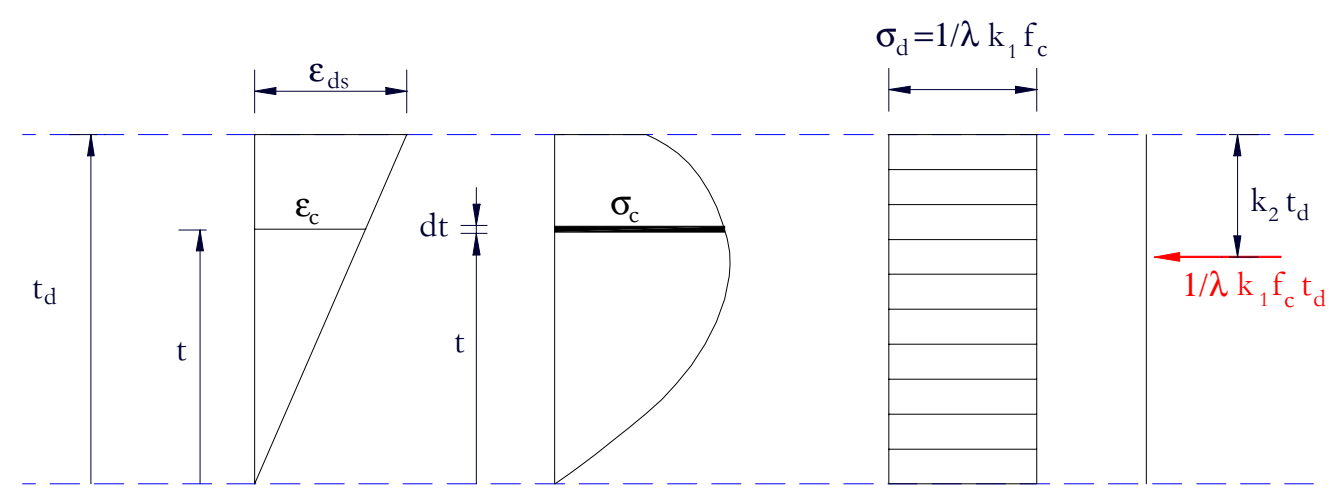

Figura 4.6 - Distribuição de tensão e deformação no concreto para uma seção sólida.

Para $0 \leq \varepsilon_{\mathrm{r}} \leq \varepsilon_{\mathrm{cr}}$, tem-se a lei de Hooke para relação tensão-deformação do concreto quando a deformação de tração ainda obedece comportamento linear:

$$
\sigma_{\mathrm{r}}=\mathrm{E}_{\mathrm{c}} \cdot \varepsilon_{\mathrm{r}}
$$

onde,

$$
\mathrm{E}_{\mathrm{c}}=2 \cdot \frac{\mathrm{f}_{\mathrm{c}}}{\varepsilon_{\mathrm{o}}}
$$

e o valor limite $\varepsilon_{\mathrm{cr}}$ é dado pela relação linear $\varepsilon_{\mathrm{cr}}=\mathrm{f}_{\mathrm{cr}} / \mathrm{E}_{\mathrm{c}}$. $\mathrm{O}$ valor da resistência do concreto à tração, segundo Cocchi \& Volpi (1996), pode ser calculada por:

$$
\mathrm{f}_{\mathrm{cr}}=1,0336 \cdot \sqrt{-\mathrm{f}_{\mathrm{c}}} \quad ; \quad \mathrm{f}_{\mathrm{c}} \mathrm{em}\left(\mathrm{kgf} / \mathrm{cm}^{2}\right)
$$

De acordo com o CEB (1991), quando a deformação de tração no concreto $\varepsilon_{\mathrm{r}}$ for superior à correspondente de fissuração $\varepsilon_{\mathrm{cr}}$, ou seja, $\varepsilon_{\mathrm{r}} \geq \varepsilon_{\mathrm{cr}}$, a expressão para cálculo da tensão de tração no concreto pode ser escrita por:

$$
\sigma_{\mathrm{r}}=\alpha_{1} \cdot \alpha_{2} \cdot \frac{\mathrm{f}_{\mathrm{cr}}}{1+\sqrt{500\left(\varepsilon_{\mathrm{r}}-\varepsilon_{\mathrm{cr}}\right.}}
$$

onde $\alpha_{1}=1$ para barras de alta aderência ou $\alpha_{1}=0,7$ para barras lisas, e $\alpha_{2}=1$ para cargas de curta duração ou $\alpha_{2}=0,7$ para cargas repetidas ou de longa duração.

As tensões médias de tração no concreto devem ser transmitidas através das fissuras. Então, segundo Cocchi \& Volpi (1996), as tensões $\sigma_{\mathrm{r}}$ precisam ser limitadas respeitando a tensão de escoamento das armaduras, através da condição ilustrada pela linha $\mathrm{AB}$ da Figura 4.7. Assim: 


$$
\sigma_{\mathrm{r}} \leq \sum_{\mathrm{j}}\left(\cos \theta_{\mathrm{cj}}\right)^{2} \frac{\rho_{\mathrm{i}}}{\mathrm{t}_{\mathrm{d}}}\left(\mathrm{f}_{\mathrm{yj}}-\mathrm{f}_{\mathrm{sj}}\right)
$$

onde $\mathrm{f}_{\mathrm{yj}}$ é a tensão de escoamento da armadura $\mathrm{j}$ (longitudinal ou transversal), $\mathrm{f}_{\mathrm{sj}}$ é a tensão média de tração na armadura j, e $\theta_{c j}$ é o ângulo entre a armadura j e a normal à superfície fissurada.

As relações tensão-deformação para a armadura longitudinal e transversal foram consideradas obedecendo o comportamento elasto-plástico perfeito, conforme representado na Figura 4.8. Desta forma, tem-se:

$$
\begin{aligned}
& \mathrm{f}_{\mathrm{s} \ell}=\mathrm{E}_{\mathrm{s}} \cdot \varepsilon_{\ell} \leq \mathrm{f}_{\mathrm{y} \ell} \\
& \mathrm{f}_{\mathrm{st}}=\mathrm{E}_{\mathrm{s}} \cdot \varepsilon_{\mathrm{t}} \leq \mathrm{f}_{\mathrm{yt}}
\end{aligned}
$$

onde $\mathrm{E}_{\mathrm{s}}$ é o módulo de elasticidade longitudinal do aço, $\mathrm{f}_{\mathrm{y} \ell}$ e $\mathrm{f}_{\mathrm{yt}}$ são, respectivamente, a tensão de escoamento da armadura longitudinal e transversal.

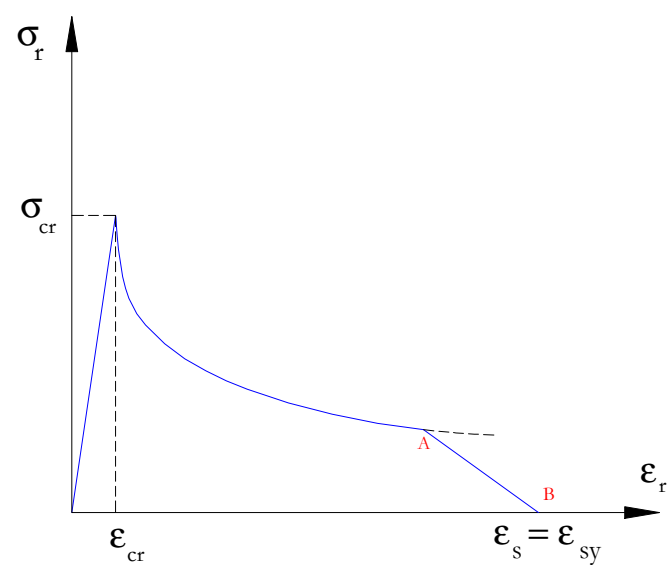

Figura 4.7 - Tensão-deformação do concreto à tração.

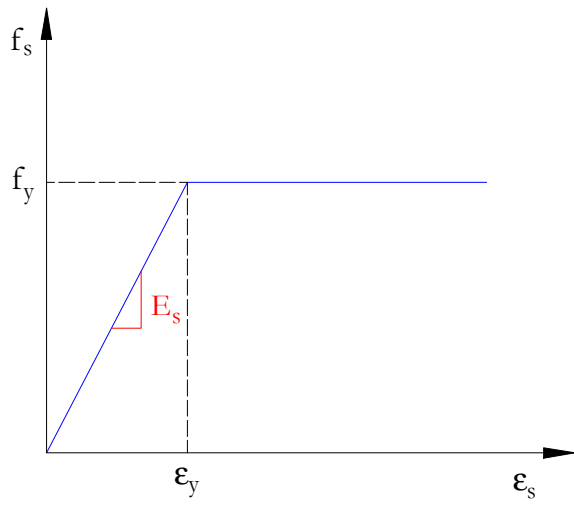

Figura 4.8 - Tensão-deformação do aço.

As tensões nos estribos são admitidas constantes dentro do elemento, podendo existir variação de deformação nos estribos de elemento para elemento. A possibilidade de variação de tensões nos estribos decorre da interação com as tensões de compressão das bielas de concreto, que também podem variar de elemento para elemento.

\subsubsection{AlgORITMO COM SISTEMA NÃO-LINEAR}

Cocchi \& Volpi (1996), baseados no trabalho de Leung \& Schnobrich (1987), apresentam um algoritmo composto por um sistema não-linear de equações de equilíbrio, de compatibilidade de deformações e das leis constitutivas do material. Neste algoritmo, considerando-se conhecidas as curvaturas $\chi_{y}, \chi_{z}$ e $\chi_{x}$, bem como a deformação longitudinal $\eta$ do CG da seção transversal, obtém-se por um processo iterativo, os esforços internos correspondentes ao estado de deformações assumido inicialmente.

Assim, para cada seção transversal cujas curvaturas e deformação longitudinal são assumidas como valores conhecidos, iterativamente será calculado através do algoritmo 
em análise, a espessura e o ângulo de inclinação de cada elemento discretizado das paredes. Conhecidas estas variáveis e fazendo um somatório da contribuição de cada elemento, obtém-se os esforços internos referentes à seção transversal em questão.

Entretanto, algumas variáveis são importantes a fim de proporcionar e agilizar a convergência do procedimento iterativo. Trata-se do fluxo de cisalhamento $q$, da deformação principal média de compressão do concreto $\varepsilon_{\mathrm{d}}(\mathrm{i})$ e do ângulo $\alpha(\mathrm{i})$, de cada elemento das paredes que compõem a seção transversal.

A partir de valores inicialmente atribuídos para o ângulo $\alpha$ e para a deformação $\varepsilon_{\mathrm{d}}(\mathrm{i})$ do concreto, deve-se verificar se a espessura obtida para o elemento, a partir da equação (4.28), confere com o valor correspondente ao obtido através da expressão do fluxo de cisalhamento. Assim, considerando a equação (4.7c), tem-se:

$$
\begin{gathered}
{\left[\sigma_{r}(i)-\sigma_{d}(i)\right] \operatorname{sen} \alpha(i) \cdot \cos \alpha(i) \cdot t_{d}(i)=q} \\
\operatorname{para} i=1, \ldots, n
\end{gathered}
$$

$\mathrm{Na}$ equação (4.40), resulta que a espessura pode ser escrita por:

$$
t_{d}^{\prime}(i)=\frac{q^{*}}{\left[\sigma_{r}(i)-\sigma_{d}(i)\right] \cdot \operatorname{sen} \alpha(i) \cdot \cos \alpha(i)}
$$

Isolando o ângulo $\alpha$ da equação (4.10) de equilíbrio na direção transversal, pode-se escrever:

$$
\alpha(i)=\operatorname{arcsen} \sqrt{\frac{\sigma_{r}(i)+\rho_{t} \cdot f_{s t}(i) / t_{d}(i)}{\sigma_{r}(i)-\sigma_{d}(i)}}
$$

Assim sendo, os valores da espessura e do ângulo de inclinação da biela de concreto, para cada elemento devem satisfazer as equações (4.41) e (4.42).

O modelo de treliça transforma qualquer tipo de problema de torção em um sistema não-linear de $n$ equações com $n$ incógnitas.

O problema consiste em encontrar a solução para o sistema não-linear, sendo que as equações apresentadas não podem ser expressas explicitamente em termos de suas incógnitas. Então, o procedimento iterativo será empregado considerando as características de algumas variáveis importantes, como o fluxo de cisalhamento, a deformação principal média de compressão e o ângulo de inclinação das bielas comprimidas de cada elemento.

\subsubsection{Cobrimento e Parcela Central da Seção Transversal}

A utilização do modelo de treliça espacial não considera a parcela central da seção transversal, nem o descolamento progressivo da camada de cobrimento de concreto.

Como o modelo admite o comportamento do elemento sob torção por uma seção vazada correspondente, os resultados teóricos obtidos comparados com os experimentais podem apresentar uma divergência nos primeiros estágios do 
carregamento. A seção central ou o 'miolo' da seção transversal, de fato, permanece não fissurada nas primeiras parcelas do carregamento, e portanto, contribuem com parte da rigidez oferecida pelo elemento estrutural sob torção. No entanto, à medida que o carregamento aumenta, a seção central não fissurada torna-se menor, e o mecanismo do modelo de treliça comporta-se melhor na simulação da situação real.

Observa-se, em alguns trabalhos experimentais, que no processo de fissuração de peças estruturais sob torção, a camada de cobrimento pode descolar-se nas seções críticas.

Quando um elemento de viga é submetido a um carregamento combinado que inclui torção, nota-se que as diagonais comprimidas tendem a empurrar as quinas da seção, e portanto desprendê-las, enquanto que os estribos tracionados tendem a segurar as mesmas. Isto significa que as partes de concreto fora da região confinada pelo estribo podem descolar-se da seção, tornando-se portanto, ineficientes, à medida que o concreto não suporta mais a solicitação de tração.

$\mathrm{Na}$ tese de doutorado de Leung (1982), duas situações foram adotadas para as dimensões externas da seção para as análises teóricas. Uma delas apresenta as dimensões reais da seção transversal, enquanto a outra apresenta as dimensões da seção definidas pela linha central dos estribos. Neste trabalho, os resultados teóricos obtidos são plotados apenas após a formação de fissuras, para as relações momento-curvatura, uma vez que o modelo espacial de treliça adotado não prevê o comportamento do elemento antes do mesmo começar a fissurar-se.

Observa-se em Leung (1982) e em Onsongo (1978), que a adoção de seção com e sem cobrimento altera significativamente os resultados dos momentos resistentes, uma vez que não está previsto o gradual descolamento do cobrimento de concreto.

O trabalho de Rahal \& Collins (1995) consiste na investigação do efeito do aumento da espessura do cobrimento de concreto no comportamento de seções de concreto armado sujeitas a ação combinada de cisalhamento e torção, tendo sido este estudo verificado por ensaios experimentais.

Segundo Rabal \& Collins (1995), o código americano ACI recomenda considerar a colaboração do cobrimento na resistência à torção com base em ensaios experimentais de vigas com cobrimentos relativamente pequenos, da ordem de $1,27 \mathrm{~cm}$ a $1,52 \mathrm{~cm}$. Estudos anteriores de elementos submetidos à torção pura mostram que cobrimentos mais espessos podem descolar-se, o que faz reduzir consideravelmente a resistência da seção. Em função disto, o código canadense CSA recomenda desprezar a contribuição do cobrimento de concreto no cálculo da resistência à torção da seção transversal.

Os ensaios experimentais realizados por Rabal \& Collins (1995) mostram que a espessura do cobrimento pode melhorar o comportamento de seções de concreto armado submetidas ao cisalhamento simples, ou ação combinada de cisalhamento e torção. Nestes ensaios observou-se que para o cobrimento igual a $2,3 \mathrm{~cm}$, não houve descolamento mesmo depois da carga última ter sido aplicada. Já para a série com espessura de $4,3 \mathrm{~cm}$, nos casos próximos à torção pura e cisalhamento simples, quando o carregamento relativo ao descolamento do cobrimento foi atingido, a seção atingiu a carga última com um valor não superior a $4 \%$ do anterior. E para outras relações intermediárias entre cisalhamento e momento de torção, o aumento da resistência não 
foi superior a 14\%, após o descolamento ter sido observado.

Rahal \& Collins (1995) também observaram, a partir dos ensaios experimentais, que a abertura das fissuras para situações próximas à torção pura ou cisalhamento simples foi menor que as observadas para relações intermediárias entre torção e cisalhamento.

Segundo Hsu (1985a), quando o cobrimento é excessivo ele pode descolar-se antes do momento de torção máximo ser atingido. Isto significa que o momento de torção resistente pode ser menor que o previsto. Entretanto, quando a camada de cobrimento de concreto é muito fina, a resistência à torção da peça pode exceder à prevista. A fim de prevenir estes inconvenientes, as análises desenvolvidas por Hsu (1985a) incluem apenas seções cujas espessuras do cobrimento estão dentro do intervalo $0,25 \leq \overline{\mathrm{c}} / \mathrm{t}_{\mathrm{d}} \leq 0,75$, onde $\bar{c}$ é a distância medida a partir da face externa até a face interior dos estribos. Caso a relação seja superior a 0,75 o cobrimento deve ser desprezado.

Em Hsu (1985b) têm-se que a situação ótima para a torção ocorre quando a espessura do cobrimento de concreto é tal que a linha central do fluxo de cisalhamento coincida com a linha central da armadura. A linha central da armadura é definida como a linha da face interna do estribo, desde que esta esteja suficientemente próxima à linha centroidal das armaduras longitudinal e transversal combinadas. No modelo proposto por Hsu (1985b), a linha central do fluxo de cisalhamento é considerada no meio da espessura da zona comprimida $t_{d}$, ou seja, a uma distância $t_{d} / 2$ da face externa da seção transversal.

Por este motivo, se a distância da face externa da seção até a face interna da linha do estribo é menor que $t_{d} / 2$, então a linha de atuação do fluxo de cisalhamento estará fora da assumida teoricamente. Isto faz com que o valor teórico encontrado para o momento de torção resistente seja inferior ao real. Caso contrário, a resistência à torção real da peça ficará superestimada, segundo os resultados teóricos.

Neste trabalho, a consideração da camada de cobrimento c segue as recomendações conservativas de Rahal \& Collins (1996). Admite-se que o descolamento ocorre se a espessura da camada de concreto exceder a 30\% da relação área/perímetro da seção transversal, ou seja, c $\geq 0,3 \mathrm{~A} / \mathrm{p}$.

\subsubsection{RESULTADOS NUMÉRICOS E EXPERIMENTAIS}

Serão apresentados alguns resultados numéricos utilizando o modelo de Cocchi \& Volpi (1995), os quais serão comparados com os resultados experimentais da literatura técnica, bem como à resposta obtida com o programa ANSYS versão 5.5.

\subsubsection{MODELAGEM COM O PROGRAMA ANSYS}

A modelagem desenvolvida no programa ANSYS constitui-se da análise não-linear física de uma viga de concreto armado de seção retangular.

O concreto foi modelado utilizando o elemento finito tridimensional Solid65, de 8 nós e graus de liberdade à translação nas 3 direções ortogonais. Uma das principais 
características deste elemento refere-se ao tratamento dado à não-linearidade física do material. O concreto é capaz de fissurar-se, esmagar-se, apresentar deformações plásticas e fluência.

Os critérios de resistência considerados neste trabalho para o concreto foram o critério Concrete, baseado no critério de William-Warnke, e o critério DP de Drucker-Prager.

Os parâmetros necessários para considerar o critério Concrete são as tensões de ruptura unixiais de tração e de compressão do concreto. Este critério prevê a ruptura de materiais frágeis, considerando os modos de ruptura devido ao esmagamento e à fissuração, em função da consideração de estado de tensões multi-axiais.

De acordo com o critério de Drucker-Prager, a superfície de ruptura pode ser aproximada por um cone com vértice sobre o eixo hidrostático. Analiticamente, pode ser descrito em termos de dois parâmetros. As incógnitas necessárias para a definição destes parâmetros são o ângulo de atrito interno do material $\phi$ e o coeficiente de coesão $c$. Para o concreto, o ângulo e a coesão podem ser escritos em função da tensão de ruptura à tração $f_{c r}$ e da tensão de ruptura à compressão $f_{c}$, podendo ser obtidos a partir das seguintes expressões:

$$
\mathrm{f}_{\mathrm{c}}=\frac{2 \mathrm{c} \cos \phi}{1-\operatorname{sen} \phi} \quad \mathrm{f}_{\mathrm{cr}}=\frac{2 \mathrm{c} \cos \phi}{1+\operatorname{sen} \phi}
$$

Com relação à armadura transversal, utilizou-se o elemento Beam23 com 3 graus de liberdade por nó: 2 translações e 1 rotação. Considerou-se o comportamento elastoplástico perfeito para os estribos.

A armadura longitudinal foi modelada utilizando elemento sólido Solid45, com 8 nós e 3 graus de liberdade referentes à translação e material com comportamento elasto-plástico perfeito.

\subsubsection{Resultados OBTIDOS}

Foram analisadas as seções tranversais de duas vigas para as quais têm-se resultados experimentais da literatura técnica. Uma delas é a viga $\mathrm{B} 1$, equivalente à viga $\mathrm{B} 6$ ensaiada por $H s u$ (1968), a fim de verificar o comportamento sob torção pura. A viga B2, correspondente à viga B4 de Hsu (1968), foi analisada sob torção pura e torção com força normal.

A seção transversal das vigas analisadas encontram-se ilustradas na Figura 4.9, com as dimensões em centímetros. A Tabela 4.1 contém as especificações das armaduras.

A viga $\mathrm{B} 1$ foi modelada numericamente a fim de analisar o comportamento do modelo sob torção pura. Observa-se na Figura 4.10, que os resultados obtidos com o modelo de treliça espacial considerando as propriedades não-lineares dos materiais, aproximam-se de forma bastante satisfatória dos resultados experimentais. Segundo a equação recomendada por Rahal \& Collins (1996), c $\geq 0,3 \mathrm{~A} / \mathrm{p}$, não ocorre descolamento da camada de cobrimento, uma vez que a espessura da camada é $1,27 \mathrm{~cm}$. 
Tabela 4.1 - Área da seção transversal das armaduras e respectiva tensão de escoamento.

\begin{tabular}{|c|c|c|c|c|}
\hline \multirow{2}{*}{} & \multicolumn{2}{|c|}{$\begin{array}{c}\text { Viga B1 } \\
\mathrm{f}_{\mathrm{c}}=288 \mathrm{kgf} / \mathrm{cm}^{2}\end{array}$} & \multicolumn{2}{c|}{$\mathrm{f}_{\mathrm{c}}=305 \mathrm{kgf} / \mathrm{cm}^{2}$} \\
\cline { 2 - 5 } & Área & $\mathrm{f}_{\mathrm{y}}\left[\mathrm{kgf} / \mathrm{cm}^{2}\right]$ & Área & $\mathrm{f}_{\mathrm{y}}\left[\mathrm{kgf} / \mathrm{cm}^{2}\right]$ \\
\hline $\begin{array}{c}\text { Armadura } \\
\text { superior }\end{array}$ & $2 \phi 6,41 \mathrm{~cm}^{2}$ & 3317 & $2 \phi 3,88 \mathrm{~cm}^{2}$ & 3200 \\
\hline $\begin{array}{c}\text { Armadura } \\
\text { inferior }\end{array}$ & $2 \phi 6,41 \mathrm{~cm}^{2}$ & 3317 & $2 \phi 3,88 \mathrm{~cm}^{2}$ & 3200 \\
\hline Estribo & $\begin{array}{c}\phi 1,27 \mathrm{~cm}^{2} \\
\mathrm{c} / 5,72 \mathrm{~cm}\end{array}$ & 3227 & $\begin{array}{c}\phi 1,27 \mathrm{~cm}^{2} \\
\mathrm{c} / 9,20 \mathrm{~cm}\end{array}$ & 3234 \\
\hline
\end{tabular}

Duas situações foram consideradas na análise numérica da viga B1. Em uma delas utilizou-se a resistência à tração $\mathrm{f}_{\mathrm{cr}}$ calculada segundo a equação (4.36), e na outra, $\mathrm{f}_{\mathrm{cr}} *=35,95 \mathrm{kgf} / \mathrm{cm}^{2}$, valor este correspondente ao início da fissuração, segundo a resposta experimental. A Figura 4.10 mostra a influência da resistência à tração do concreto no comportamento da viga à torção, segundo o modelo numérico.

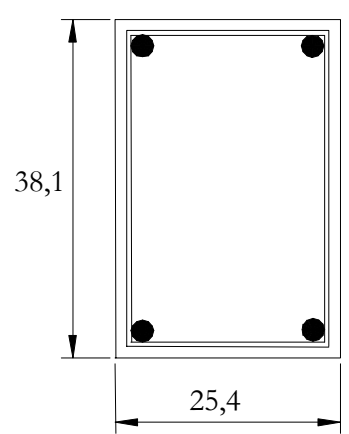

Figura 4.9 - Vigas B1 e B2.

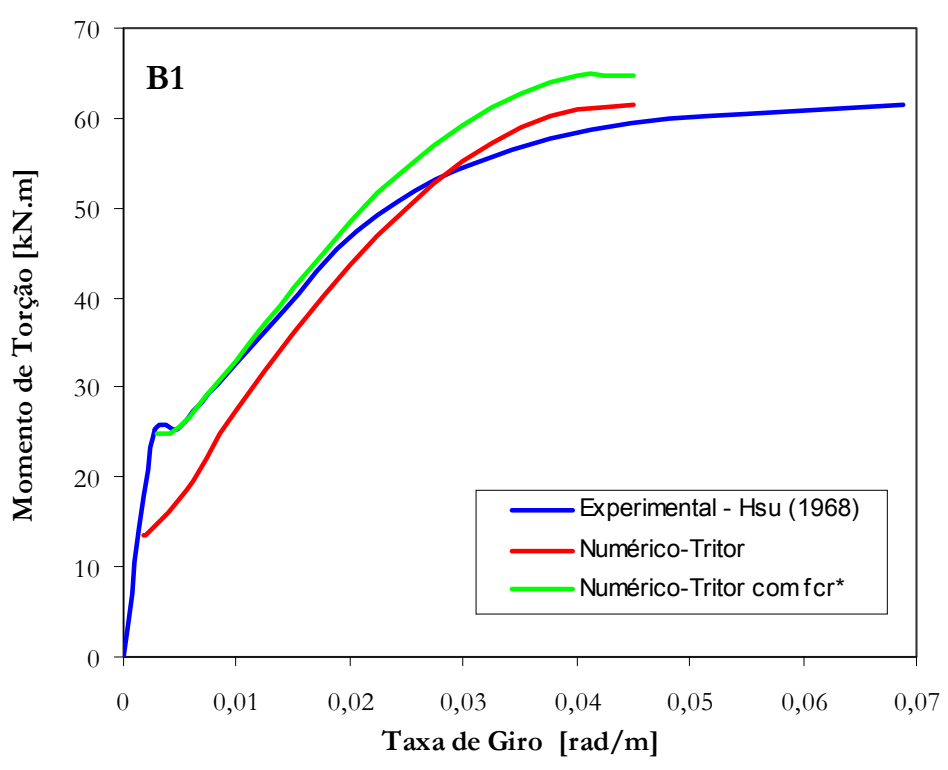

Figura 4.10 - Viga B1 sob torção pura.

A viga B2 foi analisada sob torção pura, conforme apresentado na Figura 4.11. Nesta figura, pode-se observar a resposta obtida experimentalmente por Hsu (1968), o comportamento utilizando o modelo numérico descrito neste trabalho, bem como as análises desenvolvidas utilizando o programa ANSYS. Duas curvas numéricas são apresentadas obtidas a partir do algoritmo proposto por Cocchi \& Volpi (1996). Uma delas resulta da utilização do valor experimental da tensão de tração $\mathrm{f}_{\mathrm{cr}}{ }^{*}=27,8 \mathrm{kgf} / \mathrm{cm}^{2}$, e a outra, da utilização da equação (4.36).

Pode-se observar que as curvas obtidas utilizando o ANSYS, embora incluam a nãolinearidade física dos materiais envolvidos, são razoavelmente inferiores com relação aos valores últimos e rígidas segundo a taxa de giro por torção.

Utilizando o elemento sólido Solid65 com o critério Concrete, representado por $\mathrm{C}$ na legenda da Figura 4.11, associado ao critério de Drucker-Prager, este último representado por DP, a fim de considerar o efeito da fissuração na resposta à torção da viga, observa- 
se que o comportamento obtido foi linear até o ponto de ruptura. O momento crítico para o qual verifica-se convergência é muito inferior ao experimental.

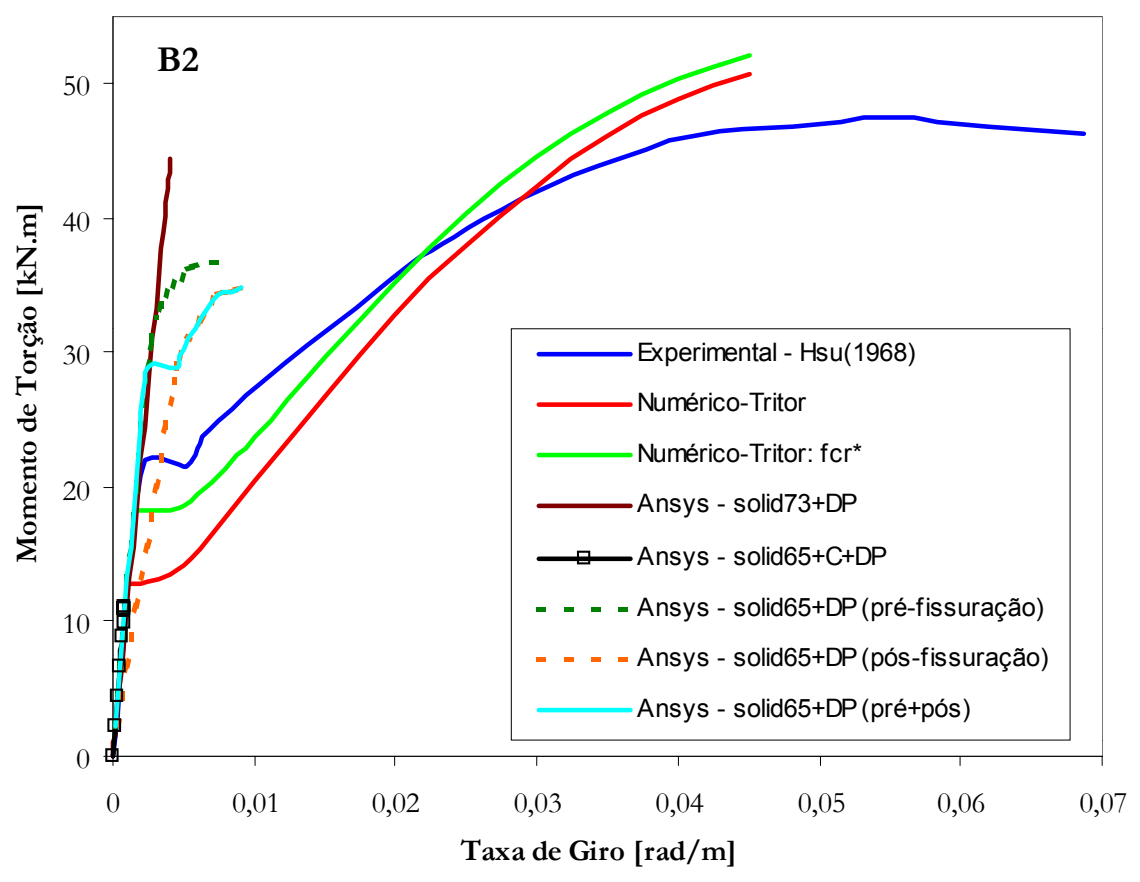

Figura 4.11 - Viga B2 sob torção pura.

$\mathrm{Na}$ Figura 4.11 também estão representadas as situações pré e pós fissuração, na análise com o ANSYS considerando o critério de Drucker-Prager. No trabalho de Bhatti (1996), o autor considera o módulo de elasticidade e o coeficiente de Poisson diferentes para o concreto na fase não-fissurada com relação à fase fissurada. Bhatti (1996) considera ainda outros efeitos, como o coeficiente de amolecimento na fase fissurada. Estas considerações visam simular o concreto como um material de comportamento ortótropo na fase fissurada, devido às diferentes respostas sob tração e sob compressão.

Assim, modelou-se a viga B2 utilizando o critério de Drucker-Prager considerando, na fase fissurada, o módulo de elasticidade do concreto igual a $E=f_{c} / \varepsilon_{o}$, sendo $\varepsilon_{o} o$ valor da deformação do concreto quando a tensão máxima é igual a $f_{c}$, bem como o coeficiente de Poisson igual a 0,3. Observa-se uma resposta mais adequada, com uma fase não-linear mais bem definida, porém ainda com comportamento rígido.

Uma outra tentativa foi desenvolvida utilizando-se o elemento Solid73, apresentando 6 graus de liberdade por nó, 3 de translação e 3 de rotação. A resposta obtida foi linear, conforme ilustra o gráfico da Figura 4.11, sem apresentar fissuração.

A Figura 4.12 mostra o quadro de fissuração da seção sob solicitação última, utilizandose o critério Concrete com Drucker-Prager, obtido da simulação utilizando o programa ANSYS. Nota-se a ausência de fissuração na parte central. Os elementos não fissurados próximos às quinas representam as armaduras longitudinais. 


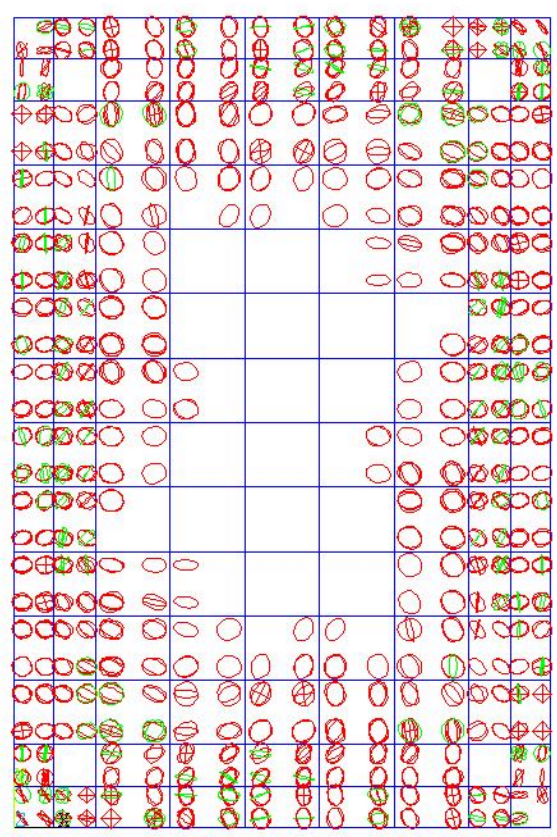

Figura 4.12 - Quadro de fissuração na seção transversal da viga B2 - ANSYS.

A Figura 4.13 ilustra as respostas numéricas e experimentais da viga B2 sob torção e força normal de compressão. O aumento da capacidade de absorção de momento de torção deve-se à existência de compressão na seção transversal. No exemplo, foi considerada uma deformação axial constante igual a $-1,5 \mathrm{E}-4$ na seção transversal, correspondente a uma solicitação de compressão igual a $-45,74 \mathrm{kN}$.

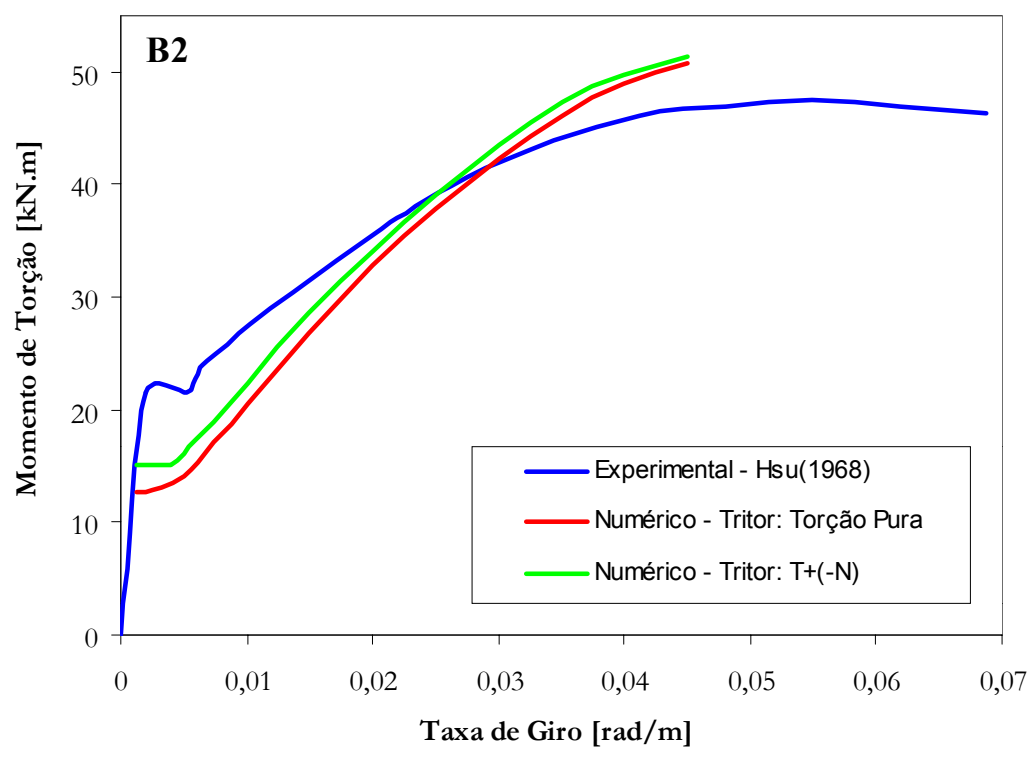

Figura 4.13 - Viga B2 sob torção e força normal de compressão.

Enfim, apresentou-se até então, a descrição do comportamento do concreto sob solicitações combinadas de torção e força axial através de duas formulações numéricas.

Uma delas, consiste na aplicação do modelo de treliça espacial utilizando a teoria modificada dos campos comprimidos MCFT, a fim de descrever o comportamento não- 
linear físico do concreto. Este modelo numérico considera a seção transversal, inicialmente sólida no período pré-fissuração, através de uma seção vazada como consequência da fissuração. Despreza-se a influência da parte interna de concreto na seção transversal. A seção vazada é então considerada submetida a um estado plano de tensões. Devem ser satisfeitas as condições de equilíbrio e de compatibilidade, bem como as leis constitutivas dos materiais envolvidos. O problema computacional consiste na resolução do sistema de equações não-lineares, através de procedimento iterativo e incremental.

A modelagem numérica no programa ANSYS foi desenvolvida utilizando elementos sólidos para o concreto e a armadura longitudinal, e elementos lineares para os estribos.

Com relação às respostas numéricas obtidas do programa ANSYS, verifica-se a dificuldade de se alcançar resultados satisfatórios utilizando-se as ferramentas e hipóteses básicas dos elementos disponíveis, na tarefa de descrever o comportamento do concreto-armado. Nos casos analisados, a convergência do processo não-linear ocorreu para deformações inferiores à resposta experimental. A modificação no valor do módulo de elasticidade longitudinal e do coeficiente de Poisson, na tentativa de descrever o comportamento do concreto após fissurar-se, segundo apresentado por Bhatti (1996) e utilizando o critério de Drucker-Prager, permite avançar mais alguns pontos na curva momento de torção-taxa de giro.

Com relação aos resultados obtidos utilizando o modelo de treliça espacial e a teoria modificada dos campos comprimidos, pode-se observar que nos casos de torção pura e torção com força normal, os resultados são bastante satisfatórios. Conclui-se portanto, que o modelo de treliça espacial considerando as leis constitutivas dos materiais, onde admitiu-se o amolecimento do concreto à compressão, bem como o enrijecimento na armadura devido à presença de trechos de concreto não fissurado entre as fissuras, é eficiente na obtenção dos esforços internos resultantes de ações combinadas, mesmo desprezando o núcleo da seção transversal.

Porém, todo este tratamento teórico é eficiente nos casos onde a torção é solicitação predominante sobre as demais. Será apresentado a seguir, o modelo proposto por Hannachi \& Fouré (1996), indicado aos casos onde existe torção, porém a flexão é ação dominante. No trabalho destes autores, a rigidez à torção depende do nível de fissuração por flexão da peça de concreto, dentre outros fatores.

\subsection{RigidEZ À TORÇÃo SEGUNDO HANNACHI \& FourÉ (1996)}

Conforme apresentado no Capítulo 2, o modelo teórico de Hannachi \& Fouré (1996) aplica-se ao cálculo da rigidez à torção de vigas de concreto armado, fissuradas por flexão e submetidas a pequenos momentos de torção. Os procedimentos necessários à utilização do método proposto por Hannachi \& Fouré (1996) serão descritos a seguir. Neste item, manteve-se, , em linhas gerais, a notação utilizada pelos autores.

Em uma seção de uma viga de comprimento $L$ submetida à força $\mathrm{N}$, momento fletor $\mathrm{M}$ e de torção $\mathrm{M}_{\mathrm{t}}$, comportando $n$ fissuras idênticas, tem-se que $\mathrm{s}_{\mathrm{m}}$ é igual ao espaçamento médio entre fissuras e $t_{\mathrm{m}}$ é a abertura média das fissuras. 
O momento de torção $\mathrm{M}_{\mathrm{t}}$ admitido por Hannachi \& Fouré (1996) limita-se apenas à parcela dada pela torção de Saint-Venant. A contribuição dos materiais constituintes, no caso aço e concreto, são considerados separadamente na seção da fissura. Assim, $\mathrm{M}_{\mathrm{ta}}$ é a parcela do momento torçor resistida pela armadura e $\mathrm{M}_{\mathrm{tb}}$ é a parcela resistida apenas pelo concreto, de tal forma que $\mathrm{M}_{\mathrm{t}}=\mathrm{M}_{\mathrm{ta}}+\mathrm{M}_{\mathrm{tb}}$ na região da fissura.

Hannachi \& Fouré (1996) decompõem a rotação total de torção em dois termos, num deles tem-se a rotação das parcelas não-fissuradas, e no outro, a rotação concentrada na fissura. Assim,

$$
\theta=\int_{0}^{\mathrm{L}}\left(\frac{\mathrm{d} \theta}{\mathrm{d} z}\right) \mathrm{dz}+\sum_{\mathrm{j}=1}^{\mathrm{n}} \delta \theta_{j}
$$

A contribuição do concreto simples ou concreto sem armadura na rotação por torção é:

$$
\delta \theta_{o}=\frac{M_{t} L}{n}\left[\frac{1}{\left(G J_{t}\right)_{b}}-\frac{1}{\left(G J_{t}\right)_{o}}\right]
$$

onde $\delta \theta_{o}$ é a rotação concentrada em cada seção com fissura resistida apenas pelo concreto, $\left(G_{t}\right)_{b}$ é a contribuição do concreto sem armadura na rigidez média global, e $\left(G_{t}\right)_{0}$ é a rigidez devido ao concreto entre fissuras, na ausência de armaduras.

A contribuição do concreto armado pode ser escrita por:

$$
\delta \theta_{1}=\frac{\mathrm{M}_{\mathrm{t}} \mathrm{L}}{\mathrm{n}}\left[\frac{1}{\overline{\overline{\mathrm{GJ}}}}-\frac{1}{\left(\mathrm{GJ}_{\mathrm{t}}\right)_{1}}\right]
$$

onde $\delta \theta_{1}$ é a rotação concentrada na seção com fissura resistida pelo conjunto concreto e armadura, $\left(\mathrm{GJ}_{\mathrm{t}}\right)_{1}$ é a rigidez média do concreto armado entre fissuras, e $\overline{\mathrm{GJ}_{\mathrm{t}}}$ é a rigidez à torção global após a fissuração.

Uma vez que a presença das armaduras nas seções fissuradas modificam a contribuição ao cisalhamento nestas regiões, deve-se introduzir um fator de correção $\lambda$ de tal forma que:

$$
\left(\mathrm{GJ}_{\mathrm{t}}\right)_{1}=\lambda\left(\mathrm{GJ}_{\mathrm{t}}\right)_{\mathrm{o}}
$$

Pode-se observar que em uma seção na fissura, a parcela do momento de torção equilibrada pelo concreto é função da rotação $\delta \theta_{1}$, mas a proporcionalidade é alterada pela presença das armaduras. Assim, um novo fator $\mu$ de correção deve ser introduzido.

$$
\delta \theta_{1}=\mu . \delta \theta_{o} \cdot \frac{\mathrm{M}_{\mathrm{tb}}}{\mathrm{M}_{\mathrm{t}}}
$$

Considerando-se o efeito de pino das armaduras nas seções fissuradas, resulta:

$$
\delta \theta_{1}=\frac{\mathrm{M}_{\mathrm{ta}}}{\mathrm{R}_{\mathrm{a}}}
$$

onde $\mathrm{R}_{\mathrm{a}}$ é a rigidez à torção devido unicamente às armaduras na seção da fissura. 
As relações (4.45), (4.46), (4.47), (4.48) e (4.49) permitem escrever:

$$
\frac{1}{\overline{\mathrm{GJ}_{\mathrm{t}}}}=\frac{1}{\lambda\left(\mathrm{GJ}_{\mathrm{t}}\right)_{\mathrm{b}}}+\frac{\mu\left[\frac{1}{\left(G J_{t}\right)_{b}}-\frac{1}{\left(G J_{t}\right)_{o}}\right]}{1+\left[\frac{1}{\left(G J_{t}\right)_{b}}-\frac{1}{\left(G J_{t}\right)_{o}}\right] \mu \cdot s_{m} \cdot R_{a}} \quad \text { onde } \quad s_{m}=\frac{L}{n}
$$

Assim, para o cálculo da rigidez à torção global após a fissuração $\overline{\mathrm{GJ}_{\mathrm{t}}}$, é necessário conhecer a rigidez $\mathrm{R}_{\mathrm{a}}$ e os parâmetros de correção $\lambda$ e $\mu$, os quais serão desenvolvidos mais adiante.

\subsubsection{CONTRIBUIÇÃo DAS ARMADURAS}

É conhecido que a contribuição das armaduras, tanto a longitudinal como a transversal, é muito pequena na resistência à torção de vigas não-fissuradas de concreto armado. Após a fissuração, Hannachi \& Fouré (1996) consideram a contribuição das armaduras através do efeito de pino. Os resultados experimentais observados por Hannachi \& Fouré (1996) mostram que é o concreto que participa sempre com maior intensidade.

Sendo $\mathrm{r}$ a distância ao eixo de rotação da armadura mais distante, o máximo deslizamento no nível da armadura pode ser expresso por:

$$
g=r . \delta \theta
$$

onde a rotação concentrada em uma fissura $\delta \theta$ pode ser estimada pela equação:

$$
\delta \theta=M_{t} s_{m}\left[\frac{1}{\overline{G_{t}}}-\frac{1}{G_{o} J_{t}}\right]
$$

O deslizamento pode então ser obtido, uma vez conhecidos experimentalmente os valores de $s_{m}, G_{o}, J_{t}$ e $\overline{G_{t}}$, na fase de máximo desenvolvimento da fissuração e para o momento de torção em torno de um terço do valor do momento de fissuração na torção pura.

Hannachi \& Fouré (1996) observaram experimentalmente que o deslizamento médio, em vigas de seção quadrada e retangular, sólidas e vazadas, foi da ordem de 0,01 a $0,02 \mathrm{~mm}$. Assim, concluem que a influência da armadura pode ser observada uma vez que o deslizamento diminue à medida em que a porcentagem de armadura aumenta. Enfim, consideram satisfatório admitir um comportamento linear para o efeito de pino.

$\mathrm{Na}$ busca de se obter uma relação entre a força transversal $\mathrm{V}$ e o deslizamento relativo g, Hannachi \& Fouré (1996) consideraram um problema análogo resolvido pela Mecânica dos Solos, relativo ao comportamento de uma estaca cravada no solo sob ação de força transversal. A expressão (4.53) permite obter a força transversal $\mathrm{V}$ em função do deslizamento $\mathrm{g}$ com as seguintes notações: $\mathrm{E}_{\mathrm{bo}}$ é o módulo de deformação longitudinal do concreto com relação à origem, $\mathrm{E}_{\mathrm{s}}$ é o módulo de deformação do aço e $\phi$ é o diâmetro da armadura. 


$$
\mathrm{V}=\frac{\mathrm{E}_{\mathrm{bo}} \cdot \phi}{8}\left[\pi \cdot \frac{\mathrm{E}_{\mathrm{s}}}{\mathrm{E}_{\mathrm{bo}}}\right]^{\frac{1}{4}} \cdot \mathrm{g}
$$

Embora existam expressões mais apropriadas ao cálculo da força tangencial V, como por exemplo as obtidas experimentalmente do estudo de chumbadores imersos em concreto e sujeitos a uma força transversal, utilizou-se neste trabalho o modelo original proposto por Hannachi \& Fouré (1996).

Hannachi \& Fouré (1996) compararam a relação entre V e g dada pela equação (4.53) com vários resultados experimentais da literatura técnica, os quais referem-se à resistência última ao esforço cortante, e portanto muito além do domínio linear. Os autores concluem que a relação (4.53) é uma boa aproximação, observando a inclinação da curva na origem.

A rigidez de torção $\mathrm{R}_{\mathrm{a}}$ devido à contribuição das armaduras na fissura pode ser calculada uma vez que $\mathrm{M}_{\mathrm{t}_{\mathrm{a}}}=\mathrm{R}_{\mathrm{a}} \cdot \delta \theta_{1}$. Na região da seção fissurada, a rotação concentrada $\delta \theta_{1}$ é medida em torno do eixo normal à seção, passando pelo centro de torção. Conforme ilustra a Figura 4.14, o deslizamento no nível da armadura $i$ distante de $\mathrm{r}$ do centro de torção é:

$$
\mathrm{g}_{\mathrm{i}}=\mathrm{r}_{\mathrm{i}} \cdot \delta \theta_{\mathrm{i}}
$$

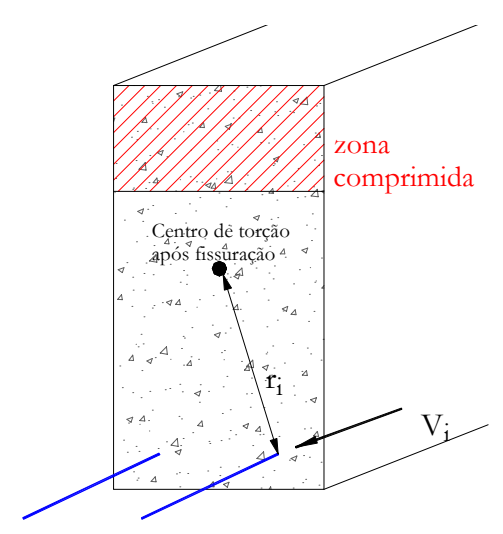

Figura 4.14 - Força transversal equilibrada pela armadura longitudinal. Hannachi \& Fouré (1996).

A força transversal $\mathrm{V}_{\mathrm{i}}$ equilibrada para cada armadura $i$ é dada pela expressão (4.53). Esta força é perpendicular à reta que passa pelo centro de torção e pela armadura considerada. Assim, a parcela $\mathrm{M}_{\mathrm{ta}}$ de torção equilibrada pela armadura pode ser escrita por:

$$
\mathrm{M}_{\mathrm{ta}}=\sum_{\mathrm{i}=1}^{\mathrm{m}} \mathrm{V}_{\mathrm{i}} \cdot \mathrm{r}_{\mathrm{i}}=\frac{\mathrm{E}_{\mathrm{bo}}}{8}\left[\pi \cdot \frac{\mathrm{E}_{\mathrm{a}}}{\mathrm{E}_{\mathrm{bo}}}\right]^{\frac{1}{4}} \delta \theta_{1} \sum_{\mathrm{i}=1}^{\mathrm{m}} \phi_{\mathrm{i}} \cdot \mathrm{r}_{\mathrm{i}}^{2}
$$

e portanto, a rigidez devido à consideração de efeito de pino $\mathrm{R}_{\mathrm{a}}$ vale:

$$
\mathrm{R}_{\mathrm{a}}=\frac{\mathrm{E}_{\mathrm{bo}}}{8}\left[\pi \cdot \frac{\mathrm{E}_{\mathrm{a}}}{\mathrm{E}_{\mathrm{bo}}}\right]^{\frac{1}{4}} \sum_{\mathrm{i}=1}^{\mathrm{m}} \phi_{\mathrm{i}} \cdot \mathrm{r}_{\mathrm{i}}^{2}
$$




\subsubsection{CONTRIBUIĻÃO DO CONCRETO}

Na região fissurada, o módulo $G^{*}$ é constante nas fibras paralelas à linha média e é função da posição da fibra na seção da fissura. $\mathrm{Na}$ zona comprimida, o módulo resultante pode ser adotado igual a $G_{0}$ da elasticidade linear, hipótese que é aceitável no domínio não-linear, segundo Hannachi \& Fouré (1996), para pequenas tensões de cisalhamento.

Em problemas de instabilidade, as tensões de cisalhamento permanecem suficientemente pequenas. Assim, na zona tracionada, pode-se adotar a hipótese de que o módulo fictício $G^{*}$ decresce linearmente e na proporção da distância à linha neutra, de valor $G_{o}$ até o valor $G_{1}$, na fibra mais tracionada. O valor de $G_{1}$ é função do parâmetro que caracteriza a fissuração do concreto.

O estudo de Hannachi \& Fouré (1996) foi apresentado para o caso de problemas com flexão em apenas uma direção, ilustrado na Figura 4.15 (a). Neste trabalho, o valor do módulo fictício $G^{*}$ foi obtido considerando a proposta de Hannachi \& Fouré (1996), e portanto, variando de $G_{o}$ à $G_{1}$, conforme mostra a Figura 4.15 (b).

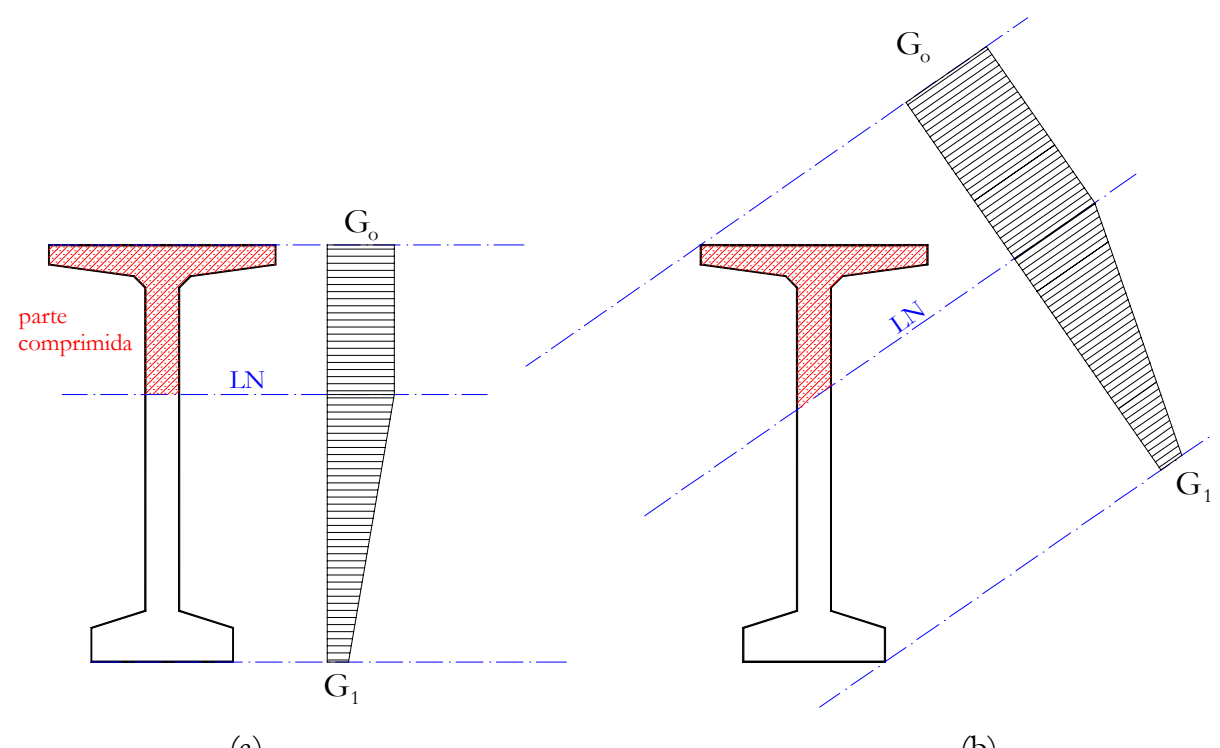

(a)

(b)

Figura 4.15 - Módulo de elasticidade transversal na seção fissurada.

\subsubsection{EXPRESSÃO DO MÓDULO G}

Conhecida a rigidez $\overline{\mathrm{GJ}_{\mathrm{t}}}$ experimental e desprezando, em primeira aproximação, a contribuição das armaduras, pode-se determinar o valor de $G_{1}$ de tal forma que $\overline{\mathrm{GJ}_{\mathrm{t}}}=\left(\mathrm{GJ}_{\mathrm{t}}\right)_{\mathrm{b}}$. Hannachi \& Fouré (1996) mostram que a relação entre $G_{1} / G_{\mathrm{o}}$ em função do parâmetro de fissuração $\mathrm{t}_{\mathrm{m}} / \mathrm{s}_{\mathrm{m}}$ conhecido experimentalmente, pode ser representada por curvas hiperbólicas como a expressa na equação (4.57): 


$$
\frac{G_{1}}{G_{o}}=\frac{a}{a+\frac{t_{m}}{s_{m}}}
$$

onde $a$ é uma constante.

Observando a importância do efeito de pino das armaduras, Hannachi \& Fouré (1996) buscam relacionar a constante $a$ ao parâmetro $R_{a} / G_{o} J_{t}$. $O$ valor da constante $a$ correspondente ao caso onde não existem armaduras, ou seja $R_{a} / G_{o} J_{t}=0$, é aproximadamente igual a $0,4 \mathrm{E}-03$. Considerando apenas a contribuição do concreto, resulta:

$$
\frac{G_{1}}{G_{o}}=\frac{1}{1+2500\left(\frac{t_{m}}{s_{m}}\right)}
$$

Desta forma, $G_{1}$ corresponde ao módulo tangente na origem.

\subsubsection{EXPRESSÃO DA RIGIDEZ $\left(\mathrm{G}_{\mathrm{t}}\right)_{\mathrm{b}}$}

Quando o modulo G* é variável na seção, as expressões aproximadas da rigidez à torção podem ser estabelecidas, segundo Hannachi \& Fouré (1996), na hipótese da elasticidade não-linear, de acordo com o tipo de seção.

- Para uma seção transversal de paredes finas: $\left(\mathrm{GJ}_{\mathrm{t}}\right)_{\mathrm{b}} \approx \frac{1}{3} \sum_{\mathrm{i}} \overline{\mathrm{G}}_{\mathrm{i}} \int_{0}^{\ell_{\mathrm{i}}} \mathrm{e}(\mathrm{s})^{3} \mathrm{ds}$ onde e(s) é a espessura, $\ell$ é o comprimento de cada elemento que compõe a seção e s é a abscissa curvilínea. O módulo fictício médio $\overline{\mathrm{G}}$ é dado por: $\overline{\mathrm{G}}=\frac{1}{\mathrm{~A}} \int_{0}^{\ell} \mathrm{G} *(\mathrm{~s}) \cdot \mathrm{e}(\mathrm{s}) \cdot \mathrm{ds}$.

- Para uma seção cheia: $\left(\mathrm{GJ}_{\mathrm{t}}\right)_{\mathrm{b}} \approx \overline{\mathrm{G}} \mathrm{J}_{\mathrm{t}}$

onde s é o contorno, A é a área e $\bar{G}=\frac{1}{A} \iint_{s} G^{*}(x, y) d s$, sendo $J_{t}$ a inércia à torção utilizada em regime elástico linear.

\subsubsection{SIMPLIFICAÇÕES COMPLEMENTARES}

A primeira simplificação consiste em admitir que a rigidez média do concreto entre fissuras na ausência de armaduras $\left(\mathrm{GJ}_{\mathrm{t}}\right)_{\mathrm{o}}$ é igual à rigidez elástica linear. Assim:

$$
\left(\mathrm{GJ}_{\mathrm{t}}\right)_{\mathrm{o}} \cong \mathrm{G}_{\mathrm{o}} \mathrm{J}_{\mathrm{t}}
$$

Por outro lado, a expressão geral (4.50) da rigidez global apresenta os parâmetros $\lambda$ e $\mu$, que levam em conta a influência das armaduras nos termos avaliados na ausência de 
armadura. Estes parâmetros tendem a 1 quando as armaduras tendem a 0 . Substituindo estes parâmetros por um único fator corretivo $\psi$, a expressão simplificada proposta resulta em:

$$
\frac{1}{\overline{\mathrm{GJ}_{t}}}=\psi \cdot\left[\frac{1}{\mathrm{G}_{\mathrm{o}} J_{t}}+\frac{\left[\frac{1}{\left(\mathrm{GJ}_{t}\right)_{b}}-\frac{1}{\mathrm{G}_{\mathrm{o}} J_{t}}\right]}{1+\left[\frac{1}{\left(\mathrm{GJ}_{\mathrm{t}}\right)_{\mathrm{b}}}-\frac{1}{\mathrm{G}_{\mathrm{o}} J_{t}}\right] \mathrm{s}_{\mathrm{m}} \cdot \mathrm{R}_{\mathrm{a}}}\right]
$$

Hannachi \& Fouré (1996) observam a tendência de variação do fator de correção $\psi$ com o parâmetro de fissuração $\mathrm{t}_{\mathrm{m}} / \mathrm{s}_{\mathrm{m}}$, diferente para cada tipo de seção, através da expressão linear dada pela equação (4.58). Assim:

$$
\psi=1+\mathrm{b}\left(10^{3} \frac{\mathrm{t}_{\mathrm{m}}}{\mathrm{s}_{\mathrm{m}}}\right)
$$

onde: $\quad b=0,05$ para seções delgadas retangulares e duplo T;

$\mathrm{b}=0,125$ para seções cheias quadradas;

$\mathrm{b}=-0,25$ para seções vazadas.

Segundo os autores deste modelo, o ponto fraco deste método reside na necessidade de distinguir os vários tipos de seção por meio de coeficientes empíricos.

\subsection{RigideZ À TORÇão E POSIÇÃo do CENTRO DE TORÇÃo SEGUNDO FOURÉ \& HANNACHI (1999)}

O estudo apresentado por Fouré \& Hannachi (1999) trata particularmente dos problemas de estabilidade em 3 dimensões, ou seja, flambagem na flexão composta oblíqua e inclinada, onde aparece solicitação de torção. As tensões de cisalhamento correspondentes são geralmente muito pequenas, mas no caso de estruturas delgadas, as rotações correspondentes podem ter um efeito não desprezível em termos de $2^{\underline{a}}$ ordem. As solicitações principais são a força normal e os momentos fletores. As fissuras que podem aparecer são resultantes da flexão no plano da seção dos elementos da estrutura. O nível das tensões de cisalhamento devido à torção permanece geralmente inferior àquele que provocaria inclinação considerável das fissuras de flexão, fora do plano das seções. A possibilidade de surgirem fissuras de cisalhamento independente das de flexão é excluída.

Segundo Fouré \& Hannachi (1999), a solução do problema de estabilidade requer o cálculo correto das rigidezes fora do domínio linear, levando em conta a fissuração e a plastificação do concreto, bem como a plastificação das armaduras. Os referidos autores observam que o problema encontra-se satisfatoriamente resolvido para rigidez axial e de flexão. Mas não para a rigidez à torção pura e para os diversos termos de rigidez que interferem no comportamento de vigas de perfil delgado aberto sob torção mista, com empenamento impedido. Desta forma, verificam que o problema de cálculo embora já estudado não está completamente resolvido, em particular com relação ao cálculo da rigidez à torção pura. Isto porque a maioria dos estudos encontrados na literatura técnica trataram com maior interesse os elementos estruturais submetidos à grande torção, e esta gerando fissuração oblíqua por cisalhamento. Em grande parte destes 
casos, a avaliação da rigidez fundamenta-se no modelo clássico de treliça.

Fouré \& Hannachi (1999) observam que não existe nenhum resultado de ensaio que avalie a rigidez à torção de vigas fissuradas por flexão, para nenhum tipo de seção plana. Alguns ensaios realizados pelos próprios autores referem-se à vigas-caixão fissuradas por cortante. Fouré \& Hannachi (1999) apresentam um ambicioso programa de ensaio, no qual 16 vigas, incluindo seção quadrada sólida e vazada, retangulares de diversas larguras e seção duplo T simétrica, foram solicitadas por flexão simples ou composta, a fim de provocar diversos estados de fissuração, até a plastificação das armaduras tracionadas. Em cada um destes estados, a medida da rotação de torção devido ao pequeno binário permitiu determinar a rigidez à torção. Nestes ensaios, 3 fases correspondentes à níveis de flexão crescente foram realizadas. Em cada uma destas fases, após a aplicação do momento fletor, o deslocamento era mantido constante e o binário de torção aplicado em etapas crescentes. A última etapa corresponde, geralmente, ao aparecimento nítido de fissuras de cisalhamento inclinadas prolongadas das fissuras de flexão.

Porém, Fouré \& Hannachi (1999) perceberam, no programa experimental, a dificuldade de medir de forma confiável o valor da rigidez à torção referente à inclinação na origem. Um alternativa empregada por estes autores foi estimar a rigidez tangente média entre 2 etapas sucessivas de aplicação do binário de torção.

Fouré \& Hannachi (1999) consideram que o trabalho anterior proposto por Hannachi \& Fouré (1996), embora baseado nos mesmo parâmetros, que são: forma da seção, estado de fissuração, abertura e espaçamento entre fissuras, e armadura longitudinal perde a generalidade uma vez que a influência do tipo de seção transversal é considerada por parâmetros semi-empíricos.

De uma forma geral, Fouré \& Hannachi (1999) buscam cumprir os seguintes objetivos:

- Colocar em evidência que, na zona comprimida, o módulo de deformação transversal do concreto pode ser igual ao módulo de elasticidade linear $G_{o}$, com uma aproximação satisfatória na maioria dos casos, baseado em resultados de ensaios de compressão e torção em cilindros vazados;

- Propor um novo método mais geral de previsão da rigidez à torção pura de uma viga fissurada por flexão, sendo esta a rigidez tangente à origem, sob binário tendendo à zero, para um viga previamente fissurada por flexão. Os valores experimentais obtidos para a rigidez à torção mostram que o método é fortemente afetado de incerteza.

O método proposto por Fouré \& Hannachi (1999) considera uma lei de variação da rigidez ao longo do comprimento da viga pela definição de um comprimento de perturbação p com relação à fissura. $\mathrm{Na}$ idealização adotada, supõe-se que existe entre as fissuras uma zona onde a rigidez à torção é aquela da elasticidade linear apenas para o concreto. Esta zona situa-se onde o comprimento de perturbação p é inferior à metade da distância entre as fissuras, conforme ilustra a Figura 4.16. No entanto, em casos onde a distância entre fissuras é menor do que p, ocorre superposição do comprimento de perturbação, sendo que a rigidez máxima deve ser inferior ao valor da rigidez não fissurada $G_{o} J_{t_{0}}$. 
Assim, Fouré \& Hannachi (1999) propõem que a rigidez à torção $G_{\mathrm{t}}(\mathrm{x})$ é igual à $\mathrm{G}_{\mathrm{o}} \mathrm{J}_{\mathrm{to}}$ para todas as distâncias iguais ou superiores à p, e decresce parabolicamente até o valor mínimo $\left(G J_{t}\right)_{f}$ na seção onde existe a fissura. Desta forma, recomendam:

$$
\begin{gathered}
G J_{t}(x)=G_{o} J_{t_{o}}-\left[G_{o} J_{t_{o}}-\left(G J_{t}\right)_{f}\left(\frac{x}{p}\right)^{2}=\left[1-F\left(\frac{x}{p}\right)^{2}\right] G_{o} J_{t_{o}}\right. \\
\text { onde } F=1-\frac{\left(G J_{t}\right)_{f}}{G_{o} J_{t_{o}}} \text { sendo } 0 \leq F<1 .
\end{gathered}
$$

Segundo Fouré \& Hannachi (1999), a distância p depende da altura e da abertura da fissura, bem como da presença das armaduras. Um parâmetro importante com relação ao comprimento de perturbação é a altura de descontinuidade da fissura que é limitada no ponto que a fissura atinge a abertura limite. Abaixo deste valor de abertura existe a possibilidade de transmissão de cisalhamento pelo contato entre as superfícias ásperas da fissura por atrito ou engrenamento. Os autores em questão verificam que, baseado nos resultados experimentais, até que a abertura limite equivalente a $0,02 \mathrm{~mm}$ seja atingida não ocorre redução da rigidez à torção, permanecendo igual à da viga não fissurada.

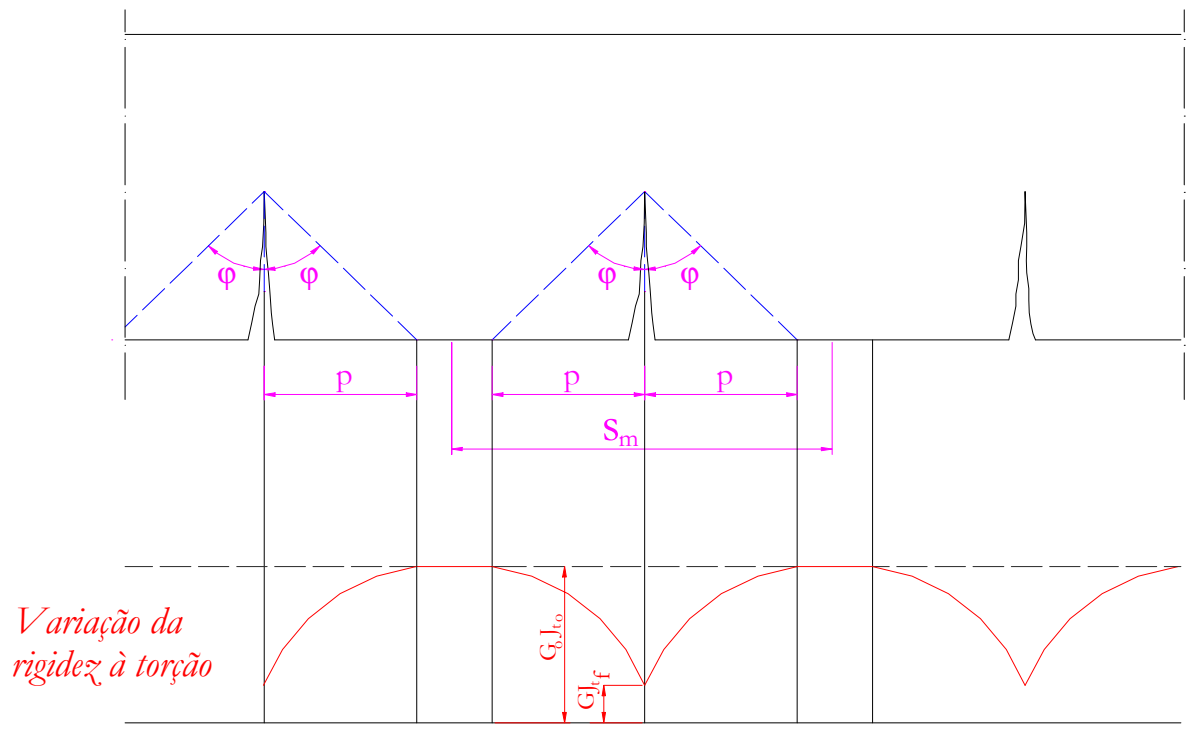

Figura 416 - Variação da rigidez à torção em função do comprimento de perturbação p.

Fouré \& Hannachi (1999) definem como rigidez média à torção $\overline{\mathrm{GJ}_{\mathrm{t}}}$ o valor médio da rigidez no comprimento $\mathrm{s}_{\mathrm{m}}$. Desta forma, o valor $\overline{\mathrm{GJ}}$ depende do comprimento de perturbação $\mathrm{p}$, uma vez que deve-se levar em conta se existem trechos com rigidez não fissurada, no caso onde $\mathrm{p}<\mathrm{s}_{\mathrm{m}} / 2$. Ou ainda, se existem trechos onde a máxima rigidez no comprimento $\mathrm{s}_{\mathrm{m}}$ é inferior ao valor $\mathrm{G}_{\mathrm{o}} \mathrm{J}_{\mathrm{t}_{\mathrm{o}}}$, ou seja, para $\mathrm{p}>\mathrm{s}_{\mathrm{m}} / 2$. 


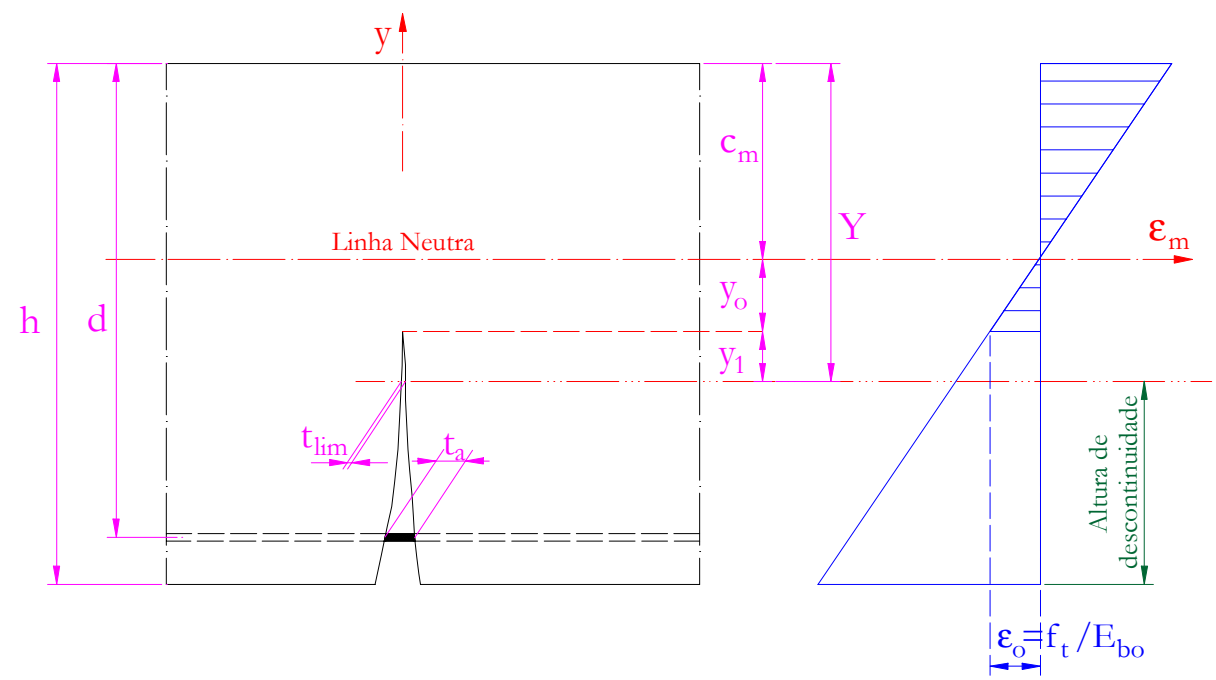

Figura 4.17 - Diagrama de deformação na seção fissurada.

O comprimento de perturbação $\mathrm{p}$ foi definido admitindo-se uma variação linear da abertura da fissura com relação à ordenada y na altura da seção. Assim, $\mathrm{y}_{1}$ é a altura sobre a qual o cisalhamento é transmitido pela fissura, conforme mostra a Figura 4.17.

$$
\mathrm{y}_{1}=\left(\mathrm{d}-\mathrm{c}_{\mathrm{m}}-\mathrm{y}_{\mathrm{o}}\right) \frac{\mathrm{t}_{\mathrm{lim}}}{\mathrm{t}_{\mathrm{a}}}
$$

Sendo $\varphi$ o ângulo de propagação ilustrado na Figura 4.16, tem-se:

$$
\mathrm{p}=\operatorname{tg}(\varphi)(\mathrm{h}-\mathrm{Y})=\operatorname{tg}(\varphi)\left[\mathrm{h}-\mathrm{c}_{\mathrm{m}}-\mathrm{y}_{\mathrm{o}}-\left(\mathrm{d}-\mathrm{c}_{\mathrm{m}}-\mathrm{y}_{\mathrm{o}}\right) \frac{\mathrm{t}_{\mathrm{lim}}}{\mathrm{t}_{\mathrm{a}}}\right]
$$

No entanto, a priori, o valor do ângulo $\varphi$ é desconhecido.

As expressões propostas por Fouré \& Hannachi (1999) para o cálculo da rigidez média $\overline{\mathrm{GJ}} \mathrm{t}$ à torção, em função do valor do comprimento de perturbação p, são:

$$
\begin{aligned}
& \theta(s)=\frac{M_{t}(s-2 p)}{G_{o} J_{t_{0}}}+2 \int_{0}^{p} \frac{M_{t}}{G J_{t}(x)} d x=\frac{M_{t}}{\overline{G J_{t}}} \\
& \mathrm{p}<\frac{\mathrm{s}_{\mathrm{m}}}{2} \\
& \therefore \overline{\mathrm{GJ}_{\mathrm{t}}}=\frac{\mathrm{G}_{\mathrm{o}} \mathrm{J}_{\mathrm{t}_{\mathrm{o}}}}{1+\frac{2 \mathrm{p}}{\mathrm{s}}\left(\frac{\operatorname{arctgh}(\sqrt{\mathrm{F}})}{\sqrt{\mathrm{F}}}-1\right)} \\
& \theta(\mathrm{s})=2 \int_{\mathrm{p}-\frac{\mathrm{s}_{\mathrm{m}}}{2}}^{\mathrm{p}} \frac{\mathrm{M}_{\mathrm{t}}}{\mathrm{GJ} \mathrm{t}(\mathrm{x})} \mathrm{dx}=\frac{\mathrm{M}_{\mathrm{t}}}{\overline{\mathrm{GJ}_{\mathrm{t}}}} \\
& \mathrm{p}>\frac{\mathrm{s}_{\mathrm{m}}}{2} \\
& \therefore \overline{\mathrm{GJ}_{\mathrm{t}}}=\frac{\mathrm{G}_{\mathrm{o}} \mathrm{J}_{\mathrm{to}}}{\frac{2 \mathrm{p}}{\mathrm{s}} \frac{1}{\sqrt{\mathrm{F}}}\left(\operatorname{arctgh}(\sqrt{\mathrm{F}})-\operatorname{arctgh}\left(\left(1-\frac{\mathrm{s}}{2 \mathrm{p}}\right) \sqrt{\mathrm{F}}\right)\right)}
\end{aligned}
$$

onde $\theta$ é a rotação por torção da seção e $\mathrm{M}_{\mathrm{t}}$ é o momento de torção aplicado. 
Observa-se que o valor de p é inicialmente desconhecido, uma vez que depende do ângulo de propagação $\varphi$. Portanto, como o cálculo da rigidez média à torção $\overline{\mathrm{GJ}_{\mathrm{t}}}$ depende de p e do valor da rigidez mínima na fissura $\left(\mathrm{GJ}_{\mathrm{t}}\right)_{\mathrm{f}}, \overline{\mathrm{GJ}_{\mathrm{t}}}$ é ainda incógnito.

O equilíbrio da seção fissurada por flexão e submetida a um binário de torção $\mathrm{M}_{\mathrm{t}}$ pode ser analisado na Figura 4.18, representando o caso de uma seção simétrica em relação à ordenada y. A proposta de Fouré \& Hannachi (1999) considera que a zona de concreto não fissurado colabora através do binário $\mathrm{M}_{\mathrm{tb}}^{\prime}$ e do esforço cortante $\mathrm{T}_{\mathrm{b}}$ igual e oposto ao resistido pelas armaduras $\mathrm{T}_{\mathrm{a}}$. $\mathrm{O}$ esforço $\mathrm{T}_{\mathrm{b}}$ encontra-se aplicado no centro de torção $\mathrm{D}_{\mathrm{b}}$ da seção de concreto não fissurado. Segundo os autores citados, o binário $\mathrm{M}_{\mathrm{tb}}^{\prime}$ corresponde à contribuição através de linhas de cisalhamento fechadas ou fluxo de cisalhamento.

A contribuição das armaduras é considerada de forma conjunta, representando o efeito de pino. Assim, tem-se:

$$
\begin{gathered}
\mathrm{T}_{\mathrm{a}}=\sum_{\mathrm{i}} \mathrm{T}_{\mathrm{i}} \cos \left(\alpha_{\mathrm{i}}\right) \\
\mathrm{M}_{\mathrm{t}_{\mathrm{a}}}=\sum_{\mathrm{i}} \mathrm{T}_{\mathrm{i}} \cdot \mathrm{r}_{\mathrm{i}}=-\mathrm{T}_{\mathrm{a}} \cdot \mathrm{r}_{\mathrm{a}}
\end{gathered}
$$

$$
\text { onde } r_{i}(t)=\sqrt{x_{i}^{2}+\left(t-y_{i}\right)^{2}} \text { e } \operatorname{tg}\left(\alpha_{i}(t)\right)=\frac{t-y_{i}}{x_{i}}
$$

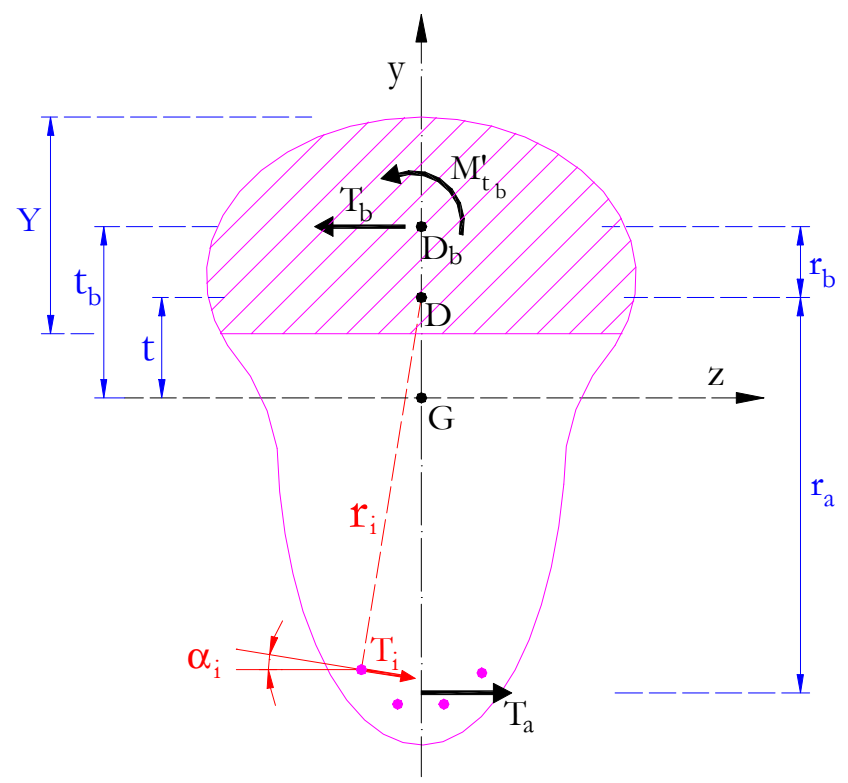

Figura 4.18 - Equilíbrio de forças na seção.

Vale observar que as distâncias $r_{i}$ e as inclinações $\alpha_{i}$ são definidas em relação ao centro de torção D da seção fissurada, a priori desconhecido.

O binário $\mathrm{M}_{\mathrm{t}}$ total de torção aplicado na seção é:

$$
\mathrm{M}_{\mathrm{t}}=\mathrm{M}_{\mathrm{tb}}^{\prime}-\mathrm{T}_{\mathrm{a}} \cdot \mathrm{r}_{\mathrm{a}}-\mathrm{T}_{\mathrm{b}} \cdot \mathrm{r}_{\mathrm{b}}
$$

e a rotação unitária na seção da fissura pode ser escrita por: 


$$
\left(\frac{\mathrm{d} \theta}{\mathrm{dx}}\right)_{\mathrm{f}}=\frac{\mathrm{M}_{\mathrm{t}}}{(\mathrm{GJ})_{\mathrm{t}}}
$$

de onde deduz-se que a parcela do binário equilibrado pelo concreto não fissurado é:

$$
\mathrm{M}_{\mathrm{tb}}^{\prime}=\left(\mathrm{GJ}_{\mathrm{t}}\right)_{\mathrm{b}}\left(\frac{\mathrm{d} \theta}{\mathrm{dx}}\right)_{\mathrm{f}}=\frac{\left(\mathrm{GJ}_{\mathrm{t}}\right)_{\mathrm{b}}}{\left.(\mathrm{GJ})_{\mathrm{t}}\right)_{\mathrm{f}}} \cdot \mathrm{M}_{\mathrm{t}}
$$

onde $\left(G_{t}\right)_{b}$ é a rigidez à torção pura da parte não fissurada de concreto na seção da fissura, que depende da forma da seção e da altura comprimida Y. Pode-se calcular $\left(G J_{t}\right)_{b}=G_{o} \cdot J_{t b}$, onde $G_{o}$ é o módulo de deformação transversal da elasticidade linear e $\mathrm{J}_{\mathrm{t}}$ é a inércia à torção da parte comprimida de concreto.

Com relação à contribuição das armaduras dada pelo efeito de pino na rotação por torção, Fouré \& Hannachi (1999) admitem que cada barra equilibra um esforço transversal $\mathrm{T}_{\mathrm{i}}$, perpendicular ao raio que une o centro de torção $\mathrm{D}$ da seção fissurada à própria armadura. A mesma analogia considerada por Hannachi \& Fouré (1996) com relação ao comportamento de estacas cravadas no solo sob ação de uma força horizontal, da Mecânica dos Solos, é também utilizada por Fouré \& Hannachi (1999):

$$
\mathrm{T}_{\mathrm{i}}=\frac{\mathrm{E}_{\mathrm{bo}} \cdot \phi_{\mathrm{i}}}{8}\left(\pi \cdot \frac{\mathrm{E}_{\mathrm{s}}}{\mathrm{E}_{\mathrm{bo}}}\right)^{\frac{1}{4}} \cdot \mathrm{g}_{\mathrm{i}}
$$

onde $\mathrm{E}_{\mathrm{s}}$ é o módulo de elasticidade do aço, $\mathrm{E}_{\mathrm{bo}}$ é o módulo de deformação longitudinal do concreto na origem, $\phi_{\mathrm{i}}$ é o diâmetro da barra e $\mathrm{g}_{\mathrm{i}}$ é o deslocamento transversal relativo da barra de uma parte à outra da fissura, conforme ilustra a Figura 4.19.

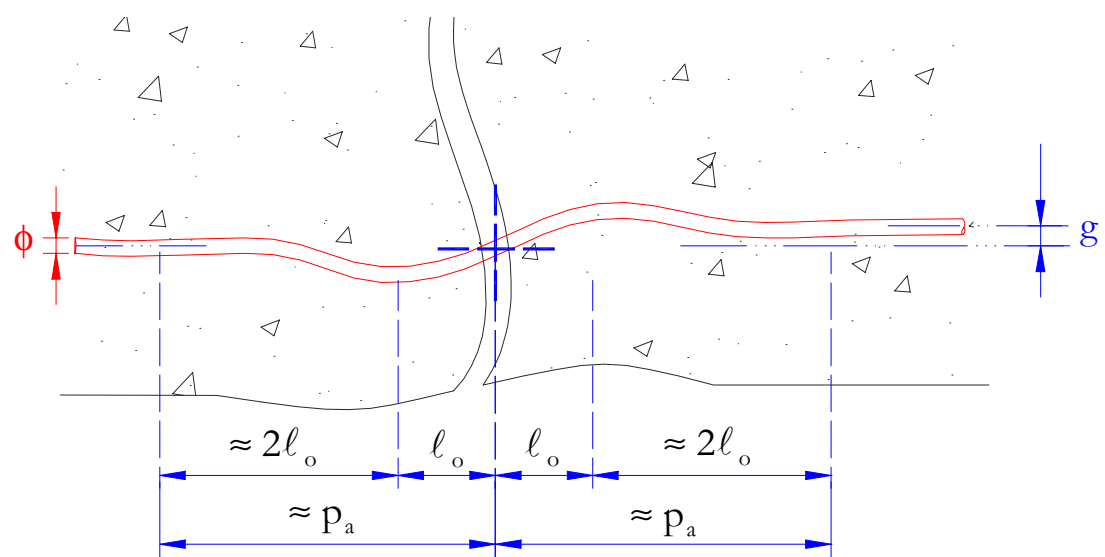

Figura 4.19 - Efeito de pino e comprimento de perturbação pa na armadura longitudinal.

Segundo Fouré \& Hannachi (1999), o comprimento de perturbação $\mathrm{p}_{\mathrm{a}}$ associado ao efeito de pino pode ser estimado à partir do cálculo elástico. Desta forma, tem-se:

$$
\mathrm{p}_{\mathrm{a}} \approx 3 \ell_{\mathrm{o}} \operatorname{com} \ell_{\mathrm{o}}=2 \phi\left(\pi \cdot \frac{\mathrm{E}_{\mathrm{s}}}{\mathrm{E}_{\mathrm{bo}}}\right)^{\frac{1}{4}}
$$

O esforço transversal equilibrado pelas armaduras está associado às deformações, e 
portanto, à rotação $\theta_{\mathrm{a}} \mathrm{e}$ à distância $\mathrm{p}_{\mathrm{a}}$ de uma parte à outra da fissura. Esta rotação é tal que $g_{i}=\theta_{a} \cdot r_{i}$. Vale observar que os valores obtidos para o deslizamento g encontramse no domínio linear.

Pode-se observar que $\mathrm{p} \mathrm{e} \mathrm{p}_{\mathrm{a}}$ constituem os comprimentos de perturbação no concreto e na armadura, respectivamente, devido à fissura e ao efeito de pino. Da mesma forma que desenvolvido anteriormente para o cálculo da rotação $\theta(\mathrm{s})$ e da rigidez média à torção $\overline{\mathrm{GJ}_{\mathrm{t}}}$, pode existir eventual superposição das zonas perturbadas, quando $\mathrm{p}_{\mathrm{a}}>\mathrm{s}_{\mathrm{m}} / 2$. Porém, quando esta superposição ocorrer para $\mathrm{p}_{\mathrm{a}} \gg \mathrm{s}_{\mathrm{m}} / 2$ e $\mathrm{s}_{\mathrm{m}} / 2<\ell_{\mathrm{o}}$, o mecanismo de transmissão de esforços pelas armaduras não se desenvolve mais segundo a teoria proposta. Por outro lado, quanto menor for a rotação $\theta_{a}$ em relação às deformações ao longo do comprimento $\mathrm{s}_{\mathrm{m}} / 2$, menor será o esforço $\mathrm{T}_{\mathrm{i}}$ transmitido pela armadura.

Fouré \& Hannachi (1999) observam, a partir dos resultados dos ensaios, que os comprimentos de perturbação $\mathrm{p}$ e $\mathrm{p}_{\mathrm{a}}$ foram sempre inferiores à $\mathrm{s}_{\mathrm{m}} / 2$.

A partir da relação momento-rotação, escreve-se também, conforme desenvolvido para p e $\overline{\mathrm{GJ}_{\mathrm{t}}}$, as expressões da rotação $\theta_{\mathrm{a}}$ :

$$
\begin{aligned}
& \mathrm{p}<\frac{\mathrm{s}_{\mathrm{m}}}{2}<\mathrm{p}_{\mathrm{a}} \Rightarrow \theta_{\mathrm{a}}=\frac{\mathrm{M}_{\mathrm{t}}\left(\mathrm{s}_{\mathrm{m}}-2 \mathrm{p}\right)}{\mathrm{G}_{\mathrm{o}} \mathrm{J}_{\mathrm{t}}}+2 \int_{0}^{\mathrm{p}} \frac{\mathrm{M}_{\mathrm{t}}}{\mathrm{GJ}_{\mathrm{t}}(\mathrm{x})} \mathrm{dx}=\frac{2 \mathrm{M}_{\mathrm{t}}}{\mathrm{G}_{\mathrm{o}} \mathrm{J}_{\mathrm{o}}}\left[\frac{\mathrm{s}_{\mathrm{m}}}{2}-\mathrm{p}\left(1-\frac{\operatorname{arctgh} \sqrt{\mathrm{F}}}{\sqrt{\mathrm{F}}}\right)\right] \\
& \mathrm{p}<\mathrm{p}_{\mathrm{a}}<\frac{\mathrm{s}_{\mathrm{m}}}{2} \Rightarrow \theta_{\mathrm{a}}=\frac{\mathrm{M}_{\mathrm{t}} \cdot 2\left(\mathrm{p}_{\mathrm{a}}-\mathrm{p}\right)}{\mathrm{G}_{\mathrm{o}} \mathrm{J}_{\mathrm{to}}}+2 \int_{0}^{\mathrm{p}} \frac{\mathrm{M}_{\mathrm{t}}}{\mathrm{GJ} \mathrm{J}_{\mathrm{t}}(\mathrm{x})} \mathrm{dx}=\frac{2 \mathrm{M}_{\mathrm{t}}}{\mathrm{G}_{\mathrm{o}} \mathrm{J}_{\mathrm{o}}}\left[\mathrm{p}_{\mathrm{a}}-\mathrm{p}\left(1-\frac{\operatorname{arctgh} \sqrt{\mathrm{F}}}{\sqrt{\mathrm{F}}}\right)\right] \\
& \mathrm{p}_{\mathrm{a}}<\mathrm{p}<\mathrm{s}_{\mathrm{m}} / 2 \Rightarrow \mathrm{\theta}_{\mathrm{a}}=2 \int_{\mathrm{p}-\mathrm{p}_{\mathrm{a}}}^{\mathrm{p}} \frac{\mathrm{M}_{\mathrm{t}}}{\mathrm{GJ}_{\mathrm{t}}(\mathrm{x})} \mathrm{dx}=\frac{2 \mathrm{M}_{\mathrm{t}}}{\mathrm{p}_{\mathrm{a}}<\mathrm{s}_{\mathrm{m}} / 2<\mathrm{p} \mathrm{J}_{\mathrm{o}}} \frac{\mathrm{p}}{\sqrt{\mathrm{F}}}\left[\operatorname{arctgh} \sqrt{\mathrm{F}}-\operatorname{arctgh}\left(1-\frac{\mathrm{p}_{\mathrm{a}} \sqrt{\mathrm{F}}}{\mathrm{p}}\right)\right] \\
& \mathrm{s}_{\mathrm{m}} / 2<\mathrm{p}_{\mathrm{a}}<\mathrm{p} \Rightarrow \theta_{\mathrm{a}}=2 \int_{\mathrm{s}_{\mathrm{s}}}^{\mathrm{p}} \frac{\mathrm{M}_{\mathrm{t}}}{\mathrm{G} J_{\mathrm{t}}(\mathrm{x})} \mathrm{dx}=\frac{2 \mathrm{M}_{\mathrm{t}}}{\mathrm{G}_{\mathrm{o}} / 2<\mathrm{J}_{\mathrm{to}}} \frac{\mathrm{p}}{\sqrt{\mathrm{F}}}\left[\operatorname{arctgh} \sqrt{\mathrm{F}}-\operatorname{arctgh}\left(1-\frac{\mathrm{s}_{\mathrm{m}} \sqrt{\mathrm{F}}}{2 \mathrm{p}}\right)\right]
\end{aligned}
$$

Com relação à posição do centro de torção, conforme ilustrado na Figura 4.17, Fouré \& Hannachi (1999) definem como $\mathrm{D}$ o centro de torção da seção fissurada e $\mathrm{D}_{\mathrm{b}}$ o centro de torção da região comprimida. Quando a região comprimida for um retângulo, o centro de torção $\mathrm{D}_{\mathrm{b}}$ encontra-se situado no centro de gravidade desta. $\mathrm{O}$ mesmo vale para o caso de uma seção $\mathrm{T}$ ou duplo $\mathrm{T}$, cuja inércia à torção e posição do centro $\mathrm{D}_{\mathrm{b}}$ serão calculados considerando a região comprimida formada por um conjunto de retângulos. Conhecendo-se a posição do centro $D_{b}$, o valor do comprimento $t_{b}$ definido na Figura 4.17 é então conhecido. 
O cálculo da posição do centro de torção $\mathrm{D}$ de toda a seção fissurada depende de alguns parâmetros desconhecidos, e portanto, apenas será obtido desenvolvendo-se um procedimento iterativo. Assim, resolve-se o problema obtendo-se as 4 incógnitas: p, $\left(G J_{t}\right)_{f}, \theta_{a}$ e t, sendo t a distância do CG ao centro D de torção da seção fissurada.

Para isto, pode-se escrever que a distância $r_{b}$ entre os centros de torção $\mathrm{D}$ e $\mathrm{D}_{\mathrm{b}}$, ilustrada na Figura 4.17, é dada por:

$$
\begin{gathered}
\mathrm{r}_{\mathrm{b}}=-\frac{\mathrm{M}_{\mathrm{t}}-\mathrm{M}_{\mathrm{ta}}-\mathrm{M}_{\mathrm{tb}}^{\prime}}{\mathrm{T}_{\mathrm{b}}}=\frac{\mathrm{M}_{\mathrm{t}}\left[1-\frac{(\mathrm{GJ})_{\mathrm{b}}}{(\mathrm{GJ})_{\mathrm{t}}}\right]-\mathrm{k} \theta_{\mathrm{a}} \sum_{\mathrm{i}} \phi_{\mathrm{i}} \cdot \mathrm{r}_{\mathrm{i}}^{2}(\mathrm{t})}{\mathrm{k} \theta_{\mathrm{a}} \sum_{\mathrm{i}} \phi_{\mathrm{i}} \cdot \mathrm{r}_{\mathrm{i}}(\mathrm{t}) \cdot \cos \left(\alpha_{\mathrm{i}}(\mathrm{t})\right)} \\
\text { onde } \left.\mathrm{k}=\frac{\mathrm{E}_{\mathrm{bo}}\left(\pi \frac{\mathrm{E}_{\mathrm{s}}}{8}\right)^{\frac{1}{4}}}{\mathrm{E}_{\mathrm{bo}}}\right)^{\mathrm{T}_{\mathrm{i}}=\mathrm{k} \phi_{\mathrm{i}} \mathrm{r}_{\mathrm{i}} \theta_{\mathrm{a}}} \\
\mathrm{T}_{\mathrm{a}}=-\mathrm{T}_{\mathrm{b}}=\mathrm{k} \theta_{\mathrm{a}} \sum_{\mathrm{i}} \phi_{\mathrm{i}} \mathrm{r}_{\mathrm{i}}(\mathrm{t}) \cos \alpha_{\mathrm{i}}(\mathrm{t}) \\
\mathrm{M}_{\mathrm{ta}}=-\mathrm{T}_{\mathrm{a}} \mathrm{r}_{\mathrm{a}}=\mathrm{k} \theta_{\mathrm{a}} \sum_{\mathrm{i}} \phi_{\mathrm{i}} \mathrm{r}_{\mathrm{i}}(\mathrm{t})^{2}
\end{gathered}
$$

Sendo $t=t_{b}-r_{b}$ conforme mostra a Figura 4.17, isolando-se $\left(G_{t}\right)_{f}$ na expressão (4.81) resulta uma expressão implícita para a rigidez da seção de concreto armado na seção da fissura, uma vez que $\theta_{\mathrm{a}}$ é função de $\left(\mathrm{GJ}_{\mathrm{t}}\right)_{\mathrm{f}}$. Assim:

$$
\left(G J_{t}\right)_{f}=\frac{\left(G J_{t}\right)_{b}}{1-\frac{k \theta_{a}}{M_{t}}\left[\sum_{i} \phi_{i} \cdot r_{i}^{2}(t)+\left(t_{b}-t\right) \sum_{i} \phi_{i} \cdot r_{i}(t) \cdot \cos \left(\alpha_{i}(t)\right)\right]}
$$

Isolando-se t na equação (4.81), resulta também uma expressão implícita:

$$
t=t_{b}-\frac{1-\frac{\left(G J_{t}\right)_{b}}{\left(G J_{t}\right)_{f}}-\frac{k \theta_{a}}{M_{t}} \sum_{i} \phi_{i} \cdot r_{i}^{2}(t)}{\frac{k \theta_{a}}{M_{t}} \sum_{i} \phi_{i} \cdot r_{i}(t) \cdot \cos \left(\alpha_{i}(t)\right)}
$$

Nestas condições, Fouré \& Hannachi (1999) recomendam utilizar-se de um procedimento iterativo admitindo-se, na primeira iteração, a seção de concreto sem armaduras. Assim, supondo $\overline{\mathrm{GJ}_{\mathrm{t}}}$ conhecido e igual ao valor experimental, tem-se:

\begin{tabular}{|l|ll|}
\hline \multirow{4}{*}{ Primeira iteração } & Adotar: & $\left(\mathrm{GJ}_{\mathrm{t}}^{\prime}\right)_{\mathrm{f}}=\left(\mathrm{GJ}_{\mathrm{t}}\right)_{\mathrm{b}}$ \\
& & $\mathrm{t}^{\prime}=\mathrm{t}_{\mathrm{b}}$ \\
\cline { 2 - 3 } & Calcular: & Com $\left(\mathrm{GJ}_{\mathrm{t}}^{\prime}\right)_{\mathrm{f}}$ calcula-se F : eq. (4.63) \\
& & Com F e $(\overline{\mathrm{GJ}})$ calcula-se $\mathrm{p}^{\prime}$ : eq. (4.67) ou (4.69) \\
& & Calcula-se $\theta_{\mathrm{a}}^{\prime}:$ eq (4.77), (4.78), (4.79) ou (4.80) \\
& & Recalcula-se $\left(\mathrm{GJ} \mathrm{J}_{\mathrm{t}}^{\prime \prime}\right)_{\mathrm{f}}$ com a eq. (4.83) \\
& & Recalcula-se $\mathrm{t}^{\prime \prime}$ com a eq. (4.84) \\
\hline
\end{tabular}

Reinicia-se o processo na segunda iteração, adotando-se $\left(G_{t}^{\prime \prime}\right)_{f}$ e $t^{\prime \prime}$ como valores de 
partida. Repete-se o processo até que os valores adotados e calculados para $\left(G_{\mathrm{t}}\right)_{\mathrm{f}}$ e $\mathrm{t}$ verifiquem a tolerância estabelecida como critério de convergência.

Uma vez atingida a convergência, o valor do comprimento de perturbação p permite calcular o parâmetro $\varphi$ ou ângulo de propagação, ilustrado na Figura 4.16 e incógnita da equação (4.65), na qual deve-se admitir $t_{a}$ igual à abertura medida $t_{m}$.

Pode-se observar que o caso básico é aquele que parte da rigidez $\overline{\mathrm{GJ}_{\mathrm{t}}}$ experimental e do valor $\mathrm{t}_{\mathrm{lim}}=0,02 \mathrm{~mm}$ da abertura limite das fissuras e cujo término do processo iterativo leva ao valor do ângulo de propagação $\varphi$.

Fouré \& Hannachi (1999) verificaram que os resultados obtidos são muito dispersos, o que provavelmente resulta da incerteza da estimativa do valor experimental de $\overline{\mathrm{GJ}_{\mathrm{t}}}$. Além disto, sabe-se que o ângulo de propagação $\varphi$ depende, sem dúvida alguma, da quantidade de armaduras. Porém, observam que introduzir um valor de $\varphi$ variável torna o problema muito mais difícil de ser resolvido segundo o método proposto, inclusive no que se refere à validação experimental.

Fouré \& Hannachi (1999) observam que o valor calculado de $\varphi$ varia muito fortemente, em torno de $\pm 20 \%$, com uma variação de $\pm 5 \%$ no valor de $\overline{\mathrm{GJ}_{\mathrm{t}}}$ introduzido no cálculo. Portanto, a grande incerteza sobre a estimativa de $\varphi$ tem um influência moderada sobre o valor de $\overline{\mathrm{GJ}_{\mathrm{t}}}$. Admitindo uma abertura limite de $\mathrm{t}_{\text {lim }}=0,02 \mathrm{~mm}$, os valores calculados de $\varphi$ para os diversos tipos de seção ensaiados por Fouré \& Hannachi (1999) variaram entre $1^{\circ}$ e $17^{\circ}$.

Porém, a escolha de um único valor de $\varphi$ para o cálculo de $\overline{\mathrm{GJ}_{\mathrm{t}}}$ pode penalizar um pouco as vigas fortemente armadas, cuja rigidez será subestimada. No entanto, baseado em resultados a partir da média do espaçamento obtido considerando o conjunto de fissuras e as fissuras principais, Fouré \& Hannachi (1999) recomendam considerar $\varphi=6,3^{\circ}$. Outra alternativa, segundo os autores em questão consiste em desprezar a zona tracionada de altura $y_{o}+y_{1}$ no cálculo de $\left(G J_{t}\right)_{b}$ na seção da fissura. Desejandose introduzir uma segurança no sentido de reduzir $\overline{\mathrm{GJ}_{\mathrm{t}}}$, pode-se ainda utilizar um valor de $\varphi$ maior do que o proposto acima.

Enfim, o método proposto por Fouré \& Hannachi (1999) para o cálculo da rigidez à torção $\overline{\mathrm{GJ}}$ de uma viga fissurada sob flexão possui bases racionais que permitem interferir em alguns parâmetros essenciais como o espaçamento e a abertura média das fissuras, a área não fissurada em uma seção da fissura e a inércia à torção do concreto correspondente, bem como a contribuição do efeito de pino das armaduras nas fissuras.

Apesar da grande dispersão, os resultados dos ensaios permitem calcular o valor do ângulo de propagação $\varphi$ que traduz o comprimento perturbado de uma parte à outra da fissura. A partir deste valor é possível calcular a rigidez média à torção da seção fissurada, ou seja, $\overline{\mathrm{GJ}_{\mathrm{t}}}$. Em linhas gerais, pode-se dizer que o método proposto por Fouré \& Hannachi (1999) constitui-se de uma ferramente científica de simulação que 
pode ser introduzida em um programa computacional suficientemente sofisticado de cálculo do comportamento não-linear de estruturas, associado com o cálculo automatizado do espaçamento e da abertura de fissuras. Sua utilização em estudos paramétricos permite também validar os cálculos simplificados de $\overline{\mathrm{GJ}_{\mathrm{t}}}$.

Com relação ao cálculo da posição do centro de torção D, Fouré \& Hannachi (1999) observam que, em alguns ensaios, a rotação de torção das seções dos apoios da viga pode ser imposta em torno do eixo do centro de gravidade. Isto significa que a ação de um binário externo $\mathrm{M}_{\mathrm{to}}$ é teoricamente equivalente à superposição de um binário de torção pura $\mathrm{M}_{\mathrm{t}}$ e de um esforço cortante aplicado no centro de torção D. Porém, admitiu-se nos ensaios, com erro desprezível, $\mathrm{M}_{\mathrm{t}}=\mathrm{M}_{\mathrm{to}}$. E admitindo-se o giro em torno do centro de gravidade, a força $T_{a}$ devido ao efeito de pino das armaduras não depende mais da posição de $\mathrm{D}$, e portanto:

$$
\begin{gathered}
\mathrm{T}_{\mathrm{a}}=\mathrm{k} \theta_{\mathrm{a}} \sum_{\mathrm{i}} \phi_{\mathrm{i}} \cdot \mathrm{r}_{\mathrm{i}} \cdot \cos \left(\alpha_{\mathrm{i}}\right) \\
\operatorname{com} \mathrm{r}_{\mathrm{i}}=\sqrt{\mathrm{x}_{\mathrm{i}}{ }^{2}+\mathrm{y}_{\mathrm{i}}^{2}} \text { e } \operatorname{tg}\left(\alpha_{\mathrm{i}}\right)=\frac{\mathrm{y}_{\mathrm{i}}}{\mathrm{x}_{\mathrm{i}}}
\end{gathered}
$$

sendo estas expressões independentes da distância t do centro de gravidade da seção ao centro de torção D.

\subsubsection{CálCulo das Características À TORÇão APENAS do CONCRETO Na SeÇão da Fissura e da Posição do Centro de Torção}

\subsubsection{CASO EM QUE A SEÇÃO COMPRIMIDA É UM RETÂNGULO}

O módulo de deformação transversal é suposto igual à $G_{0}$ da elasticidade linear. Deduzse então que $\left(\mathrm{GJ}_{\mathrm{t}}\right)_{\mathrm{b}}=\mathrm{G}_{\mathrm{o}} \cdot \mathrm{J}_{\mathrm{tb}}$. A inércia à torção é dada por:

$$
\begin{aligned}
& J_{t b}=k\left(\frac{Y}{b}\right) \frac{b \cdot Y^{3}}{3} \text { se } Y \leq b \\
& J_{t b}=k\left(\frac{b}{Y}\right) \frac{Y \cdot b^{3}}{3} \text { se } Y>b
\end{aligned}
$$

onde b é a largura da seção transversal e Y é a altura da comprimida.

As expressões do fator $\mathrm{k}$ são as seguintes fórmulas empíricas obtidas com aproximação muito boa dos valores teóricos da Resistência dos Materiais, segundo Fouré \& Hannachi (1999):

$$
\begin{gathered}
\mathrm{k}=1-0,63 \frac{\mathrm{Y}}{\mathrm{b}} \text { se } 0 \leq \mathrm{Y} \leq \mathrm{b} / 2 \\
\mathrm{k}=1,086-\frac{1}{0,505+\frac{\mathrm{b}}{\mathrm{Y}}} \text { se } \mathrm{b} / 2 \leq \mathrm{Y} \leq \mathrm{b}
\end{gathered}
$$

O centro de torção situa-se no centro de gravidade do retângulo, portanto, tem-se: 


$$
\mathrm{t}_{\mathrm{b}}=\overline{\mathrm{GD}_{\mathrm{b}}}=\frac{1}{2}(\mathrm{~h}-\mathrm{Y})
$$

onde $\overline{\mathrm{GD}_{\mathrm{b}}}$ é o segmento de reta entre o CG da seção e o centro de torção $\mathrm{D}_{\mathrm{b}}$.

\subsubsection{CASO DA SEÇÃO DUPLO T}

A região comprimida pode ser uma seção em $\mathrm{T}$ simples que é o conjunto de dois retângulos, ou eventualmente, apenas um, de tal forma que a inércia total seja $\mathrm{J}_{\mathrm{tb}}=\mathrm{J}_{\mathrm{t} 1}+\mathrm{J}_{\mathrm{t} 2}$. Assim, $\mathrm{J}_{\mathrm{t} 1}$ e $\mathrm{J}_{\mathrm{t} 2}$ correspondem a cada um dos retângulos que formam a zona comprimida. Uma vez que a linha neutra corte a mesa, haverá apenas a contribuição de um retângulo.

O centro de torção, que encontra-se na interseção das linhas médias da alma e da mesa, pode ser obtido por:

$$
\mathrm{t}_{\mathrm{b}}=\overline{\mathrm{GD}_{\mathrm{b}}}=\frac{1}{2}(\mathrm{~h}-\mathrm{e})
$$

onde e é a espessura da mesa, caso a LN corte a alma. 


\section{Capítulo}

$$
\text { (05) Programa Computacional Tritor para }
$$

\author{
Programa COMPUTACIONAL TRITOR PARA \\ ANÁLISE NÃO-LINEAR DE ESTRUTURAS
}

\subsection{CONSIDERAÇÕES INICIAIS}

O programa computacional Tritor desenvolvido neste trabalho destina-se ao cálculo de esforços solicitantes em estruturas através da discretização em elementos de barras, considerando a não-linearidade física dos materiais envolvidos.

Como recursos disponíveis no programa Tritor, pode-se citar a possibilidade de desenvolver uma análise considerando deslocamentos impostos e a deformabilidade das ligações por meio de constantes de mola, o que pode ser útil na simulação do comportamento de vigas em suspensão, conforme ensaios de instabilidade lateral realizados por Mast (1993, 1994).

O programa Tritor tem como base o equacionamento matricial clássico de pórticos espaciais, para análise elástico-linear, via processo dos deslocamentos. Na aplicação à estruturas de concreto armado, a rigidez da seção transversal leva em conta os materiais envolvidos, considerando seus módulos de elasticidade. O cálculo dos esforços, em cada elemento finito de barra discretizado, pode ser realizado através de análise linear ou nãolinear. Em ambos os casos, a seção transversal de concreto com armaduras longitudinais deve ser discretizada. Considerando a lei constitutiva de cada material, calculam-se os esforços na seção através da contribuição de cada elemento retangular discretizado da seção transversal.

O cálculo dos esforços na seção transversal é feito a partir do estado de deformação obtido em função dos deslocamentos nodais do elemento finito de barra.

Uma vez calculados os esforços resistentes da seção, os mesmos são comparados com o vetor de forças aplicado, a fim de verificarem-se as condições de equilíbrio. Caso o vetor resultante desta diferença não seja igual a zero ou não verifique uma certa tolerância especificada pelo usuário, inicia-se um processo iterativo de reaplicação do delta de força desequilibrado. Este procedimento se repete até que seja atingida a convergência para uma dada tolerância.

O modelo teórico estrutural proposto por Cocchi \& Volpi (1996) foi implementado no programa Tritor e constitui uma alternativa para calcular os esforços resistentes de uma seção de concreto armado sob ação conjunta de torção, flexão bi-lateral e força axial. Este modelo, descrito no capítulo 4 deste trabalho, representa uma análise inelástica em elementos de concreto armado, considerando o comportamento de treliça espacial após a fissuração da seção sob torção dominante.

Caso a flexão seja solicitação predominante sobre a torção, o modelo numérico de 
Hannachi \& Fouré (1996) permite calcular a perda de rigidez à torção após a fissuração por flexão.

Assim, este capítulo destina-se à descrição de alguns procedimentos e subrotinas desenvolvidas no programa Tritor, para o qual serão discutidos os resultados numéricos obtidos, a seguir, nos capítulos 6 e 7 .

\subsection{ReCURSOS DisPONÍVEIS NO PROGRAMA TRITOR}

Quatro tipos de análises podem ser realizadas no programa Tritor, as quais encontramse descritas na Tabela 5.1.

A análise tipo 1 considera o comportamento elástico-linear dos materiais. As análises tipo 2 e 3 consideram a não-linearidade física dos materiais envolvidos e a variação da rigidez à torção linear e não-linear, ou seja, Lampert (1973) e Hannachi \& Fouré (1996), respectivamente. A análise tipo 4 corresponde à modelagem numérica com cálculo dos esforços solicitantes a partir da seção vazada resultante da fissuração em espiral, e portanto, da analogia de treliça espacial utilizada na proposta de Cocchi \& Volpi (1996).

Tabela 5.1 - Análises disponíveis no programa Tritor.

\begin{tabular}{|c|c|c|c|c|}
\hline $\begin{array}{c}\text { Tipos } \\
\text { de } \\
\text { análise }\end{array}$ & $\begin{array}{c}\text { Comportamento do } \\
\text { concreto }\end{array}$ & $\begin{array}{c}\text { Comportamento } \\
\text { das armaduras } \\
\text { passivas }\end{array}$ & $\begin{array}{c}\text { Comportamento } \\
\text { das armaduras } \\
\text { ativas }\end{array}$ & $\begin{array}{c}\text { Modelo numérico } \\
\text { para consideração } \\
\text { da torção }\end{array}$ \\
\hline 1 & elástico-linear & elástico-linear & elástico-linear & Lampert (1973) \\
\hline 2 & $\begin{array}{c}\text { não-linear com região de } \\
\text { enrijecimento à tração }\end{array}$ & $\begin{array}{c}\text { encruamento positivo } \\
\text { ou elastoplástico } \\
\text { perfeito }\end{array}$ & $\begin{array}{c}\text { elastoplástico } \\
\text { perfeito }\end{array}$ & Hsu (1968) \\
\hline 3 & $\begin{array}{c}\text { não-linear com região de } \\
\text { enrijecimento à tração }\end{array}$ & $\begin{array}{c}\text { encruamento positivo } \\
\text { ou elastoplástico } \\
\text { perfeito }\end{array}$ & $\begin{array}{c}\text { elastoplástico } \\
\text { perfeito }\end{array}$ & Hannachi \& Fouré (1996) \\
\hline 4 & $\begin{array}{c}\text { não-linear com região de } \\
\text { enrijecimento à tração }\end{array}$ & $\begin{array}{c}\text { elastoplástico perfeito } \\
\text { (não incorporada }\end{array}$ & Cocchi \& Volpi (1996) \\
\hline
\end{tabular}

Para utilização das expressões simplificadas de Lampert (1973), onde o momento de torção antes e após a fissuração pode ser representado por diagrama bi-linear, o valor limite que define a entrada na fase fissurada foi definido, neste trabalho, pelo momento de ruptura de uma peça de concreto simples correspondente, sob torção pura. Esta forma de análise tem se mostrado razoável em situações onde a flexão é predominante sobre a torção, e portanto, o mecanismo estrutural da peça fissurada é governado pela flexão.

No modelo de Hannachi \& Fouré (1996), a rigidez à torção pós-fissuração por flexão depende da abertura da fissura, do espaçamento da mesma, da taxa de armadura e do efeito de pino oferecido por esta última.

No modelo de ações combinadas de torção, flexão bi-lateral e força axial apresentado 
por Cocchi \& Volpi (1996), os esforços resistentes para dado estado de deformações da seção considera a seção sólida por meio de uma seção vazada correspondente, sendo o núcleo central desprezado. Neste trabalho, considerou-se também a possibilidade de incluir a contribuição do núcleo no cálculo dos esforços normais e de flexão. Vale lembrar que o modelo original de Cocchi \& Volpi (1996) não se aplica a elementos protendidos.

Será a seguir apresentado o cálculo do estado de deformação do elemento a partir dos deslocamentos nodais e, em seguida, o cálculo dos esforços resistentes na seção transversal. Uma vez que estes dependem das leis constitutivas dos materiais, no caso aço e concreto, serão descritas as leis de comportamento dos materiais consideradas neste trabalho. $\mathrm{Na}$ sequência, serão apresentados alguns procedimentos necessários para o cálculo da rigidez à torção segundo Lampert (1973) e Hannachi \& Fouré (1996) e, finalmente, um fluxograma geral do programa Tritor.

\subsection{Cálculo do Estado de Deformação do Elemento}

O estado de deformações do elemento deve ser definido em função dos deslocamentos nodais do mesmo. Para este fim, é necessário escrever uma expressão algébrica em termos de todos os deslocamentos nodais do elemento, ou seja, uma expressão na forma:

$$
\Delta=\mathrm{N}_{1} \Delta_{1}+\mathrm{N}_{2} \Delta_{2}+\ldots+\mathrm{N}_{\mathrm{n}} \Delta_{\mathrm{n}}=\sum_{\mathrm{i}=1}^{\mathrm{n}} \mathrm{N}_{\mathrm{i}} \Delta_{\mathrm{i}}=[\mathrm{N}]\{\Delta\}
$$

onde $\Delta$ é a componente de deslocamento em questão; $\Delta_{\mathrm{i}}$ relaciona-se ao o $i$-ésimo grau de liberdade do elemento; $\mathrm{N}_{\mathrm{i}}$ é a função de forma correspondente a $\Delta_{\mathrm{i}}$, n é o número total de graus de liberdade dos nós do elemento.

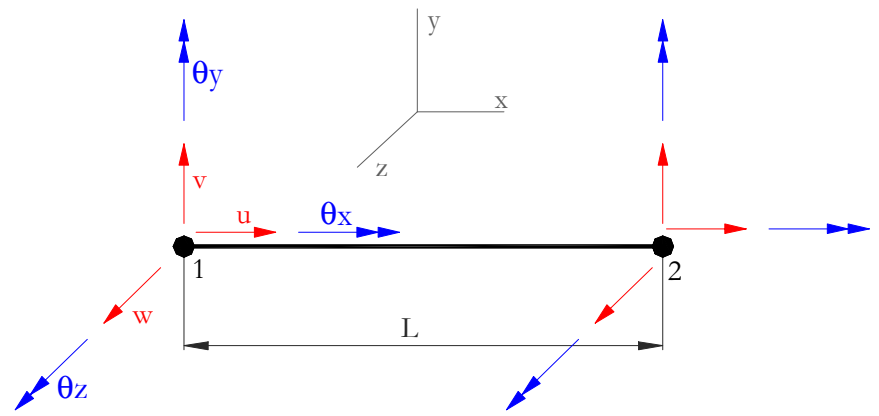

Figura 5.1 - Elemento finito de pórtico espacial e graus de liberdade nodais.

Admitindo que seções planas permanecem planas, o campo de deslocamentos assumido para os graus de liberdade ilustrados na Figura 5.1, pode ser escrito segundo as equações (5.2), (5.3) e (5.4).

$$
\begin{gathered}
\mathrm{u}(\mathrm{x})=\mathrm{a}_{1}(\mathrm{u})+\mathrm{a}_{2}(\mathrm{u}) \mathrm{x} \\
\mathrm{v}(\mathrm{x})=\mathrm{b}_{1}(\mathrm{v})+\mathrm{b}_{2}(\mathrm{v}) \mathrm{x}+\mathrm{b}_{3}(\mathrm{v}) \mathrm{x}^{2}+\mathrm{b}_{4}(\mathrm{v}) \mathrm{x}^{3} \\
\mathrm{w}(\mathrm{x})=\mathrm{c}_{1}(\mathrm{w})+\mathrm{c}_{2}(\mathrm{w}) \mathrm{x}+\mathrm{c}_{3}(\mathrm{w}) \mathrm{x}^{2}+\mathrm{c}_{4}(\mathrm{w}) \mathrm{x}^{3}
\end{gathered}
$$


onde $\mathrm{u}$ representa a função de deslocamentos na direção $\mathrm{x}$; $\mathrm{v}$ refere-se aos deslocamentos na direção y e w aos deslocamentos na direção $z$. As constantes $a_{1}, a_{2}, b_{1}$, $\mathrm{b}_{2}, \mathrm{~b}_{3}, \mathrm{~b}_{4}, \mathrm{c}_{1}, \mathrm{c}_{2}, \mathrm{c}_{3}$ e $\mathrm{c}_{4}$ dependem das condições de contorno do elemento finito.

Para a equação (5.2), sendo os deslocamentos nodais em 1 e 2 iguais a $u(0)=u 1$ e $\mathrm{u}(\mathrm{L})=\mathrm{u} 2$, respectivamente, resulta a deformação longitudinal dada em (5.5):

$$
\eta=\frac{\mathrm{du}(\mathrm{x})}{\mathrm{dx}}=\frac{\mathrm{u}_{2}-\mathrm{u}_{1}}{\mathrm{~L}} \quad \text { sendo } \quad \mathrm{u}(\mathrm{x})=\mathrm{u}_{1}+\frac{\left(\mathrm{u}_{2}-\mathrm{u}_{1}\right)}{\mathrm{L}} \mathrm{x}
$$

Para a equação (5.3), as condições de contorno são: $v(0)=\mathrm{v}_{1}, \mathrm{v}(\mathrm{L})=\mathrm{v}_{2} \mathrm{e} \frac{\mathrm{dv}(\mathrm{x})}{\mathrm{dx}}=\theta_{\mathrm{z}}$. Em $\mathrm{x}=0$ a rotação nodal será definida por $\theta_{z 1}$, e na outra extremidade, ou $\mathrm{x}=\mathrm{L}$, por $\theta_{\mathrm{z} 2}$. Assim sendo, resulta:

$$
\begin{aligned}
\mathrm{v}(\mathrm{x})=\mathrm{v}_{1}+ & \theta_{\mathrm{z} 1} \mathrm{x}+\frac{1}{2 \mathrm{~L}^{2}}\left(-6 \mathrm{v}_{1}+6 \mathrm{v}_{2}-4 \theta_{\mathrm{z} 1} \mathrm{~L}-2 \theta_{\mathrm{z} 2} \mathrm{~L}\right) \mathrm{x}^{2}+ \\
& -\frac{2}{\mathrm{~L}^{3}}\left(-\mathrm{v}_{1}+\mathrm{v}_{2}-\frac{\mathrm{L}}{2} \theta_{\mathrm{z} 1}-\frac{\mathrm{L}}{2} \theta_{\mathrm{z} 2}\right) \mathrm{x}^{3}
\end{aligned}
$$

e desenvolvendo-se o cálculo da curvatura $\chi_{z}$ em relação ao eixo z, tem-se

$$
\chi_{z}=\frac{d^{2} v(x)}{d^{2}}=a(x) \theta_{z 1}+b(x) \theta_{z 2}+c(x)\left(-v_{1}+v_{2}\right)
$$

sendo:

$$
\mathrm{a}(\mathrm{x})=\left(\frac{-4}{\mathrm{~L}}+\frac{6}{\mathrm{~L}^{2}} \mathrm{x}\right) \quad \mathrm{b}(\mathrm{x})=\left(\frac{-2}{\mathrm{~L}}+\frac{6}{\mathrm{~L}^{2}} \mathrm{x}\right) \quad \mathrm{c}(\mathrm{x})=\left(\frac{6}{\mathrm{~L}^{2}}-\frac{12}{\mathrm{~L}^{3}} \mathrm{x}\right)
$$

Da mesma forma, para o deslocamento lateral w, pode-se escrever:

$$
\begin{gathered}
\mathrm{w}(\mathrm{x})=\mathrm{w}_{1}-\theta_{\mathrm{y} 1} \mathrm{x}+\frac{1}{2 \mathrm{~L}^{2}}\left(-6 \mathrm{w}_{1}+6 \mathrm{w}_{2}+4 \theta_{\mathrm{y} 1} \mathrm{~L}+2 \theta_{\mathrm{y} 2} \mathrm{~L}\right) \mathrm{x}^{2}+ \\
-\frac{2}{\mathrm{~L}^{3}}\left(-\mathrm{w}_{1}+\mathrm{w}_{2}+\frac{\mathrm{L}}{2} \theta_{\mathrm{y} 1}+\frac{\mathrm{L}}{2} \theta_{\mathrm{y} 2}\right) \mathrm{x}^{3}
\end{gathered}
$$

e a curvatura $\chi_{\mathrm{y}}$ em y:

$$
\chi_{\mathrm{y}}=\frac{\mathrm{d}^{2} \mathrm{w}(\mathrm{x})}{\mathrm{dx}^{2}}=-\mathrm{a}(\mathrm{x}) \boldsymbol{\theta}_{\mathrm{y} 1}-\mathrm{b}(\mathrm{x}) \boldsymbol{\theta}_{\mathrm{y} 2}+\mathrm{c}(\mathrm{x})\left(-\mathrm{w}_{1}+\mathrm{w}_{2}\right)
$$

Assim, a partir dos deslocamentos nodais $\{\mathrm{u}\}$ obtidos da relação linear dada por $\{\mathrm{F}\}=[\mathrm{k}]\{\mathrm{u}\}$, onde $\{\mathrm{F}\}$ representa o vetor de forças nodais e $[\mathrm{k}]$ é a matriz de rigidez linear clássica para elementos de barra tri-dimensionais, calculam-se as curvaturas de flexão e a deformação axial, segundo as equações (5.7), (5.10) e (5.5), respectivamente.

\subsection{CÁlCULO DOS ESFORÇOS RESISTENTES}

A seção transversal de concreto armado deve ser discretizada nas duas direções, a fim de 
se calcular, em cada elemento retangular discretizado da seção, a deformação longitudinal em função do estado de deformação, ou seja, em função da deformação axial $\eta$ e das curvaturas $\chi_{\mathrm{y}}$ e $\chi_{z}$ da seção. A Figura 5.2 ilustra a discretização da seção transversal em elementos retangulares.

O valor da deformação longitudinal em cada elemento retangular discretizado da seção transversal, a partir do qual serão calculadas as tensões, dependendo da lei constitutiva do material em questão, é dado por:

$$
\varepsilon_{\ell}=\eta-\mathrm{y}(\mathrm{i}) \chi_{\mathrm{z}}-\mathrm{z}(\mathrm{i}) \chi_{\mathrm{y}}
$$

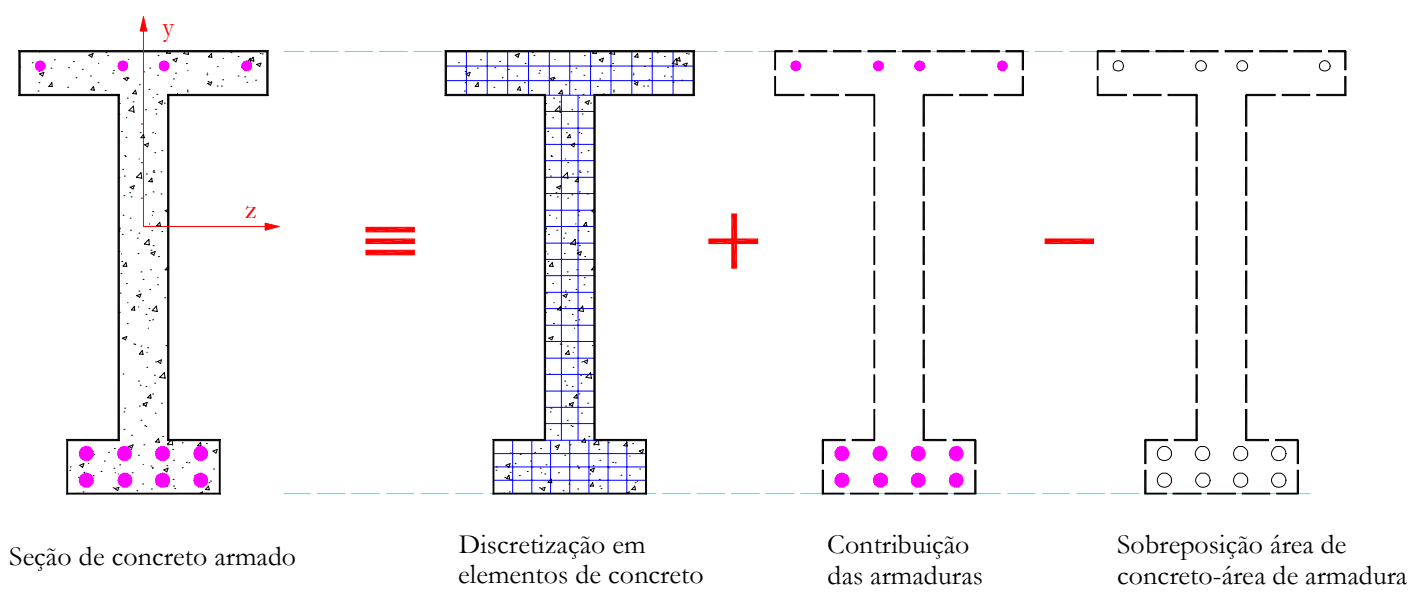

Figura 5.2 - Sistema de coordenadas e discretização da seção de concreto armado.

Assim, o cálculo dos esforços em cada seção transversal é desenvolvido no programa Tritor através da discretização da seção transversal em vários elementos retangulares. Em cada um destes elementos, a partir do estado de deformações da seção transversal, calculam-se as tensões segundo o comportamento de cada material envolvido. Os esforços cortantes são obtidos da verificação das condições de equilíbrio em cada elemento de barra definido no programa de pórtico espacial.

\subsection{LEIS CONSTITUTIVAS DOS MATERIAIS}

\subsubsection{CONCRETO À COMPRESSÃo}

Segundo Rahal (1993), até tensões em torno de $60 \mathrm{MPa}$, a relação tensão-deformação do concreto pode ser razoavelmente representada por uma parábola. A Figura 5.3 mostra uma curva parabólica cujo pico refere-se à tensão limite $\mathrm{f}_{\mathrm{c}}$ com deformação $\varepsilon_{\mathrm{c}}^{\prime}$. Esta relação pode ser matematicamente expressa por:

$$
\sigma_{\mathrm{c}}=\mathrm{f}_{\mathrm{c}}\left[2 \frac{\varepsilon_{\mathrm{c}}}{\varepsilon_{\mathrm{c}}^{\prime}}-\left(\frac{\varepsilon_{\mathrm{c}}}{\varepsilon_{\mathrm{c}}^{\prime}}\right)^{2}\right]
$$


O valor da tensão de pico $\mathrm{f}_{\mathrm{c}}$ será substituído por $0,85 \mathrm{f}_{\mathrm{c}}$, valor este referente à deformação $\varepsilon_{\mathrm{c}}^{\prime}$. Após atingida a deformação $\varepsilon_{\mathrm{c}}^{\prime}$, admite-se tensão constante no concreto igual a $0,85 f_{c}$ até que a deformação alcance o valor limite igual a -0,0035. Desta forma, tem-se o comportamento clássico dado pelo diagrama parábola-retângulo.

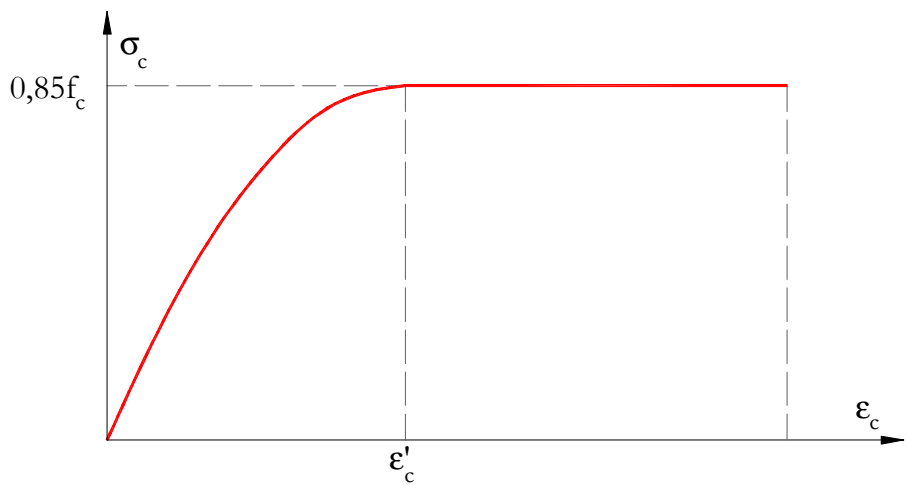

Figura 5.3 - Comportamento tensão-deformação do concreto sob compressão unixial.

\subsubsection{CONCRETo À Tração E Zona de ENRIJECIMENTo}

A região de concreto que circunda a armadura longitudinal é influenciada pela capacidade da armadura longitudinal de absorver esforços de tração nos chamados trechos de enrijecimento. Assim sendo, a região do concreto que efetivamente participa do enrijecimento é chamada de zona de tension-stiffening ou zona de envolvimento da armadura.

O efeito de tension-stiffening refere-se ao enrijecimento oferecido pelo concreto não fissurado entre duas fissuras, ao redor da armadura tracionada. Formalmente, segundo Yamamoto (1999), a zona de envolvimento da armadura é considerada igual a 7,5 vezes o diâmetro da armadura. No entanto, Yamamoto (1999) sugere como valor recomendável utilizar 2,5申, conforme ilustra a Figura 5.4.
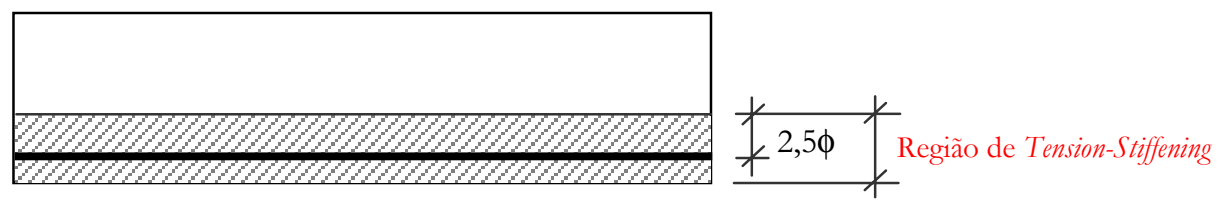

Figura 5.4 - Zona recomendável com efeito de tension-stiffening segundo Yamamoto (1999).

A lei utilizada neste trabalho para representar o concreto tracionado na zona enrijecida, dentre as várias lei propostas encontradas na literatura, é a apresentada por Vebo \& Ghali (1977) apud El-Metwally et al. (1990) e ilustrada na Figura 5.5, sendo:

$$
\varepsilon_{1}=\frac{1,2 \mathrm{f}_{\mathrm{t}}}{\mathrm{E}_{\mathrm{c}}} \quad \varepsilon_{2}=\frac{2,1 \mathrm{f}_{\mathrm{t}}}{\mathrm{E}_{\mathrm{c}}} \quad \varepsilon_{3}=\frac{11,1 \mathrm{f}_{\mathrm{t}}}{\mathrm{E}_{\mathrm{c}}}
$$

Para regiões de concreto na seção transversal fora da região com o efeito de enrijecimento, considera-se que o concreto tracionado obedece a Lei de Hooke até atingir a deformação limite correspondente à fissuração, e uma vez fissurado, a tensão de tração 
absorvida é assumida igual a zero neste trabalho.

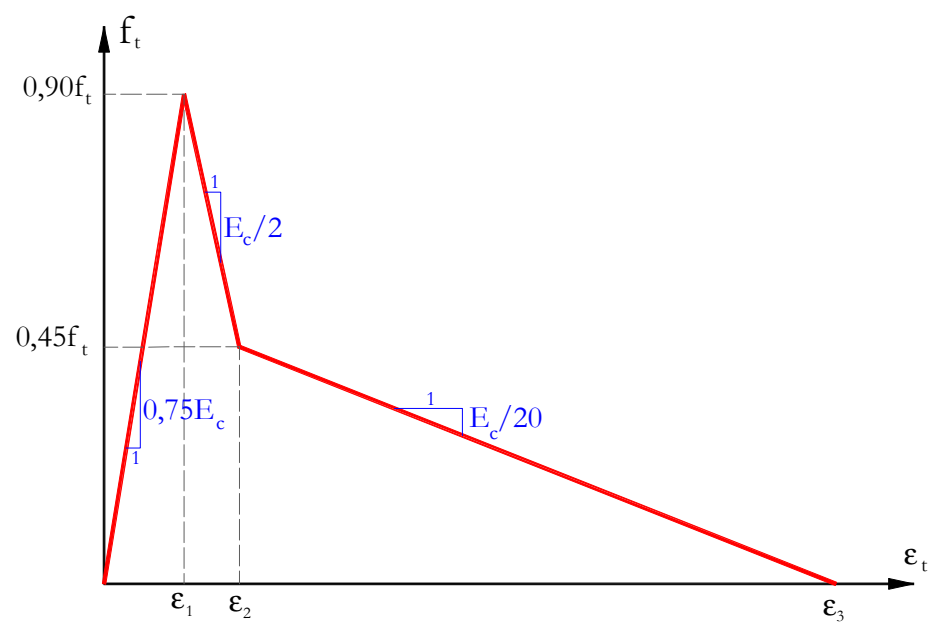

Figura 5.5 - Diagrama tensão-deformação do concreto à tração na zona enrijecida.

\subsubsection{ARMADURAS LONGITUDINAIS}

Com relação às armaduras passivas, pode-se considerar comportamento elastoplástico perfeito ou com encruamento positivo, por meio de diagrama bi-linear representando o efeito de hardening. Neste caso, o módulo de elasticidade do trecho após o escoamento é igual a $1 \%$ do módulo $\mathrm{E}$ da reta inicial.

Para as armaduras ativas, admite-se comportamento elastoplástico perfeito, com prédeformação devido à protensão.

\subsection{ESFORÇOS NODAIS NAS COORDENADAS LOCAIS DO ELEMENTO FINITO}

Uma vez calculados os momentos resistentes de flexão e torção, bem como a força normal, as forças cortantes nas direções y e z são obtidas por equilíbrio no elemento finito.

Sendo $N_{1}, M_{x 1}, M_{y 1}$ e $M_{z 1}$ os esforços solicitantes obtidos na seção do nó $j$ e $N_{2}, M_{x 2}, M_{y 2}$ e $\mathrm{M}_{\mathrm{z} 2}$ os esforços calculados na seção do nó $k$, tem-se, por equilíbrio, que os esforços finais do elemento finito, nas coordenadas locais são dados pela equação (5.14):

$$
\left\{\begin{array}{c}
\mathrm{N} \\
\mathrm{V}_{\mathrm{y}} \\
\mathrm{V}_{\mathrm{z}} \\
\mathrm{M}_{\mathrm{x}} \\
\mathrm{M}_{\mathrm{y}} \\
\mathrm{M}_{\mathrm{z}}
\end{array}\right\}_{\text {nój }}=\left\{\begin{array}{c}
-\left(\mathrm{N}_{1}+\mathrm{N}_{2}\right) / 2 \\
\left(\mathrm{M}_{\mathrm{z} 1}+\mathrm{M}_{\mathrm{z} 2}\right) / \mathrm{L} \\
-\left(\mathrm{M}_{\mathrm{y} 1}+\mathrm{M}_{\mathrm{y} 2}\right) / \mathrm{L} \\
-\left(\mathrm{M}_{\mathrm{x} 1}+\mathrm{M}_{\mathrm{x} 2}\right) / 2 \\
-\mathrm{M}_{\mathrm{y} 1} \\
-\mathrm{M}_{\mathrm{z} 1}
\end{array}\right\} \mathrm{e} \quad\left\{\begin{array}{c}
\mathrm{N} \\
\mathrm{V}_{\mathrm{y}} \\
\mathrm{V}_{\mathrm{z}} \\
\mathrm{M}_{\mathrm{x}} \\
\mathrm{M}_{\mathrm{y}} \\
\mathrm{M}_{\mathrm{z}}
\end{array}\right\}_{\text {nók }}=\left\{\begin{array}{c}
\left(\mathrm{N}_{1}+\mathrm{N}_{2}\right) / 2 \\
-\left(\mathrm{M}_{\mathrm{z} 1}+\mathrm{M}_{\mathrm{z} 2}\right) / \mathrm{L} \\
\left(\mathrm{M}_{\mathrm{y} 1}+\mathrm{M}_{\mathrm{y} 2}\right) / \mathrm{L} \\
\left(\mathrm{M}_{\mathrm{x} 1}+\mathrm{M}_{\mathrm{x} 2}\right) / 2 \\
\mathrm{M}_{\mathrm{y} 2} \\
\mathrm{M}_{\mathrm{z} 2}
\end{array}\right\}
$$


Calculados os esforços nodais nas coordenadas locais, pode-se verificar o equilíbrio entre o vetor de carregamento aplicado e o vetor de forças nodais internas. Caso não se verifique o equilíbrio, dentro de uma certa tolerância, deve-se reaplicar o delta não equilibrado de forças até a convergência, via procedimento iterativo.

\subsection{RIGIDEZ À TORÇÃo APROXIMADA POR DIAGRAMA BI-LINEAR}

A rigidez à torção após a fissuração em elementos de seção retangular pode ser calculada pela expressão proposta por Lampert (1973). A aplicação desta fórmula está associada ao seguinte postulado: "A quantidade total de armadura longitudinal e transversal, e não a forma com que se encontra distribuida na seção transversal, governam a rigidez à torção do membro estrutural sob torção”. Assim sendo,

$$
G J_{\text {tfiss }}=\frac{E_{s}\left(b_{o} h_{o}\right)^{2} A_{h}(1+m)}{u s} \text { sendo } m=\frac{\left(A_{s}+A_{s}^{\prime}\right) s}{A_{h} u}
$$

onde, $\mathrm{E}_{\mathrm{s}}$ é o módulo de elasticidade do $\mathrm{açc}_{\mathrm{c}} \mathrm{b}_{\mathrm{o}}$ é a distância horizontal entre as armaduras longitudinais nas quinas da seção, $h_{o}$ é a distância vertical entre as armaduras longitudinais nas quinas da seção; $A_{h}$ é a área da seção do estribo; u é o perímetro e s é o espaçamento entre os estribos.

O cálculo do momento de torção segue relação elástico-linear até a fissuração. Um dos pontos importantes definido no desenvolvimento do programa Tritor, refere-se à rigidez a ser utilizada no cálculo do momento de torção, uma vez conhecida a taxa de giro. Pôde-se observar que a definição do ponto teórico de fissuração sob torção pura ou torção combinada é ainda um tópico não muito bem definido na literatura técnica.

O trabalho de Karayannis \& Constantin (2000) consiste na confirmação experimental da aplicação da teoria de fissuração distribuída na análise do comportamento de seções de concreto simples sob torção. Em trabalho anterior, Karayannis (2000) apresenta um modelo numérico para tal avaliação. Neste tópico, algumas expressões disponíveis na literatura técnica com relação ao momento de ruptura de peças de concreto simples podem ser encontradas. Segundo $H s u$ (1968), baseado em resultados experimentais, o momento de fissuração de peças de concreto armado é em torno de 1 a 1,3 vez superior ao momento de ruptura de uma viga correspondente de concreto simples.

Hsu (1968) propõe que o momento de ruptura $\mathrm{M}_{\mathrm{t}_{-} \text {up }}$ por torção de uma viga de seção retangular de concreto simples pode ser obtido por:

$$
M_{t_{-} \text {up }}=6 \cdot\left(x^{2}+10\right) \cdot y \cdot \sqrt[3]{f_{c}}
$$

sendo x e y as dimensões horizontal e vertical da seção, respectivamente, em polegadas, e $f_{c}$ é a resistência à compressão de um corpo-de-prova cilíndrico de concreto, em psi.

Baseado nestas observações, e visando utilizar considerações empíricas a favor da segurança, o programa Tritor considera o início da fissuração sob torção de uma viga de concreto armado igual ao momento de ruptura por torção de uma viga correspondente de concreto simples, através da aproximação proposta por Hsu (1968). Assim que a etapa de carregamento aplicada atinge o valor para o qual admitiu-se, teoricamente, que 
a mesma encontra-se em fase fissurada, o cálculo do momento resistente de torção continua sendo obtido linearmente, porém, o valor da rigidez de torção fissurada é calculado segundo proposto por Lampert (1973) na equação (5.15).

O momento de torção após a fissuração é calculado no programa Tritor da seguinte forma:

$$
\mathrm{M}_{\mathrm{t}}=\mathrm{M}_{\mathrm{t}_{-} \text {up }}+\mathrm{GJ}_{\mathrm{tfiss}}\left(\chi_{\mathrm{x}}-\chi_{\mathrm{xup}}\right)
$$

sendo $\chi_{\mathrm{xup}}$ a taxa de giro por torção referente ao momento de torção de ruptura $\mathrm{M}_{\mathrm{t}_{-} \text {up }}$ de uma viga equivalente de concreto simples.

Este comportamento foi adotado por Lampert (1973) em sua proposta para cálculo da rigidez à torção e à flexão antes e após a fissuração. Lampert (1973) considera duas situações distintas: flexão predominante sobre a torção e a situação inversa. Para flexão predominante, Lampert (1973) sugere utilizar a mesma expressão para cálculo da rigidez à torção na fase pós-fissuração, por reconhecer a dificuldade em se estabelecer um mecanismo estrutural adequado neste período.

\subsection{Parâmetros NeCESSÁrios ao Cálculo da Rigidez À Torção SEGUNDO HANNACHI \& FOURÉ (1996)}

Para considerar a variação da rigidez à torção devido ao estado de fissuração por flexão, é necessário conhecer $\mathrm{o}$ valor da abertura de fissura $\mathrm{t}_{\mathrm{m}}$ e do espaçamento $\mathrm{s}_{\mathrm{m}}$ das mesmas.

Utilizou-se neste trabalho a recomendação do CEB-FIP (1999), o qual sugere que para todos os níveis de fissuração, a abertura de fissura pode ser calculada por:

$$
\mathrm{t}_{\mathrm{m}, \mathrm{k}}=1,7 \mathrm{~s}_{\mathrm{m}} \varepsilon_{\mathrm{sm}}
$$

onde $t_{\mathrm{m}, \mathrm{k}}$ é o valor característico da abertura de fissuras, $\mathrm{s}_{\mathrm{m}}$ é o espaçamento médio entre fissuras e $\varepsilon_{\mathrm{sm}}$ é a deformação média do aço. Portanto, o valor médio $t_{\mathrm{m}}$ é igual a $\mathrm{s}_{\mathrm{m}} \varepsilon_{\mathrm{sm}}$.

O espaçamento médio $\mathrm{s}_{\mathrm{m}}$ pode ser calculado por:

$$
\mathrm{s}_{\mathrm{m}}=2 \mathrm{c}+\frac{\alpha_{\mathrm{b}} \phi}{\rho}
$$

onde c é o cobrimento, $\alpha_{\mathrm{b}}$ é o coeficiente de aderência, $\phi$ é o diâmetro da armadura e $\rho$ é a taxa de armadura. O coeficiente de aderência $\alpha_{b}$ pode assumir os valores apresentados na Quadro 5.1.

A deformação média $\varepsilon_{\mathrm{sm}}$ do aço pode ser escrita por: 


$$
\varepsilon_{\mathrm{sm}}=\varepsilon_{\mathrm{s}}-0,40 \varepsilon_{\mathrm{sr} 1} \text { onde } \varepsilon_{\mathrm{sr} 1}=\frac{\mathrm{f}_{\mathrm{ct}, \mathrm{min}}}{\rho \mathrm{E}_{\mathrm{a}}}
$$

onde $\varepsilon_{\mathrm{s}}$ é a deformação da armadura, $\mathrm{E}_{\mathrm{a}}$ é o módulo de elasticidade do aço e $\mathrm{f}_{\mathrm{ct}, \text { min }}$ é a resistência à tração do concreto.

Quadro 5.1 - Valores dos coeficientes de aderência.

\begin{tabular}{|c|l|l|}
\hline \multirow{2}{*}{ Barras de alta aderência } & $\alpha_{\mathrm{b}}=0,125$ & Boa aderência \\
\cline { 2 - 3 } & $\alpha_{\mathrm{b}}=0,20$ & Demais casos \\
\hline \multirow{3}{*}{ Cordoalhas de protensão } & $\alpha_{\mathrm{b}}=0,19$ & Boa aderência \\
\cline { 2 - 3 } & $\alpha_{\mathrm{b}}=0,30$ & Demais casos \\
\hline \multirow{2}{*}{ Barras lisas ou fios } & $\alpha_{\mathrm{b}}=0,25$ & Boa aderência \\
\cline { 2 - 3 } & $\alpha_{\mathrm{b}}=0,40$ & Demais casos \\
\hline
\end{tabular}

Uma vez conhecidos o espaçamento e a abertura das fissuras, pode-se calcular o fator de correção $\psi$, a contribuição do efeito de pino $R_{a}$, e a rigidez $\left(G J_{t}\right)_{b}$ que depende de $G_{o}$ e $\mathrm{G}_{1}$, a fim de se obter a rigidez à torção média pós-fissuração por flexão $\overline{\mathrm{GJ}_{\mathrm{t}}}$.

Numericamente, a partir do estado de deformações longitudinal da seção, calculou-se a equação da reta que define a posição da $\mathrm{LN}$, e posteriormente, obteve-se o valor do parâmetro $G_{1}$ referente ao módulo de elasticidade transversal do ponto mais tracionado da seção. Da colaboração de cada elemento tracionado ou comprimido, segundo a distância do ponto central de cada um até a $\mathrm{LN}$, obtém-se a rigidez $\left(\mathrm{GJ}_{\mathrm{t}}\right)_{\mathrm{b}}$.

O cálculo da contribuição das armaduras através do efeito de pino depende da distância do CG da armadura até o centro de torção da seção fissurada. Como a posição do centro de torção D de toda a seção fissurada depende de alguns parâmetros desconhecidos, que segundo Fouré \& Hannachi (1999) pode ser calculada por um procedimento iterativo de tentativa e erro, conforme apresentado no item 4.4 do capítulo 4, optou-se neste trabalho por uma alternativa simplificada. Calculou-se o centro de torção $\mathrm{D}_{\mathrm{b}}$ da região comprimida e admitiu-se que o centro de torção $\mathrm{D}$ da seção fissurada encontra-se na metade da distância entre o CG da seção e o centro de torção $\mathrm{D}_{\mathrm{b}}$. Uma vez que o estudo de Hannachi \& Fouré (1996) depende de parâmetros empíricos, não se justifica um procedimento complicado para a estimativa da posição do centro de torção D, o qual apenas interfere na resposta final, através da rigidez oferecida pelo efeito de pino.

É conhecido que a contribuição das armaduras, tanto a longitudinal como a transversal, é muito pequena na resistência à torção de vigas não-fissuradas de concreto armado. Os resultados experimentais observados por Hannachi \& Fouré (1996) e da análise dos parâmetros da expressão (4.60) mostram que é o concreto que participa sempre com maior intensidade no valor final da rigidez à torção pós-fissuração por flexão.

Conhecida a posição do centro $\mathrm{D}$ de torção, pode-se calcular a contribuição das armaduras, que depende da distância do CG de cada armadura ao centro de torção D, do módulo de deformação longitudinal do concreto $\mathrm{E}_{\mathrm{bo}}$ com relação à origem, do 
módulo de deformação do aço $\mathrm{E}_{\mathrm{s}}$ e do diâmetro das armaduras tracionadas.

\subsection{CONTRIBUIÇÃo dO NúClEO NÃO-FISSURADO NO MODELO ESTRUTURAL DE COCCHI \& VOLPI (1996)}

O modelo de ações combinadas de Cocchi \& Volpi (1996) despreza a colaboração do núcleo central, uma vez que trabalha com a correspondente seção vazada. No programa Tritor, pode-se também calcular a contribuição do núcleo central à flexão vertical e lateral, bem como devido à força normal. O núcleo resultante é discretizado em elementos retangulares, para os quais calculam-se as deformações longitudinais através da equação (5.11) e as tensões correspondentes, obedecendo as leis constitutivas dos materiais envolvidos. Do somatório da contribuição de cada elemento, tem-se os esforços resistentes do núcleo central. Estes últimos, esforços normais e momento fletor vertical e lateral obtidos para o núcleo, são somados aos obtidos do modelo de ações combinadas, mantendo-se o momento de torção obtido do modelo de analogia de treliça espacial.

\subsection{Fluxograma Geral do Programa Tritor}

Em linhas gerais, será apresentado a seguir os fluxogramas ilustrados nas Figuras 5.6 e 5.7, representando os procedimentos básicos para o cálculo de esforços de elementos estruturais utilizando o programa Tritor, a partir dos modelos numéricos implementados.

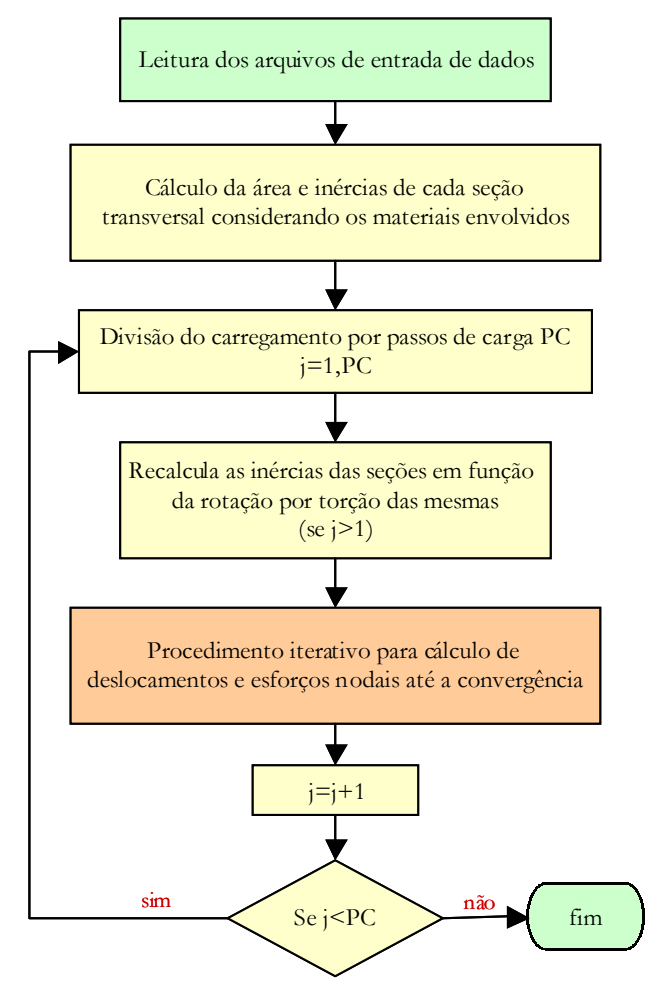

Figura 5.6 - Procedimentos gerais do programa Tritor. 
Tem-se, portanto, um procedimento incremental e iterativo mostrado na Figura 5.7, resultante da não-linearidade física dos materiais envolvidos, que pode ser realizado através da aplicação de cada um dos modelos numéricos implementados, entre eles, o de Cocchi \& Volpi (1996), Hannachi \& Fouré (1996), Lampert (1973) e Hsu (1968).

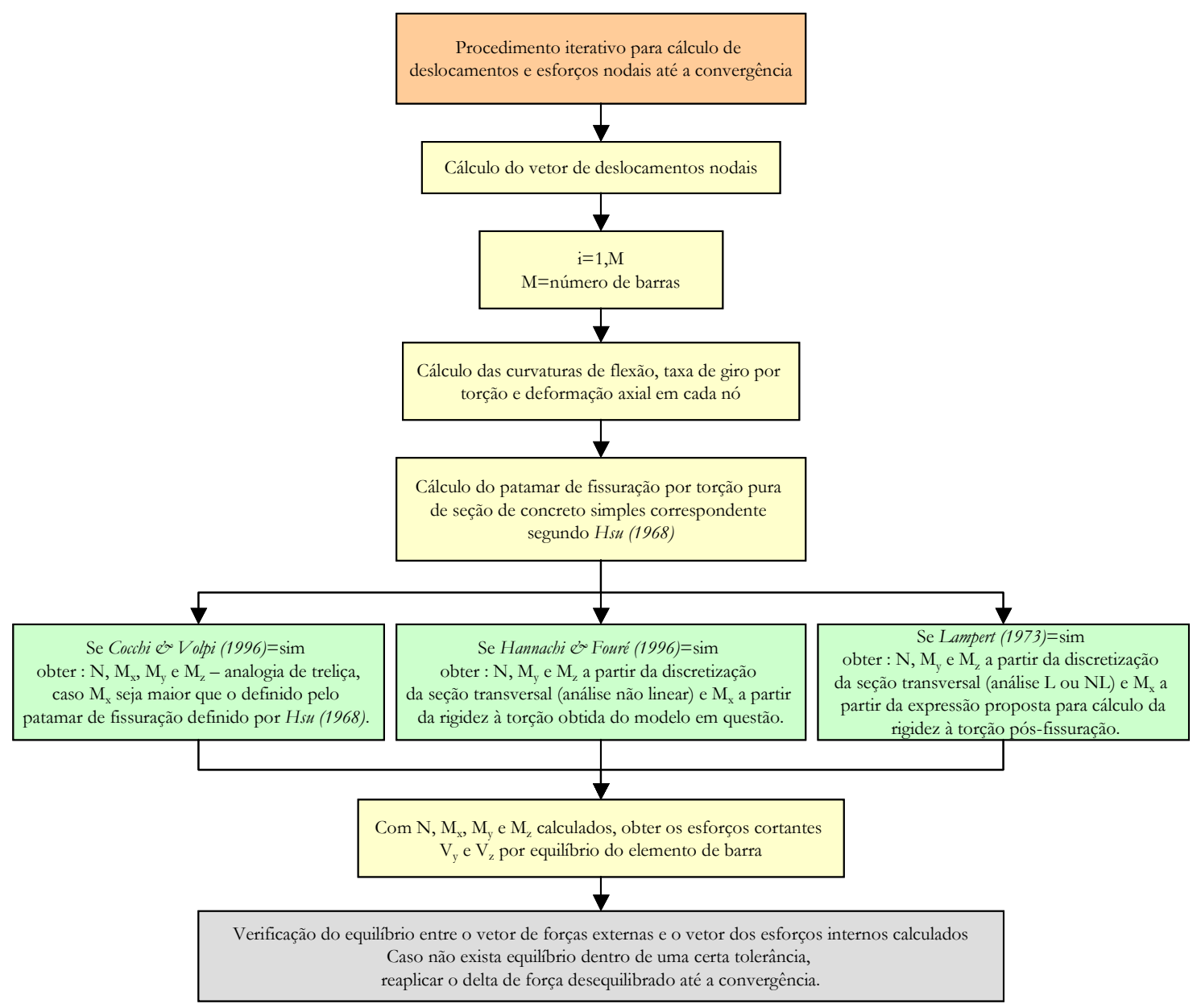

Figura 5.7 - Procedimento iterativo para cálculo de esforços. 


\section{Capítulo \\ 06}

PROGRAMA EXPERIMENTAL

\subsection{CONSIDERAÇões INICIAIS}

Apresenta-se neste capítulo um reduzido programa experimental direcionado a um melhor entendimento do problema da instabilidade lateral de vigas esbeltas de concreto armado. Uma vez que o objetivo principal deste trabalho não se refere a uma extensiva pesquisa experimental, foram ensaiadas apenas duas vigas sob tombamento lateral gradual, cujo procedimento e justificativa serão descritos mais adiante.

O programa experimental desenvolvido tem, portanto, o objetivo de simular o comportamento de vigas longas e esbeltas de concreto armado sob flexão bi-lateral e torção, contribuindo, em parte, para a validação do programa Tritor.

Em ordem, os itens apresentados à seguir neste capítulo referem-se à justificativa do tipo de ensaio realizado, às características da seção transversal da viga, à execução e instrumentação dos modelos, aos procedimentos de ensaio, bem como aos resultados experimentais obtidos referentes à leitura das deformações e dos deslocamentos e os numéricos resultantes da simulação.

\subsection{MOTIVAÇ̃̃o DO ENSAIO}

O programa experimental desenvolvido nesta tese baseia-se no ensaio de uma viga em escala real realizado por Mast (1994), no qual uma viga protendida de seção I, classificada no PCI como BT-72, com 45,45m de comprimento, foi gradualmente inclinada partindo da posição vertical, até que atingisse o colapso.

A Figura 6.1 ilustra o ensaio em escala real realizado por Mast (1994) referente a um estudo sobre a instabilidade lateral de vigas protendidas durante as fases transitórias. No ensaio, a máxima inclinação correspondente à ruptura da viga protendida foi igual a $32^{\circ}$.

O principal objetivo do ensaio de Mast (1994) foi o de investigar o comportamento de vigas de seção I fissuradas sob flexão lateral. Além disto, Mast (1994) questiona a eficiência dos contraventamentos comumente utilizados no transporte destas vigas.

As características físicas da viga ensaiada por Mast (1994) podem ser visualizadas na Figura 6.2. $\mathrm{Na}$ disposição do ensaio, o vão central foi de $38,80 \mathrm{~m}$ e, portanto, com balanços de 3,325m. Mast (1994) mediu deslocamentos e deformações durante as etapas de variação da inclinação dos apoios. A Figura 6.3 mostra o esquema utilizado por Mast (1994) para realizar o tombamento lateral gradual da viga. 


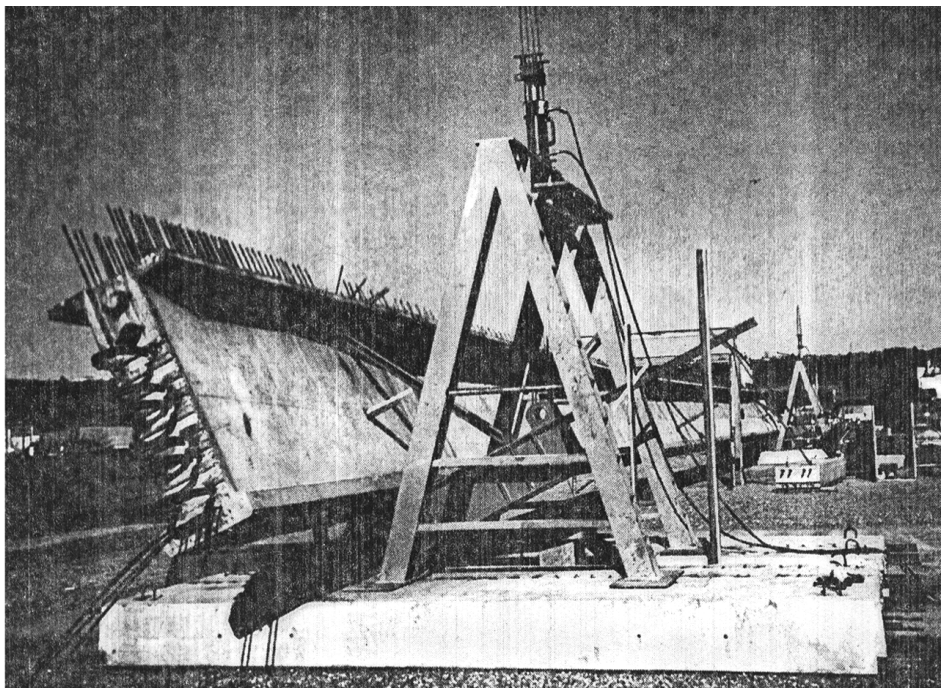

Figura 6.1 - Viga BT-72 padrão do PCI ensaiada por Mast (1994).

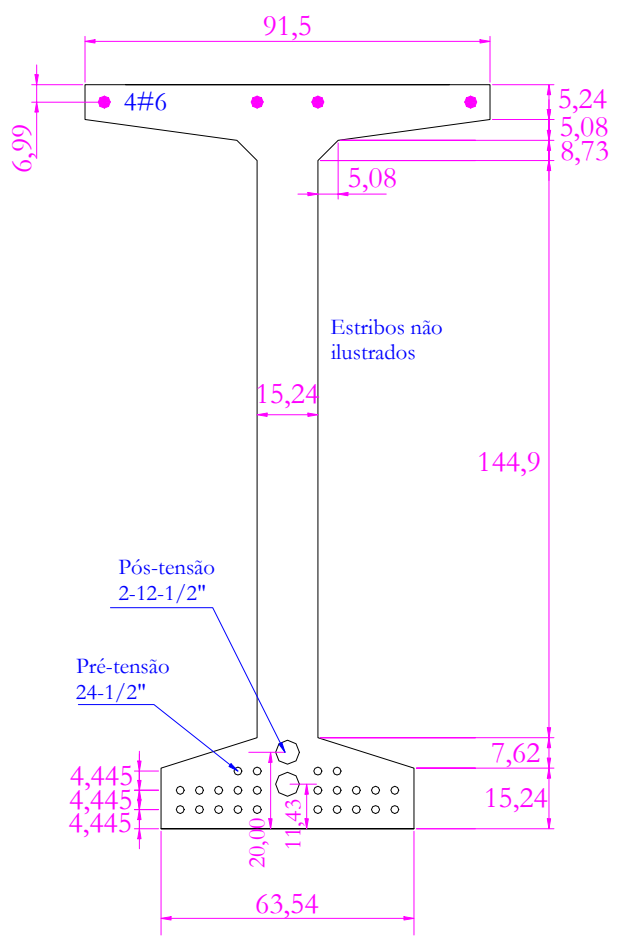

Figura 6.2 - Seção Transversal da Viga PCI BT-72 ensaiada por Mast (1994).

Mast (1994) realizou 3 ensaios com a mesma viga. Nos dois primeiros ensaios, a viga foi tombada gradualmente, de $2,5 \mathrm{em} 2,5^{\circ}$ até atingir aproximadamente $15^{\circ}$. O primeiro ensaio tinha o objetivo de verificar os procedimentos bem como a instrumentação. Já no segundo ensaio, buscava-se investigar a rigidez do sistema de contraventamento usual no transporte de vigas longas. O terceiro ensaio, realizado sem o sistema de contraventamento, foi dividido em duas fases. A primeira fase foi basicamente uma repetição do primeiro ensaio, chegando-se até $15,9^{\circ}$. A segunda fase, aproximadamente 1 hora após a primeira, consistiu em incrementos de $3 \mathrm{em} 3^{\circ}$ até atingir a ruptura, que ocorreu com inclinação em torno de $32^{\circ}$. O autor do ensaio observou uma 
descontinuidade nos dados do sistema de aquisição provavelmente devido à combinação dos efeitos de fluência e das variações de temperatura durante o intervalo de tempo entre as duas fases.

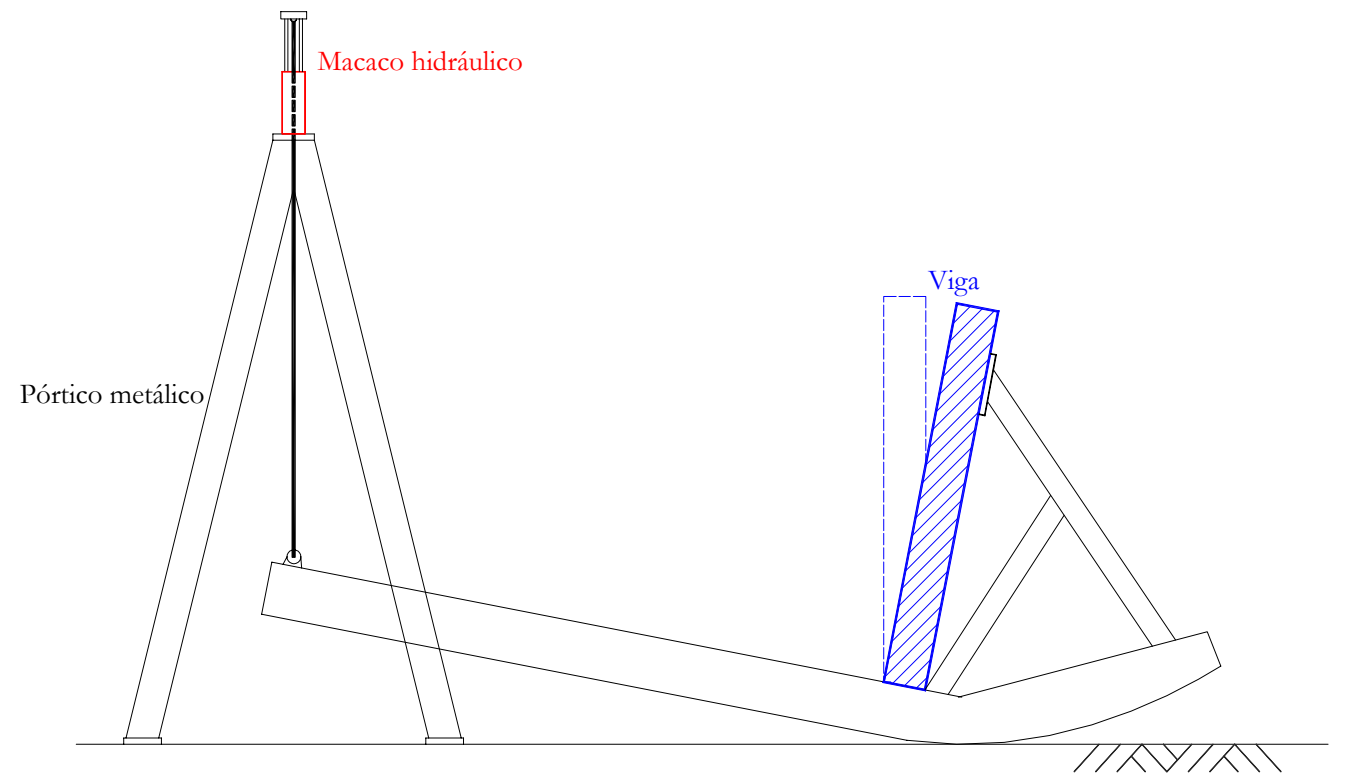

Figura 6.3 - Disposição do equipamento de ensaio utilizado por Mast (1994).

Para a viga protendida ensaiada, Mast (1994) observou que a taxa de giro no meio do vão com relação aos apoios é aproximadamente proporcional ao quadrado do ângulo de giro imposto e pode ser expresso por uma curva parabólica. Mast (1993), no estudo proposto através do cálculo de fatores de segurança para as fases transitórias, admitiu ser razoável desprezar o giro por torção. Observando os resultados experimentais, Mast (1994) confirma a aproximação anterior, uma vez que para $15^{\circ}$ de inclinação imposta mediu-se $2 \%$ de giro por torção e para $30^{\circ}$ de giro imposto nos apoios, o giro por torção foi em torno de $4 \%$ deste valor. Baseado nestes dados, a aproximação de se desprezar os efeitos de torção é de fato razoável.

A ruptura da viga protendida ensaiada por Mast (1994) ocorreu devido ao colapso por compressão na mesa inferior seguido do rompimento de toda a seção transversal à $1,2 \mathrm{~m}$ do meio do vão.

Baseado nos resultados experimentais, o autor dos ensaios observa que a viga pode suportar cargas laterais superiores à carga prevista de fissuração, sem apresentar sinais visíveis de dano quando estas cargas forem retiradas. Além disto, com relação à eficiência do sistema de contraventamento, Mast (1994) constata que a presença deste tem um efeito mínimo no comportamento da viga.

Baseado nos ensaios de Mast (1994) e a fim de desenvolver um programa experimental que pudesse representar o problema da instabilidade lateral de vigas esbeltas de concreto armado, foram ensaiadas duas vigas em escala reduzida, na proporção 1:2, submetidas apenas ao efeito do peso-próprio, correspondente à situação real das vigas pré-moldadas durante as fases transitórias e no período pré-serviço. Conforme observado até então, as fases transitórias de montagem são as mais vulneráveis a apresentarem instabilidade lateral, embora o carregamento se limite ao peso-próprio. 
Os ensaios realizados nesta tese referem-se a 2 vigas de concreto armado de seção retangular, cuja característica principal é a grande inércia à flexão vertical comparada à inércia a flexão lateral.

As características geométricas das vigas ensaiadas baseiam-se na investigação experimental apresentada por Twelmeier \& Brandmann (1985), referente ao estudo do problema da instabilidade lateral de vigas de concreto armado.

Vale observar que nos ensaios piloto de Twelmeier \& Brandmann (1985), considerou-se na investigação dos problemas de instabilidade lateral, o momento fletor lateral variando entre 5 a $10 \%$ do momento fletor vertical existente e o momento de torção foi igual a $1 \%$ do momento fletor vertical. Porém, não existem resultados publicados sobre os ensaios realizados por estes autores referente à investigação do problema da instabilidade lateral.

\subsection{Características Geométricas e Detalhamento}

A seção transversal e as dimensões das duas vigas ensaiadas neste trabalho, a partir de então designadas por vigas V1 e V2, encontram-se ilustradas nas Figuras 6.4 (a) e (b).

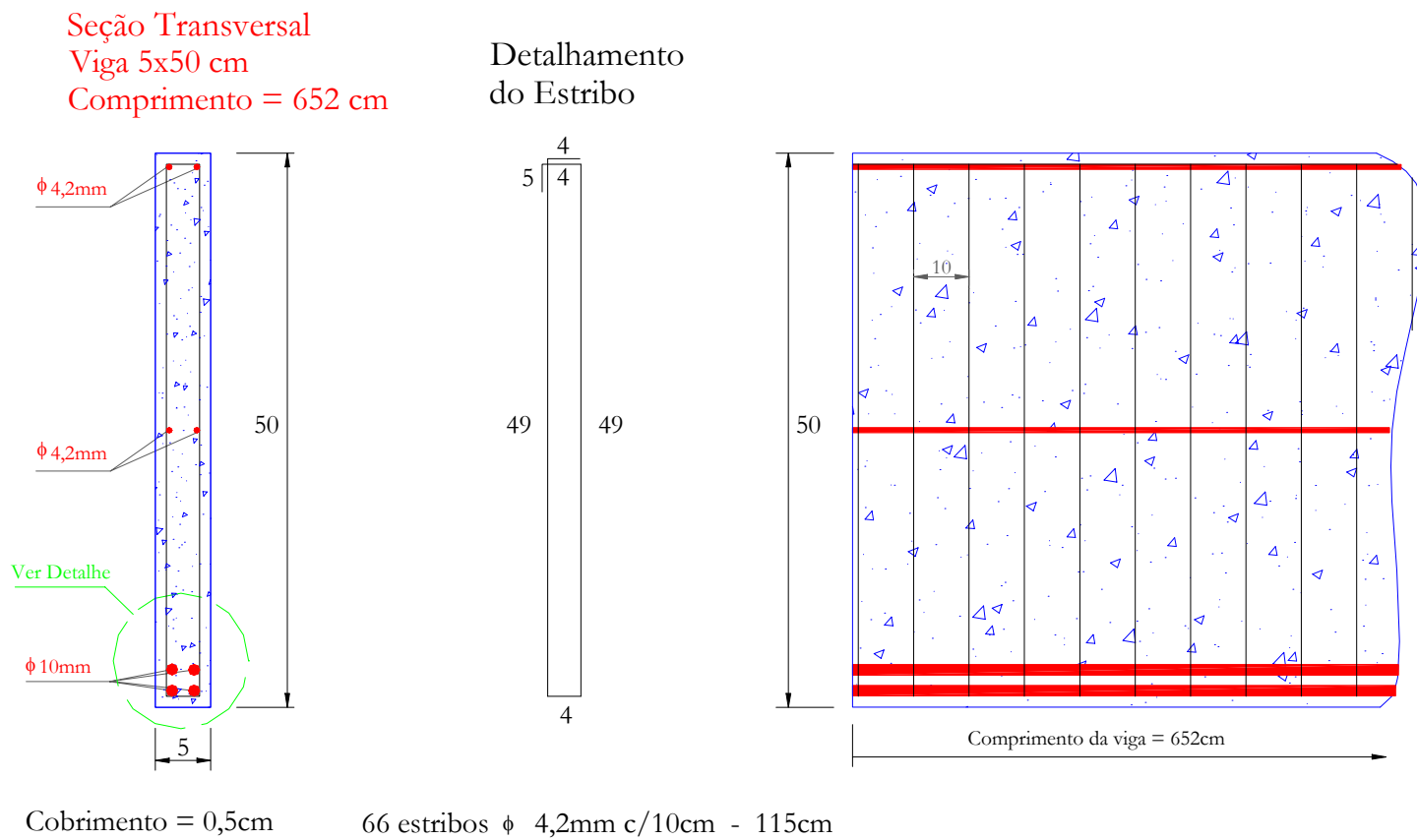

(a) Detalhamento das armaduras na seção transversal e distribuição dos estribos. 


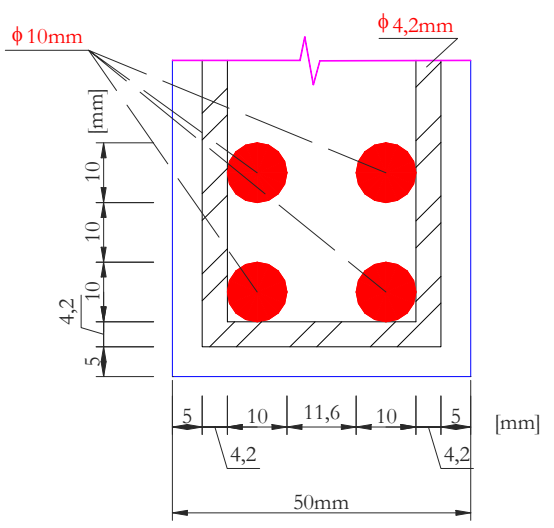

(b) Detalhamento da armadura longitudinal inferior.

Figura 6.4 - Seção transversal das vigas ensaiadas e detalhamento.

A Figura 6.5 mostra a dimensão longitudinal da viga e a posição dos apoios. O detalhamento das armaduras longitudinais encontra-se ilustrado na Figura 6.6 e a Figura 6.7 mostra a fôrma e a armação da viga V1 pronta para a concretagem.

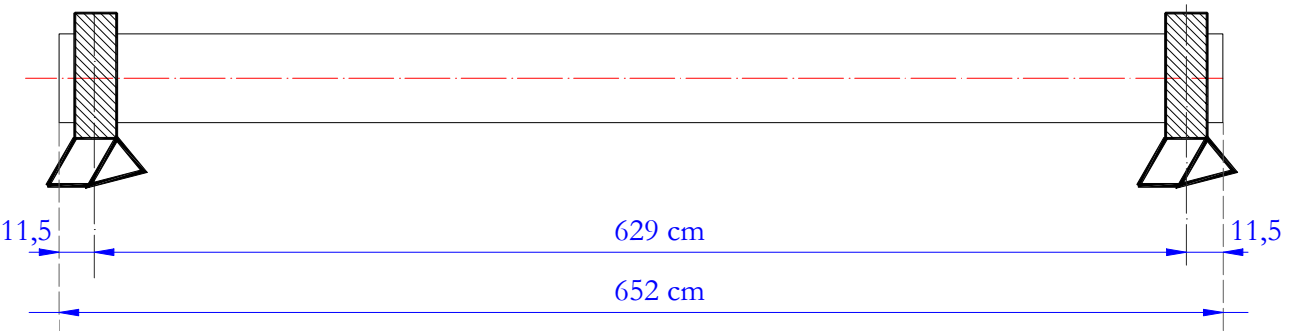

Figura 6.5 - Dimensão longitudinal da viga e posição dos apoios tipo garfo.

$4 \phi 4,2 \mathrm{~mm}(649 \mathrm{~cm})$

$2 \phi 10 \mathrm{~mm}(645 \mathrm{~cm})$

645

15

Figura 6.6 - Detalhamento da armadura longitudinal. 


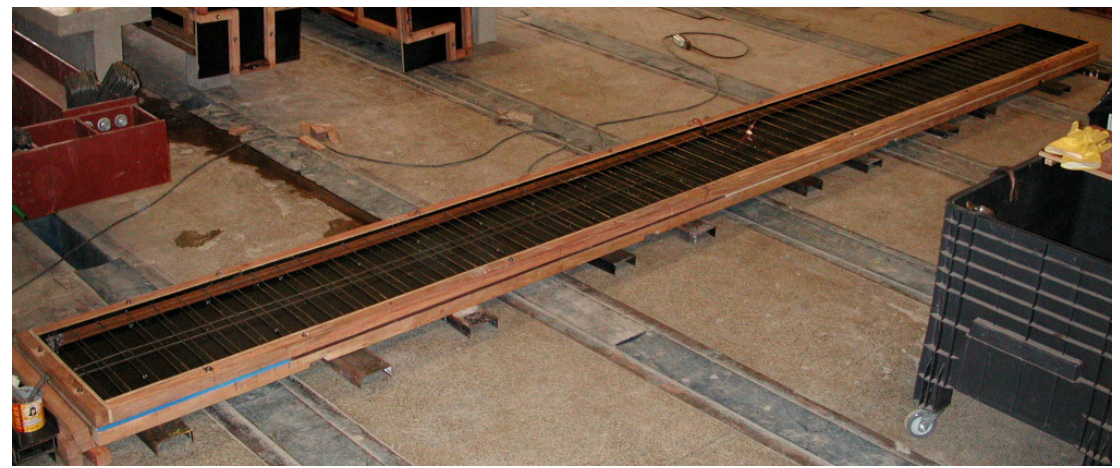

Figura 6.7 - Fôrma e armação da viga V1.

\subsection{EXeCuÇÃo DOS MOdelos e DOSAgem do CONCRETO DE GRANULOMETRIA FiNA}

Para a concretagem dos modelos utilizou-se o misturador planetário da marca CIBI, com capacidade para 250 litros e o adensamento da mistura foi feito com vibrador.

$\mathrm{Na}$ concretagem de cada uma das vigas V1 e V2, foram também moldados 6 corpos-deprova $10 \mathrm{~cm} \times 20 \mathrm{~cm}$ para determinar as resistências à compressão e à tração do concreto e 3 corpos-de-prova cilíndricos $15 \mathrm{~cm} \times 30 \mathrm{~cm}$, para posterior estimativa do módulo de elasticidade do concreto.

Uma vez que as vigas V1 e V2 representam um modelo reduzido na escala 1:2, foi necessário utilizar concreto de granulometria fina. Assim, a dosagem utilizada foi de 1:1,94:2,06:0,65, a qual refere-se às relações cimento-areia-pedrisco-fator água-cimento, respectivamente. O estudo granulométrico do pedrisco utilizado mostra que $85,8 \%$ das amostras analisadas passam na peneira de $4,2 \mathrm{~mm}$ e o diâmetro máximo característico do agregado é de $6,3 \mathrm{~mm}$, conforme resultados apresentados na Tabela 6.1. Utilizou-se cimento Portland de alta resistência inicial CP V ARI. A Figura 6.8 ilustra a textura do concreto com pedrisco, em um corpo-de-prova cilíndrico de dimensões $10 \mathrm{~cm} \times 20 \mathrm{~cm}$.

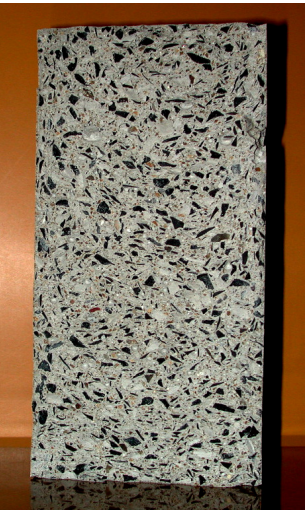

Figura 6.8 - Concreto de granulometria fina: corpode-prova $10 \mathrm{~cm} \times 20 \mathrm{~cm}$.
Tabela 6.1 - Estudo granulométrico do pedrisco.

\begin{tabular}{|c|c|c|c|}
\hline $\begin{array}{c}\text { Peneira } \\
\text { \# (mm) }\end{array}$ & $\begin{array}{c}\text { Massa retida } \\
\mathbf{( g )}\end{array}$ & $\begin{array}{c}\text { Porcentagem retida } \\
\mathbf{\%}\end{array}$ & $\begin{array}{c}\text { Porcentagem retida } \\
\text { acumulada }\end{array}$ \\
\hline 9,5 & 0 & 0,0 & 0,0 \\
\hline 6,3 & 54 & 4,2 & 4,2 \\
\hline 4,8 & 332,17 & 25,8 & 30,0 \\
\hline 2,4 & 719,6 & 55,9 & 85,8 \\
\hline 1,2 & 146,8 & 11,4 & 97,2 \\
\hline 0,6 & 23,3 & 1,8 & 99,0 \\
\hline 0,3 & 3,1 & 0,2 & 99,3 \\
\hline 0,15 & 1,3 & 0,1 & 99,4 \\
\hline Fundo & 8,1 & 0,6 & 100,0 \\
\hline & \multicolumn{3}{|c|}{ Diâmetro máximo característico: $\mathbf{6 , 3} \mathbf{~ m m}$} \\
& \multicolumn{3}{|c}{ Módulo de finura: $\mathbf{5 , 1 1}$} \\
\hline
\end{tabular}


Para cada uma das vigas moldadas utilizou-se 227 litros de concreto, incluindo o volume necessário para a moldagem dos corpos-de-prova para avaliação da resistência e do módulo de elasticidade do concreto.

A moldagem das duas vigas foi feita na posição horizontal para facilitar a concretagem e a vibração, conforme ilustra a Figura 6.9. Após a moldagem, procedeu-se à cura durante os 3 primeiros dias, através de uma manta de espuma molhada cobrindo todo o modelo.
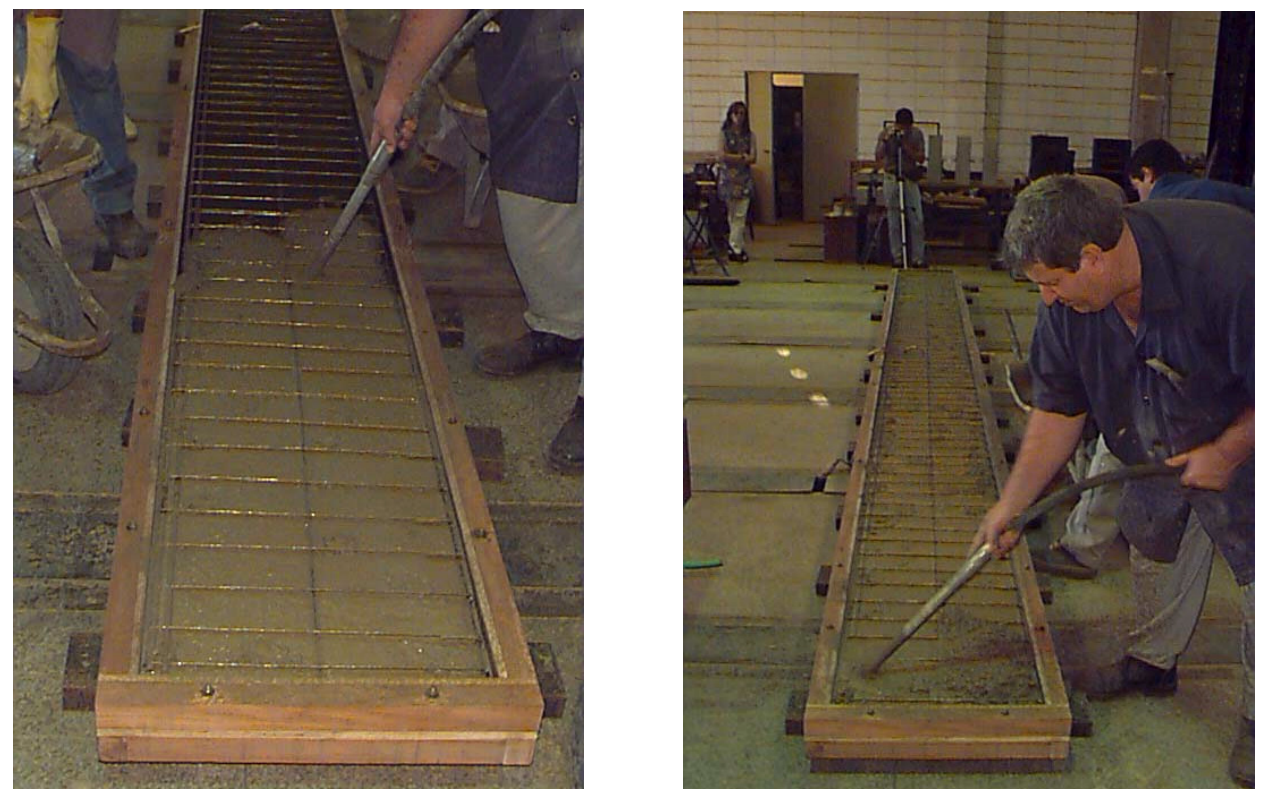

Figura 6.9 - Concretagem da viga V1.

As vigas V1 e V2 foram ensaiadas aos 15 e 12 dias, respectivamente, em virtude da disponibilidade operacional do cronograma de ensaios do Laboratório de Estruturas. Entretanto, a data de ensaio não é neste programa importante, devendo-se apenas conhecer as características físicas dos materiais envolvidos na data do ensaio.

A resistência do concreto obtida a partir do ensaio dos corpos-de-prova para a viga V1 foi de 36,4 MPa e 34,4 MPa para a viga V2. Na simulação numérica, utilizou-se 28700 MPa para o módulo de elasticidade da viga V1 e $28000 \mathrm{MPa}$ para a viga V2.

\subsubsection{INSTRUMENTAÇÃO DOS MODELOS}

Os modelos foram instrumentados com extensômetros elétricos tipo strain gage KFG 10 colados no concreto e tipo strain gage KFG 5 colados nas armaduras.

Os extensômetros elétricos foram colados em todas as armaduras longitudinais na seção central da viga, e no concreto, 3 extensômetros elétricos foram colados na face comprimida, e 3 na face tracionada, todos estes, na seção do meio do vão, como ilustra a Figura 6.10.

A simulação experimental do fenômeno da instabilidade lateral requer equipamentos para medição de grandes deslocamentos nas três dimensões. A medida dos deslocamentos foi realizada através de Estação Total TCR 1105 e TCR 705, fabricadas 
pela empresa Leica Geosystems, para as vigas V1 e V2, respectivamente. A utilização das estações totais foi a alternativa encontrada para a leitura dos deslocamentos, que além de serem grandes, existia ainda o inconveniente dos pontos de leitura mudarem de coordenadas $\mathrm{x}$, y e $\mathrm{z}$, ao longo de todo o ensaio, dificultando ainda mais a leitura através de transdutores de deslocamentos. Vale lembrar que o curso dos transdutores disponíveis no Laboratório de Estruturas é de $10 \mathrm{~cm}$ e os deslocamentos medidos chegam a $40 \mathrm{~cm}$. A utilização de equipamentos de mensuração no Laboratório de Estruturas foi realizada pela primeira vez neste trabalho.
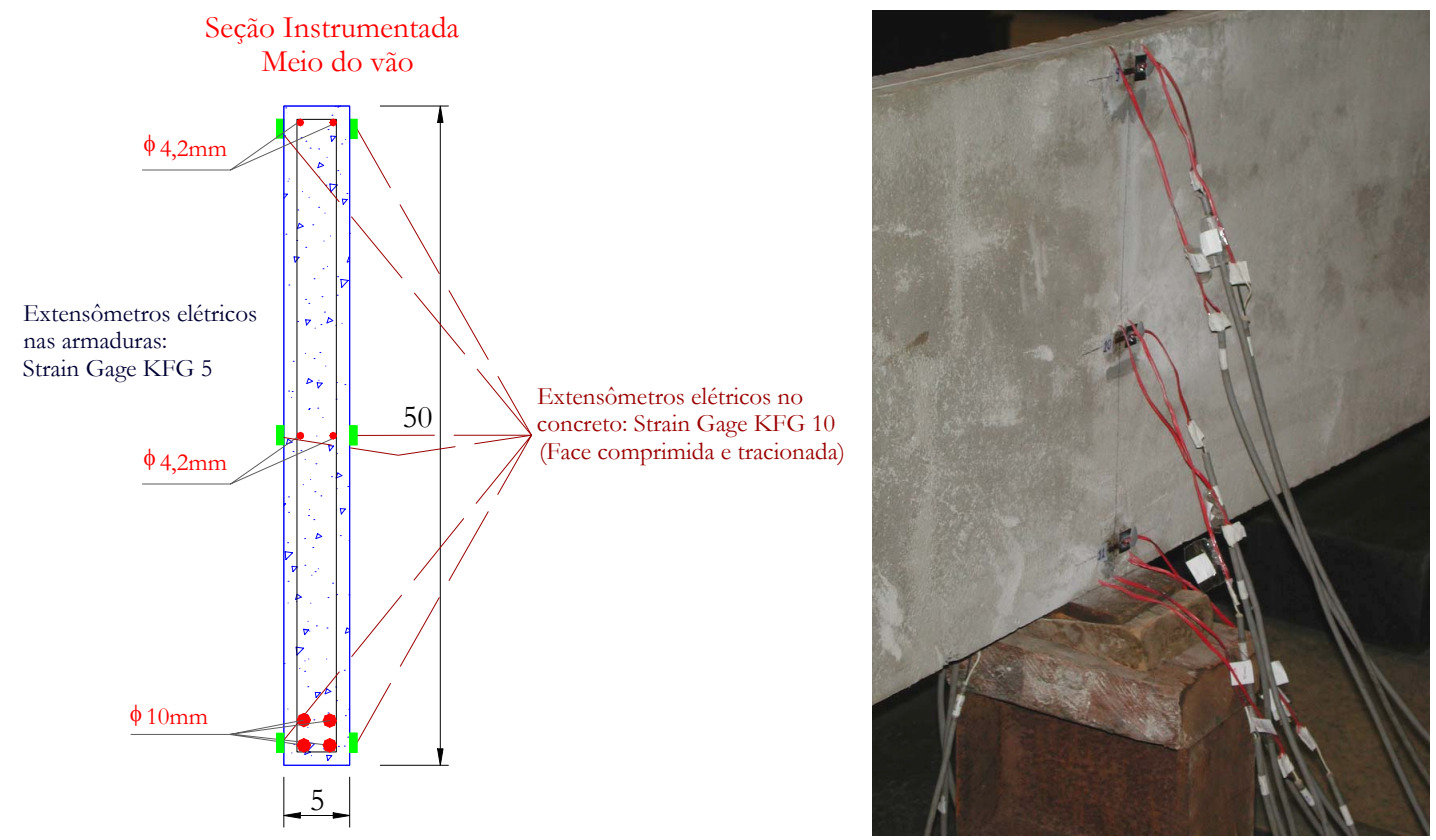

Figura 6.10 - Instrumentação da seção transversal no meio do vão

A Estação Total TCR permite a leitura das coordenadas de pontos no espaço através da emissão de um raio laser visível para a medição da distância. Uma das principais vantagens do uso desse tipo de equipamento é a visibilidade do raio laser e a capacidade de medir a distância sem o uso de refletores. $O$ ensaio pode ser feito, nesse caso, sem a necessidade da inclusão de acessórios especiais e sem o contato com a viga. Os valores de distância e ângulos medidos foram gravados na memória interna dos equipamentos e posteriormente transformados em valores de coordenadas $\mathrm{x}, \mathrm{y} \mathrm{e} z$. Ambos os equipamentos usados possuem uma precisão linear igual a $2 \mathrm{~mm}+2 \mathrm{ppm}$ e uma precisão angular de 5 segundos de arco. Isso significa que a precisão esperada para as medições das coordenadas dos pontos medidos foi da ordem de $2 \mathrm{~mm}$ para uma distância igual a $30 \mathrm{~m}$.

A leitura destas coordenadas foi gentilmente realizada por um aluno de doutorado e pelo técnico de Agrimensura do Departamento de Transportes. As Figuras 6.11 (a) e (b) mostram a TCR 705 e sua posição com relação à leitura dos pontos na viga V2.

A Figura 6.12 ilustra a disposição na viga dos 15 pontos de leitura das coordenadas no espaço, realizados pela Estação Total. Nestes pontos, a leitura das coordenadas é feita visando o ponto com a luneta da Estação Total, e emitindo o raio laser sobre o mesmo, conforme ilustra a Figura 6.13, para a leitura das coordenadas do ponto 5. 
Para a medição das coordenadas, a Estação Total foi colocada adequadamente em frente da viga, a uma distância aproximadamente igual a $11 \mathrm{~m}$ para ambos os ensaios. Em cada seção de medição, o operador da Estação Total visava o ponto de leitura e acionava o instrumento para a medição e a gravação dos dados. Os pontos foram medidos e numerados seqüencialmente a cada seção de medição. Considerando que os resultados desejados são os deslocamentos relativos dos pontos da viga, as coordenadas dos pontos medidos foram obtidas em um sistema de coordenadas arbitrário, definido no início da medição do primeiro ponto.
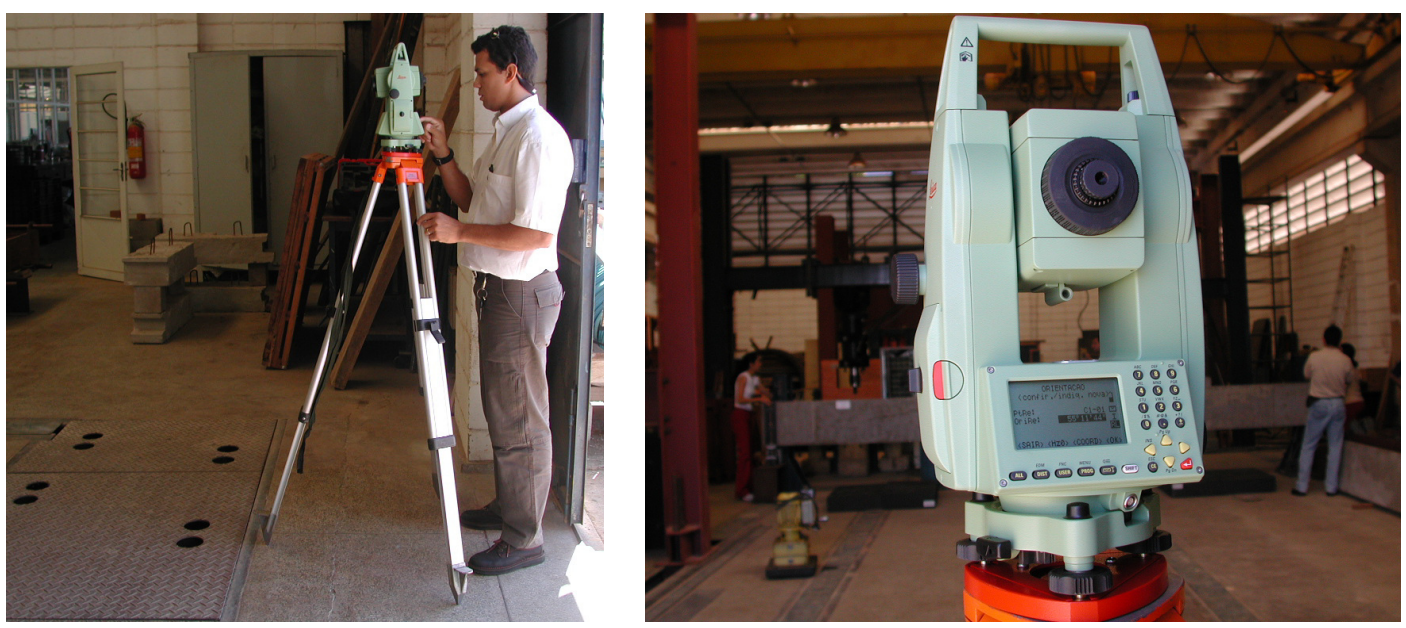

Figura 6.11 - (a) Vista da TCR 705 e (b) Vista da Estação Total e da viga V2 ao fundo.

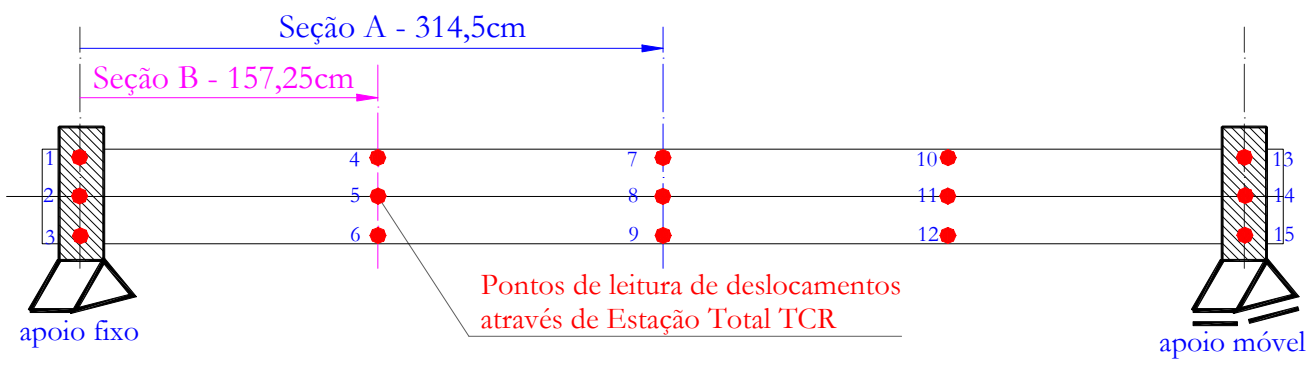

Figura 6.12 - Pontos de leitura de medida de deslocamentos no espaço.
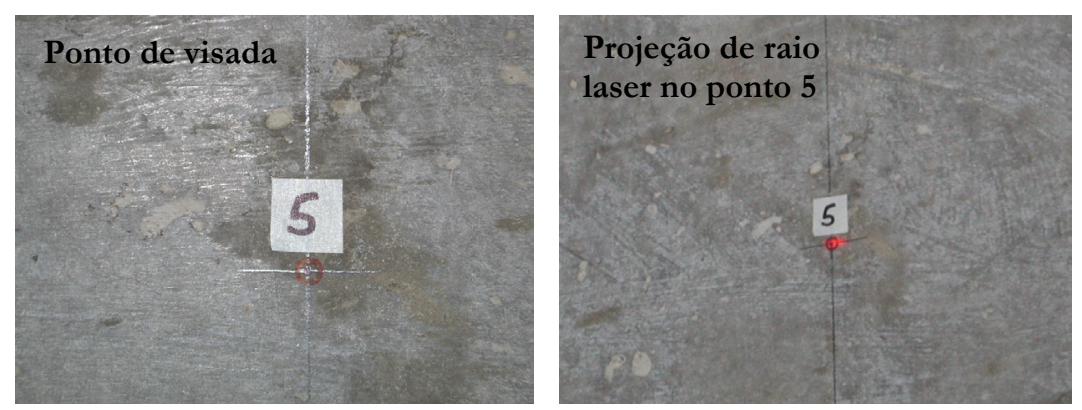

Figura 6.13 - Leitura das coordenadas (x, y, z) do ponto 5 através de raio laser - TCR 705.

\subsection{ApArelHo de Apoto EsfÉrico}

O aparelho de apoio esférico foi projetado neste trabalho a fim de impor uma rotação 
em torno do eixo da viga; mais propriamente, em torno do CG da esfera. A Figura 6.14 (a) ilustra o apoio esférico sobre um rolete, representando o apoio móvel tipo garfo, em vista frontal, enquanto a Figura 6.14(b) mostra a vista lateral do mesmo apoio. A rotação máxima atingida em torno do centro da esfera no conjunto do aparelho de apoio é de $70,56^{\circ}$, em função das dimensões geométricas projetadas para o mesmo.
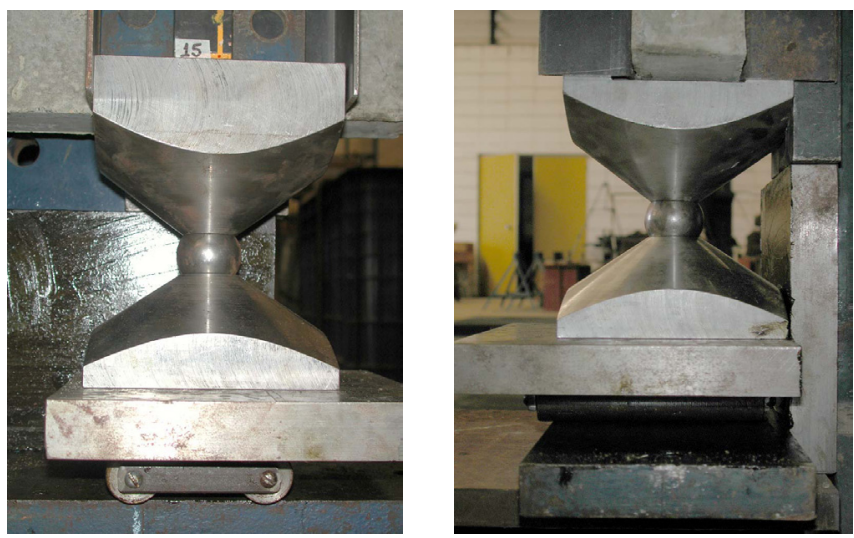

Figura 6.14 - (a) Vista frontal do apoio esférico sobre roletes e (b) Vista Lateral.

Cada aparelho consiste de duas peças sólidas, a inferior, onde se apoia a esfera metálica de $35 \mathrm{~mm}$ de diâmetro, e a superior, que se apoia sobre a esfera. Esta última possui dois dentes para encaixe dos perfis metálicos que encontram-se parafusados à viga, a fim de simular um apoio tipo garfo. Os perfis metálicos tipo U encontram-se parafusados em dois pontos médios na altura da viga.

A Figura 6.15 mostra o conjunto apoio esférico e perfis metálicos presos à viga formando o apoio tipo garfo. As características geométricas do apoio esférico projetado neste trabalho encontram-se ilustradas na Figura 6.16.
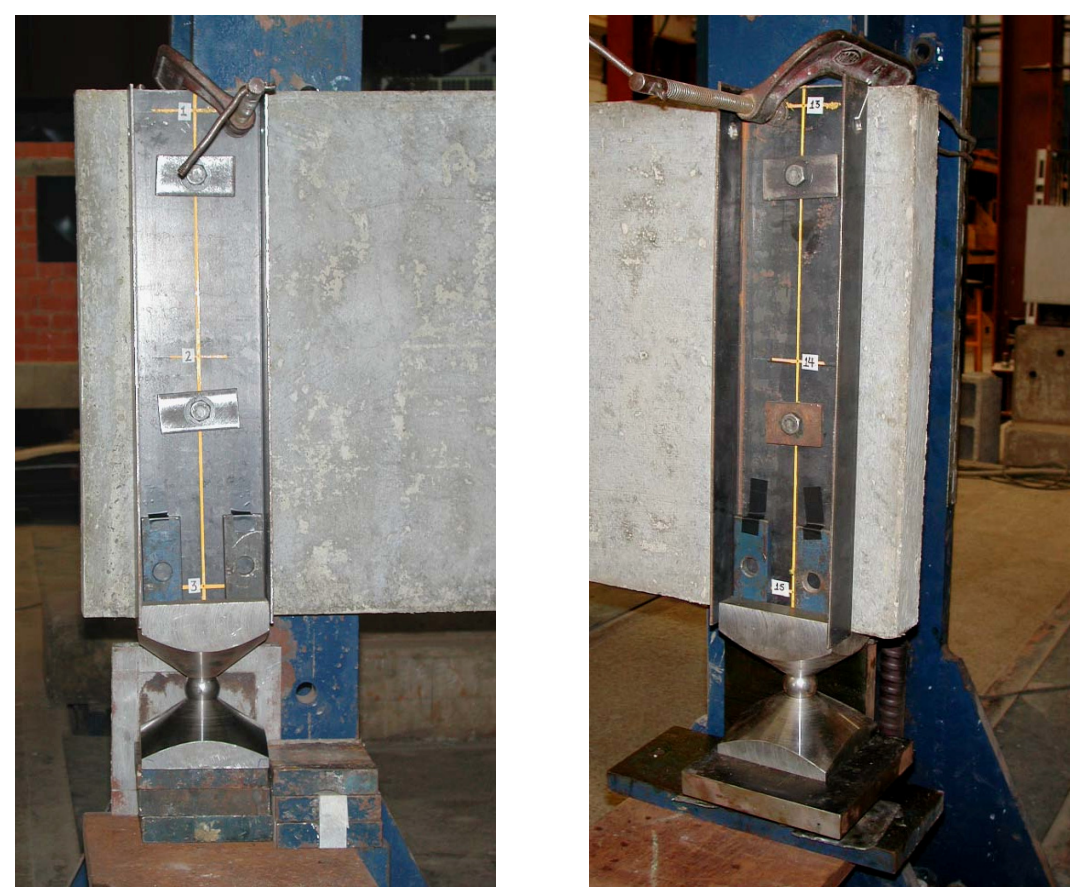

Figura 6.15 - Conjunto de apoio esférico e chapas metálicas: Apoio tipo garfo (a) fixo e (b) móvel. 

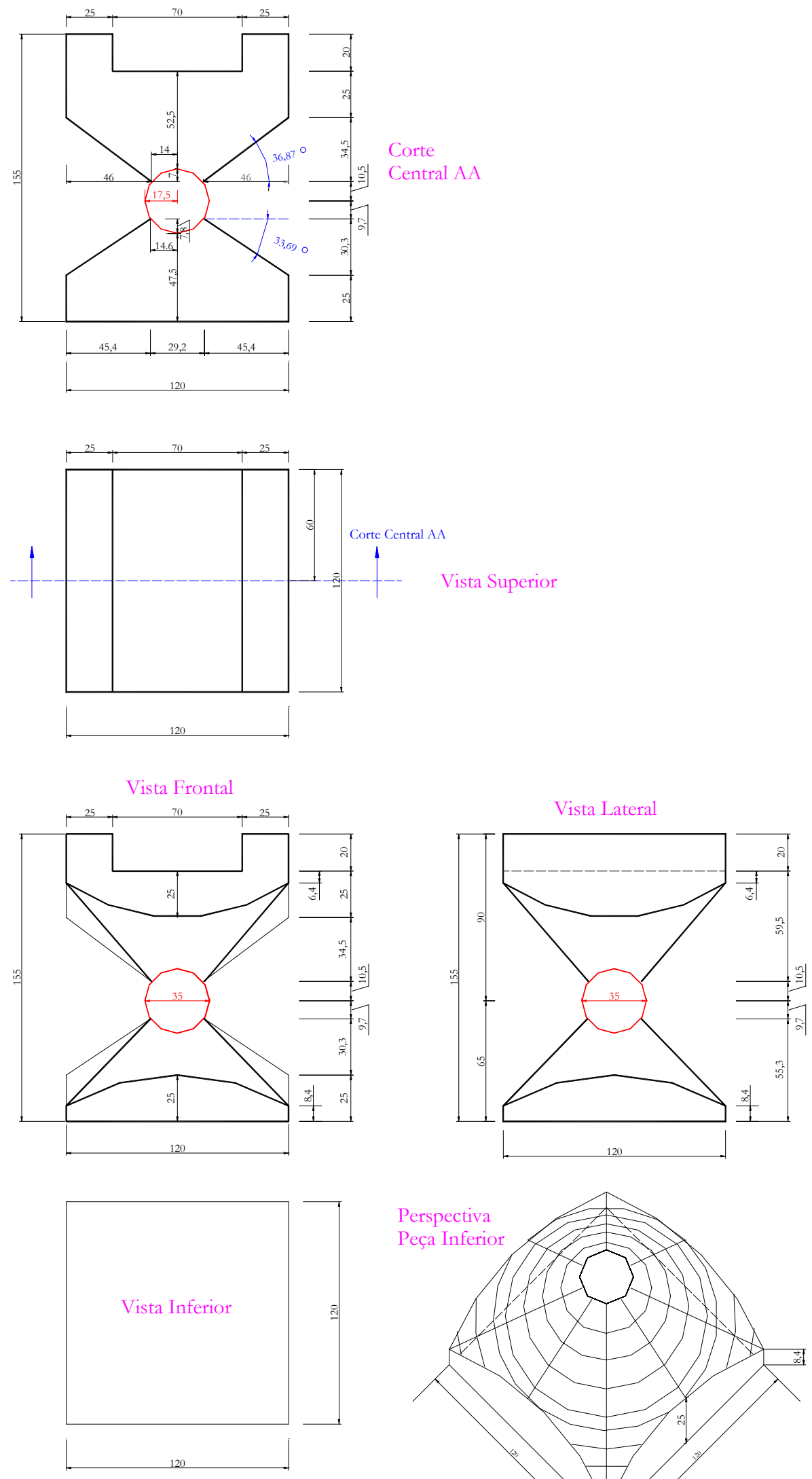

Unidade [mm]

Figura 6.16 - Geometria do aparelho de apoio esférico projetado neste trabalho. 


\section{6 PROCEDimentos do Ensaio}

As vigas foram retiradas da fôrma um dia antes do ensaio, retirando-se a borda lateral da fôrma de madeira, ao longo do comprimento, ainda na posição horizontal. Retirada esta face, a viga foi levantada juntamente com o restante da fôrma até a posição vertical, ainda no chão. Após posicionada na vertical, retirou-se o restante da fôrma, calçando-se a viga lateralmente. Os perfis metálicos foram então parafusados na viga, com parafusos passando através dos furos na viga, obtidos pela fixação de roletes de madeira na fôrma, conforme mostra a Figura 6.17.
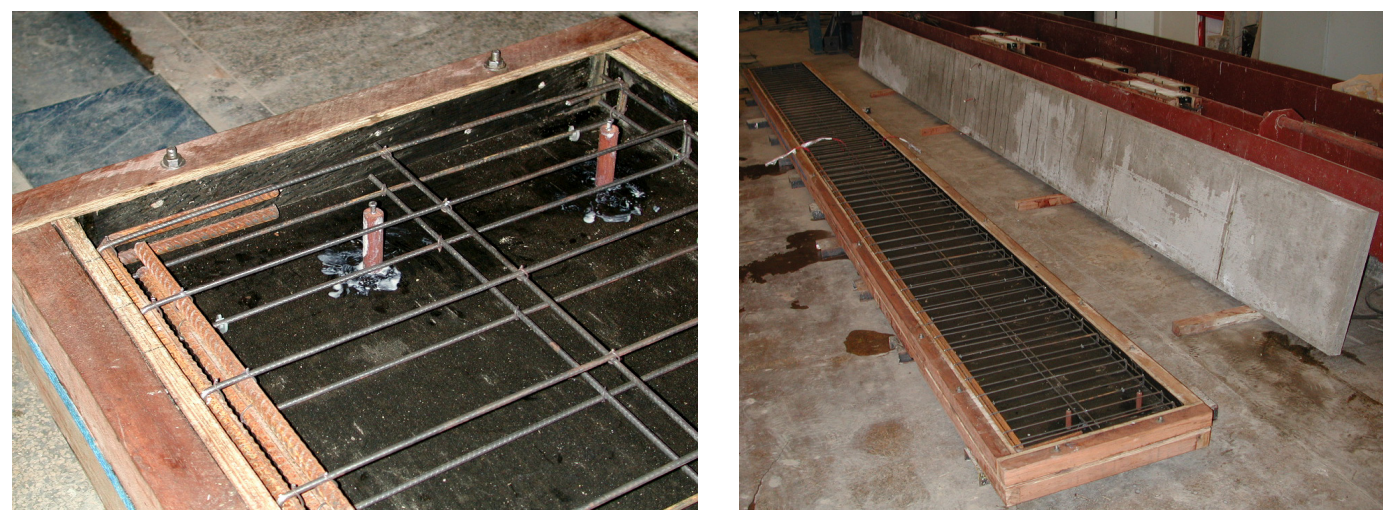

Figura 6.17 - Roletes de madeira posicionados na fôrma antes da concretagem.

Uma vez na posição vertical, ainda sobre calços no chão e travada lateralmente, foram colocadas 3 cintas de içamento presas a um balancim metálico, as quais foram ajustadas com calços a fim de garantir o esticamento de cada uma delas, o que proporcionaria uma distribuição uniforme de esforços. A Figura 6.18 ilustra a disposição de içamento para posterior posicionamento sobre os apoios tipo garfo.

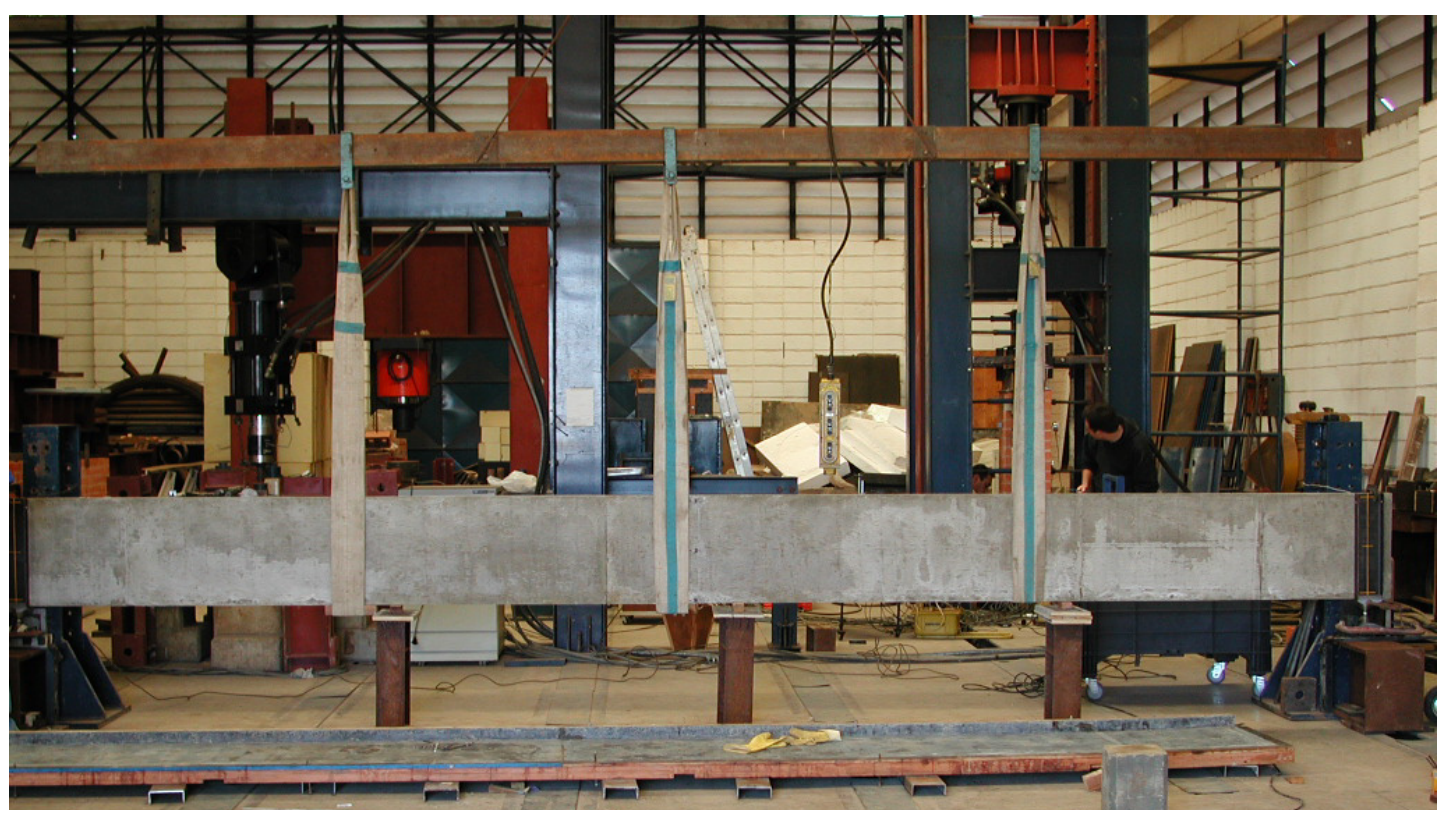

Figura 6.18 - Cintas de içamento igualmente esticadas, presas à viga e ao balacim metálico. 
Após o içamento, os perfis metálicos previamente parafusados na viga foram encaixados na peça superior do apoio, entre os dentes, posicionando enfim, a viga sobre os conjuntos de apoio. O vazio restante entre o dente do aparelho e o perfil metálico foi preenchido por pequenas placas metálicas, a fim de garantir que os perfis não escapassem do apoio.

O equipamento de ensaio montado no galpão do Laboratório de Estruturas consiste na aplicação de uma inclinação gradual à viga retangular esbelta, por meio de um sistema composto por um cabo de aço preso à ponte rolante e por outro cabo que liga as duas extremidades da viga. Dois perfis metálicos foram fixados na canaleta metálica do piso do laboratório e dispostos junto aos apoios a fim de mudar a direção do cabo de aço ligado à extremidade da viga, o que pode ser observado na vista superior mostrada na Figura 6.19.

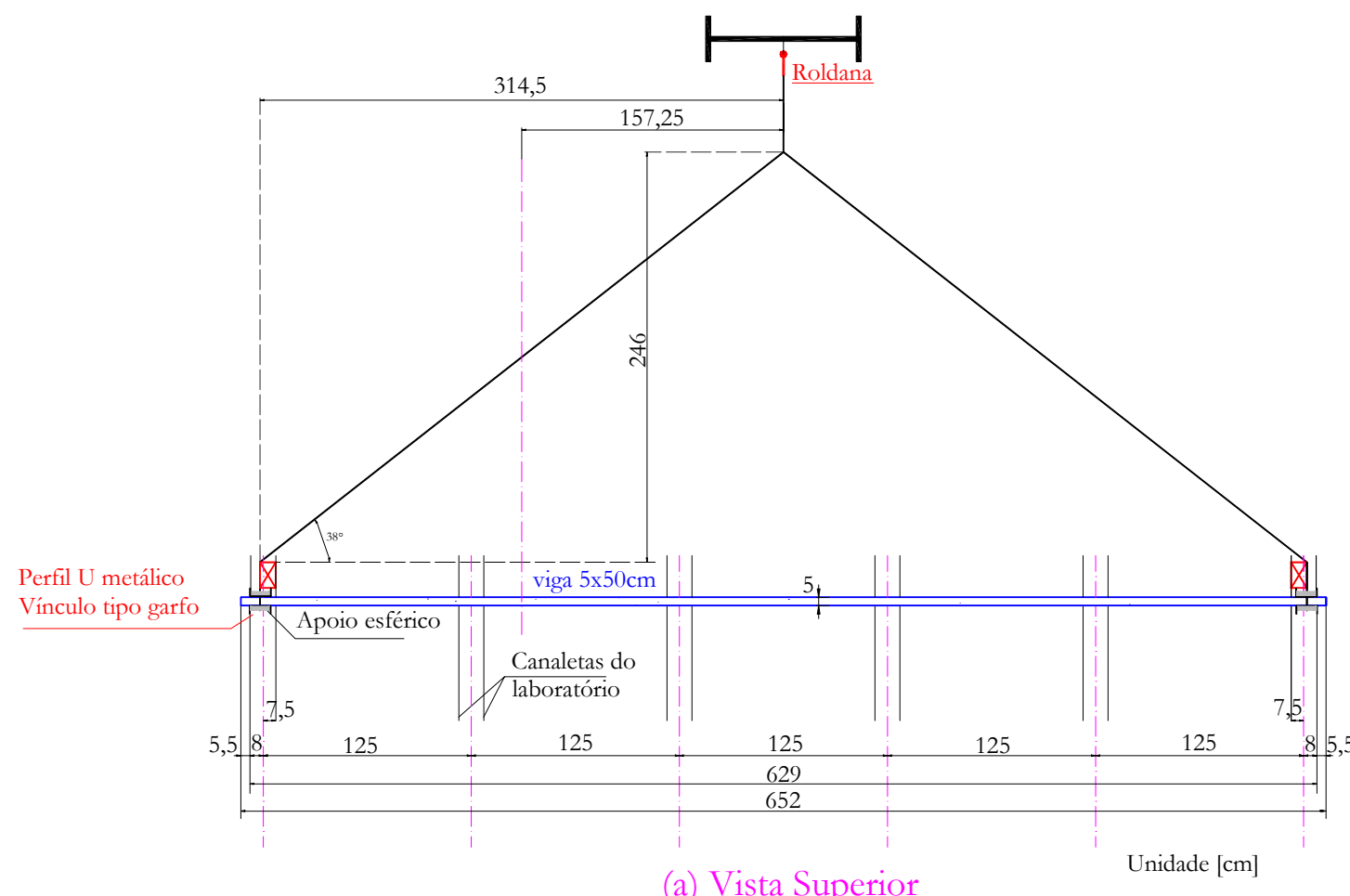

(a) Vista Superior

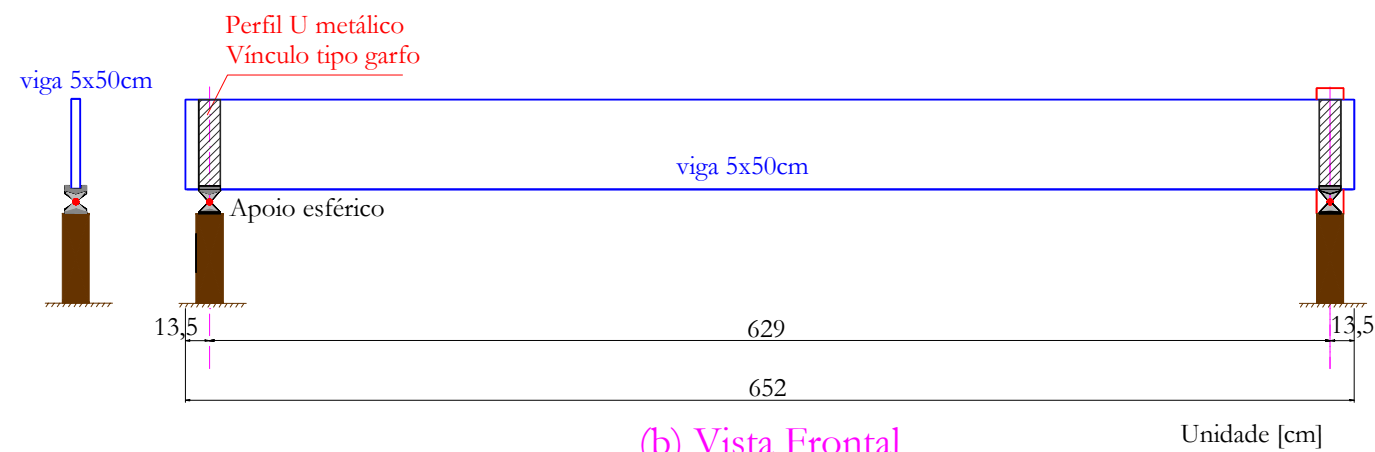

Figura 6.19 - Equipamento para aplicação da inclinação nos apoios por um único ponto.

A Figura 6.20 ilustra uma vista da seção transversal no apoio, durante o processo de liberação de giro por meio do deslocamento vertical para baixo do gancho preso à ponte rolante. Esta liberação resulta na imposição de giro nos conjuntos de apoio. 


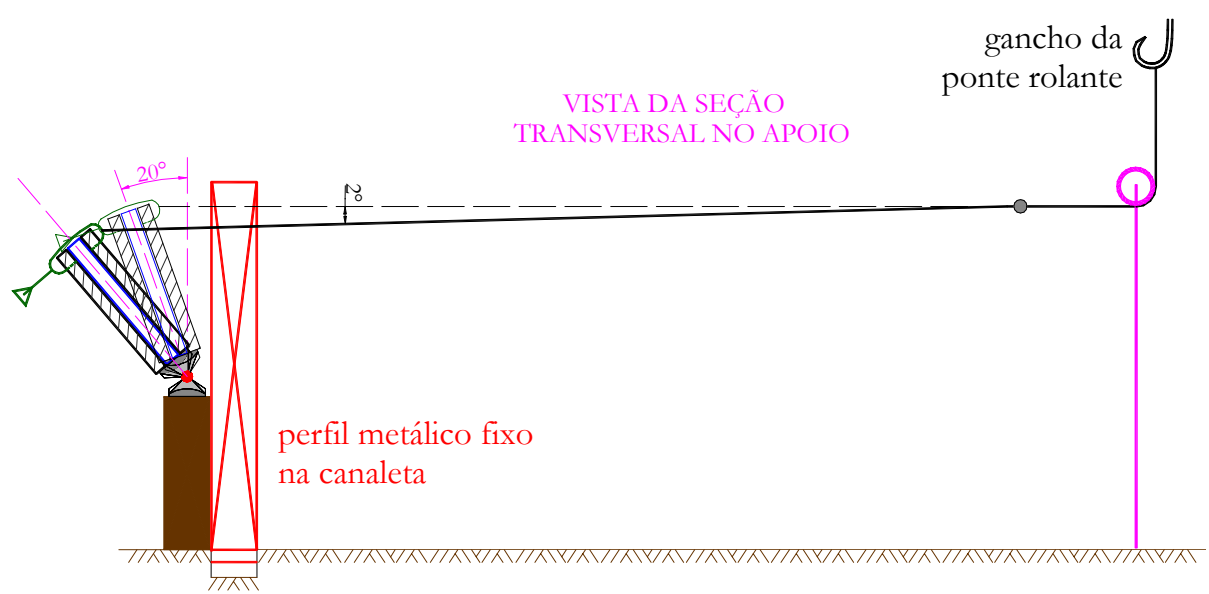

Figura 6.20 - Vista da seção transversal no apoio durante o ensaio.

Nos apoios, a direção do cabo é desviada através dos perfis metálicos engastados nas canaletas do laboratório. Tem-se, portanto, uma extremidade do cabo ligado à ponte rolante, conforme ilustra a Figura 6.21(a), e a outra extremidade presa ao cabo que está fixo nos apoios da viga.

Desta forma, liberando-se deslocamentos verticais do cabo reto preso ao gancho da ponte rolante, libera-se deslocamentos laterais nas seções dos apoios da viga, conforme mostra a Figura 6.21(b). Nesta figura, pode-se observar ainda que a região de contato entre o cabo e o perfil preso à canaleta foi engraxada a fim de diminuir o atrito durante o processo de ensaio.
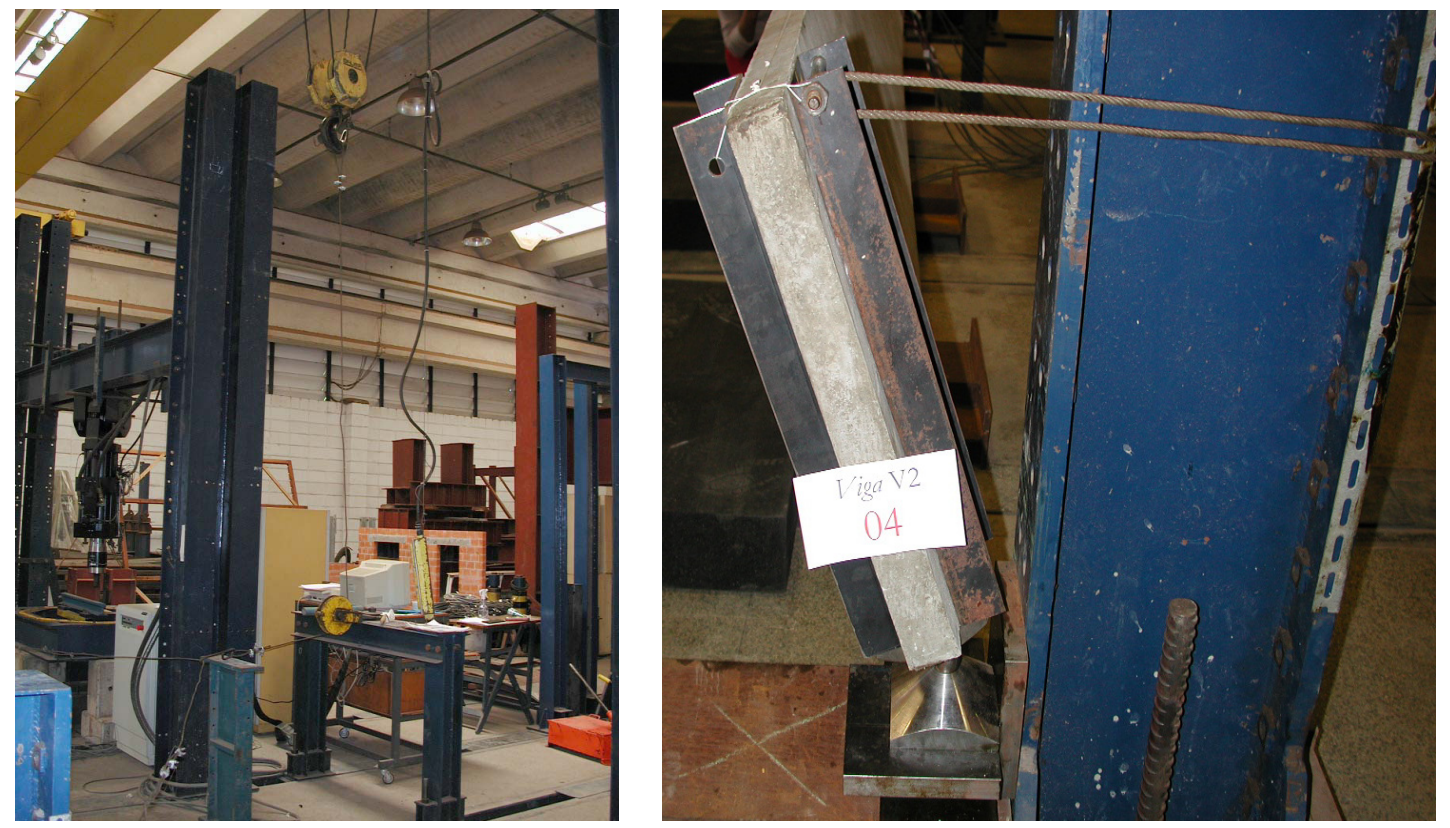

Figura 6.21 -Detalhe (a) da ponte rolante e (b) da fixação do cabo no perfil metálico.

O ensaio foi programado para etapas de giro imposto de $5 \mathrm{em} 5$ graus nos dois apoios. A fim de acompanhar o ângulo imposto foram realizadas medidas de deslocamentos laterais na face superior da viga para definir as etapas de leitura de deslocamentos e das deformações. A Figura 6.22 mostra uma fase de leitura destes deslocamentos. 


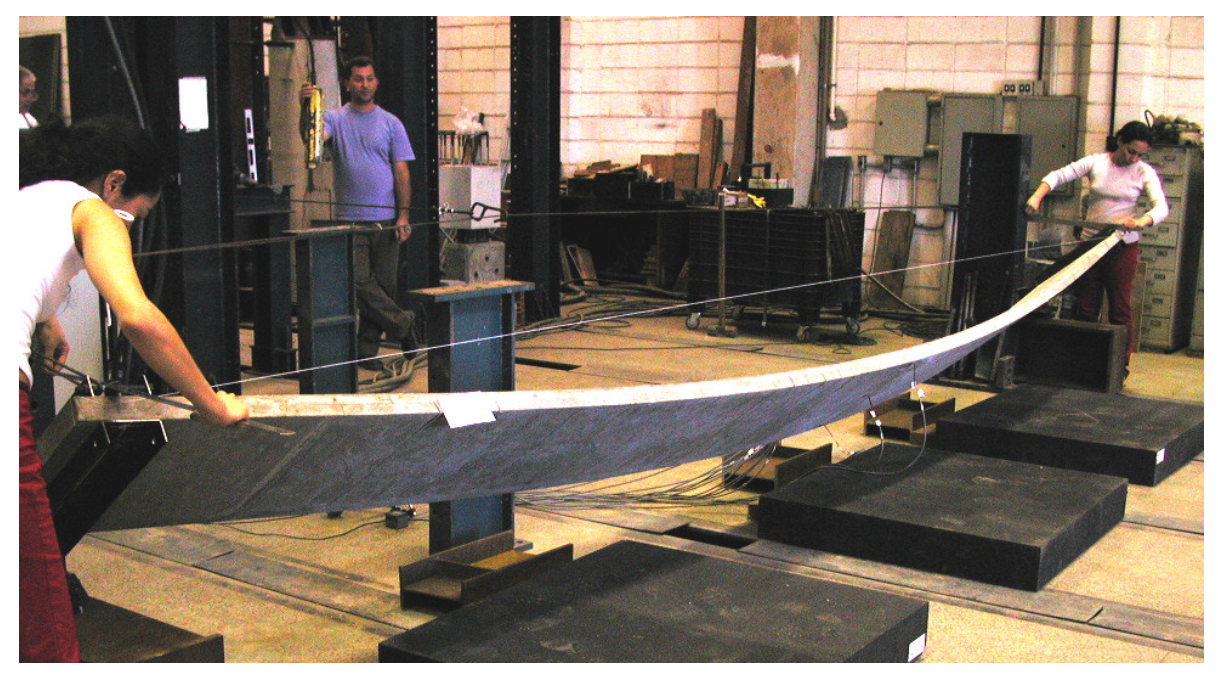

Figura 6.22 - Acompanhamento do ângulo imposto pelas medidas de deslocamentos nos apoios.

\subsubsection{Ilustração de Algumas Etapas de Giro Imposto}

Serão apresentadas a seguir algumas fotos ilustrativas das etapas de giro imposto. A Figura 6.23 (a) e (b) mostra os dois conjuntos de apoio durante a etapa 4 correspondente ao ângulo imposto de $19,80^{\circ}$.

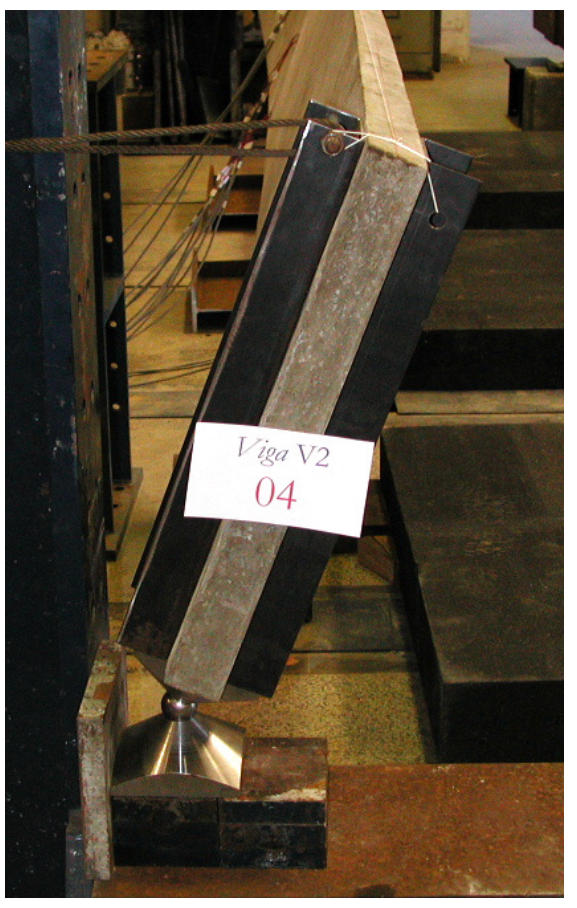

(a) Apoio fixo

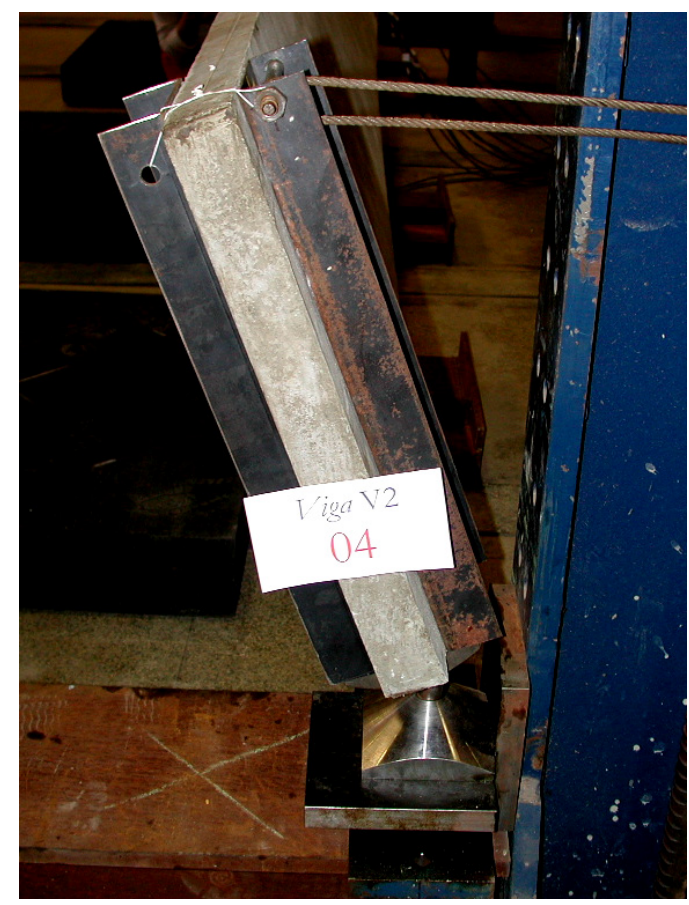

(b) Apoio móvel

Figura 6.23 - Etapa 4 de giro imposto.

Conforme descrito anteriormente, um dos conjuntos de apoio esférico encontra-se apoiado sobre roletes metálicos, a fim de simular um apoio tipo garfo móvel, no qual pode-se impor uma rotação. A Figura 6.24 (a), (b), (c), (d), (e) e (f) mostra algumas etapas do ensaio, onde pode-se visualizar o deslocamento longitudinal do apoio móvel, 
correspondentes às inclinações impostas de $10,35^{\circ}, 24,43^{\circ}, 29,42^{\circ}, 34,01^{\circ}, 39,13^{\circ}$ e $48,86^{\circ}$, respectivamente.

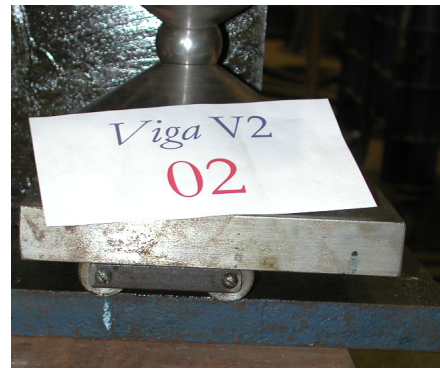

(a) $10,35^{\circ}$

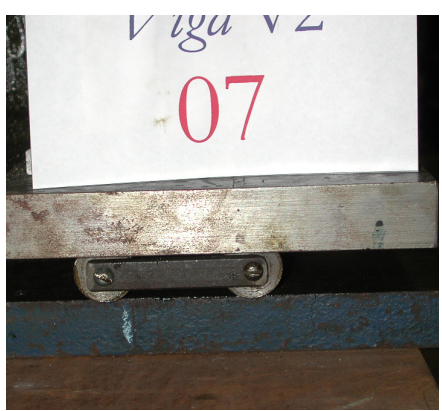

(d) $34,01^{\circ}$

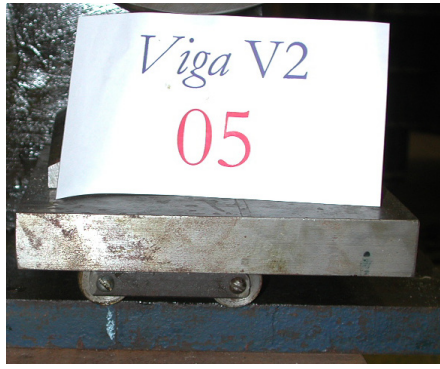

(b) $24,43^{\circ}$

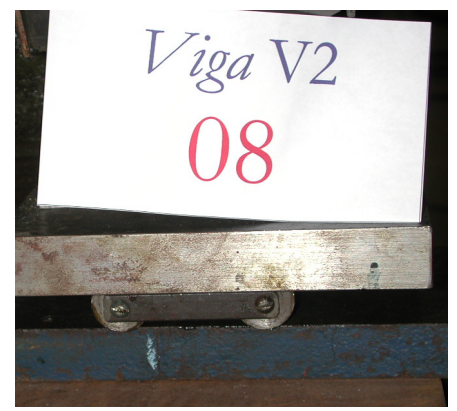

(e) $39,13^{\circ}$

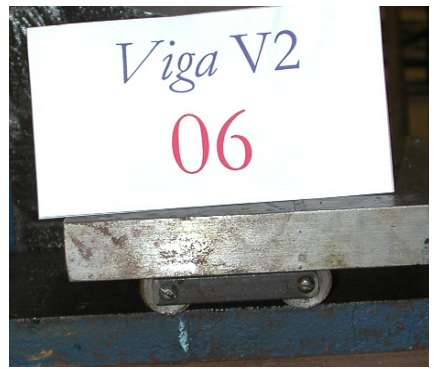

(c) $29,42^{\circ}$

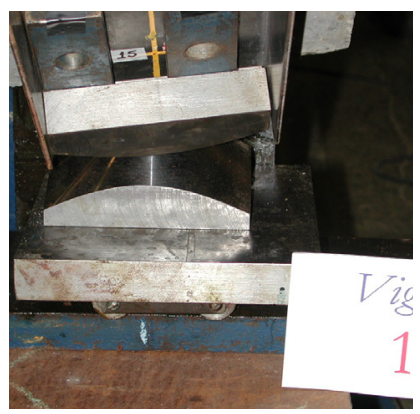

(f) $48,86^{\circ}$

Figura 6.24 - Deslocamento horizontal do apoio móvel - etapas (a) 2, (b) 5, (c) 6, (d) 7, (e) 8 e (f) 10.

O comportamento do apoio esférico com relação aos giros impostos nos apoios pode ser observado na Figura 6.25 (a), (b) e (c), referentes às etapas 7, 9 e 11 do ensaio, respectivamente.

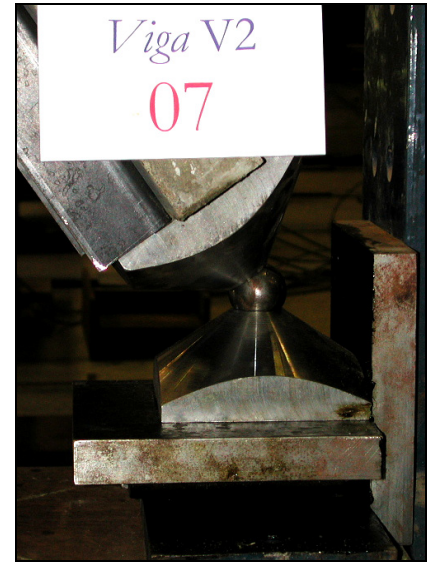

(a) $\theta_{\text {imp }}=34,01^{\circ}$

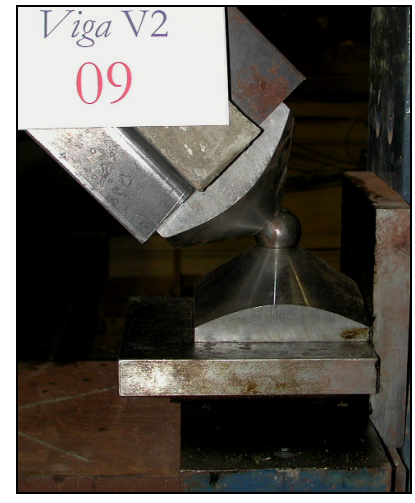

(b) $\theta_{\text {imp }}=44,41^{\circ}$

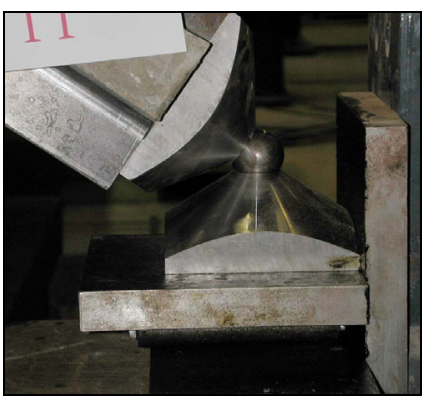

(c) $\theta_{\text {imp }}=53,77^{\circ}$

Figura 6.25 - Vista lateral do apoio móvel nas etapas (a) 7, (b) 9 e (c) 11.

As fissuras de flexão ao longo da altura da viga começaram a ser visíveis a partir da quarta etapa de ensaio, quando a inclinação imposta era de 19,80 . As Figuras 6.26 e 6.27 mostram algumas destas fissuras, próximas à seção central da viga. 


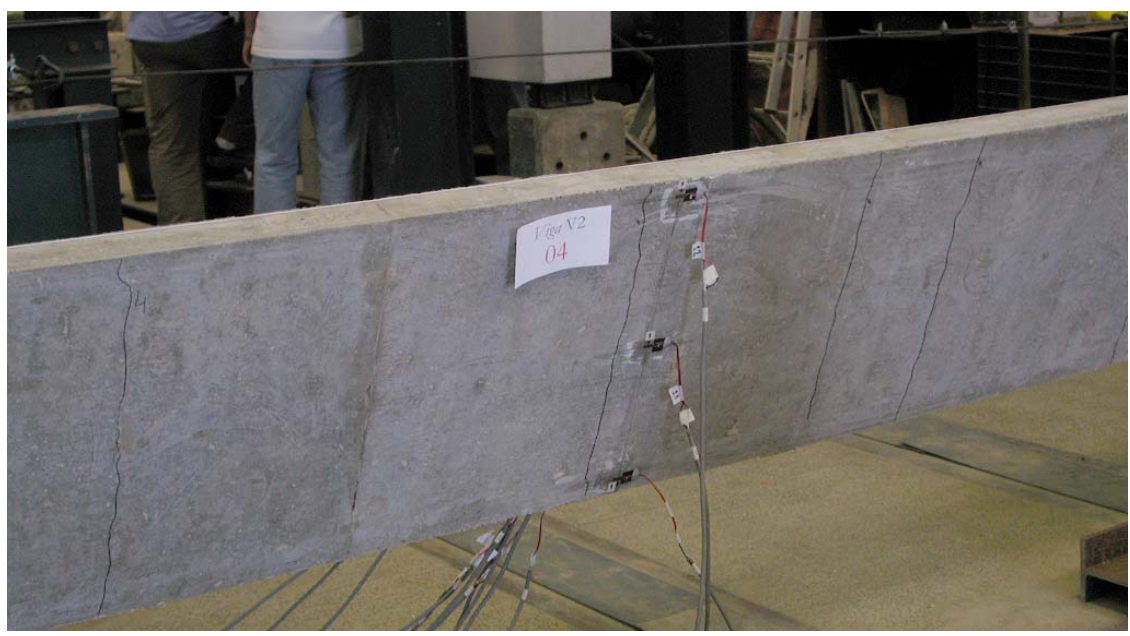

Figura 6.26 - Início do quadro de fissuração na etapa 4.

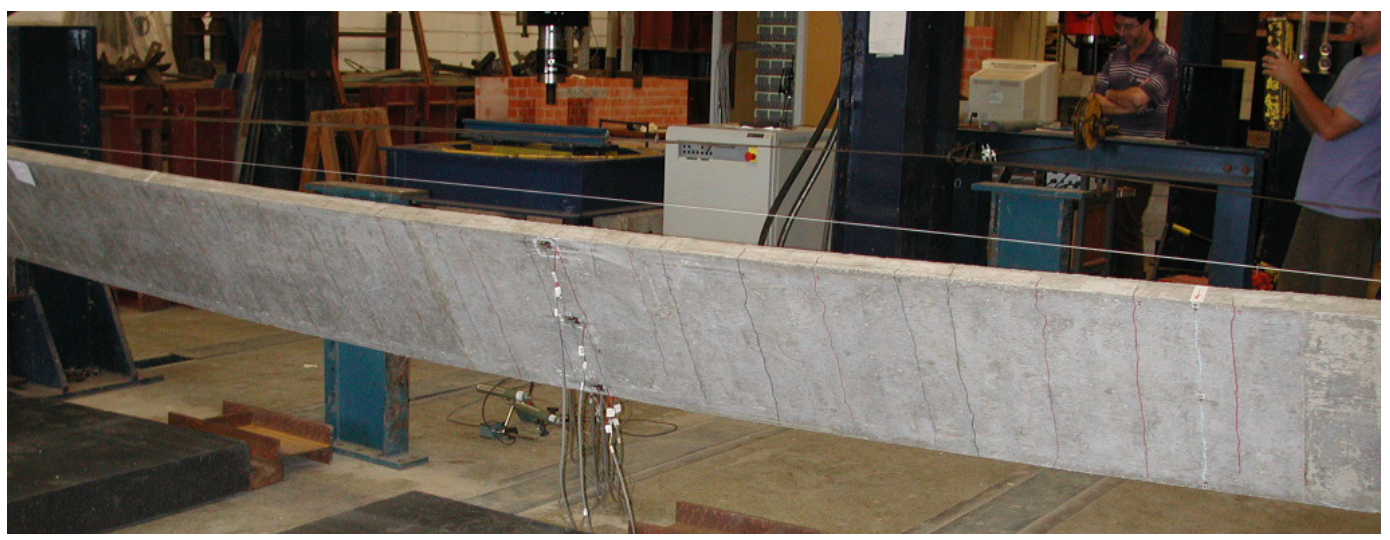

Figura 6.27 - Etapa 6 equivalente à inclinação imposta de 29,42॰.

As Figuras 6.28, 6.29 e 6.30 mostram ilustrações das etapas 10, 11 e 13 do ensaio, correspondendo respectivamente à $48,86^{\circ}, 53,77^{\circ}$ e $63,5^{\circ}$ de inclinação imposta nos apoios.

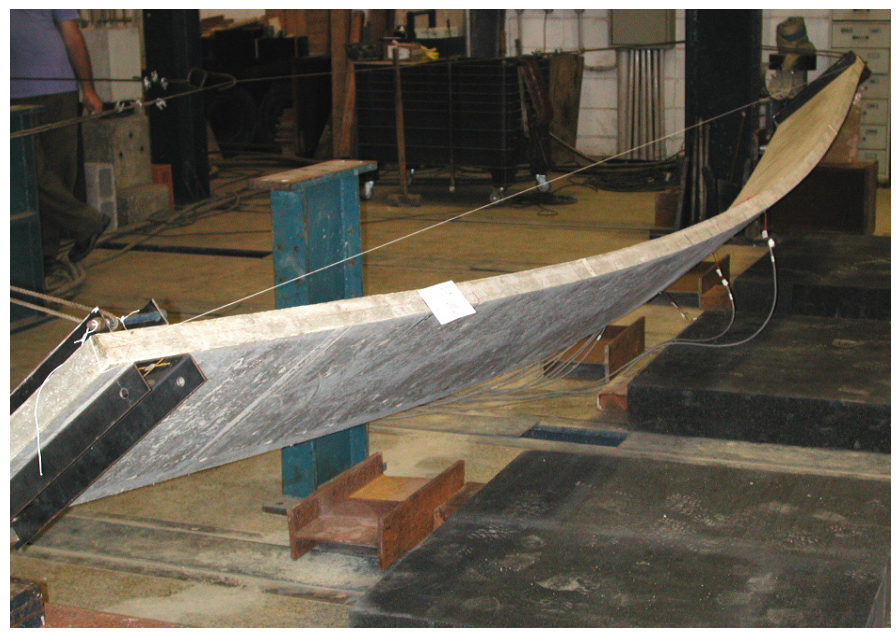

Figura 6.28 - Etapa 10 equivalente à inclinação imposta de 48,86. 


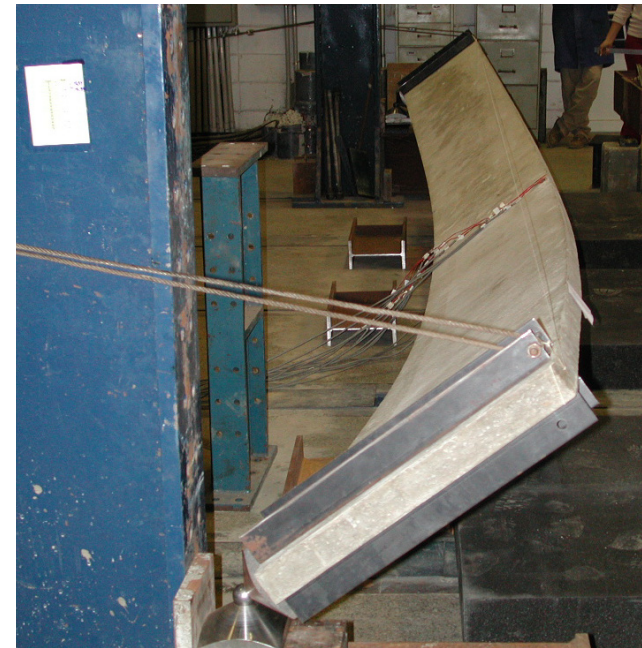

Figura 6.29 - Etapa 11: inclinação de 53,77.

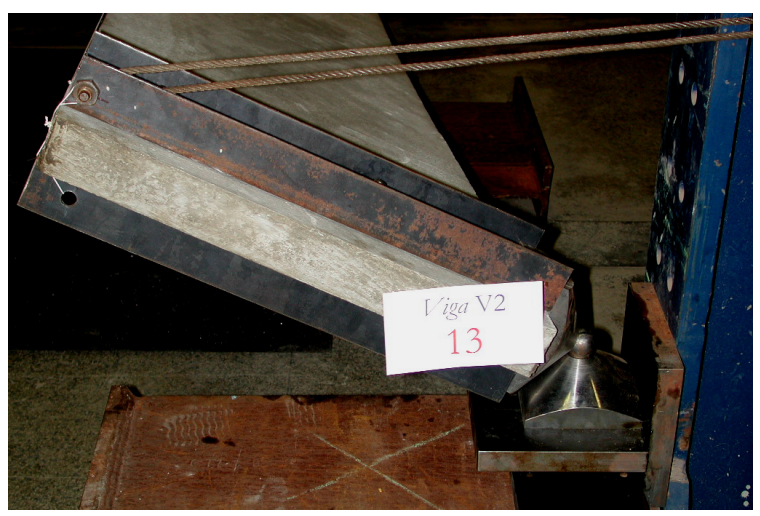

Figura 6.30 - Etapa 13: inclinação imposta de 63,5․

A última etapa de ensaio ocorreu com giro imposto de $63,5^{\circ}$, como encontra-se ilustrado nas Figuras 6.31 (a) e (b), apresentando estado crítico de fissuração por flexão bilateral, porém, naturalmente crítica devido à flexão lateral.

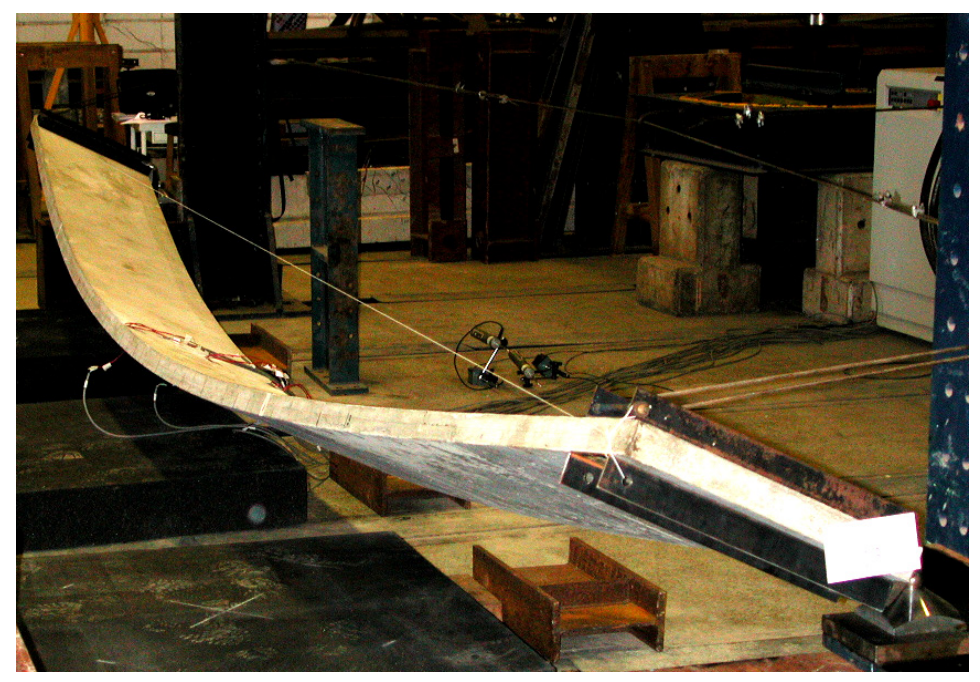

(a)

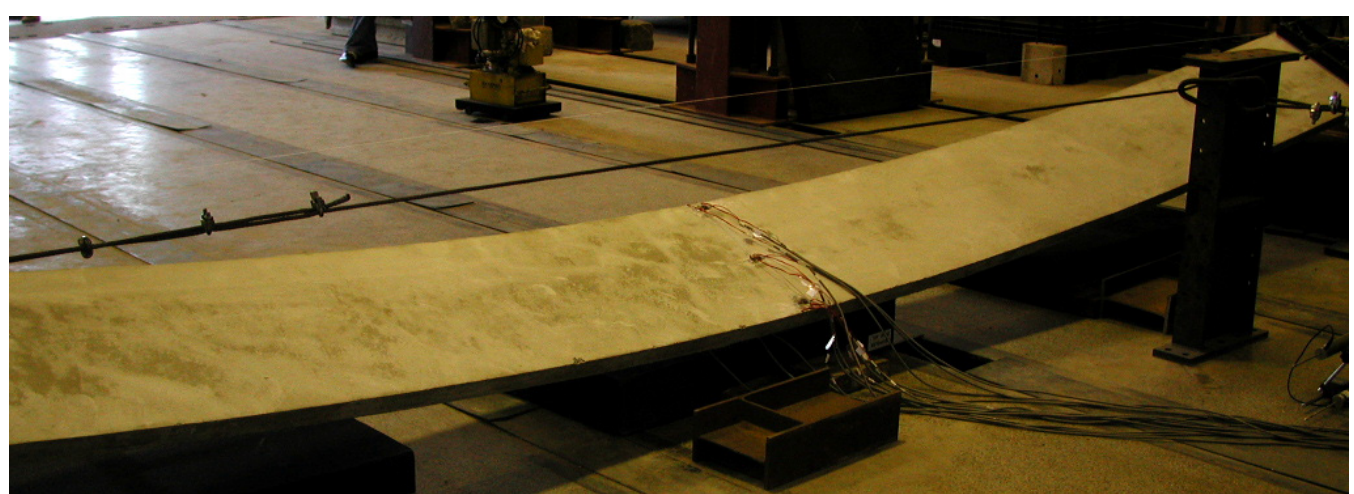

(b)

Figura 6.31 - Vista da viga V2 na última etapa do ensaio com 63,50 de inclinação imposta. 


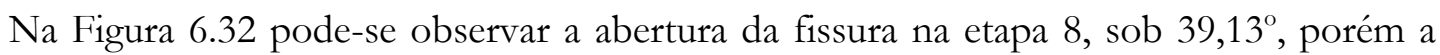
mesma iniciou-se na etapa 5 , sob $24,43^{\circ}$. Vale lembrar que o início da fissuração ocorreu na etapa 4 de giro imposto, para $19,80^{\circ}$ de inclinação.

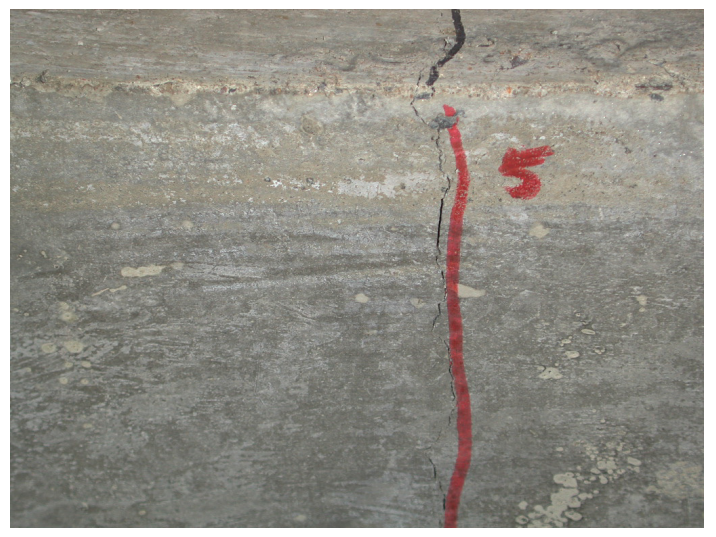

Figura 6.32 - Abertura da fissura iniciada na etapa 5 - Etapa real da foto: Etapa 8.

As Figuras 6.33 e 6.34 mostram o quadro de fissuração ao longo do comprimento das vigas V1 e V2, respectivamente. O espaçamento médio entre fissuras para ambas as vigas ensaiadas foi em torno de $13 \mathrm{~cm}$.

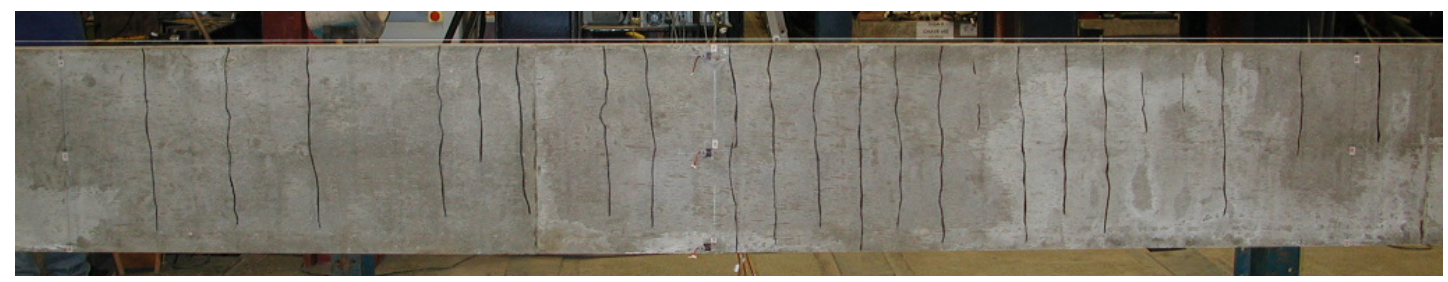

Figura 6.33 - Quadro de fissuração final da viga V1.

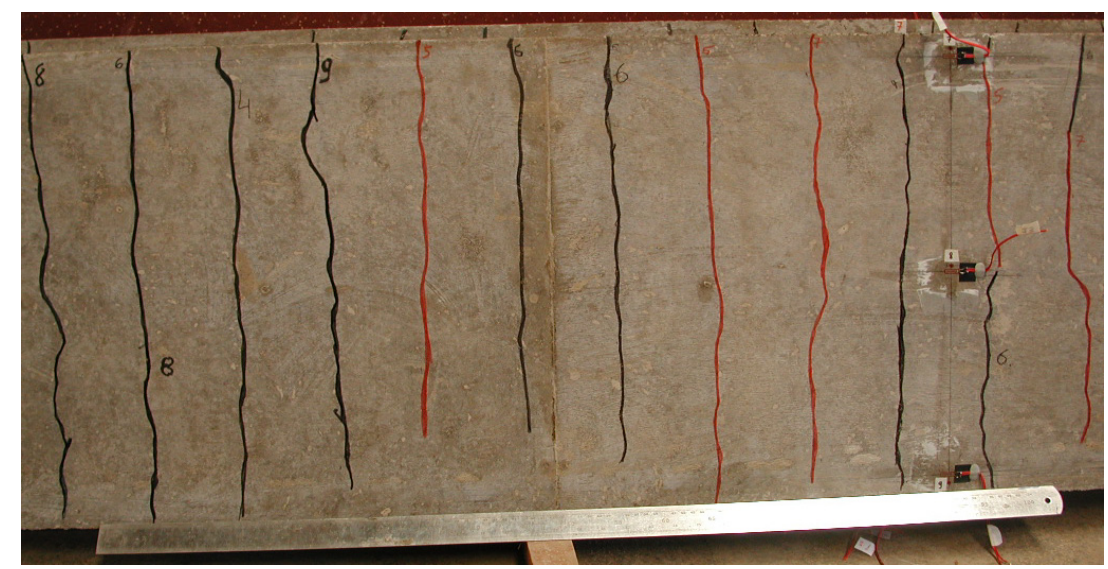

Figura 6.34 - Quadro de fissuração final da viga V2.

Após o ensaio, ambas as vigas apresentaram curvatura lateral residual, conforme ilustra a Figura 6.35. A viga V1 apresentou flecha lateral no meio do vão aproximadamente igual a 4,2 cm, enquanto a da viga V2 foi de $3,4 \mathrm{~cm}$. Observou-se, antes do ensaio, que as vigas não eram perfeitamente retas, apresentando uma imperfeição inicial com flecha lateral igual a $1,4 \mathrm{~cm}$ para a viga $\mathrm{V} 1 \mathrm{e} 0,9 \mathrm{~cm}$ para a viga $\mathrm{V} 2$. 


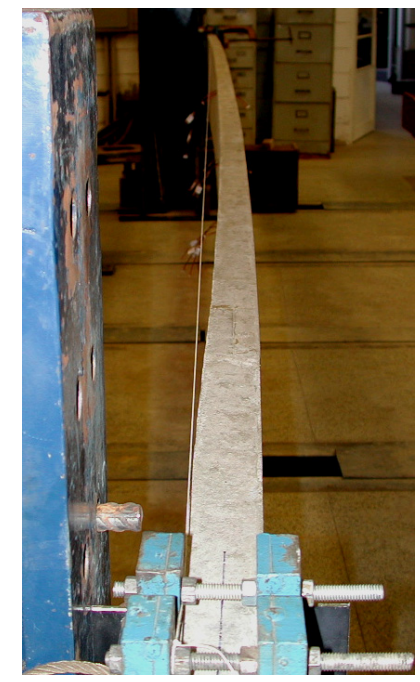

Figura 6.35 - Deformação residual final da viga V1.

\subsection{RESPOSTAS EXPERIMENTAIS}

Serão apresentadas neste item as leituras obtidas do sistema de aquisição de dados referente à instrumentação dos extensômetros elétricos colados no concreto e nas armaduras longitudinais, bem como as leituras feitas com as Estações Totais descrevendo o movimento de translação no espaço dos 15 pontos definidos para as medições.

\subsubsection{EXTENSÔMETROS NO CONCRETO}

Encontram-se representadas nos gráficos das figuras 6.36 e 6.37 as respostas experimentais gravadas pelo sistema de aquisição de dados referente à instrumentação do concreto nos pontos citados e ilustrados no item 6.4.1 para as vigas V1 e V2.

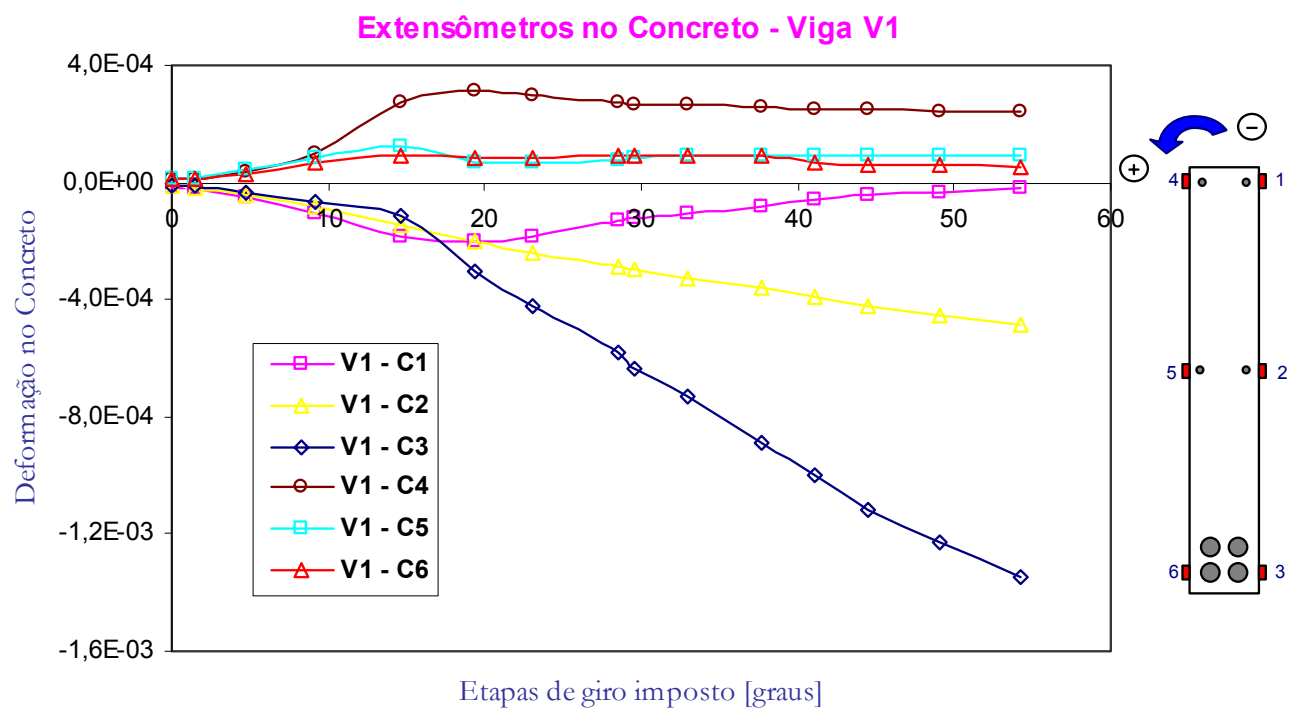

Figura 6.36 - Extensômetros no concreto da viga V1. 


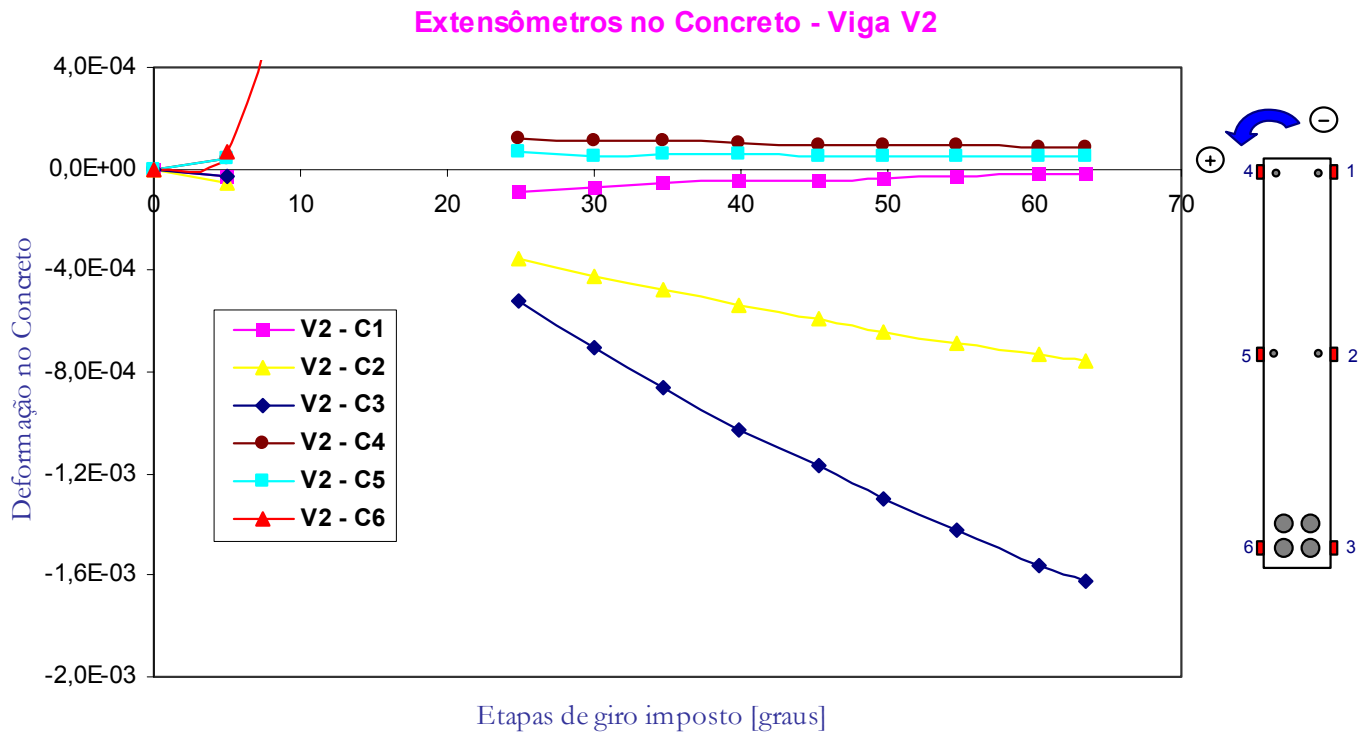

Figura 6.37 - Extensômetros no concreto da viga V2.

Devido à falha na gravação das etapas de giro imposto no ensaio da viga V2, não existem leituras das deformações nos 6 pontos instrumentados, para os passos 2, 3 e 4 de giro imposto, do total de 13 etapas.

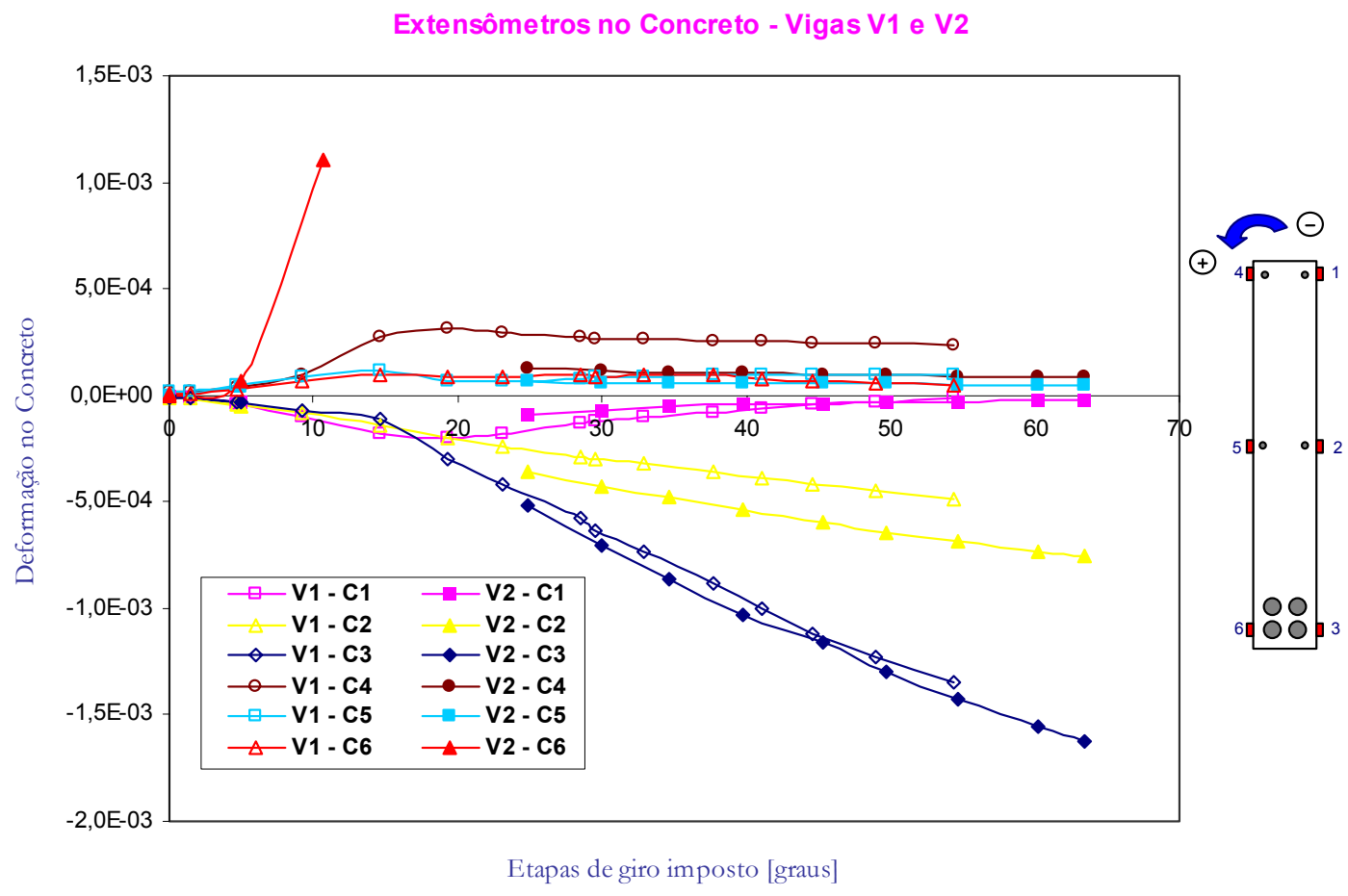

Figura 6.38 - Comparação entre as respostas experimentais no concreto para as vigas V1 e V2.

A Figura 6.38 mostra a comparação entre as respostas experimentais medidas da deformação no concreto para a viga V1 e a viga V2.

\subsubsection{Extensômetros nas ARmaduras}

As Figuras 6.39 e 6.40 ilustram as medidas de deformação obtidas nas armaduras 
longitudinais das vigas V1 e V2, respectivamente.

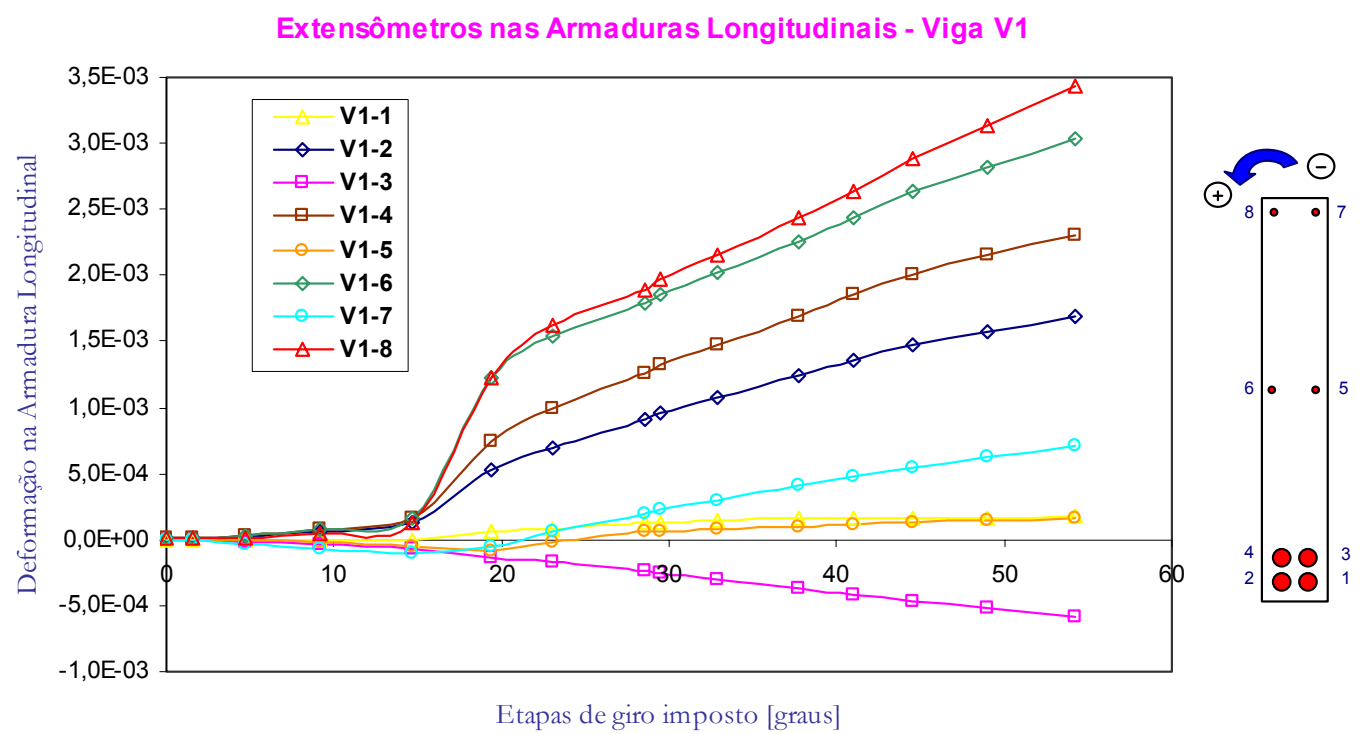

Figura 6.39 - Extensômetros nas armaduras longitudinais da viga V1.

Conforme informado anteriormente, não foram gravados no sistema de aquisição de dados as deformações nas armaduras nos passos de giro imposto 2, 3 e 4 no ensaio da viga V2, o que pode ser observado na Figura 6.40.

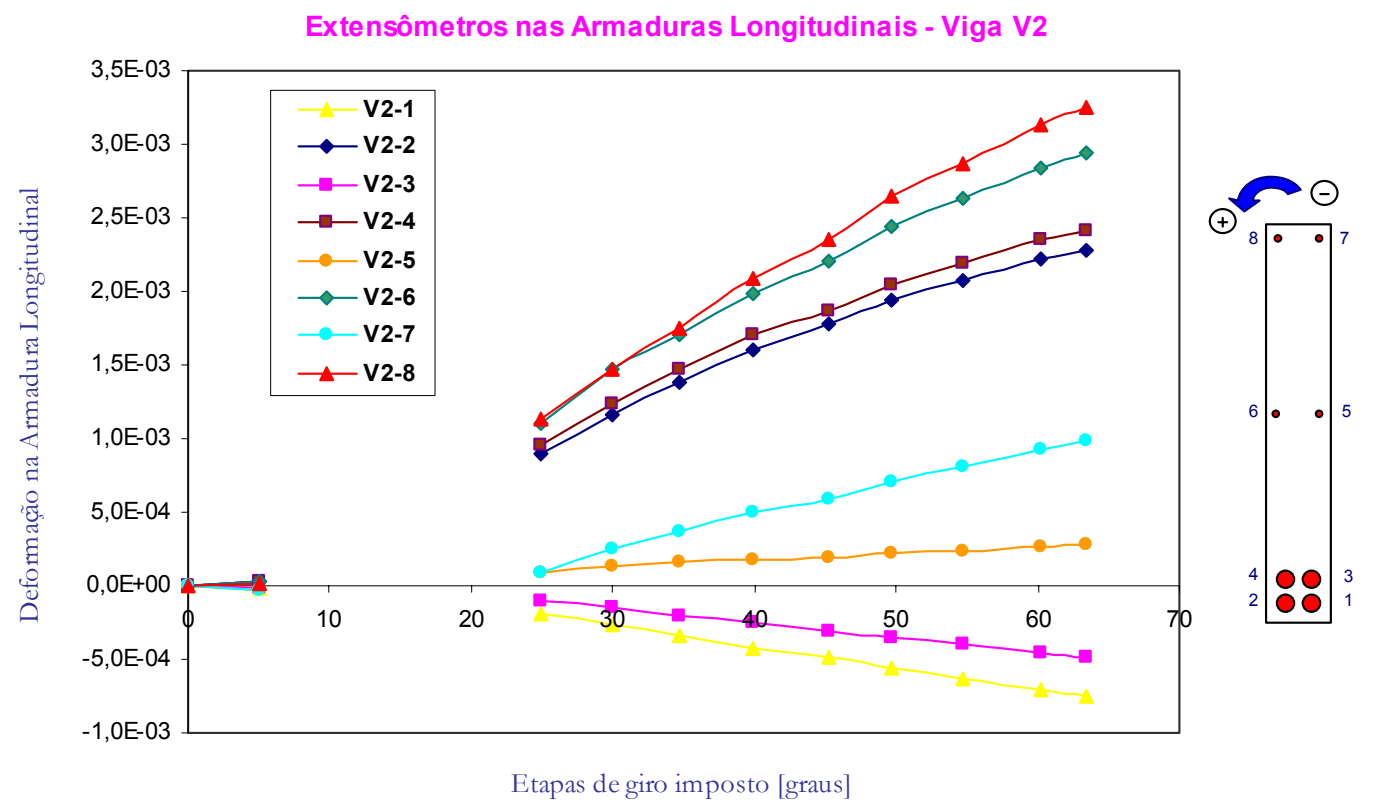

Figura 6.40 - Extensômetros nas armaduras longitudinais da viga V2.

A Figura 6.41 mostra uma comparação entre as medidas de deformação obtidas nos ensaios das duas vigas V1 e V2, para cada uma das oito armaduras longitudinais. 


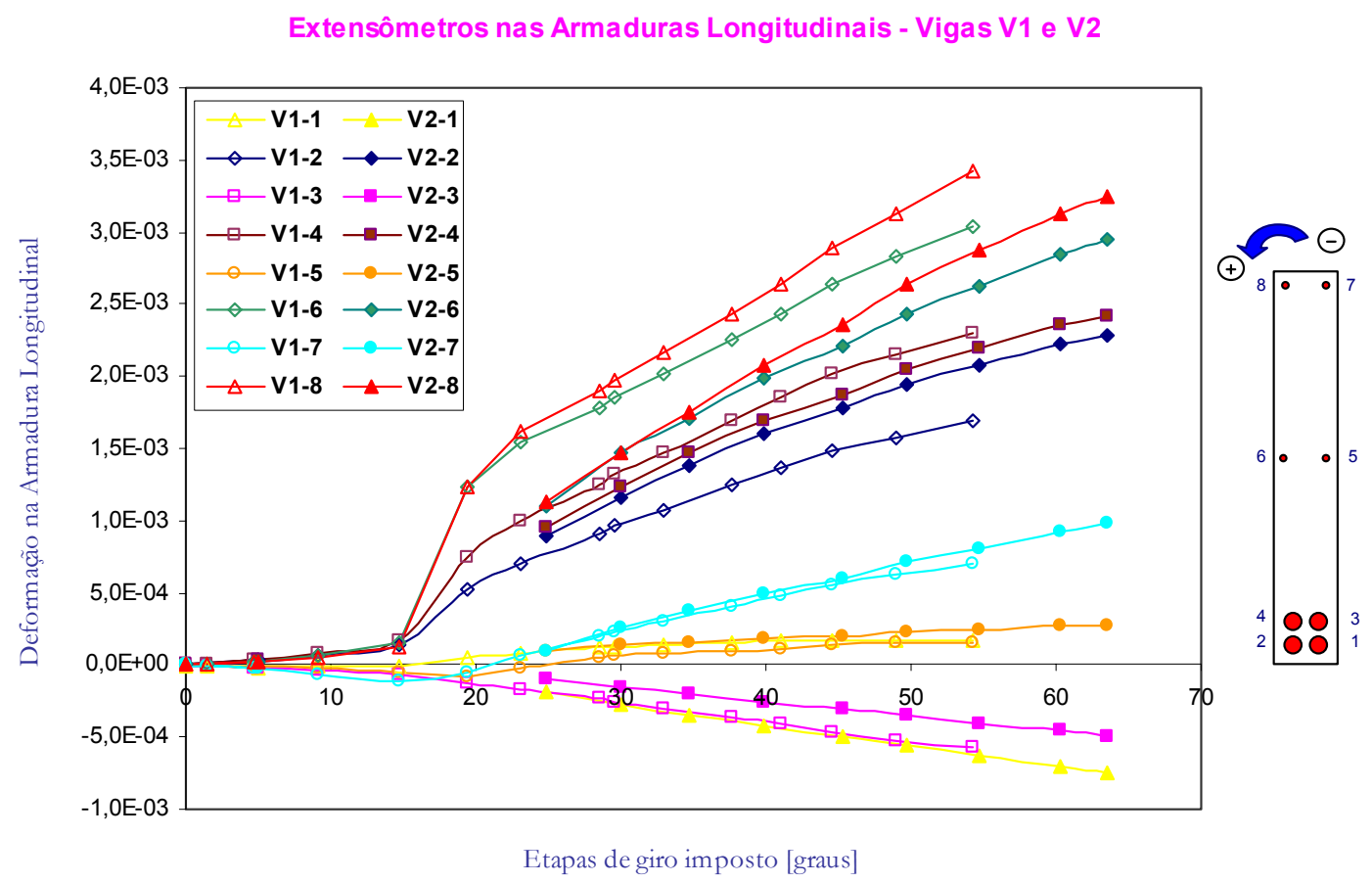

Figura 6.41 - Comparação entre as respostas experimentais nas armaduras das vigas V1 e V2.

A Figura 6.42 mostra o comportamento elástico das armaduras longitudinais durante todo o ensaio da viga V1, o que pode ser observado no referido gráfico, uma vez que a tensão de escoamento das barras de $4,2 \mathrm{~mm}$ obtidas nos ensaios de tração foi em torno de $7500 \mathrm{kgf} / \mathrm{cm}^{2}$.

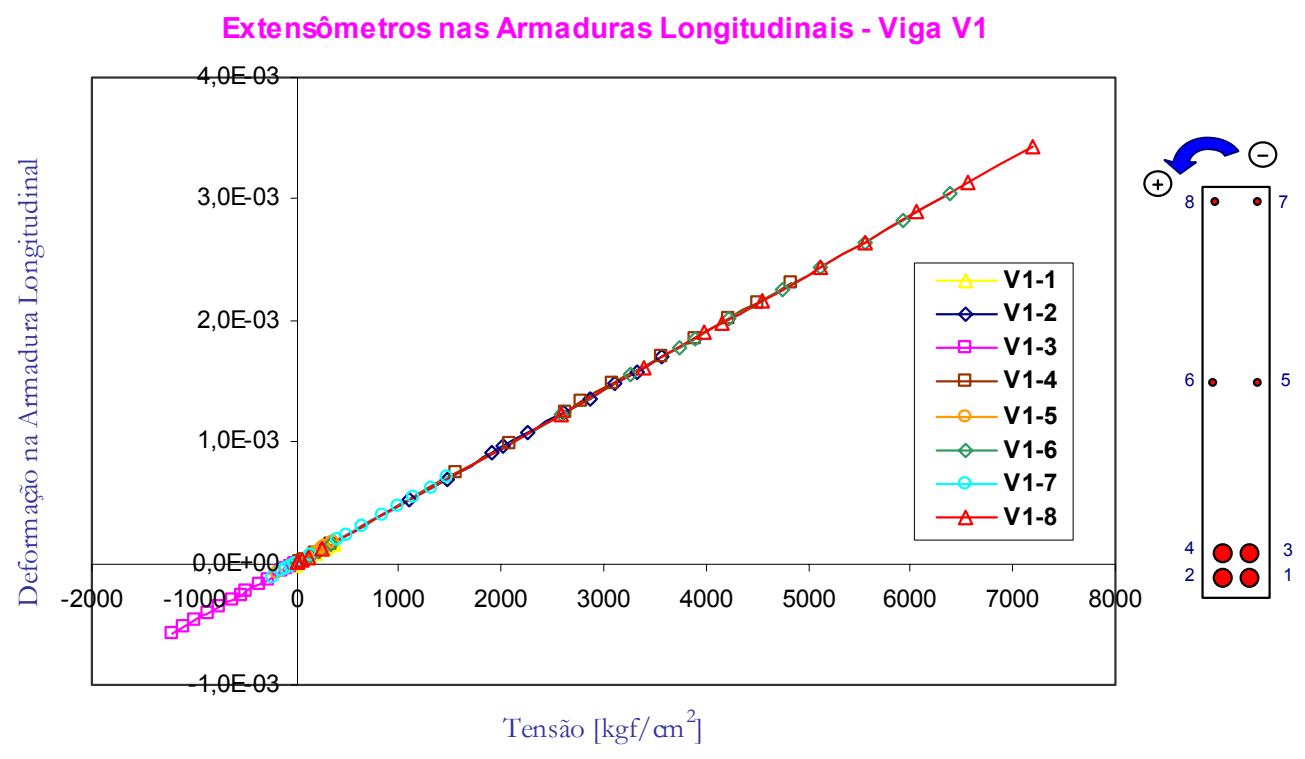

Figura 6.42 - Comportamento tensão-deformação das armaduras longitudinais da viga V1.

\subsubsection{Estações TOTAIS}

Conforme descrito anteriormente, a medida dos deslocamentos de translação ao longo das etapas de giro impostas foi obtida a partir das leituras feitas por Estações Totais. 
Para a viga V1, utilizou-se uma TCR 1105 e para a viga V2, uma TCR 705. Em cada etapa de giro, foram medidas as novas coordenadas de cada um dos 15 pontos previamente definidos.

A Figura 6.43 mostra a variação das coordenadas dos pontos lidos pela estação, ao longo das 13 etapas de giro imposto no ensaio da viga V1, enquanto a Figura 6.44 refere ao comportamento apresentado pela viga $\mathrm{V} 2$, nas 14 etapas do ensaio.

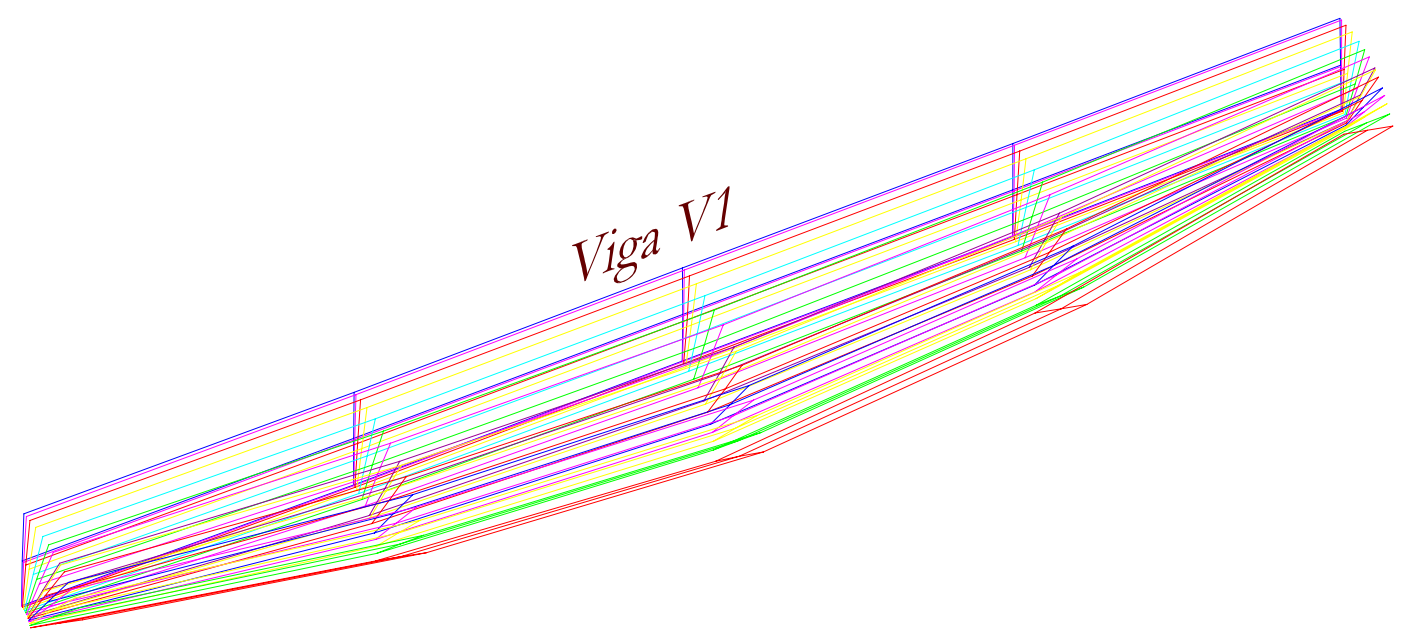

Figura 6.43 - Mudanças de posição no espaço lidos pela TCR 1105 - Ensaio da viga V1.

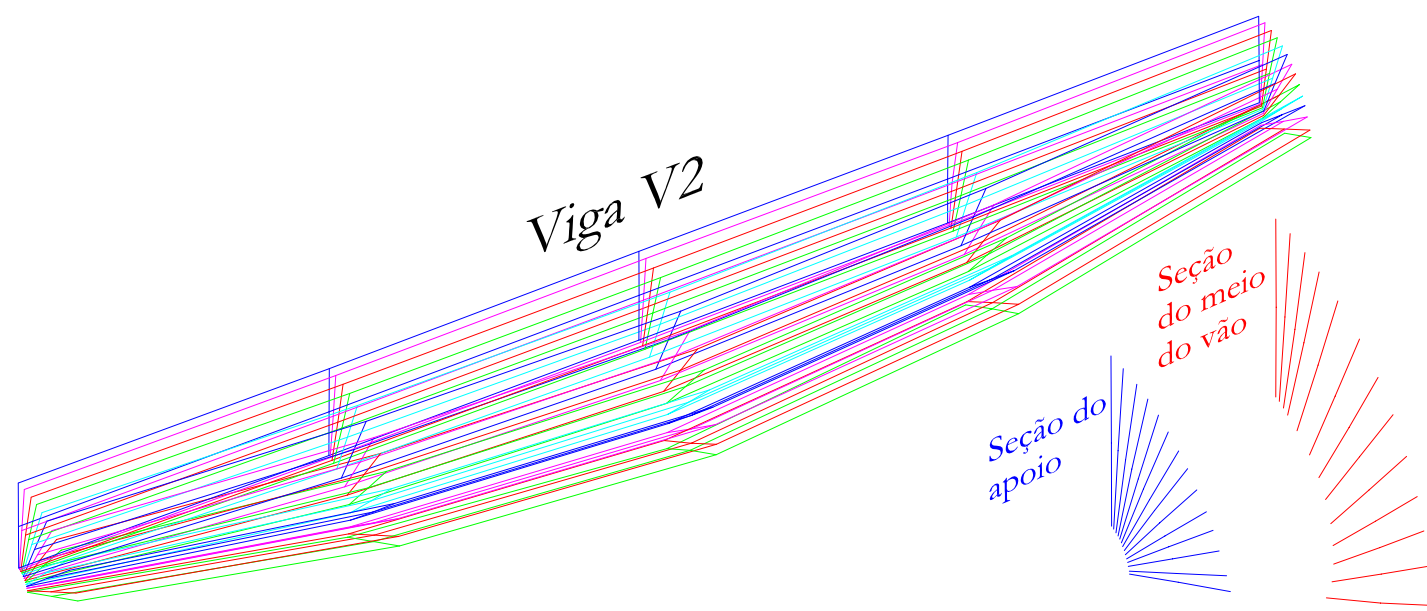

Figura 6.44 - Mudanças de posição no espaço lidos pela TCR 705 - Ensaio da viga V2.

O gráfico apresentado na Figura 6.45 mostra os deslocamentos verticais e laterais da seção no meio do vão e, portanto, dos pontos 7, 8 e 9 indicados na Figura 6.12, obtidos para a viga V1 e V2, em função das etapas de giro imposto.

O giro em torno do eixo longitudinal de cada uma das seções onde foram lidas as coordenadas dos pontos no espaço foi calculado como a média entre os valores obtidos nos três pontos que definem a seção. Assim, para a viga V1 e a viga V2, respectivamente, as Figuras 6.46 e 6.47 mostram que praticamente o giro por torção foi nulo, como era de se esperar. 


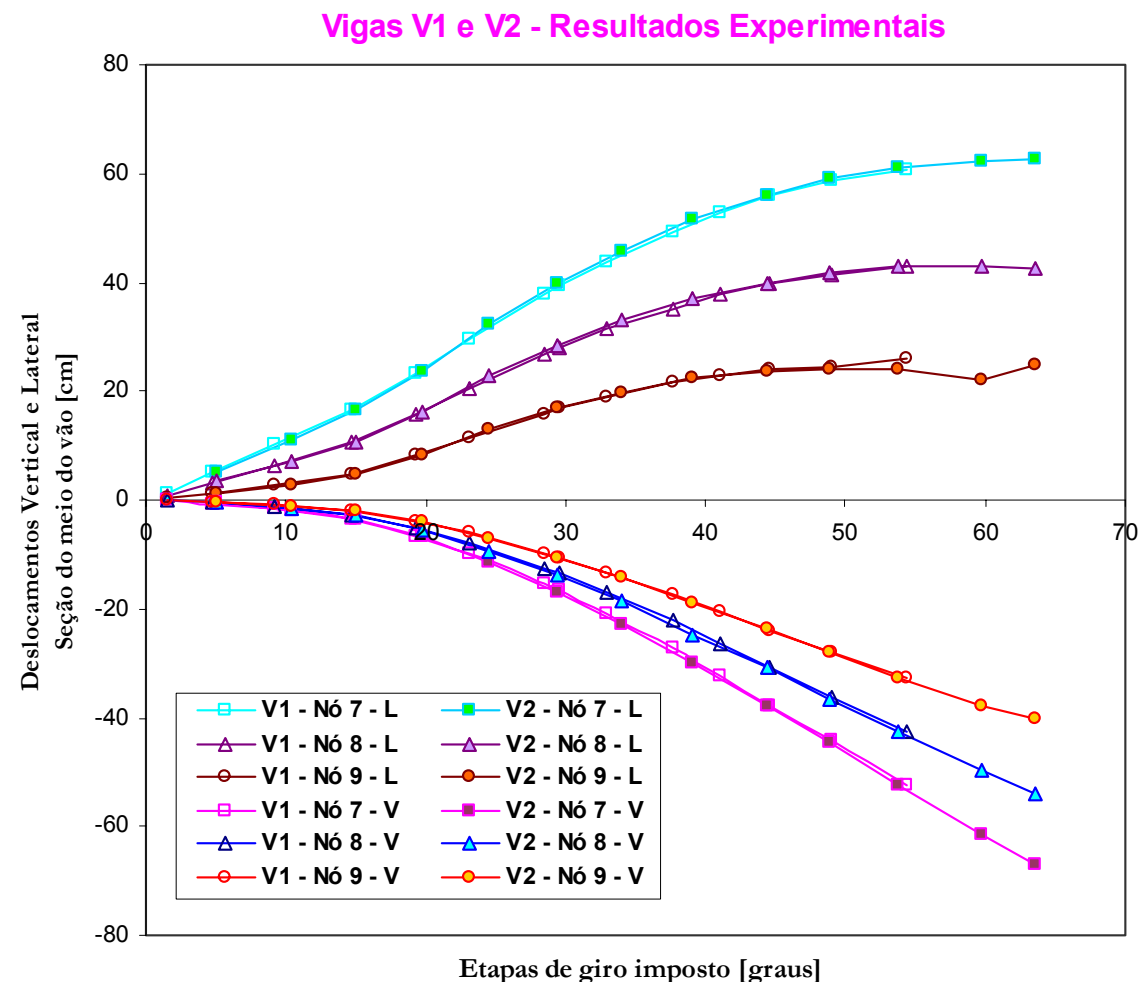

Figura 6.45 - Deslocamentos verticais e laterais dos pontos 7, 8 e 9 para as vigas V1 e V2.

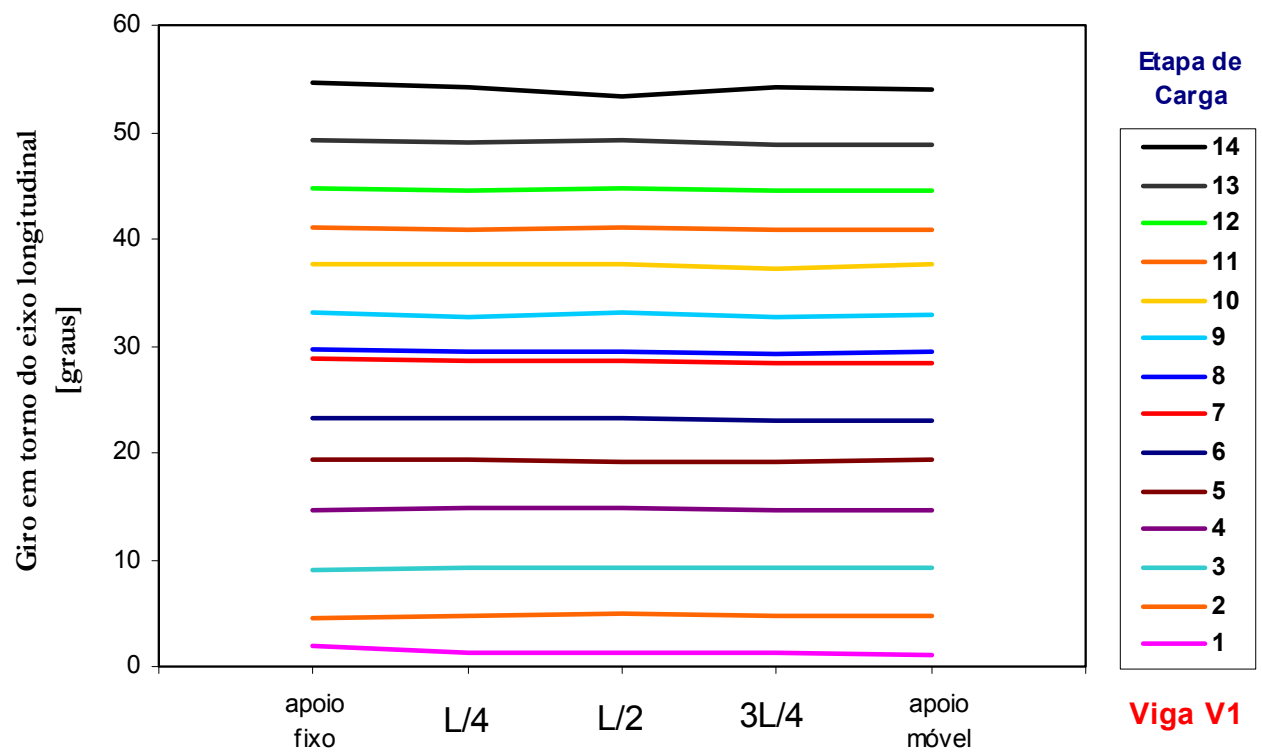

Figura 6.46 - Giro em torno do eixo longitudinal nas 5 seções transversais de medida - Viga V1.

A Figura 6.48 mostra os deslocamentos longitudinais do ponto 15, ponto este inferior na seção da viga sobre o apoio móvel e previamente definido na Figura 6.12, ao longo das etapas de giro imposto. 


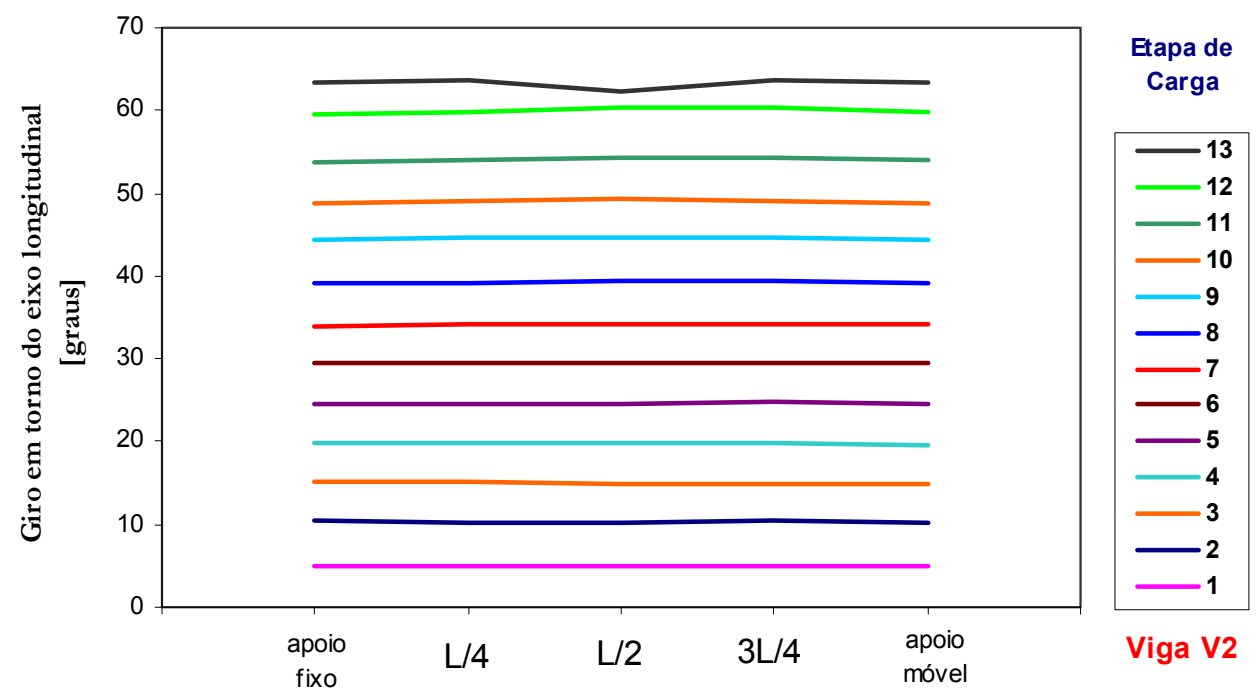

Figura 6.47 - Giro em torno do eixo longitudinal nas 5 seções transversais de medida - Viga V2.

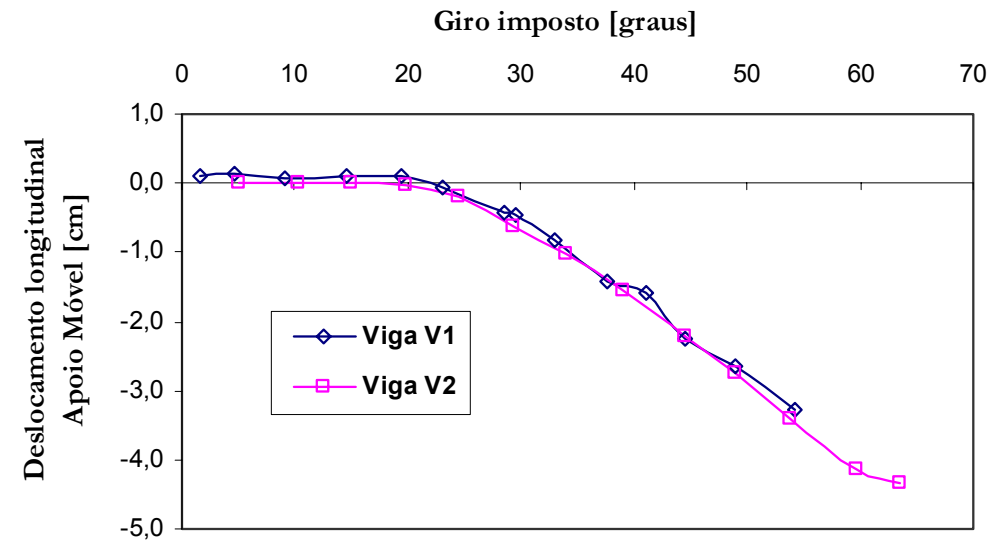

Figura 6.48 - Deslocamento longitudinal do ponto 15 - Vigas V1 e V2.

\subsection{SimulaçÃo NumÉrica dAS Vigas V1 E V2 Ensaiadas}

As vigas $\mathrm{V} 1$ e V2 ensaiadas neste trabalho foram analisadas no programa Tritor considerando sua simetria longitudinal, e portanto, o vão L/2 foi discretizado em 26 elementos longitudinais, conforme ilustra a Figura 6.49.

O carregamento constitui-se de forças verticais nos 27 nós simulando o efeito do pesopróprio. As condições de contorno correspondem ao impedimento da translação em y e em $z$ além de rotação em torno de x no nó 2 e na seção de simetria, ou no nó 27, foi impedida a translação em $x$ e as rotações em torno de y e $z$.

A seção transversal de cada nó foi discretizada em 250 elementos, e portanto, a largura da viga $(5 \mathrm{~cm})$ foi dividida por 5 e a altura $(50 \mathrm{~cm})$ por 50 . Um estudo do grau de discretização satisfatório para a seção transversal mostra que discretizá-la em 250 elementos ou 640 elementos praticamente não alterou os resultados. Porém, discretizar 
em 160 elementos resulta em maiores deslocamentos nodais.

Duas análises foram modeladas numericamente, a análise linear e a não-linear.

Vale lembrar que nos ensaios das vigas V1 e V2 o ponto em torno do qual impõe-se as rotações nos apoios é o centro de gravidade da esfera metálica do conjunto apoio tipo garfo, o qual encontra-se a $32 \mathrm{~cm}$ abaixo do CG da viga. Numericamente, foram também impostas translações nodais verticais e laterais nos apoios, sendo estas, funções do ângulo imposto a fim de simular a mudança das coordenadas dos apoios.

Os resultados a seguir apresentados foram obtidos considerando a região de enrijecimento da armadura igual a 7,5申. Utilizando a recomendação de Yamamoto (1999), ou seja $2,5 \phi$, naturalmente resulta em deslocamentos maiores. Porém, este valor é questionável, de forma que adotar 7,5 $\phi$ é aceitável na literatura técnica.

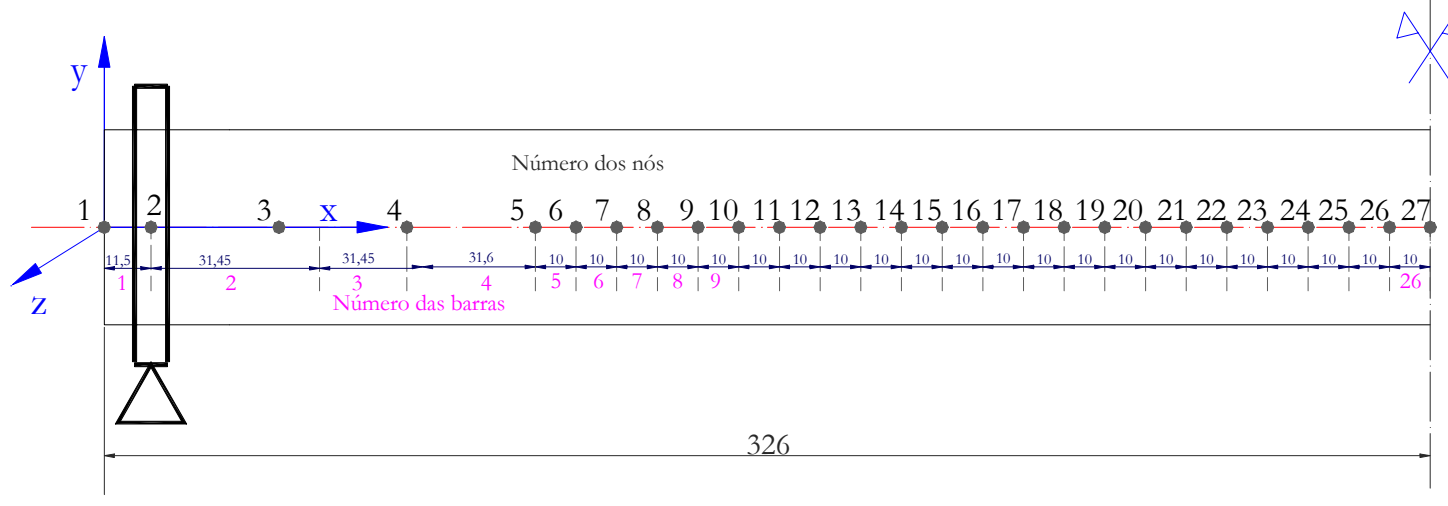

Figura 6.49 - Discretização longitudinal das vigas V1 e V2 - Números dos nós e das barras.

\subsubsection{CoMparaçÃo ENTRE RESUltados NumÉRICOS E EXPERIMENTAIS}

\subsubsection{DESLOCAMENTOS LATERAis E VerticAis}

Os deslocamentos laterais e verticais da seção do meio do vão observados para as vigas V1 e V2 ensaiadas, e medidos pelas Estações Totais, encontram-se plotados nos gráficos das Figuras 6.50 e 6.51, tendo sido comparados com os resultados numéricos obtidos do programa Tritor.

Nestas figuras, a resposta numérica linear é representada por 'Lin', naturalmente apresentando deslocamentos menores que os experimentais, e o comportamento considerando a não-linearidade dos materiais é represenrado por 'NL', nas referidas legendas.

Os resultados obtidos considerando a não-linearidade dos materiais aproximam-se razoavelmente dos resultados experimentais, com boa aproximação especialmente para os deslocamentos verticais. 


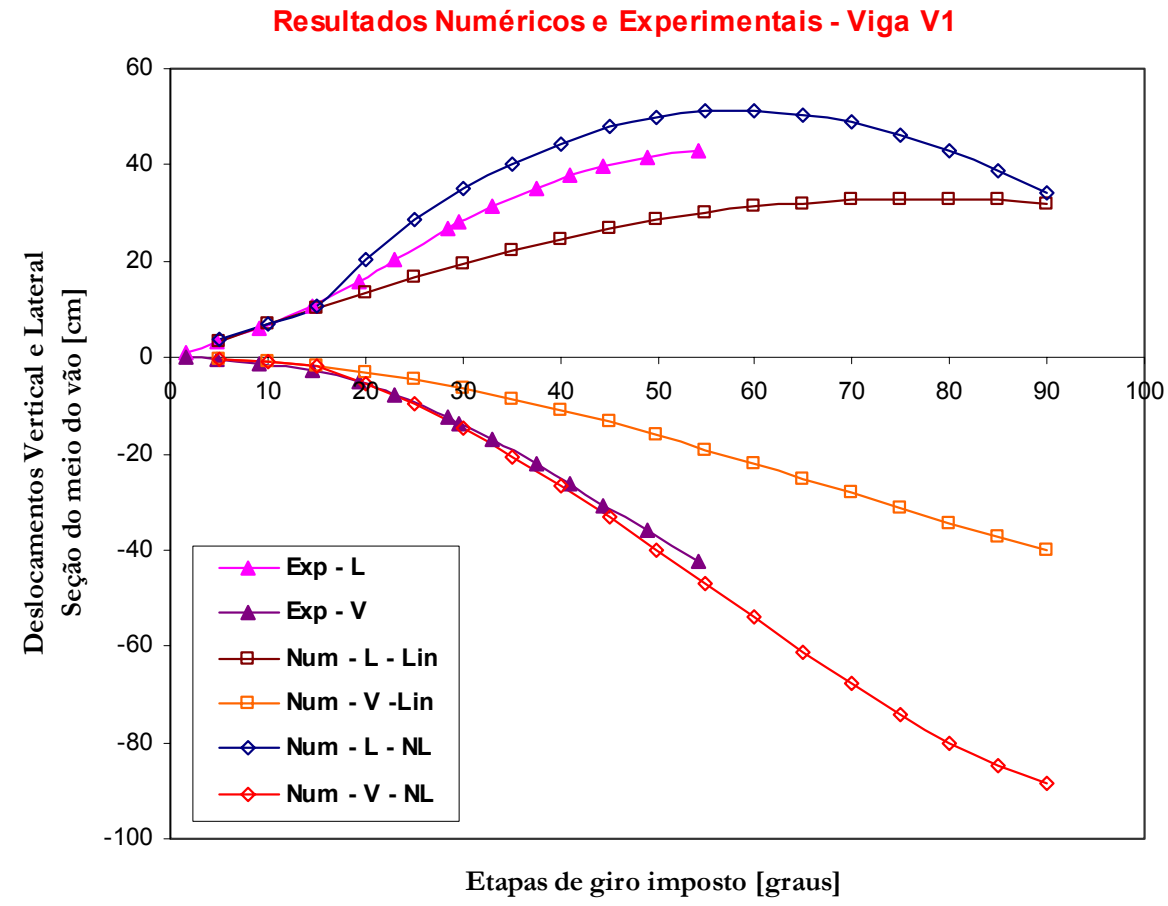

Figura 6.50 - Deslocamentos laterais e verticais da viga V1: respostas numéricas e experimentais.

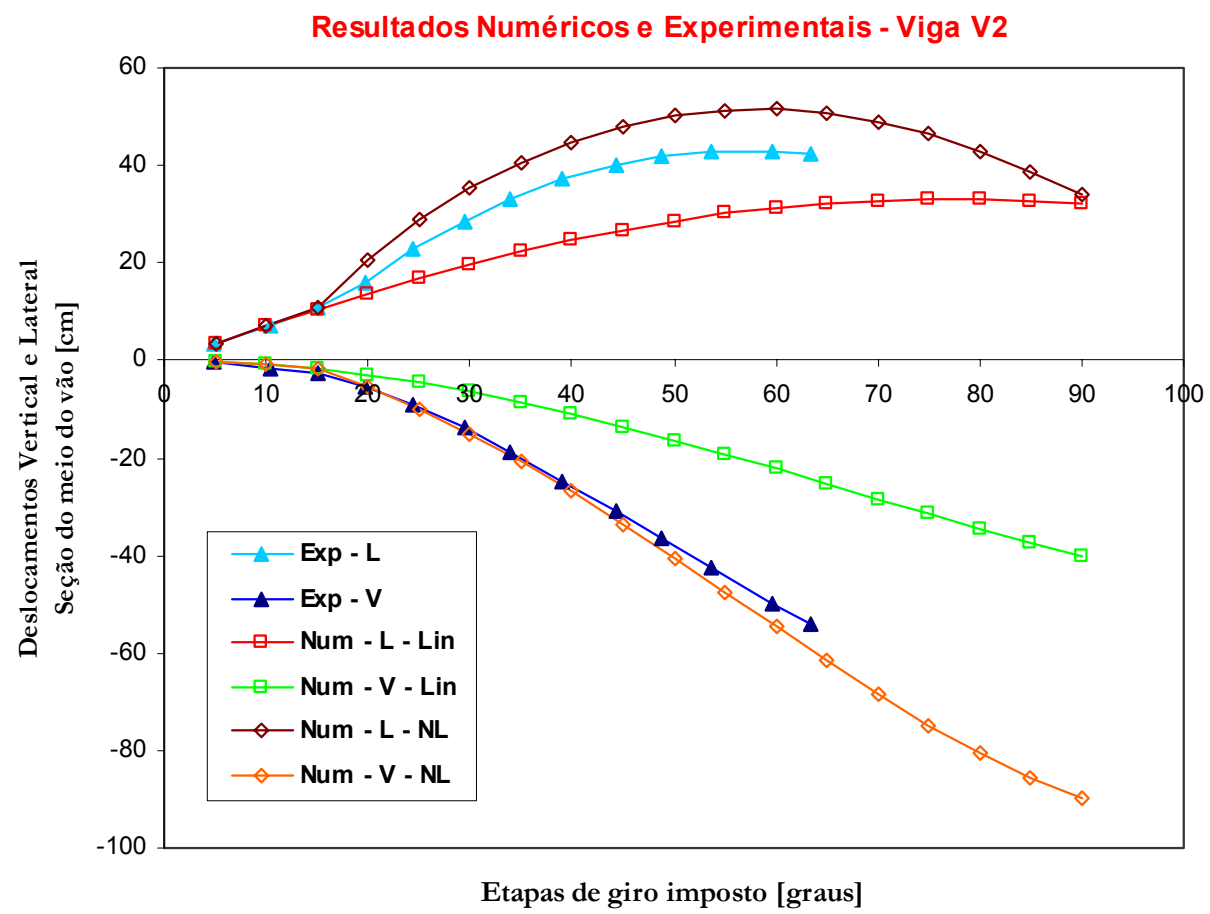

Figura 6.51 - Deslocamentos laterais e verticais da viga V2: respostas numéricas e experimentais.

A Figura 6.52 permite observar a melhor resposta numérica considerando a nãolinearidade dos materiais e a resposta experimental, esta última referente aos deslocamentos do ponto de leitura 8 da Figura 6.12, na seção central. 


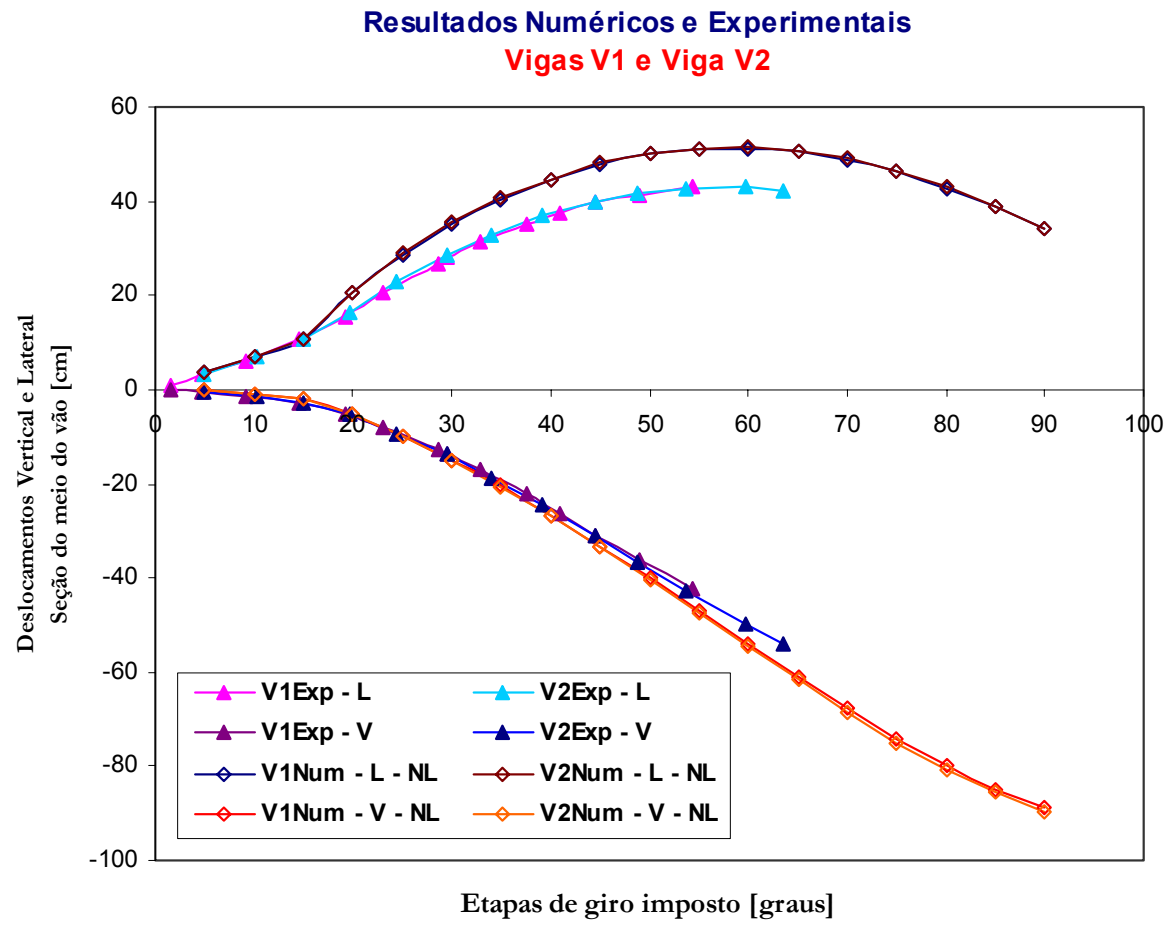

Figura 6.52 - Respostas numéricas NL e experimentais das vigas V1 e V2.

\subsubsection{DEFORMAÇÃO DO CONCRETO}

As deformações no concreto medidas pelos 6 extensômetros elétricos colados na seção do meio do vão, três na face tracionada e três na parte comprimida, foram comparadas com as deformações obtidas numericamente para cada etapa de giro imposto. A deformação em questão é a deformação longitudinal de cada ponto da seção transversal em análise.

A Figura 6.53 mostra a comparação entre as respostas numéricas e experimentais para a deformação do concreto na seção do meio do vão, para a viga V1.

Deformação no Concreto - Viga V1

Resultados Numéricos NL e Experimentais

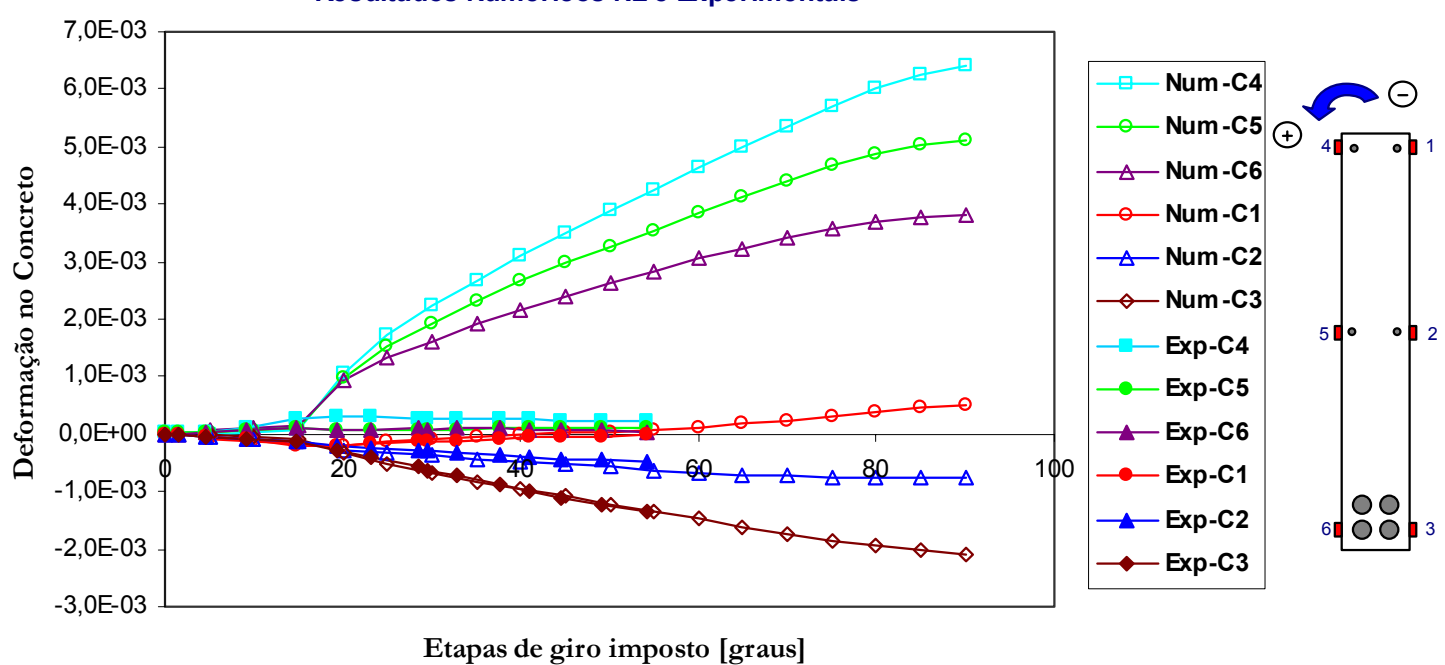

Figura 6.53 - Deformação no concreto: respostas numéricas e experimentais da viga V1. 
Nota-se que as respostas obtidas numerica e experimentalmente à compressão comparam-se muito bem entre si, o que pode ser melhor visualizado na Figura 6.54. O mesmo já não se verifica à tração, o que também é mais difícil de ocorrer especialmente quando uma fissura se abre sobre o extensômetro. Vale lembrar que o comportamento à tração do concreto está sendo considerado numericamente pelo diagrama proposto por Vebo \& Ghali (1977) apud El Metwally et al. (1990), que leva em conta o efeito da zona enrijecida por armadura.

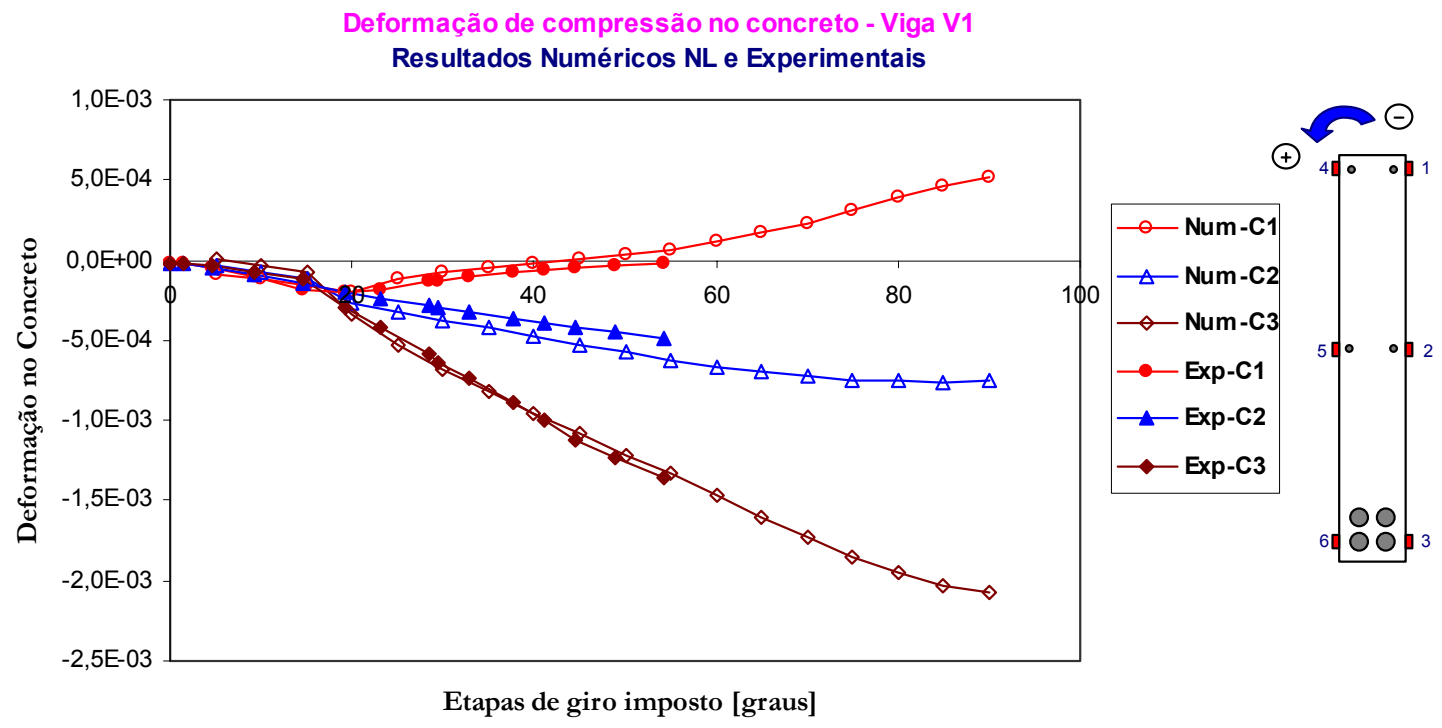

Figura 6.54 - Deformação de compressão no concreto: respostas numéricas e experimentais da viga V1.

A Figura 6.55 mostra a comparação entre os resultados experimentais obtidos para a viga $\mathrm{V} 1$ e a viga $\mathrm{V} 2$, relativos à deformação longitudinal nos elementos $\mathrm{C} 1$ à $\mathrm{C} 6$ da seção transversal do meio do vão.

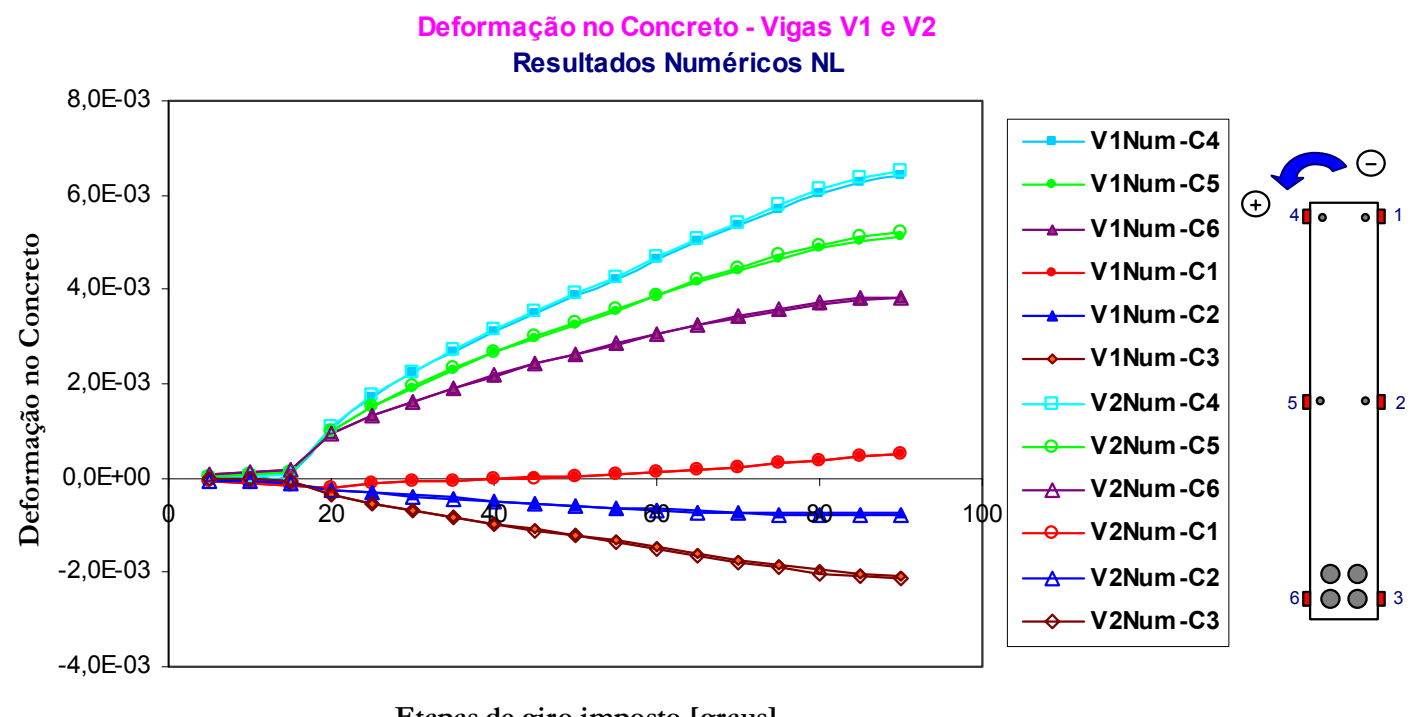

Figura 6.55 - Deformação no concreto: respostas numéricas das vigas V1 e V2. 


\subsubsection{DEFORMAÇÃO DAS ARMADURAS}

As Figuras 6.56 e 6.57 mostram a deformação nas armaduras longitudinais das vigas V1 e V2 respectivamente, comparados aos resultados experimentais.

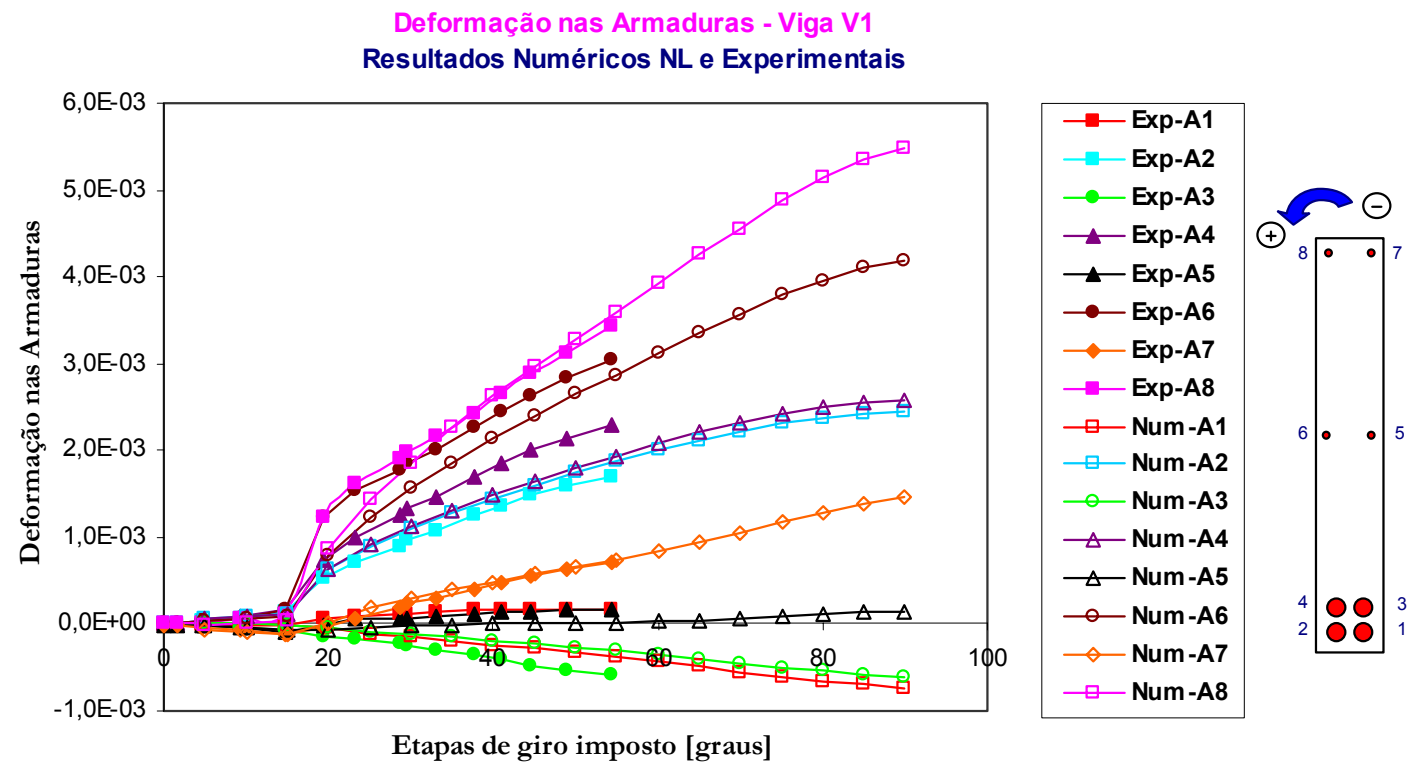

Figura 6.56 - Deformação nas armaduras longitudinais: respostas numéricas e experimentais - viga V1.

Deformação nas Armaduras - Viga V2

Resultados Numéricos NL e Experimentais

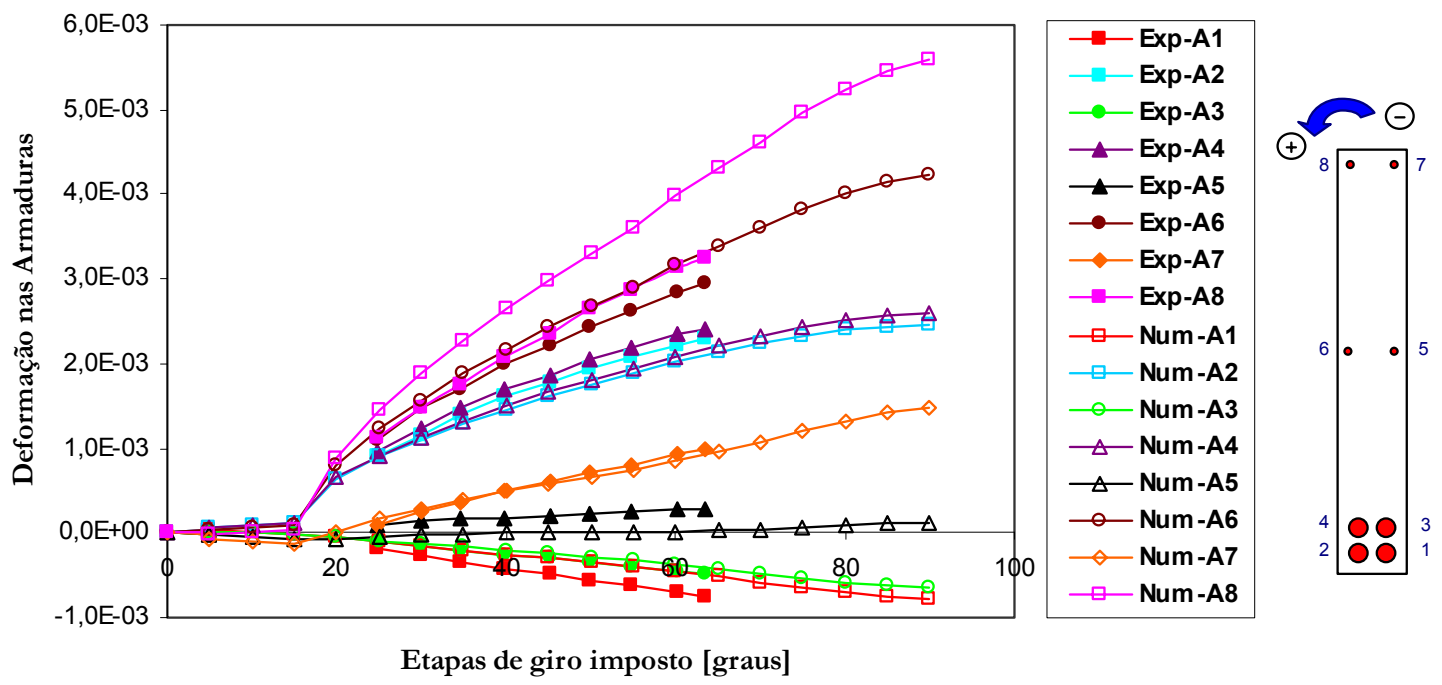

Figura 6.57 - Deformação nas armaduras longitudinais: respostas numéricas e experimentais - viga V2.

A comparação entre os resultados numéricos obtidos para as vigas V1 e V2 encontramse ilustradas na Figura 6.58, os quais são praticamente coincidentes, uma vez que as propriedades dos materiais variam muito pouco. 


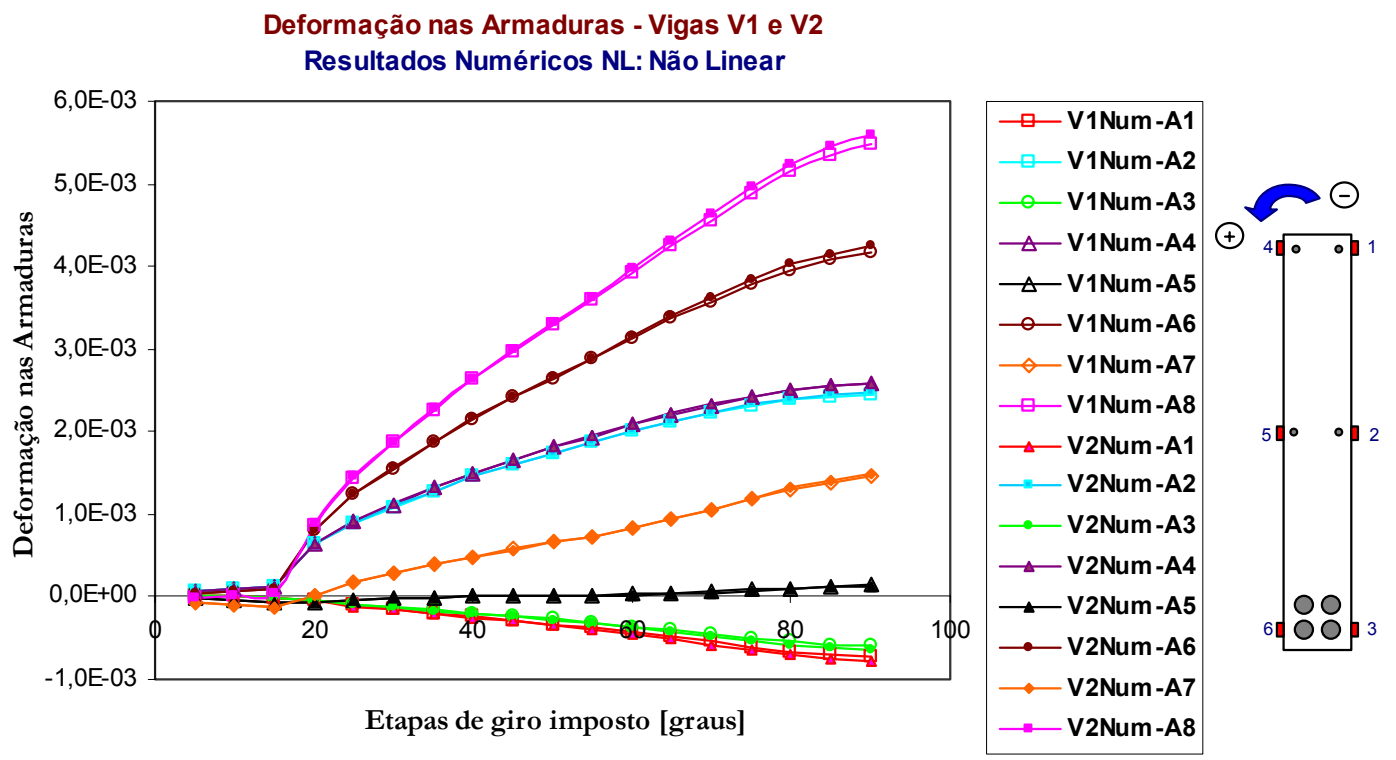

Figura 6.58 - Deformação nas armaduras longitudinais: respostas numéricas das vigas V1 e V2.

\subsubsection{MOMENTOS DE INÉRCia Vertical e LAteral}

Numericamente, considerou-se após a convergência da etapa anterior, a atualização da geometria da seção transversal, conforme ilustra a Figura 6.59, nas etapas simuladas partindo de $0^{\circ}$ até $90^{\circ}$. Assim, o campo de deslocamentos obtido simula uma alteração nos momentos de inércia.

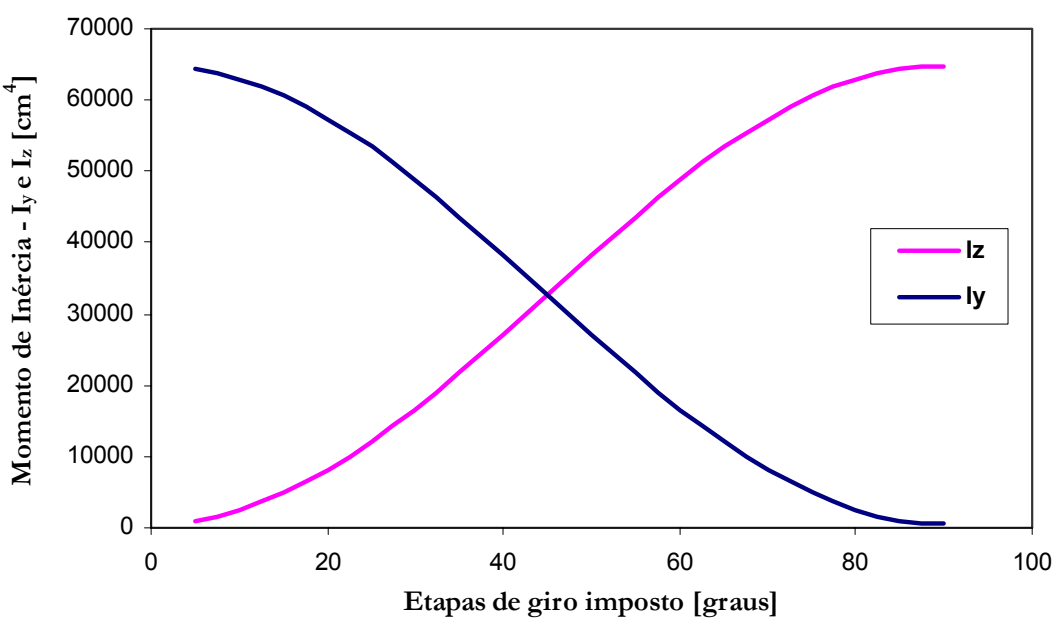

Figura 6.59 - Momento de inércia vertical e lateral versus Etapas de giro imposto.

\subsubsection{QUADRO DE FissuraçÃo - Respostas Numéricas dAS Vigas V1 e V2}

O quadro de fissuração da seção transversal central das vigas V1 e V2 para cada etapa de giro imposto, resultante da análise não-linear, encontra-se ilustrado na Figura 6.60. Até a etapa 3 equivalente à 15 graus de inclinação, os elementos de concreto tracionados não atingiram a resistência à tração. A fissuração obedece, numericamente, à consideração da zona de envolvimento da armadura. Por este motivo, alguns elementos discretizados 
atingem tensão nula à tração antes de outros mais solicitados, como pode-se observar na Figura 6.60, cuja região de enrijecimento considerada foi de $7,5 \phi$.
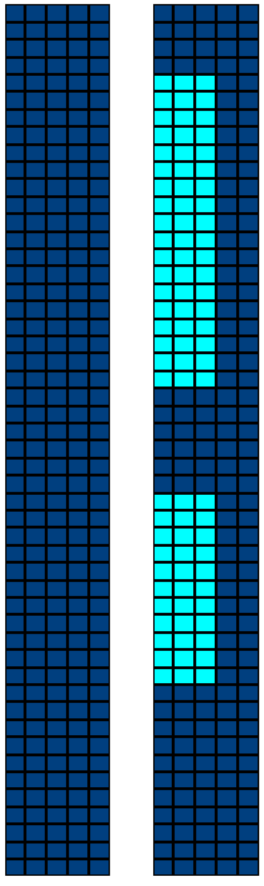

(a) 0 a $15^{\circ}$

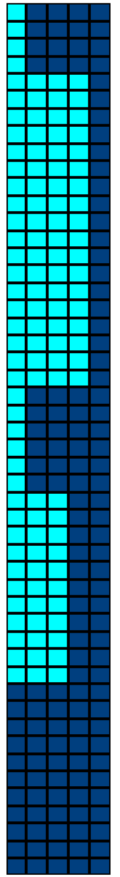

(c) $25^{\circ}$

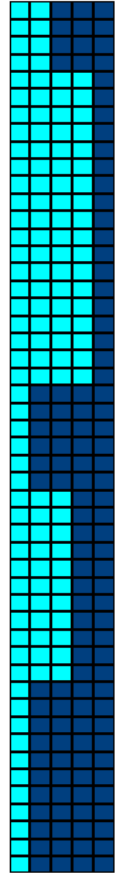

(d) $30^{\circ}$

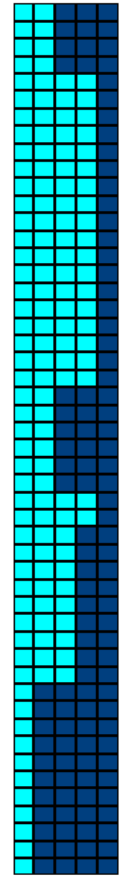

(e) $35^{\circ}$
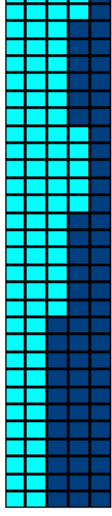

(j) $60^{\circ}$

(1) $65^{\circ}$
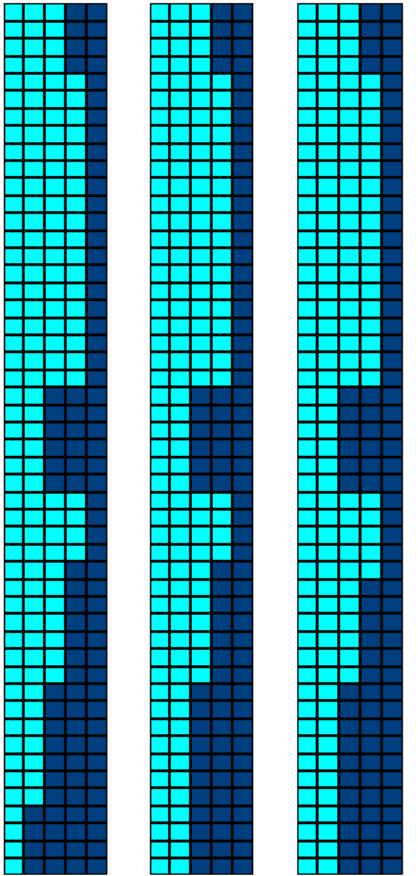

(f) $40^{\circ}$

(g) $45^{\circ}$

(h) $50^{\circ}$

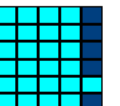

转

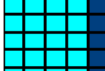

进

†t

平

$+$
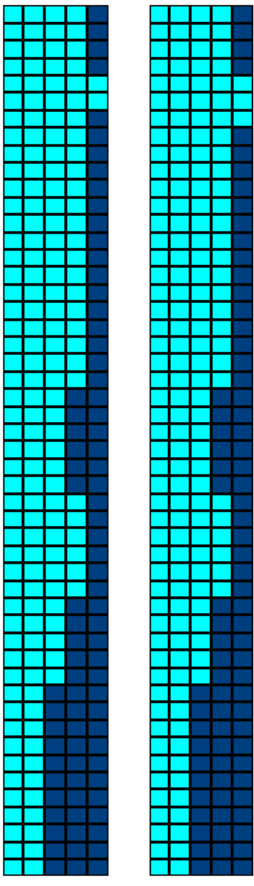

(m) $70^{\circ}$

(n) $75^{\circ}$

(o) $80^{\circ}$

(p) $85^{\circ}$

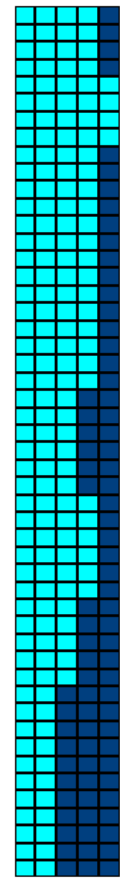

Elemento não fissurado

Figura 6.60 - Quadro de fissuração para cada etapa de giro imposto: vigas V1 e V2. 
Numericamente, em todas as 18 etapas de giro imposto, não houve esmagamento de nenhum dos 250 elementos da seção transversal central discretizada.

\subsubsection{QuAdro de Escoamento das ARMaduras - Resposta NumÉrica}

A progressão do escoamento das armaduras longitudinais ao longo das etapas de giro imposto pode ser visualizado na Figura 6.61, sendo esta a resposta numérica obtida para as vigas V1 e V2 na análise não-linear. Na Figura 6.61, as barras longitudinais da viga discretizada que atingiram o escoamento encontram-se definidas entre parênteses.

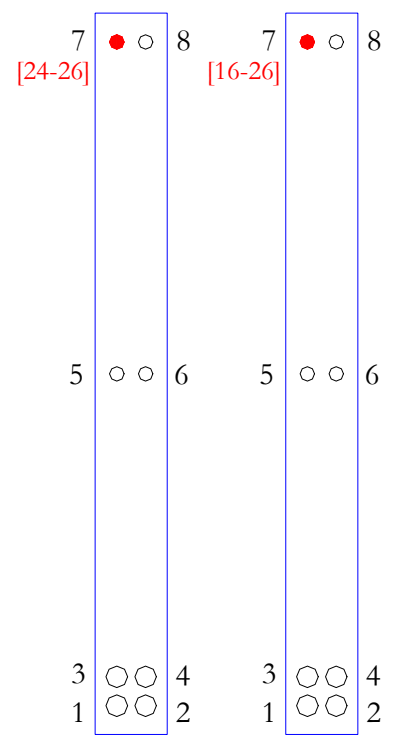

(a) $40^{\circ}$

(b) $45^{\circ}$

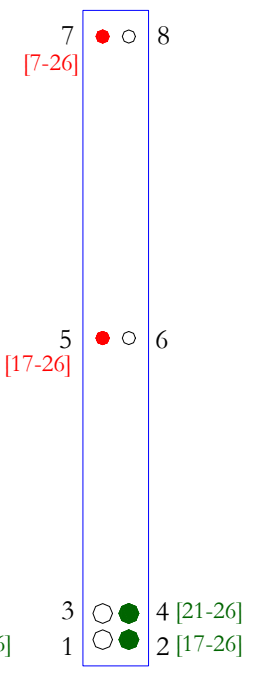

(h) $75^{\circ}$

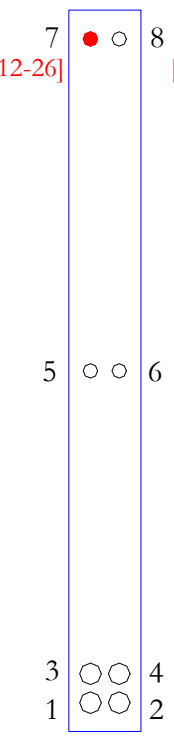

(c) $50^{\circ}$

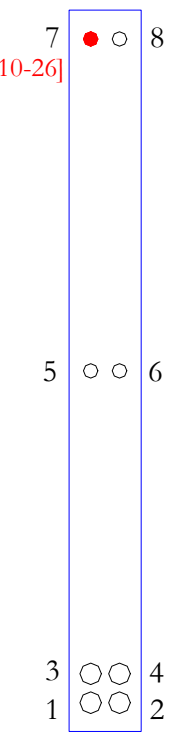

(d) $55^{\circ}$

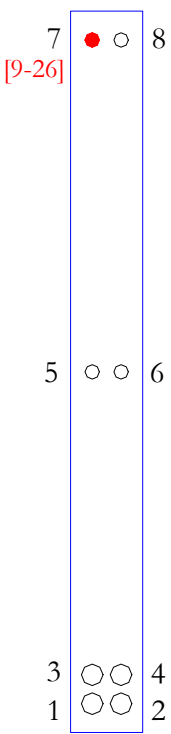

(e) $60^{\circ}$

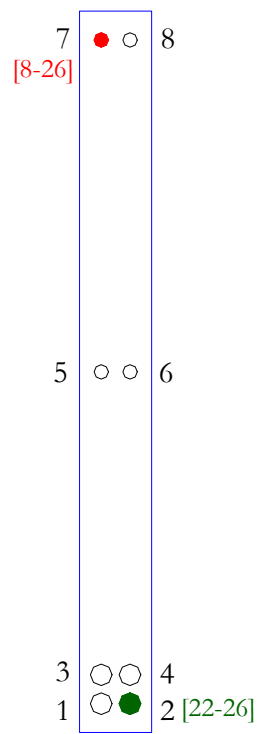

(f) $65^{\circ}$ (g) $70^{\circ}$

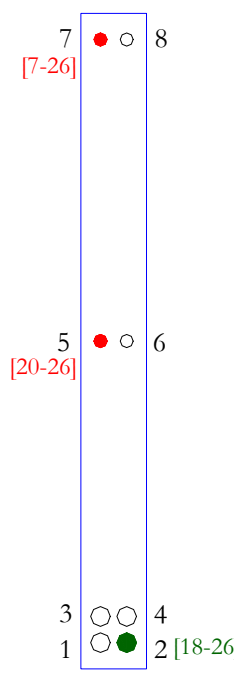

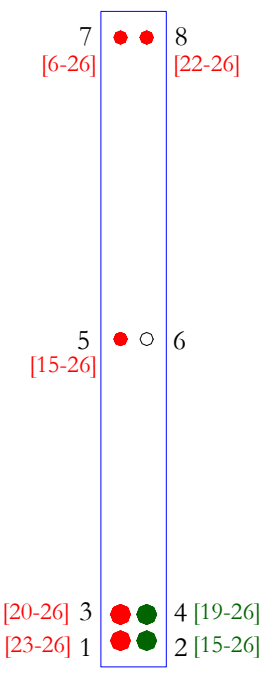

(i) $80^{\circ}$

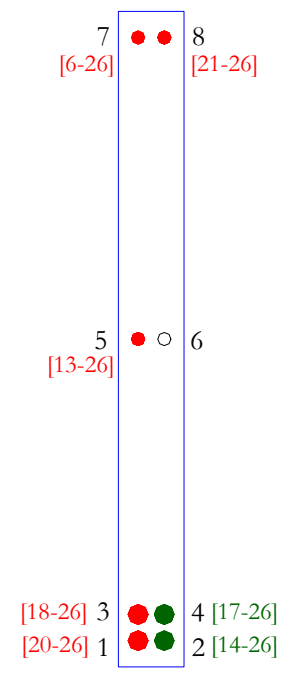

(j) $85^{\circ}$

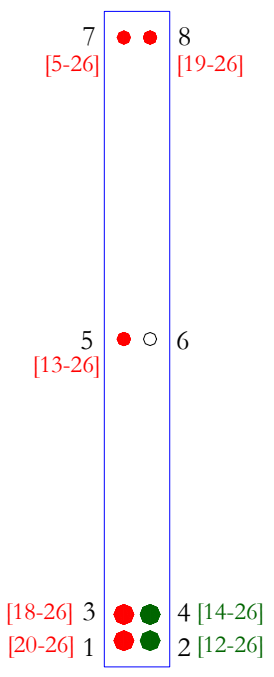

(k) $90^{\circ}$

Legenda:

Tração

Compressão

Figura 6.61 - Quadro de escoamento das armaduras longitudinais para as etapas de giro imposto (a), (b), (c), (d), (e), (f), (g), (h), (i), (j) e (k): vigas V1 e V2. 


\subsubsection{RIGIDEZ À TORÇÃO}

A Figura 6.62 mostra a resposta numérica referente à variação da rigidez à torção das vigas V1 e V2, resultante da aplicação do modelo de Hannachi \& Fouré (1996). Observase a perda de rigidez à torção ao longo das etapas de carga, aumentando de acordo com o progresso da fissuração por flexão.

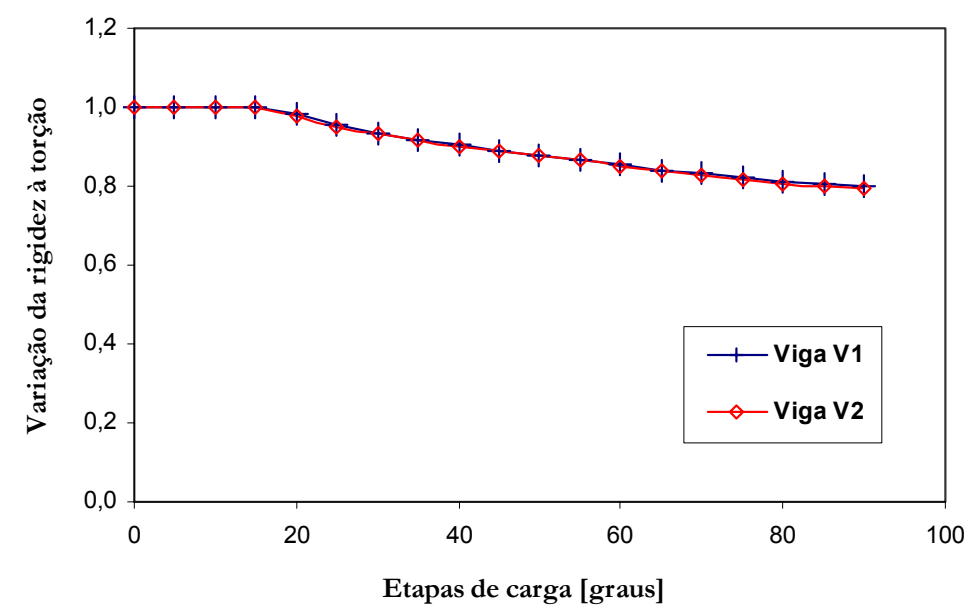

Figura 6.62 - Variação da rigidez à torção segundo modelo numérico de Hannachi \& Fouré (1996).

\subsection{CONSIDERAÇões FINAIS}

O programa experimental serviu, neste trabalho, especialmente para validar e calibrar o programa computacional implementado, ajustando-se os modelos teóricos. Pôde-se observar, que a torção é de fato muito pequena e que a flexão lateral é predominante em virtude da baixa rigidez lateral das vigas esbeltas. A perda de rigidez à torção durante toda a simulação numérica, obtida segundo proposta de Hannacbi \& Fouré (1996), chega a $20 \%$.

O comportamento não-linear dos materiais considerados apresentou-se com resposta numérica satisfatória, como foi possível observar a partir das leituras obtidas com os extensômetros elétricos no concreto e nas armaduras.

A utilização das estações totais nas leituras dos deslocamentos da viga mostrou ser uma alternativa com bons resultados, embora a precisão dos aparelhos não tenha sido comparada com nenhum outro instrumento de medida. A zona de envolvimento da armadura considerada influi na resposta numérica, tendo sido obtidos melhores resultados, nos casos de vigas sem armadura ativa, considerando a região de $7,5 \phi$.

Serão apresentados no próximo capítulo alguns exemplos, incluindo casos de vigas protendidas, com análise numérica e experimental, utilizando os diversos modelos estruturais implementados, bem como aplicações ao problema da instabilidade lateral por meio da estimativa da segurança na fase de içamento. 


\section{Capítulo}

\section{7}

\section{ANÁLISE DE RESULTADOS EXPERIMENTAIS}

E EXEMPLOS DE APLICAÇÃO

\subsection{CONSIDERAÇÕES INICIAIS}

São analisadas neste capítulo algumas situações de vigas sob consideração combinada e isoladas entre si, de flexão e torção, admitindo o comportamento não-linear dos materiais envolvidos, a fim de comparar a resposta numérica obtida do programa Tritor e os resultados experimentais disponíveis na literatura técnica.

O primeiro exemplo analisado numericamente refere-se à grelha ensaiada por Collins \& Lampert (1973). Em casos onde a torção não é solicitação predominante, a utilização da expressão para cálculo da rigidez à torção após fissuração do concreto proposta por Lampert (1973) demonstrou ser uma alternativa simples e com bons resultados. Cocchi \& Cappello (1993) analisaram numericamente a grelha em questão, considerando um modelo numérico com discretização da seção transversal sólida através de seção correspondente vazada, desprezando a resistência à tração do concreto.

A viga ensaiada por Onsongo (1978) sob torção combinada com flexão, sendo a primeira solicitação predominante, foi modelada numericamente neste trabalho através da implementação da proposta de Cocchi \& Volpi (1996).

O modelo de Hannachi \& Fouré (1996) foi aplicado a uma viga fissurada por flexão com pequeno momento de torção, a fim de observar a variação da rigidez à torção em um problema de estabilidade de forma.

A viga ensaiada em escala real por Mast (1994) foi modelada numericamente considerando a proposta de Hannachi \& Fouré (1996) e comparada com a resposta experimental. Os fatores de segurança apresentados por Mast (1993) com relação à instabilidade lateral da fase de suspensão foram comparados com a resposta numérica, utilizando elementos de mola nos apoios.

Finalmente, foi analisada numericamente uma tesoura protendida de aproximadamente $20 \mathrm{~m}$ de vão. A segurança do içamento com balanços foi estimada em função da tolerância admissível de linearidade de uma peça pré-moldada somada à tolerância no posicionamento dos cabos de suspensão. Analisou-se ainda a segurança da suspensão com cabos inclinados.

\subsection{GrelHa ENSAiada POR COLlins \& LAMPERT (1973)}

A grelha ensaiada por Collins \& Lampert (1973) e esquematizada na Figura 7.1 foi 
analisada numericamente neste trabalho com a mesma discretização em elementos de barra utilizada por Cocchi \& Cappello (1993).

A Figura 7.1 mostra cada uma das vigas que forma a grelha dividida em 8 elementos longitudinais de barra. A carga vertical sobre a viga V1 foi aplicada através de passos de carga. O processo iterativo, para o qual busca-se a convergência no passo de carga, deve-se à não-linearidade do comportamento tensão-deformação dos materiais envolvidos.

A rigidez à torção pós-fissuração foi considerada pela expressão (5.15) proposta por Lampert (1973), apresentada no capítulo 5, e o momento de torção após a fissuração foi obtido utilizando a equação (5.17). Tem-se então, uma análise classificada por tipo 2 no programa Tritor, conforme ilustra a Tabela 5.1 apresentada no capítulo 5 deste trabalho.

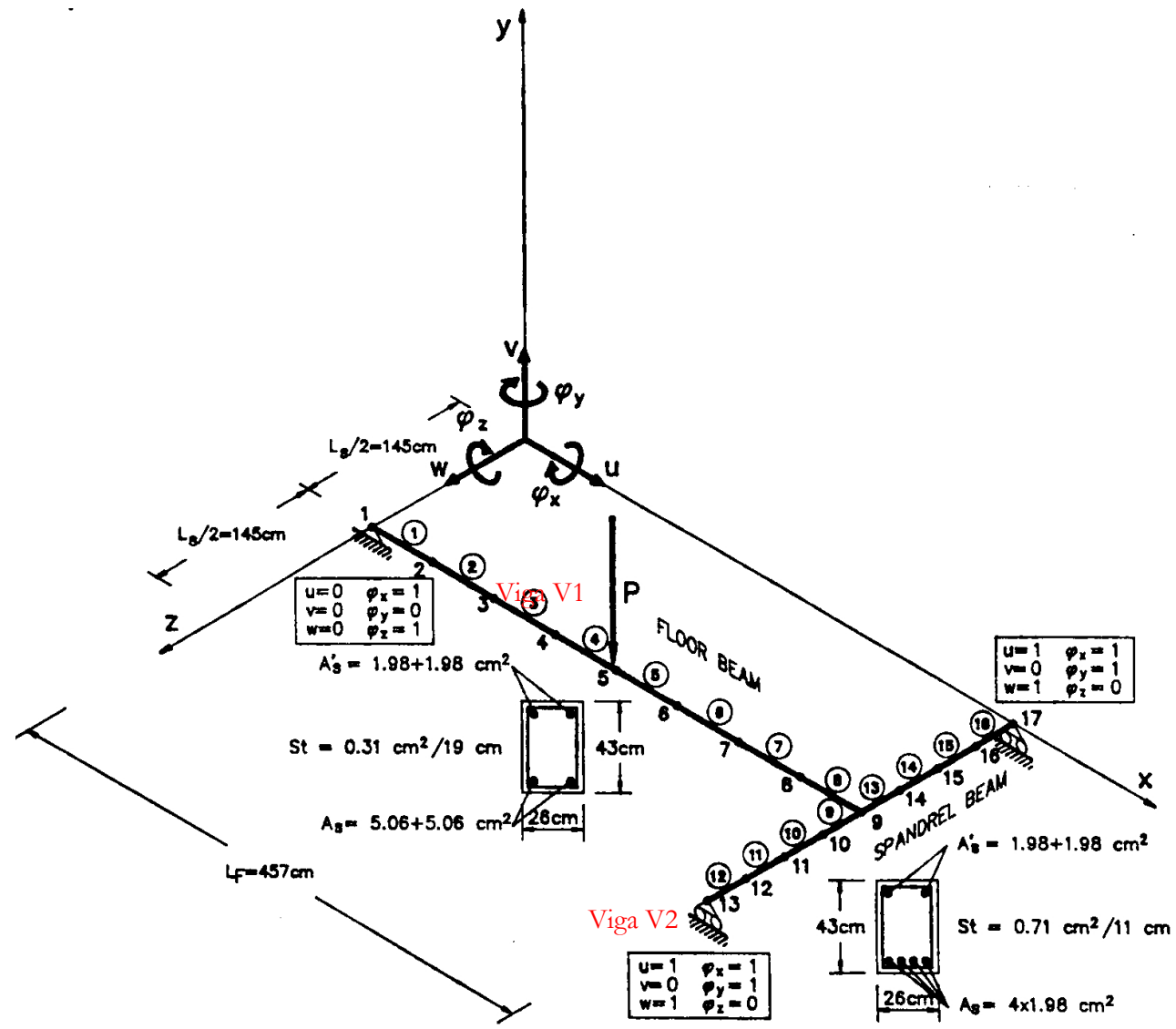

Figura 7.1 - Grelha ensaiada por Collins \& Lampert (1973).

A Figura 7.2 ilustra a disposição dos equipamentos auxiliares para o ensaio da grelha. As condições de apoio da viga solicitada por torção de compatibilidade, no caso a viga V2, podem ser representadas pelo vínculo tipo garfo, ou seja, com impedimento à torção e grau de liberdade à flexão.

Os resultados numéricos obtidos com o programa Tritor podem ser visualizados na Figura 7.3, através do diagrama força-deslocamento no nó 5, identificado na Figura 7.1. A grelha representada no gráfico da Figura 7.3, corresponde à grelha identificada por grelha S1 em Collins \& Lampert (1973). 

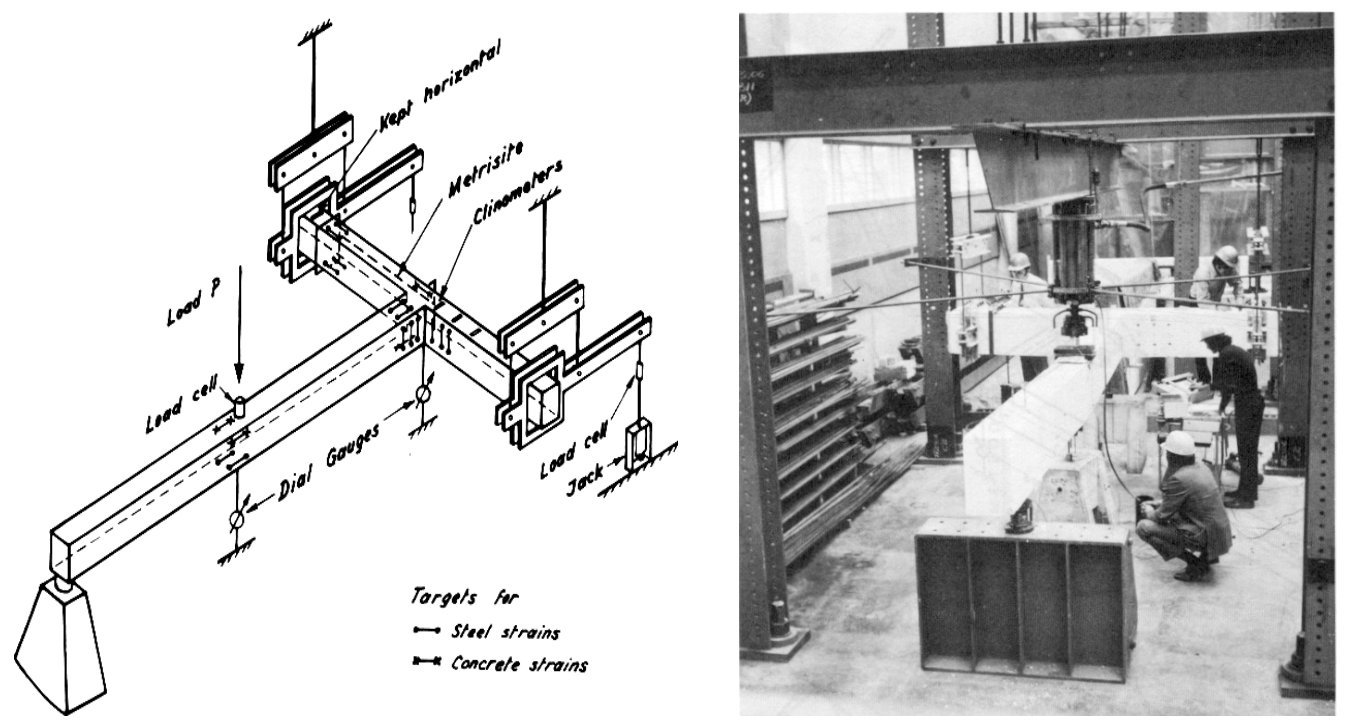

Figura 7.2 - Instrumentação e ensaio. Collins \& Lampert (1973).

Desta forma, o comportamento à torção da viga V2 obtido utilizando a proposta simplificada de Lampert (1973), pode ser observado na Figura 7.4. Esta figura mostra que uma vez bem previsto o momento de fissuração, a inclinação da reta que representa a rigidez pós-fissuração pode representar, ainda que de forma aproximada, o comportamento da mesma sob torção. Esta observação pode ser melhor fundamentada, uma vez que os resultados ilustrados na Figura 7.3, utilizando a simplificação de Lampert (1973), aproximam-se muito bem dos obtidos por Cocchi \& Cappello (1993). A resposta numérica obtida por Cocchi \& Cappello (1993) é resultante do modelo de torção combinada representada pelo comportamento de treliça espacial, e portanto, com todo o procedimento iterativo em cada elemento da seção vazada correspondente.

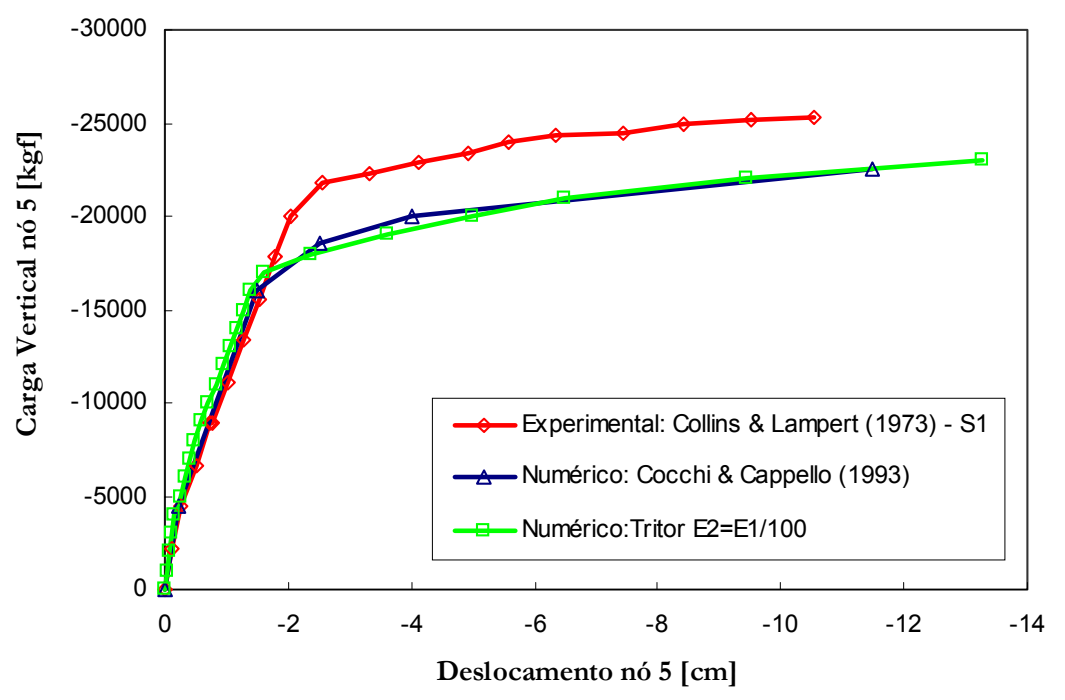

Figura 7.3 - Diagrama força-deslocamento da grelha S1.

A diferença entre a grelha S1 e a grelha S6 basicamente resume-se à diferença dos vãos. $\mathrm{Na}$ grelha S1, a viga V1 apresenta $457 \mathrm{~cm}$ enquanto a viga V2 submetida à torção tem $290 \mathrm{~cm}$ de comprimento. Na grelha S6, a viga V1 tem $290 \mathrm{~cm}$ e a viga V2 tem $457 \mathrm{~cm}$. Isto faz com que a relação momento de torção/momento fletor seja maior na grelha $\mathrm{S} 1$ 
e, portanto, a grelha S6 sofre menor influência no comportamento geral devido à torção.

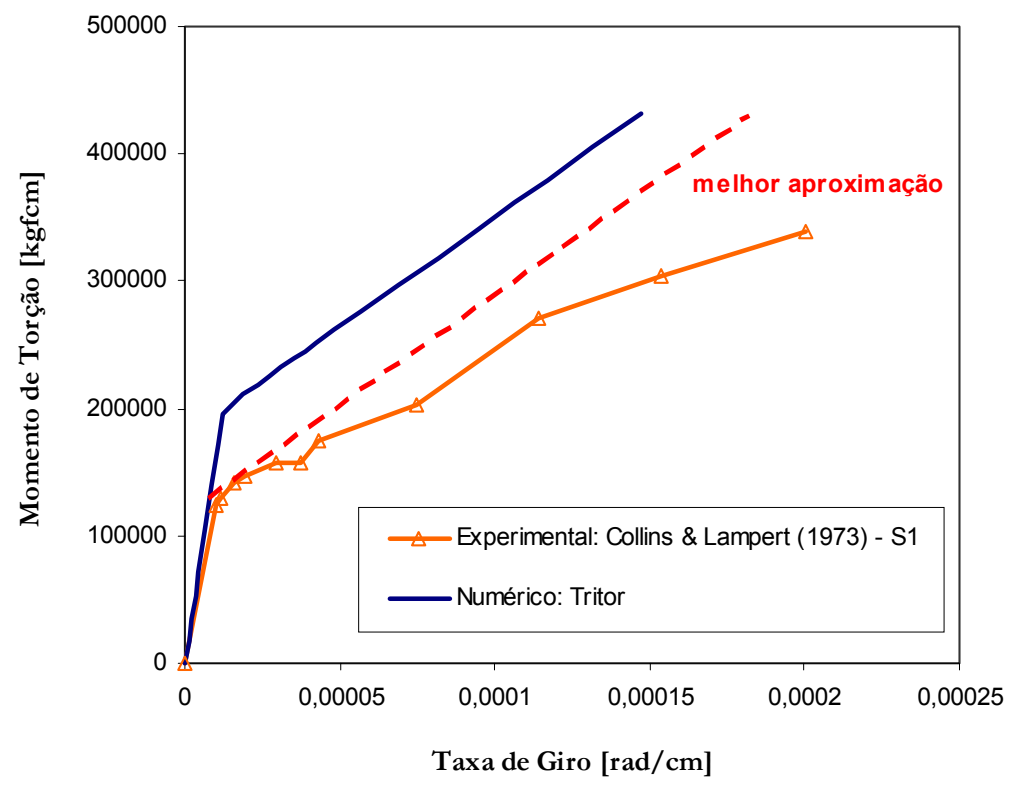

Figura 7.4 - Diagrama momento de torção-taxa de giro.

Analisando a grelha S6 cujos resultados estão ilustrados na Figura 7.5, pode-se observar que a resposta numérica obtida no programa Tritor aproxima-se satisfatoriamente dos resultados experimentais, e são praticamente coincidentes com os resultados obtidos por Cocchi \& Cappello (1993). Vale lembrar que Cocchi \& Cappello (1993) utilizaram o modelo teórico de analogia de treliça espacial.

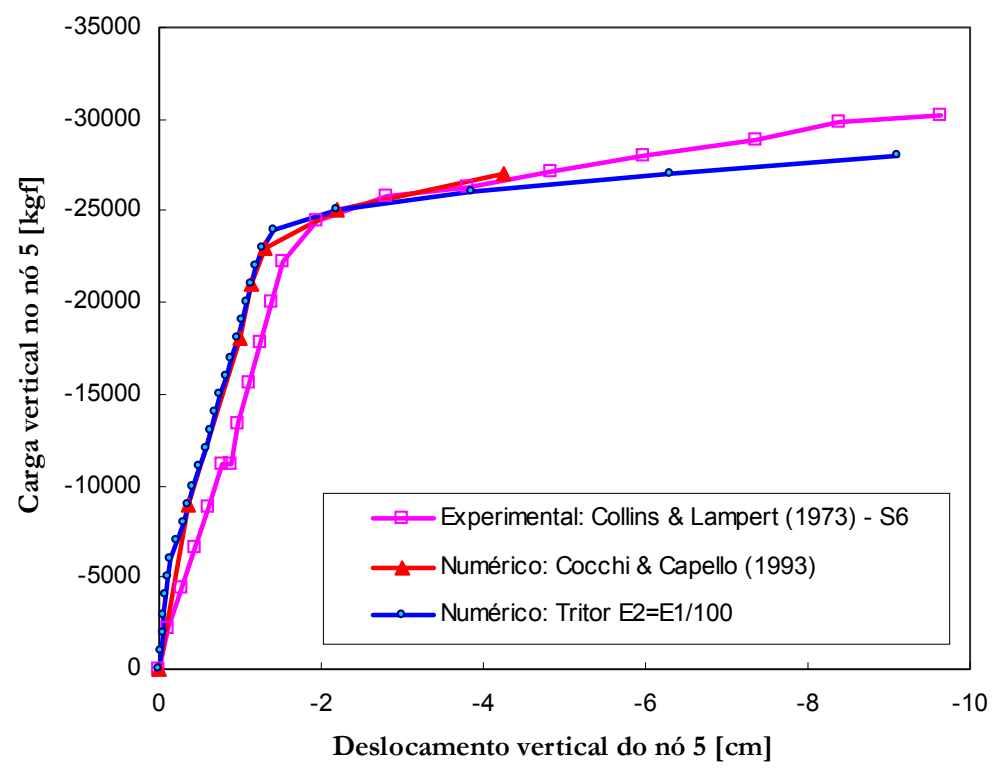

Figura 7.5 - Diagrama força-deslocamento da grelha S6.

Os resultados obtidos numericamente para a grelha S6, onde a torção na viga V2 é menor, aproximam-se ainda melhor da resposta experimental, como pode-se observar na Figura 7.5, comparada à Figura 7.3. Entende-se que em situações onde a torção não é solicitação predominante, e portanto, que define o mecanismo estrutural da peça, a proposta de Lampert (1973) para a rigidez à torção pós-fissuração é razoável e simples. 


\subsection{Viga ENSAIDA POR ONSONGO (1978) - TORÇÃo PREDOMINANTE}

Onsongo (1978) realizou ensaios experimentais em vigas de concreto super-armadas sob torção combinada com flexão para várias relações entre momento de torção $M_{t} \mathrm{e}$ momento fletor M. As vigas foram ensaiadas segundo o esquema estrutural da Figura 7.6. O detalhamento da seção transversal pode ser visualizado na Figura 7.7, cujas especificações encontram-se descritas no Quadro 7.1.

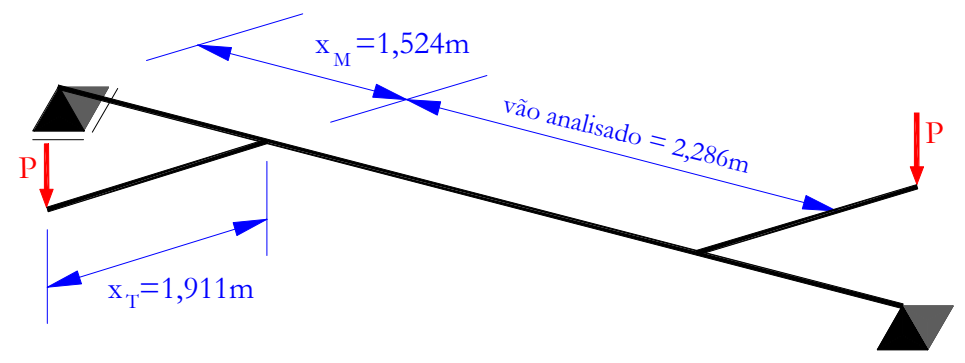

Figura 7.6 - Esquema de ensaio utilizado por Onsongo (1978).

Quadro 7.1 - Armaduras da viga TBS1.

\begin{tabular}{|c|c|c|}
\hline \multirow{2}{*}{} & \multicolumn{2}{|c|}{ Viga TBS1 } \\
\cline { 2 - 3 } & Área & $\mathrm{f}_{\mathrm{y}}\left[\mathrm{kgf} / \mathrm{cm}^{2}\right]$ \\
\hline $\begin{array}{c}\text { Armadura } \\
\text { superior }\end{array}$ & $3 \phi 1,29 \mathrm{~cm}^{2}$ & 4430 \\
\hline $\begin{array}{c}\text { Armadura } \\
\text { lateral }\end{array}$ & $6 \phi 0,71 \mathrm{~cm}^{2}$ & 4430 \\
\hline $\begin{array}{c}\text { Armadura } \\
\text { inferior }\end{array}$ & $7 \phi 5,10 \mathrm{~cm}^{2}$ & 4360 \\
\hline Estribo & $\begin{array}{l}\phi 1,29 \mathrm{~cm}^{2} \\
\mathrm{c} / 7,6 \mathrm{~cm}^{2}\end{array}$ & 4430 \\
\hline
\end{tabular}

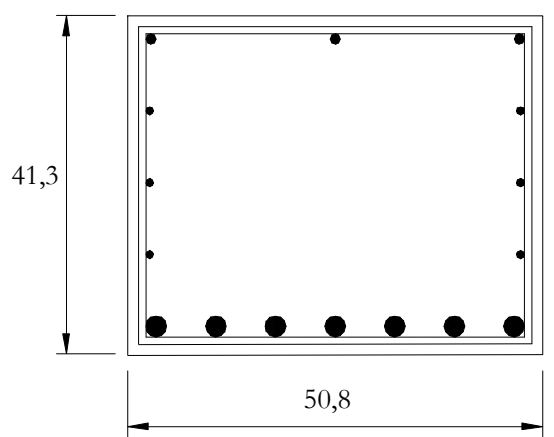

Figura 7.7 - Seção transversal da viga TBS1.

O vão analisado está solicitado por flexão vertical e torção constantes no trecho. Segundo Onsongo (1978), a série TBS ensaiada consiste de seções transversais sólidas retangulares, com relação $\delta=\mathrm{M}_{\mathrm{t}} / \mathrm{M}$ e, portanto, igual a $\delta=\mathrm{x}_{\mathrm{T}} / \mathrm{x}_{\mathrm{M}}=1,254$.

Devido às limitações resultantes da capacidade de carga das vigas, bem como dos atuadores de carga, Onsongo (1978) optou por moldar apenas o trecho central em concreto armado, sendo os braços referentes à aplicação do carregamento, bem como os trechos até os apoios, de seção vazada de aço com dimensões $305 \times 305 \times 13 \mathrm{~mm}$.

Segundo o autor dos ensaios, nas ligações entre o trecho de concreto e o trecho de aço, solicitada por flexão e cisalhamento, a armadura longitudinal foi soldada à placa na extremidade da seção de ligação, conforme mostra a Figura 7.8.

É importante observar que a disposição estrutural de ensaio deve ser adequadamente representada, para que a análise numérica seja o mais fiel possível aos resultados experimentais. 
Observando-se o esquema de ensaio realizado por Onsongo (1978) nota-se que existe um vínculo que impede deslocamentos longitudinais, gerando portanto, esforço normal na viga, vínculo este que pode ser visualizado na Figura 7.9. As placas soldadas nas extremidades da armadura longitudinal também aumentam o enrijecimento da peça com relação à deformação longitudinal das armaduras.

$\mathrm{Na}$ análise numérica tipo 4 do programa Tritor, levando-se em conta a simetria, foi analisado o trecho central sob torção e flexão constantes. Para comparar com os resultados experimentais foi, portanto, impedido o deslocamento longitudinal. Caso o mesmo não seja impedido, resultam maiores curvaturas de flexão, tanto devido à solicitação, quanto à não simetria das armaduras superiores e inferiores da viga.

Pode-se observar nos resultados experimentais de Onsongo (1978) que a relação $\mathrm{M}_{\mathrm{t}} / \mathrm{M}$ variou devido à presença de carga permanente. Considerando o peso próprio $\mathrm{p}_{1}$ dos braços metálicos utilizados para aplicação do carregamento, a relação $\delta$ real é dada por:

$$
\delta=\frac{x_{T}\left(P+\frac{p_{1} x_{T}}{2}\right)}{x_{M}\left(P+p_{1} x_{T}\right)}
$$
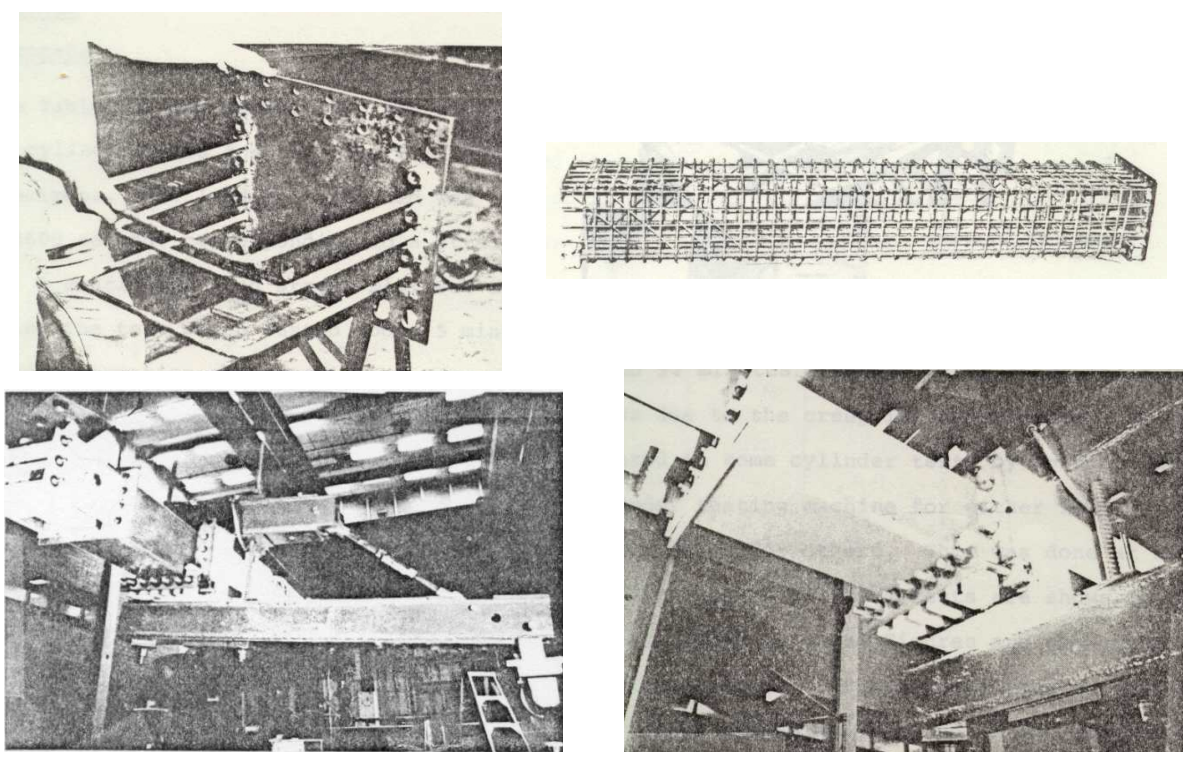

Figura 7.8 - Viga de concreto armado, placas e extensões metálicas utilizadas por Onsongo (1978).

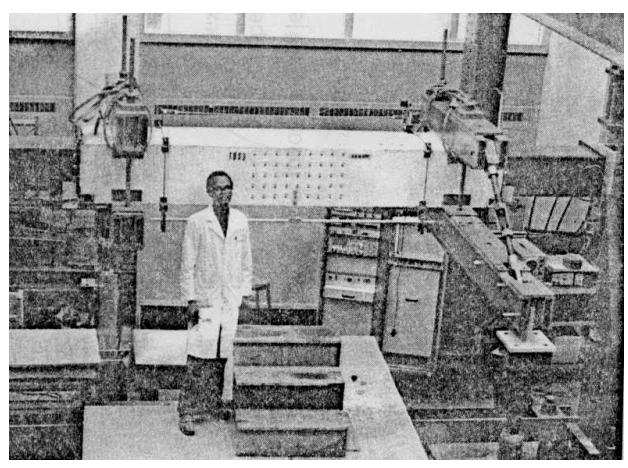

Figura 7.9 - Esquema de ensaio de Onsongo (1978). 
Para $\mathrm{p}_{1}=0$, tem-se $\delta$ constante, conforme ilustra o gráfico da Figura 7.10.

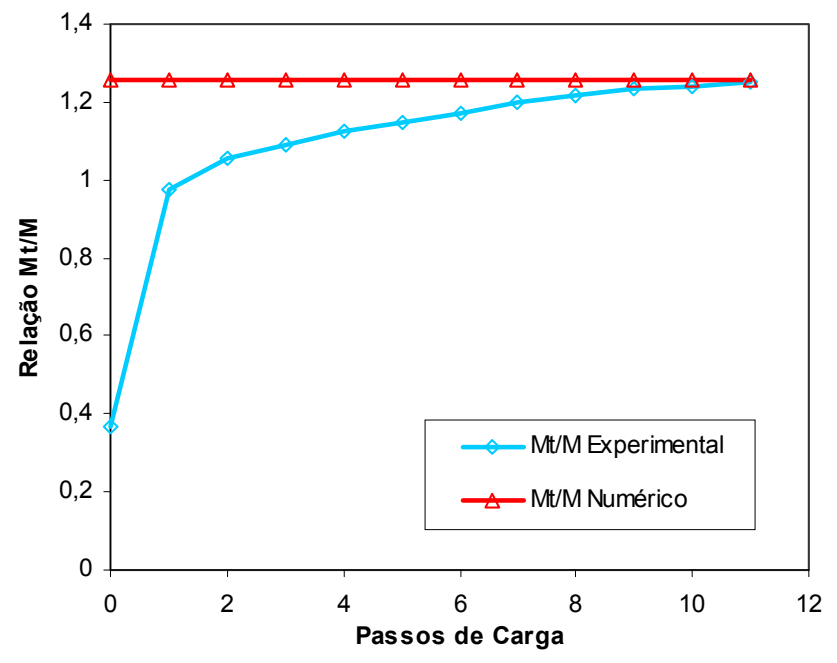

Figura 7.10 - Relação $\delta=M_{t} / M$.

Segundo Onsongo (1978), a viga TBS1 foi ensaiada 3 dias após a concretagem. A resistência à compressão medida em 4 corpos-de-prova foi de $280 \mathrm{kgf} / \mathrm{cm}^{2}$, com deformação longitudinal $\varepsilon_{\mathrm{o}}=2,5 \times 10^{-3}$.

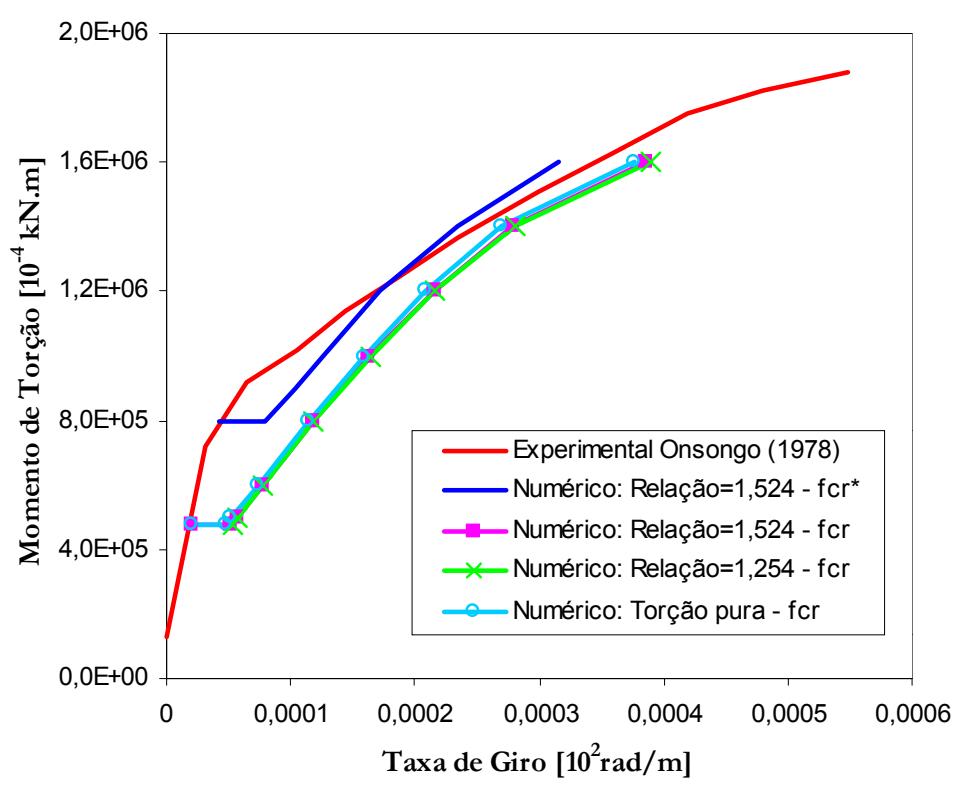

Figura 7.11 - Relação momento de torção versus taxa de giro para a viga TBS1.

Desprezando-se o peso-próprio $\mathrm{p}_{1}$, o qual afeta a relação entre momento de torção e flexão, a Figura 7.11 mostra uma comparação entre a resposta experimental de Onsongo (1978) e as numéricas, para a relação momento de torção-taxa de giro, para as seguintes análises:

. Relação $\delta=1,524$ e resistência à tração do concreto $f_{\text {cr }}$ igual a $17,45 \mathrm{kgf} / \mathrm{cm}^{2}$;

. Relação $\delta=1,524$ e $f_{\mathrm{cr}}{ }^{*}=36,12 \mathrm{kgf} / \mathrm{cm}^{2}$; tentativa de aproximação da resposta experimental;

. Relação $\delta=1,254$ e f

. Torção pura e $\mathrm{f}_{\mathrm{cr}}=17,45 \mathrm{kgf} / \mathrm{cm}^{2}$. 
Observa-se que a resposta numérica do modelo de torção combinada não é significativamente afetada pela presença da flexão, especialmente para relações entre torção e flexão próximas, como as analisadas $\operatorname{com} \delta=1,524$ e $\delta=1,254$. Porém, o valor da resistência à tração do concreto considerada afeta significativamente a resposta numérica do modelo de Cocchi \& Volpi (1996).

Vale lembrar que Lampert (1973) sugere utilizar a mesma expressão para cálculo da rigidez à torção na fase pós-fissuração, independe da solicitação predominante. Esta simplificação resulta da dificuldade em se estabelecer um mecanismo estrutural adequado quando a flexão é ação dominante sobre a torção.

A Figura 7.12 mostra a resposta flexão-curvatura da viga TBS1 para a relação $\delta=\mathrm{M}_{\mathrm{t}} / \mathrm{M}=1,254$. Estão plotadas a resposta experimental, a resposta numérica obtida considerando o modelo de solicitações combinadas com e sem o núcleo central, e a resposta numérica considerando o efeito isolado das solicitações. Neste último, o comportamento à torção é representado por diagrama bi-linear.

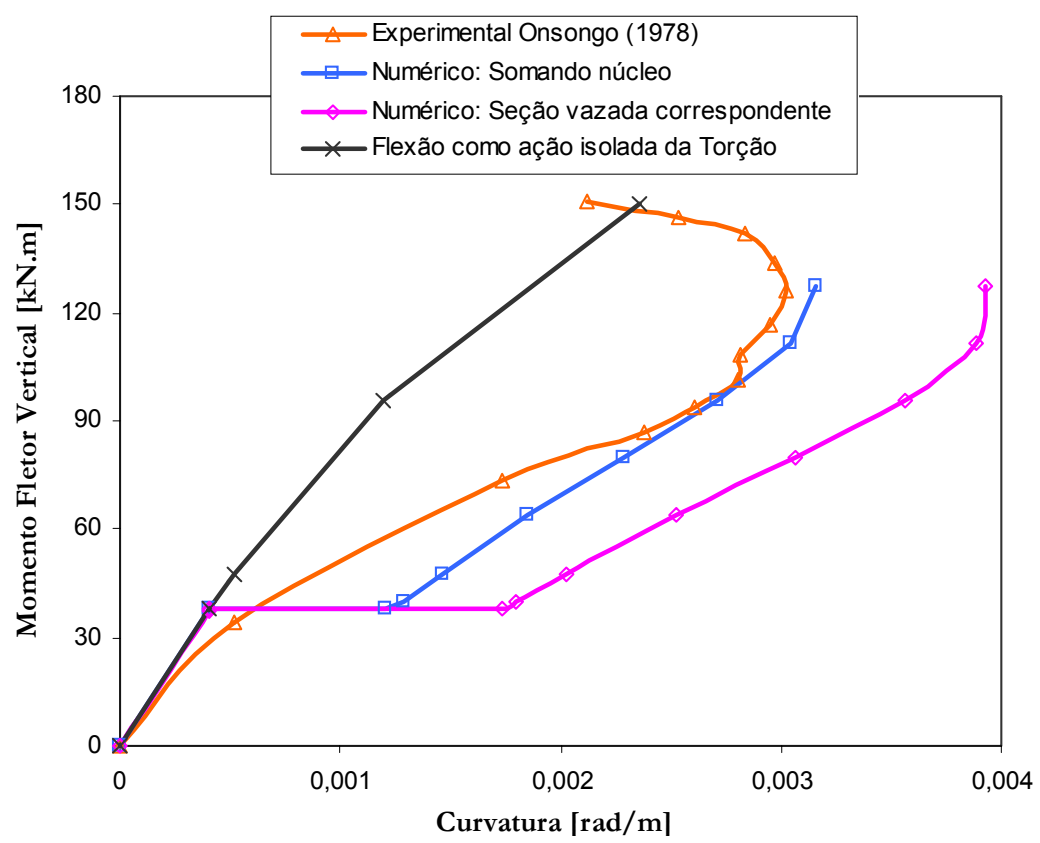

Figura 7.12 - Resposta momento fletor-curvatura para a viga TBS1.

O modelo de ações combinadas despreza a colaboração do núcleo central, uma vez que trabalha com a correspondente seção vazada. No programa Tritor, pode-se também considerar a contribuição do núcleo central à flexão vertical e lateral, bem como devido à força normal. Esta parcela é obtida calculando-se a deformação longitudinal de cada elemento do núcleo discretizado, em função das curvaturas à flexão lateral e vertical e da deformação axial da seção. Conhecida a deformação longitudinal de cada elemento, calculam-se as tensões normais obedecendo-se as leis constitutivas dos materiais, e por fim, obtém-se a contribuição do núcleo nos esforços internos da seção.

A resposta numérica obtida para $\delta=1,254$ no modelo original e, portanto, sem o núcleo central, resulta em curvaturas maiores, uma vez que o modelo considera a seção sólida representada através de seção vazada correspondente. Somar a contribuição do núcleo central, consiste em uma análise mais realista, tendo apresentado bons resultados. 


\subsection{Viga SubMetida À FleXão LATERAl E VERTICAL COM TORÇÃo}

Será analisado neste item o caso de uma viga sob flexão vertical e lateral com torção, a fim de observar o comportamento do modelo proposto por Hannachi \& Fouré (1996) considerando numericamente a variação da rigidez à torção devido à fissuração por flexão. Vale lembrar que o citado modelo é aplicável a casos onde a torção é um efeito secundário, situação esta representativa de um problema de instabilidade lateral.

A viga em questão corresponde à viga ensaiada por Twelmeier \& Brandmann (1985), em escala reduzida 1:4, como ilustra a Figura 7.13. Esta viga foi ensaiada num teste piloto pelos autores acima citados, não tendo sido publicados resultados além dos apresentados na Figura 7.13, nem mesmo são conhecidas as propriedades mecânicas dos materiais constituintes da viga, apenas a seção e as armaduras. Twelmeier \& Brandmann (1985) observam que o modo de ruptura típico ocorre por flexão acompanhada de torção e que o efeito das imperfeições geométricas iniciais é significativo conforme ilustra a Figura 7.13.

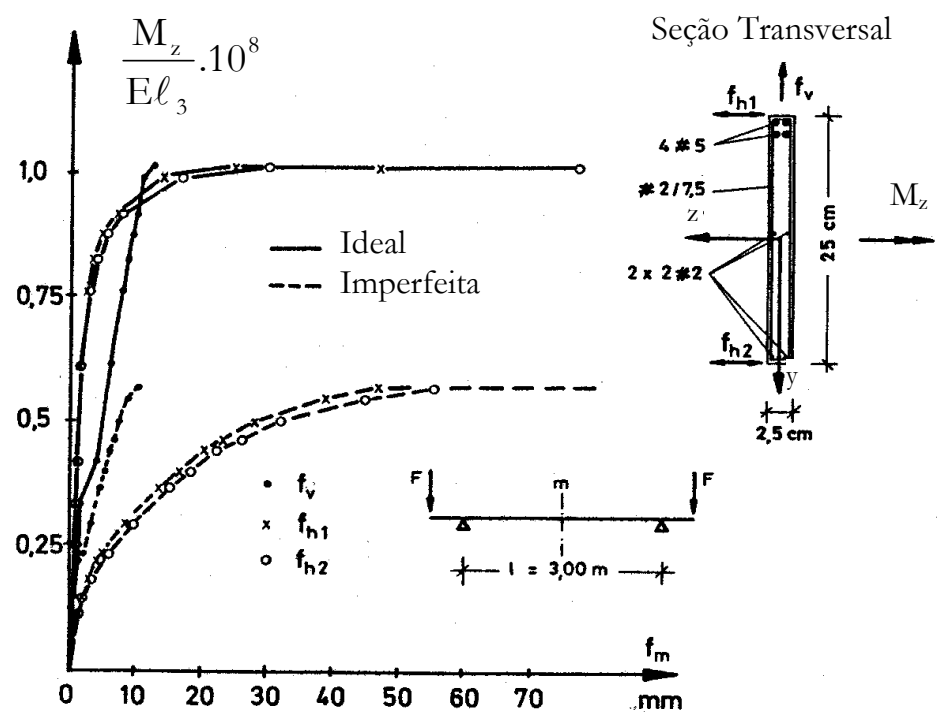

Figura 7.13 - Momento fletor vertical x deslocamento na seção do meio do vão. Twelmeier \& Brandmann( 1985).

Utilizando a simplificação de simetria, conforme ilustrado na Figura 7.14, dividiu-se a metade do vão em 10 elementos de barra. O nó 1 corresponde ao nó do apoio tipo garfo e o nó central corresponde ao nó 11, sobre o eixo de simetria. A seção transversal retangular de dimensões $2,5 \mathrm{~cm} \times 25 \mathrm{~cm}$ foi discretizada em 640 elementos.

Observando as proporções utilizadas por Twelmeier \& Brandmann (1985) para as relações entre os momentos de flexão vertical, flexão lateral e torção, a viga a partir de então identificada por viga VTB será analisada sob momento fletor vertical $M_{z}=7 \mathrm{kN} \cdot \mathrm{m}, \mathrm{M}_{\mathrm{y}}$ igual a 0,5 e $7 \%$ de $\mathrm{M}_{\mathrm{z}}$ e com $\mathrm{M}_{\mathrm{t}}=1 \% \mathrm{M}_{\mathrm{z}}$. A utilização destas proporções entre momento vertical e lateral e momento de torção tem o objetivo de simular um problema de instabilidade lateral.

O carregamento aplicado foi dividido em 70 passos de carga. A viga VTB foi analisada admitindo comportamento não-linear físico, representado por NL, análise tipo 3 no 
programa Tritor, conforme definido no capítulo 5.

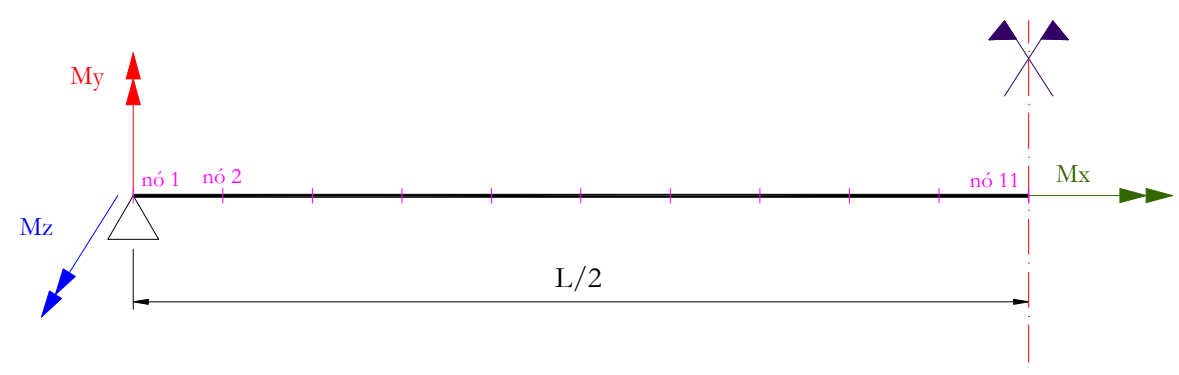

Figura 7.14 - Viga analisada numericamente no programa Tritor.

Quadro 7.2 - Especificações das armaduras da viga VTB - Escala reduzida 1:4.

\begin{tabular}{|c|c|c|c|}
\hline & $\mathbf{A}_{\mathbf{s}}\left[\mathbf{c m}^{2}\right]$ & Diâmetro $[\mathbf{c m}]$ & Estribo \\
\hline$\# \mathbf{2}$ & 0,07925 & 0,3177 & espaçamento $=1,875 \mathrm{~cm}$ \\
\hline $\mathbf{\# 5}$ & 0,49475 & 0,7937 & - \\
\hline
\end{tabular}

As Figuras 7.15 (a) e (b) ilustram os deslocamentos verticais e laterais, respectivamente, para análises considerando o momento fletor lateral $\mathrm{M}_{\mathrm{y}}$ igual a 0,5 e $7 \% \mathrm{M}_{\mathrm{z}}$, com momento de torção fixo, em todas as análises e igual a $1 \% \mathrm{M}_{z}$. Observa-se o sensível aumento dos deslocamentos verticais e laterais devido à variação de $\mathrm{M}_{\mathrm{y}}$. Vale observar que o deslocamento vertical do nó 11 devido à ação única do momento fletor vertical foi de $0,939 \mathrm{~cm}$.

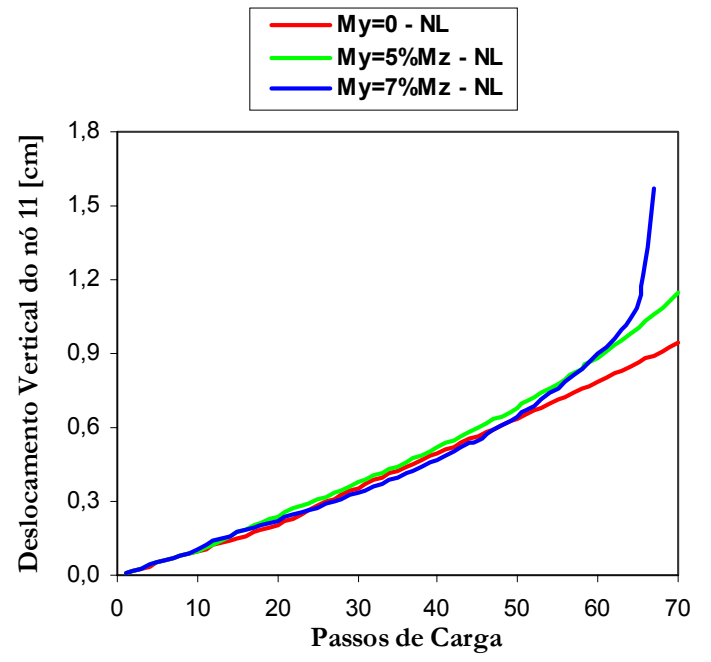

(a) Deslocamento vertical

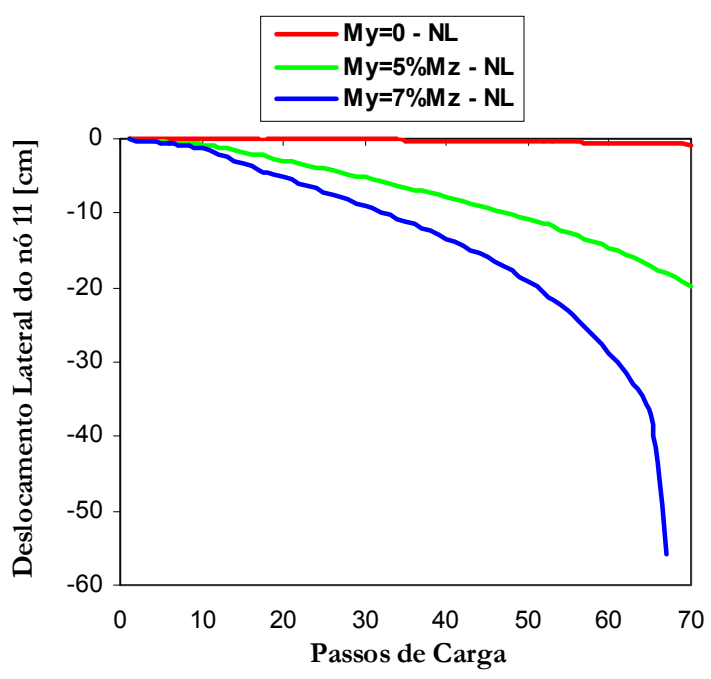

(b) Deslocamento lateral

Figura 7.15 - Deslocamentos (a) vertical e (b) lateral do nó 11 para as análises desenvolvidas.

As respostas momento fletor-curvatura vertical e lateral estão ilustradas nas Figuras 7.16 (a) e (b) referente à análise com $\mathrm{M}_{\mathrm{y}}=5 \% \mathrm{M}_{\mathrm{z}}$ e $\mathrm{M}_{\mathrm{t}}=1 \% \mathrm{M}_{\mathrm{z}}$. Devido à fissuração em estados precoces de carregamento, e por se tratar de uma peça delgada, nota-se a diminuição das rigidezes à flexão. Pode-se observar que também ocorre perda de rigidez à torção, bem menor que à ocorrida para a flexão, conforme ilustra o gráfico de momento de torção versus taxa de giro por torção, na Figura 7.17, para momento fletor lateral igual a 5 e 7\% 
de $\mathrm{M}_{\mathrm{z}}$ e momento de torção constante igual a $1 \% \mathrm{M}_{\mathrm{z}}$.

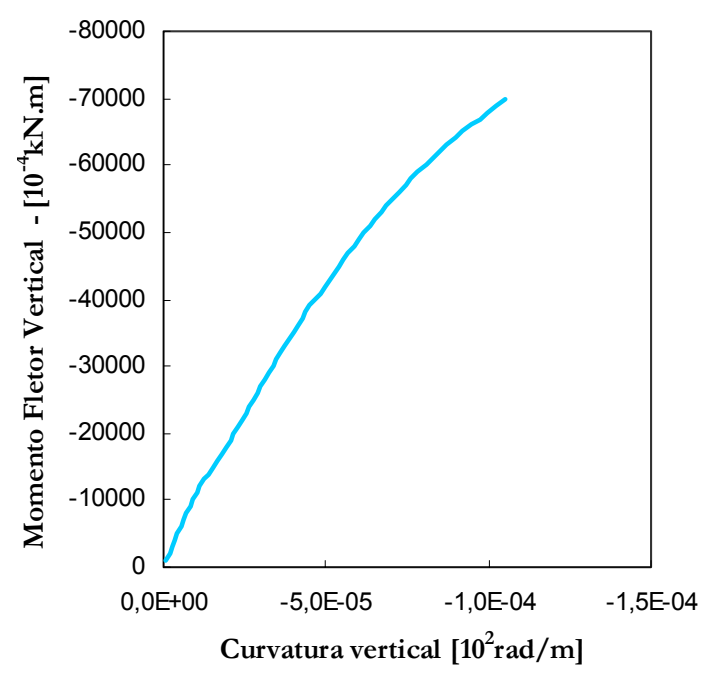

(a)

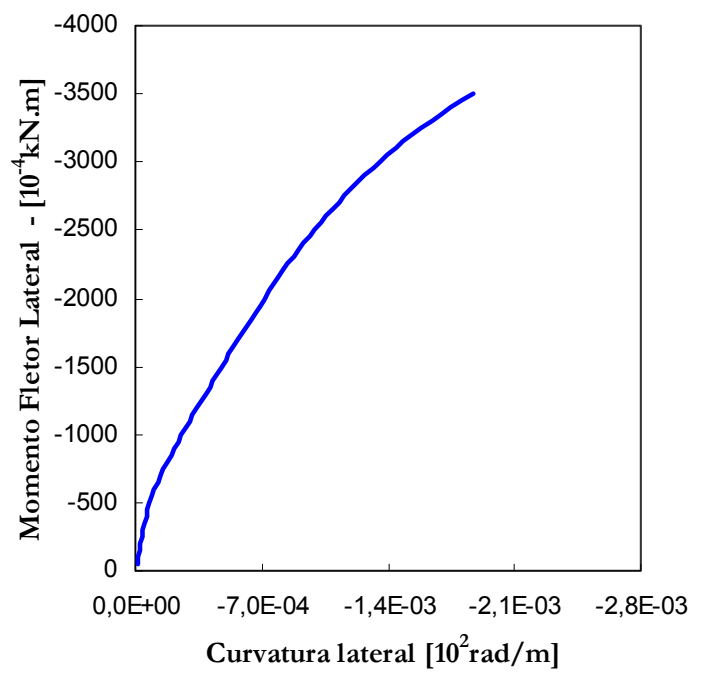

(b)

Figura 7.16 - Diagrama momento fletor versus curvatura (a) vertical e (b) lateral $-\mathrm{M}_{\mathrm{y}}=5 \% \mathrm{M}_{\mathrm{z}}$.

O comportamento momento de torção versus taxa de giro é não-linear quando se considera o modelo de Hannachi \& Fouré (1996) para calcular a rigidez à torção. No modelo citado, esta rigidez é função do nível de fissuração por flexão.

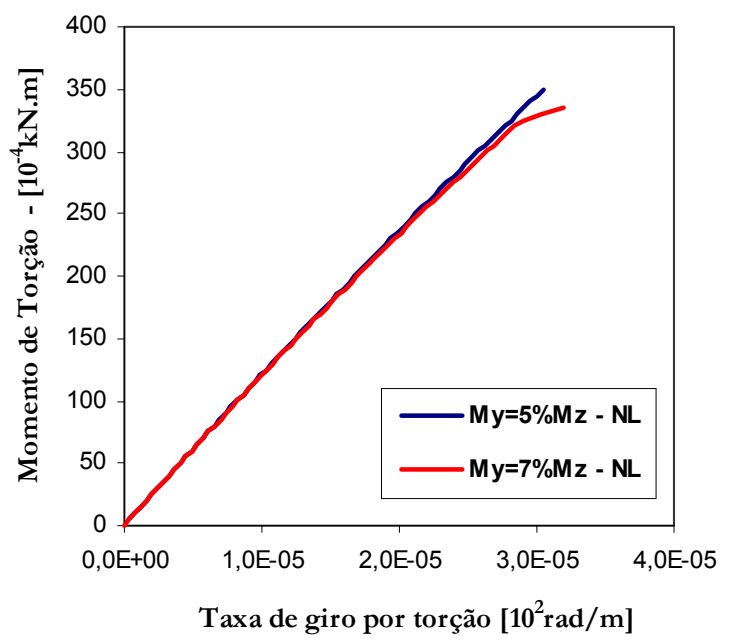

Figura 7.17 - Momento de torção versus Taxa de giro por torção $-\mathrm{M}_{\mathrm{y}}=5$ e $7 \% \mathrm{M}_{\mathrm{z}}$.

A variação da rigidez à torção, flexão lateral e flexão vertical ao longo das etapas de carregamento, pode ser visualizada nas Figuras 7.18, 7.19 e 7.20, para $\mathrm{M}_{\mathrm{y}}$ igual a 0, 5 e $7 \%$ de $\mathrm{M}_{z}$, respectivamente.

Pode-se observar que após a fissuração por flexão, todas as rigidezes começam a diminuir, porém, as rigidezes à flexão lateral e vertical passam por um patamar não fissurado e apresentam uma queda brusca para outro patamar, sendo este levemente inclinado até outra queda levando à ruptura, na situação mais crítica. A grande variação da rigidez à flexão lateral, por se tratar de uma viga esbelta, mostra o quanto esta rigidez é significativa na estabilidade estrutural do elemento. 


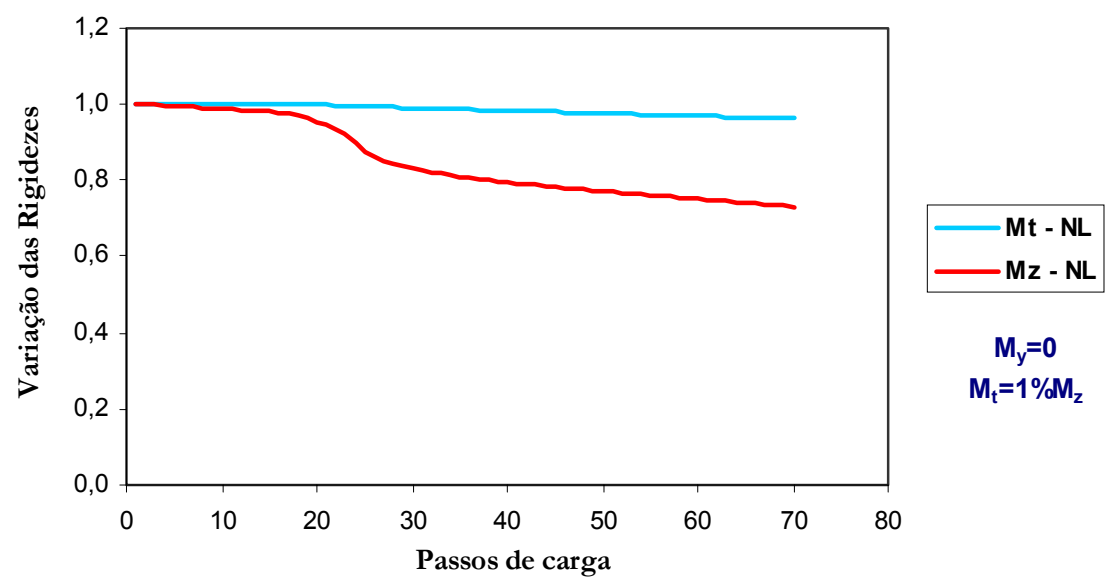

Figura 7.18 - Variação da rigidez à torção e à flexão vertical $-\mathrm{M}_{\mathrm{y}}=0$ e $\mathrm{M}_{\mathrm{t}}=1 \% \mathrm{M}_{\mathrm{z}}$.

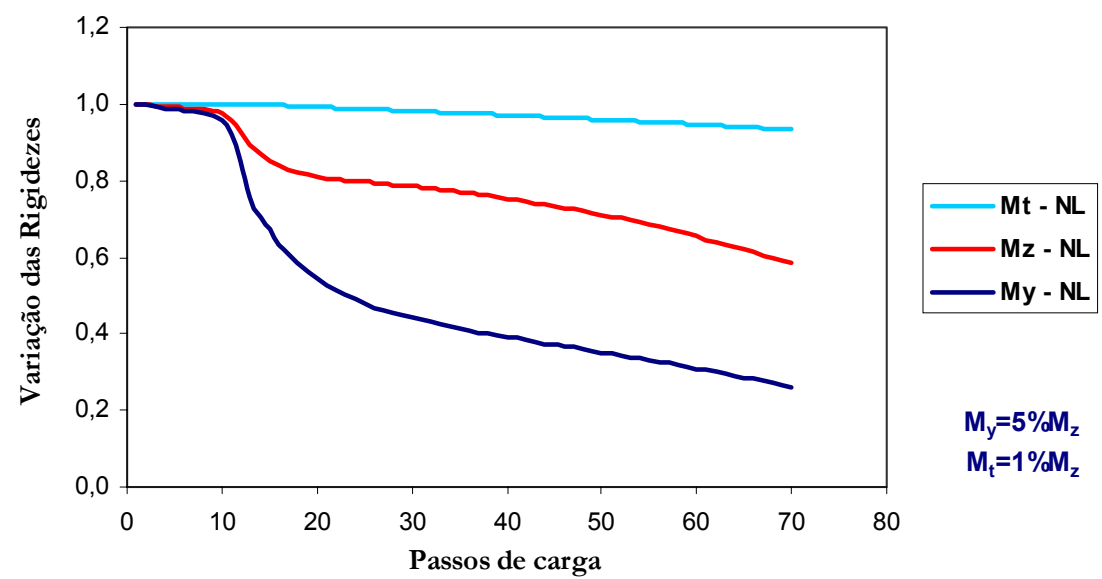

Figura 7.19 - Variação da rigidez à torção, à flexão vertical e lateral $-\mathrm{M}_{\mathrm{y}}=5 \% \mathrm{M}_{\mathrm{z}}$ e $\mathrm{M}_{\mathrm{t}}=1 \% \mathrm{M}_{\mathrm{z}}$.

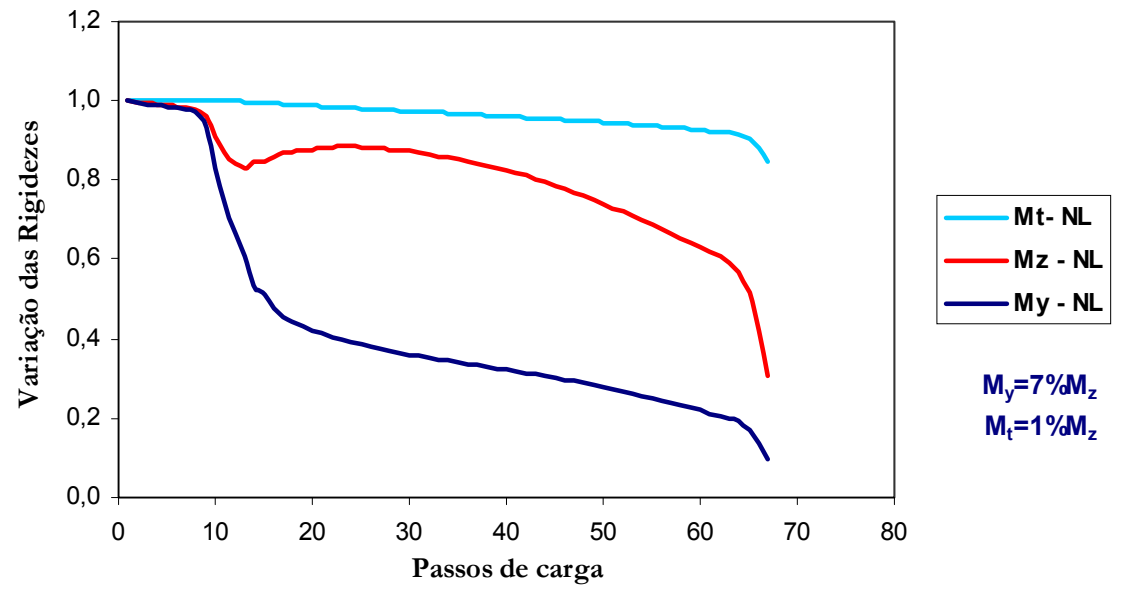

Figura 7.20 - Variação da rigidez à torção, à flexão vertical e lateral $-\mathrm{M}_{\mathrm{y}}=7 \% \mathrm{M}_{\mathrm{z}}$ e $\mathrm{M}_{\mathrm{t}}=1 \% \mathrm{M}_{\mathrm{z}}$.

Twelmeier \& Brandmann (1985), conforme ilustra a Figura 7.13, chamam a atenção para o comportamento do diagrama momento-deslocamento na instabilidade lateral, para uma viga perfeita ou ideal e uma viga com imperfeições geométricas. Os citados autores observam que uma deformação inicial pode causar uma grande flexão lateral resultando no escoamento precoce das armaduras tracionadas, quando comparado ao 
comportamento de uma viga ideal.

Segundo Twelmeier \& Brandmann (1985), após o patamar pré-fissuração na torção, a inclinação da curva é influenciada pelo efeito de pino das armaduras, juntamente com o efeito de engrenamento dos agregados. Conforme descrito no modelo teórico de Hannachi \& Fouré (1996), o mesmo considera a contribuição das armaduras e do concreto, sendo esta última a mais significativa na rigidez final.

Embora não existam respostas experimentais para a validação numérica apropriada do modelo proposto por Hannachi \& Fouré (1996), entende-se que o referido modelo conduz a resultados coerentes e razoáveis. Vale lembrar que em problemas de instabilidade lateral a torção é efeito secundário, porém, o estado de fissuração também altera a rigidez à torção da peça.

\subsection{Viga Protendida EnSaiada por Mast (1994)}

A viga protendida padrão PCI BT 72 ensaiada em escala real por Mast (1994) será a seguir analisada numericamente no programa Tritor. O referido ensaio, descrito no item 6.2 do capítulo 6 , consistiu na aplicação de etapas de giro imposto, resultando num tombamento lateral gradual até a ruptura, que ocorreu à $32^{\circ}$ de inclinação. As características geométricas da seção tranversal encontram-se ilustradas na Figura 7.21.

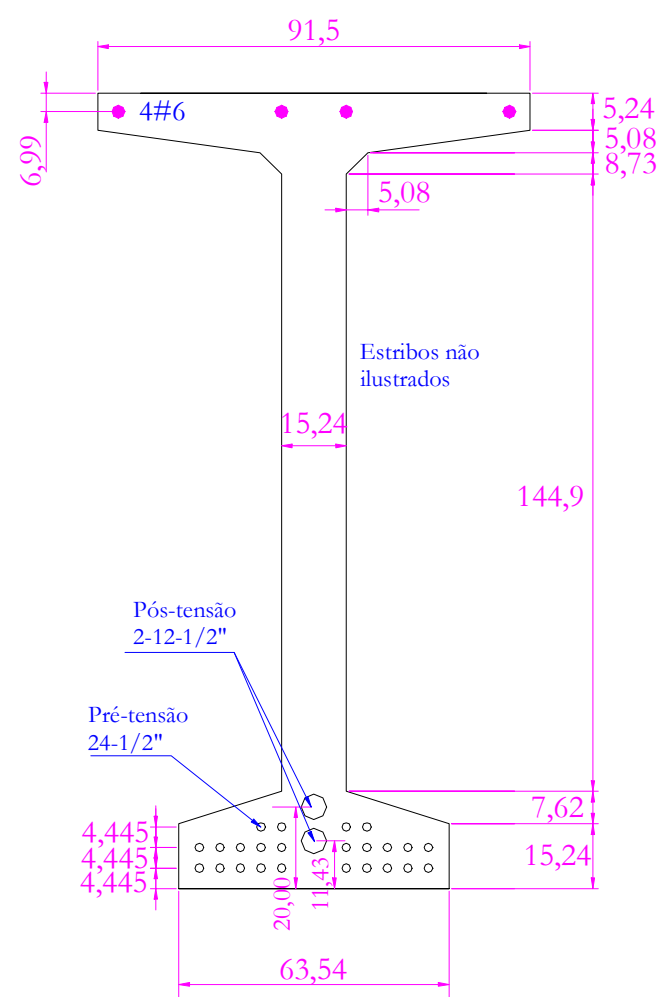

Figura 7.21 - Seção transversal do meio do vão da viga PCI BT 72 ensaiada por Mast (1994).

As seções da extremidade possuem alma com maior largura denominados de blocos de extremidade, viabilizando o posicionamento dos cabos de protensão inclinados. Segundo Mast (1994), o momento fletor vertical no meio do vão devido ao peso-próprio é de $2137 \mathrm{kNm}$. A análise numérica foi então desenvolvida para o carregamento e a 
discretização longitudinal da viga ilustrada na Figura 7.22, sendo a carga $\mathrm{P}=4168 \mathrm{kgf}$, referente aos blocos de extremidade.

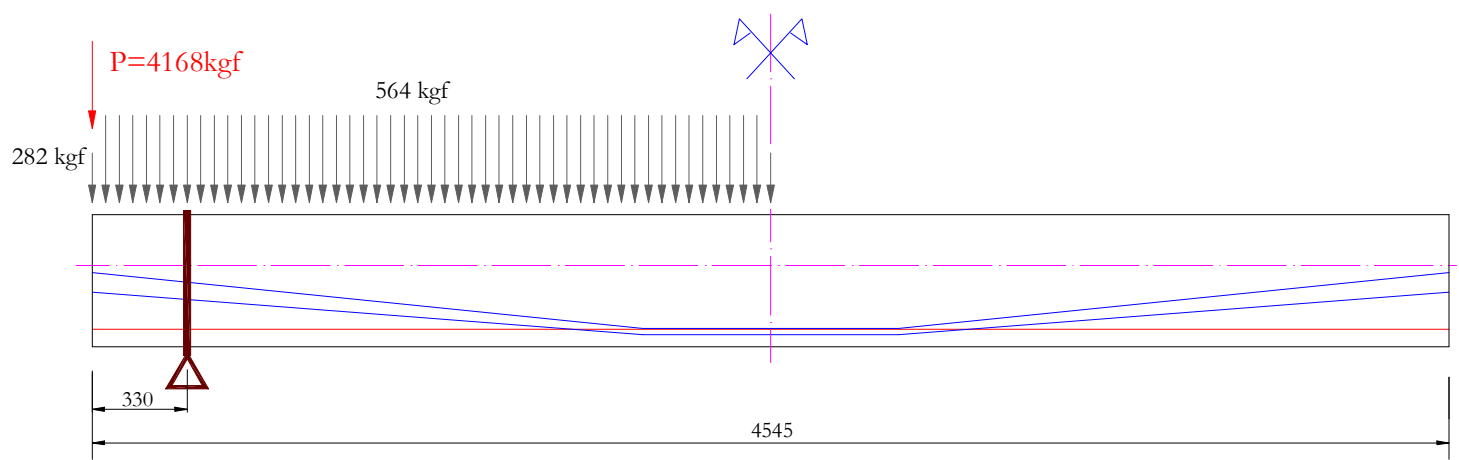

Figura 7.22 - Carregamento e dimensões da viga protendida considerados na modelagem numérica.

A força de protensão total aplicada foi igual a $4623,9 \mathrm{kN}$ sendo a excentricidade $\mathrm{e}_{\mathrm{p}}$ na seção do apoio não informada por Mast (1994). Para a análise numérica, os cabos de pré-tensão foram considerados retos em todo o comprimento da viga enquanto os cabos de pós-tensão foram admitidos inclinados conforme ilustrado na Figura 7.23. Para estes últimos, o comprimento longitudinal dos trechos com variação de inclinação foram admitidos conforme apresentado em Imper \& Las₹lo (1987), para uma viga similar, também do tipo PCI BT 72.

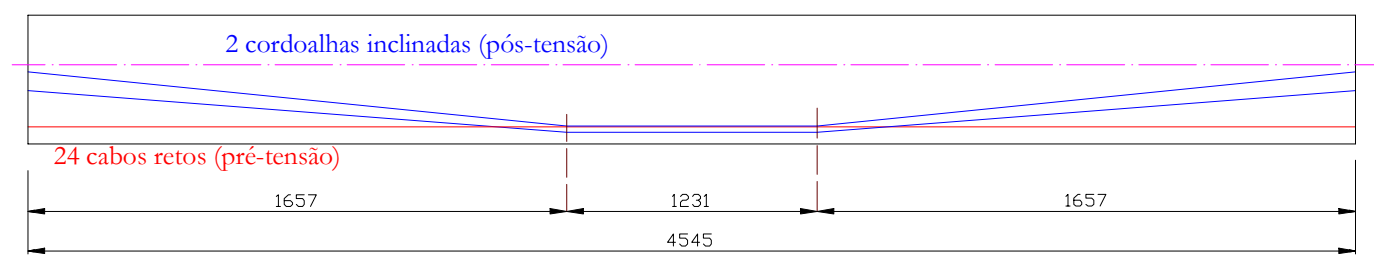

Figura 7.23 - Disposição adotada numericamente para os cabos de protensão.

As análises numéricas foram desenvolvidas para várias inclinações das cordoalhas postensionadas, e desta forma, com excentricidade $e_{\mathrm{p}}$ do cabo resultante iguais a 30, 40, 50 e $60 \mathrm{~cm}$ com relação à linha do centro de gravidade.

A Figura 7.24 mostra a relação entre as etapas de giro imposto nos apoios e o deslocamento lateral da seção do meio do vão. Estão ilustradas a curva experimental obtida por Mast (1994) juntamente com as respostas numéricas, admitindo a excentridade dos cabos igual a $40 \mathrm{~cm}$, zona de envolvimento da armadura iguais a $2,5 \mathrm{e}$ 7,5 vezes o diâmetro da armadura e considerando comportamento elasto-plástico perfeito e com encruamento positivo de $10 \%$.

Observa-se na Figura 7.24 que a influência do comportamento físico assumido para as armaduras passivas altera pouco os resultados numéricos uma vez que o escoamento ocorreu na etapa de giro igual a $35^{\circ}$. A região de tension-stiffening que representa a zona de envolvimento da armadura considerada também alterou muito pouco os resultados.

Nos exemplos analisados, ocorreu convergência numérica até que o estado limite último foi atingido por ruptura das armaduras passivas e escoamento das armaduras de protensão. Para excentricidade $e_{p}$ igual $30 \mathrm{~cm}$, o giro máximo foi de 40 graus e para $e_{p}=50 \mathrm{~cm}$ e $e_{p}=60 \mathrm{~cm}$, para giro imposto igual a 35 graus. 


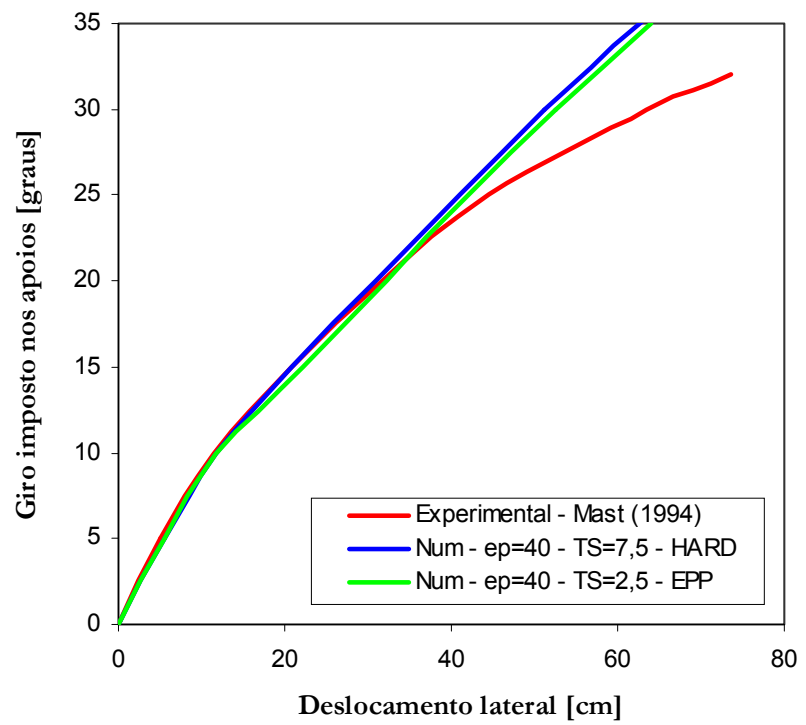

Figura 7.24 - Relação giro imposto versus deslocamento lateral $-\mathrm{e}_{\mathrm{p}}=40 \mathrm{~cm}$.

A resposta numérica apresenta menores deslocamentos nas últimas etapas de giro imposto, comparada à resposta experimental, o que é desfavorável na previsão de ruptura, caso a real excentridade do cabo resultante seja em torno de $40 \mathrm{~cm}$ abaixo da linha do centro de gravidade da viga.

A Figura 7.25 mostra a comparação entre as análises numéricas e experimentais para as várias excentricidades do cabo de protensão resultante, incluindo análise linear e nãolinear. Pode-se observar no gráfico citado a tendência das respostas numéricas em função da excentricidade do cabo, aumentando-se os deslocamentos à medida em que se aumenta a excentricidade $\mathrm{e}_{\mathrm{p}}$.

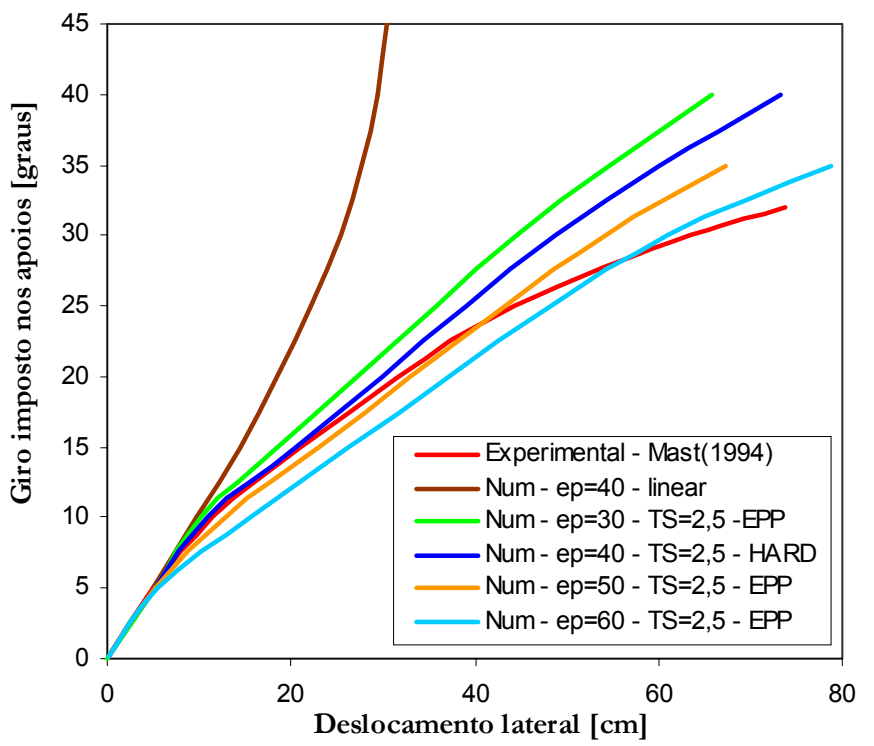

Figura 7.25 - Relação giro imposto versus deslocamento lateral - $\mathrm{e}_{\mathrm{p}}=30,40,50$ e $60 \mathrm{~cm}$.

A previsão de ruptura associada a um estudo de determinação do fator de segurança pode estar dentro de limites razoáveis, observando-se a excentridade real do cabo resultante. 
Apenas a fim de observar as respostas numéricas, e considerando uma excentricidade $e_{p}$ de $40 \mathrm{~cm}$, a Figura 7.26 permite comparar a resposta linear com a não-linear, dos deslocamentos laterais e verticais do nó na seção sobre o eixo de simetria, em função das etapas de giro imposto.

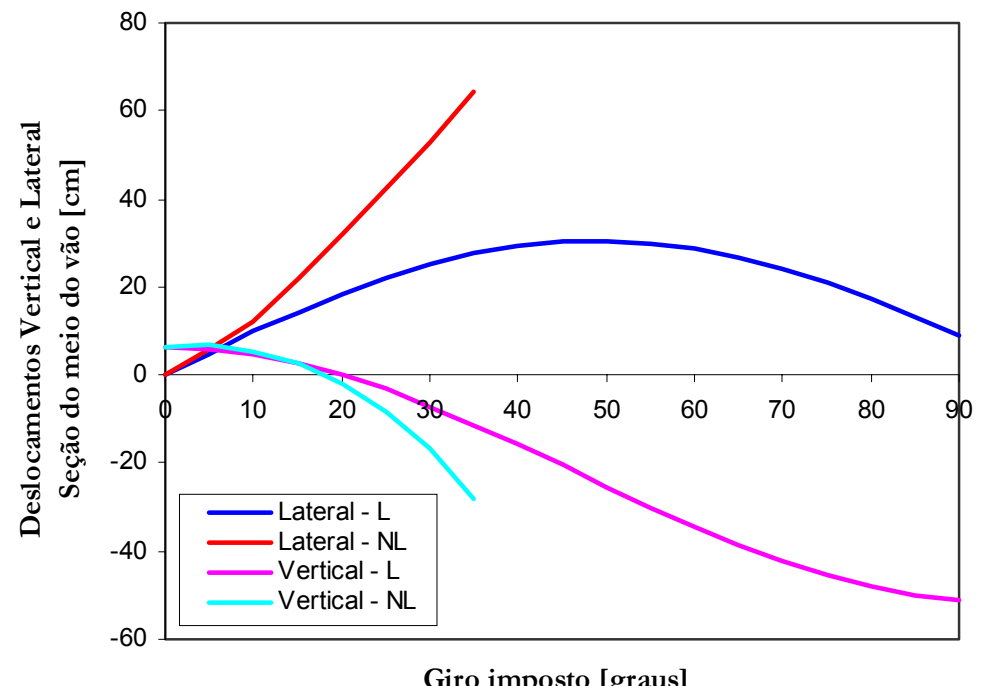

Figura 7.26 - Deslocamentos para $e_{\mathrm{p}}=40 \mathrm{~cm}$ considerando análise linear e não linear.

A Figura 7.27 mostra, para excentriciade $e_{p}$ igual a $50 \mathrm{~cm}$, a deformação de compressão dos pontos nela identificados, ou seja, nas quinas superiores e inferiores, bem como em um elemento na metade da altura da viga, em ambas as faces. Observa-se que na viga protendida, os pontos C3 e C6 na base da viga apresentam deformação de compressão no estado em vazio, ou seja, devido ao peso-próprio e à protensão. Uma vez iniciadas as etapas de giro imposto, o ponto C3 é descomprimido enquanto o ponto C6 é ainda mais comprimido. Os pontos C1 e C4 na face superior e os pontos C2 e C5 no meio da altura da viga também apresentam comportamentos opostos entre si, durante as etapas de giro aplicadas.
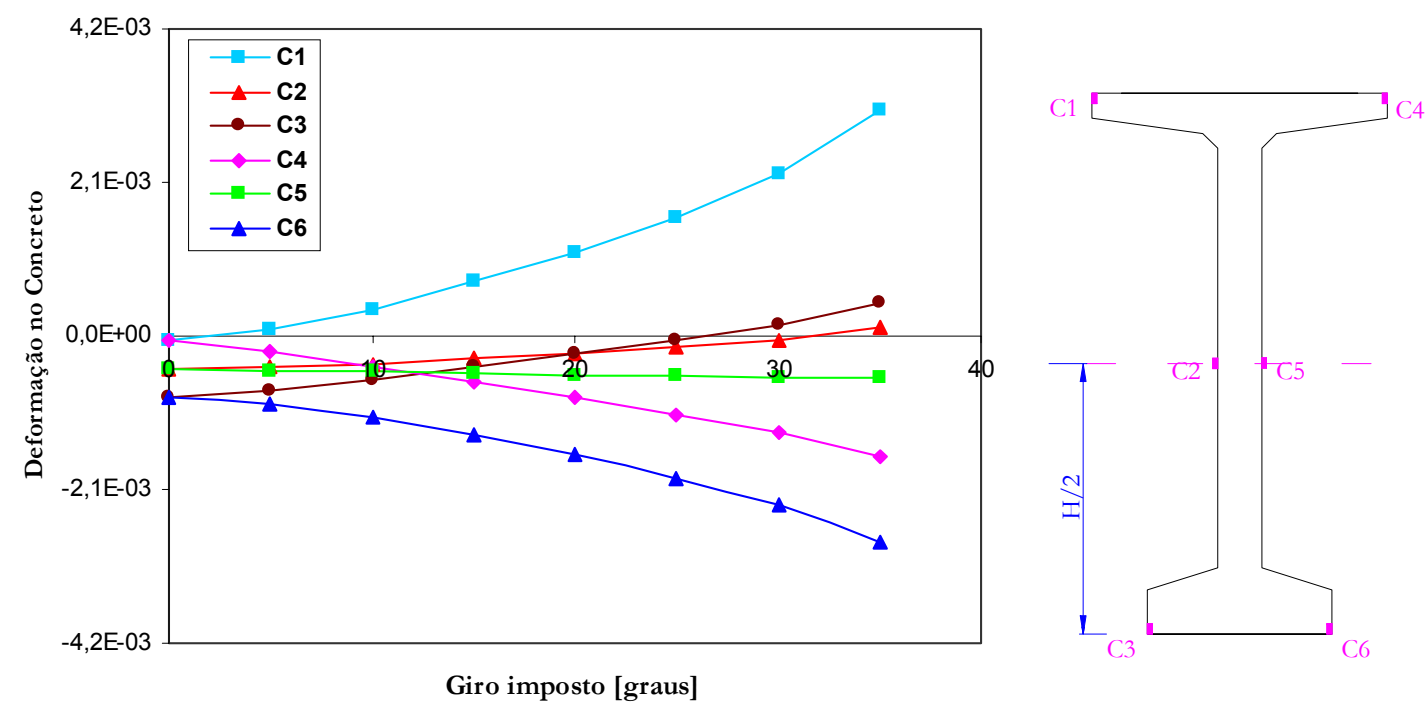

Figura 7.27 - Deformação no concreto para $\mathrm{e}_{\mathrm{p}}=50 \mathrm{~cm}$ - Análise numérica. 
Já as armaduras passivas na mesa superior, no estado em vazio, iniciam-se précomprimidas, sendo que a armadura Asl-1 atinge maior tração, seguidas pelas armaduras Asl-2 e Asl-3, enquanto a armadura Asl-4 mantém-se comprimida, conforme pode-se notar no gráfico da Figura 7.28.
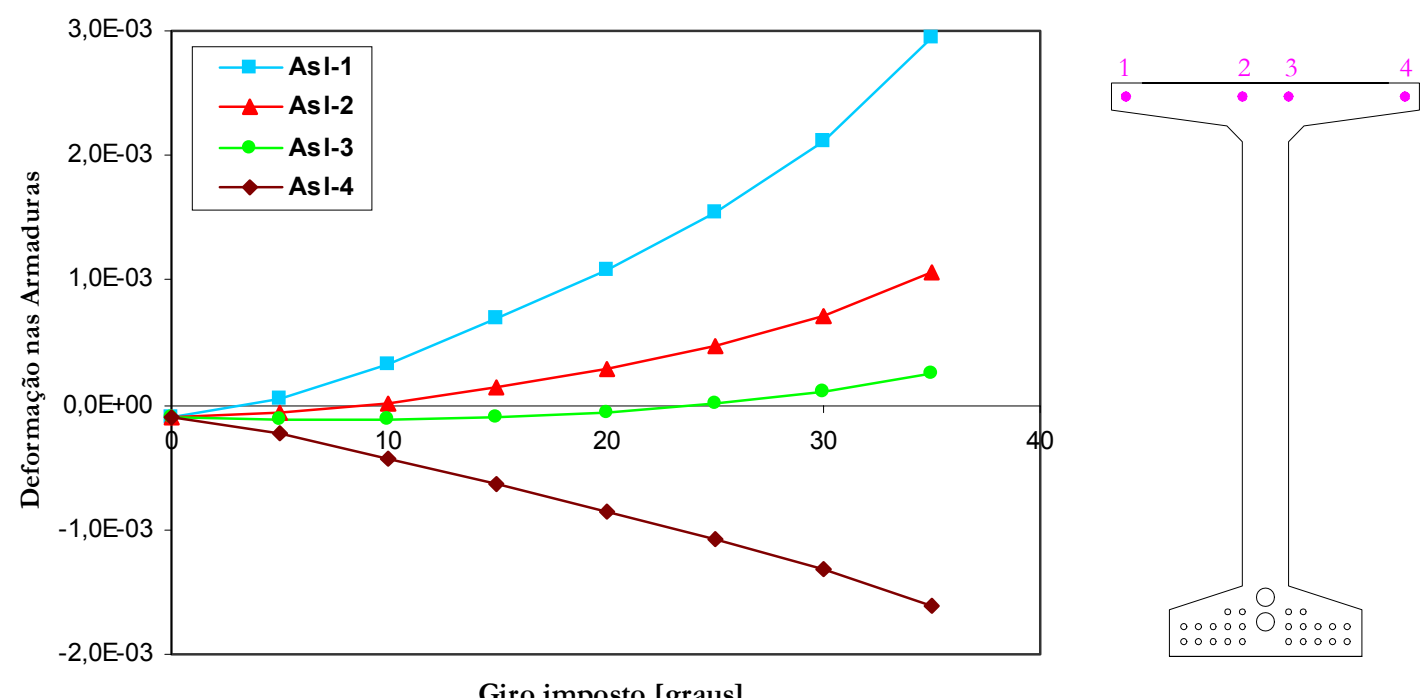

Giro imposto [graus]

Figura 7.28 - Deformação nas armaduras passivas para $\mathrm{e}_{\mathrm{p}}=50 \mathrm{~cm}$ - Análise numérica.

Pode-se observar que as respostas numéricas obtidas nos gráficos das Figuras $7.27 \mathrm{e}$ 7.28 confirmam o comportamento esperado para os materiais, conforme a posição dos pontos analisados na seção transversal.

A consideração de imperfeições iniciais obviamente aumenta os deslocamentos laterais, conforme ilustrado na Figura 7.29, tendo sido neste caso admitida uma flecha inicial igual $1,7 \mathrm{~cm}$ no meio do vão e $e_{\mathrm{p}}=40 \mathrm{~cm}$. Desta análise considerando flecha lateral, podese analisar o comportamento à torção do elemento estrutural.

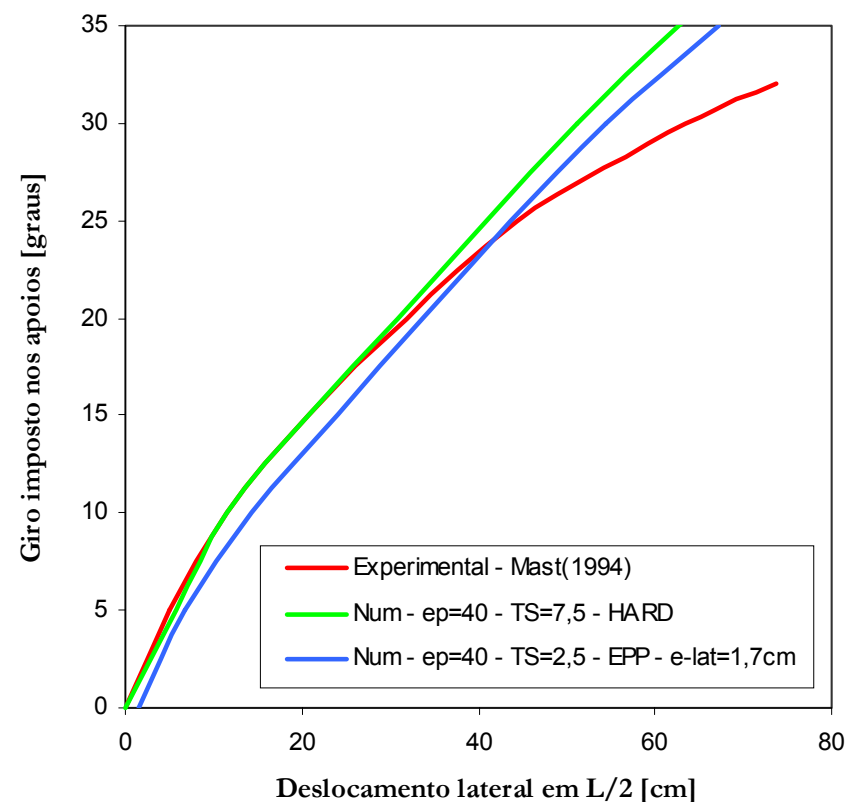

Figura 7.29 - Efeito das imperfeições iniciais na resposta numérica: curvatura lateral inicial. 
A Figura 7.30 ilustra a variação da rigidez à torção devido à fissuração por flexão da peça para algumas situações de excentricidades $e_{p}$ do cabo de protensão resultante. Esta resposta numérica resulta da aplicação do modelo de Hannachi \& Fouré (1996). Observase que embora o processo de fissuração da peça inicie-se a partir de $10^{\circ}$ de giro imposto, é próximo próximo a $15^{\circ}$ que o nível de fissuração começa a ser suficiente para alterar a rigidez à torção da peça, segundo o modelo implementado.

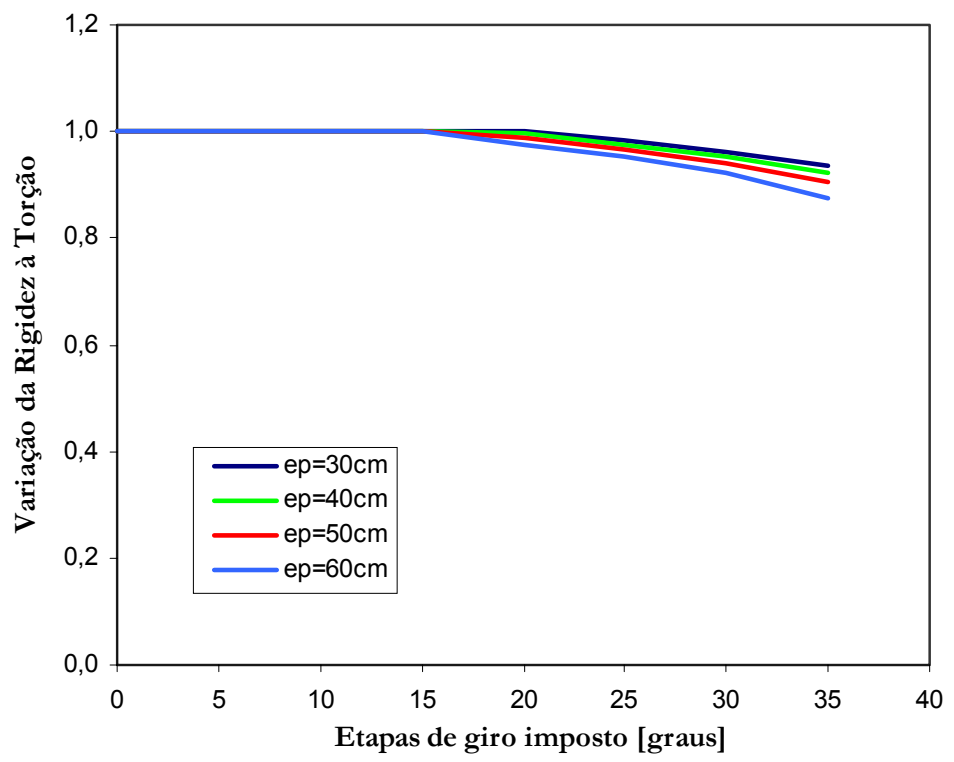

Figura 7.30 - Variação da rigidez à torção - resposta numérica para excentricidades de 30, 40, 50 e $60 \mathrm{~cm}$.

O quadro de fissuração obtido numericamente para a viga protendida modelada com $\mathrm{e}_{\mathrm{p}}=50 \mathrm{~cm}$, sem considerar o efeito de imperfeições iniciais, pode ser visualizado na Figura 7.31.

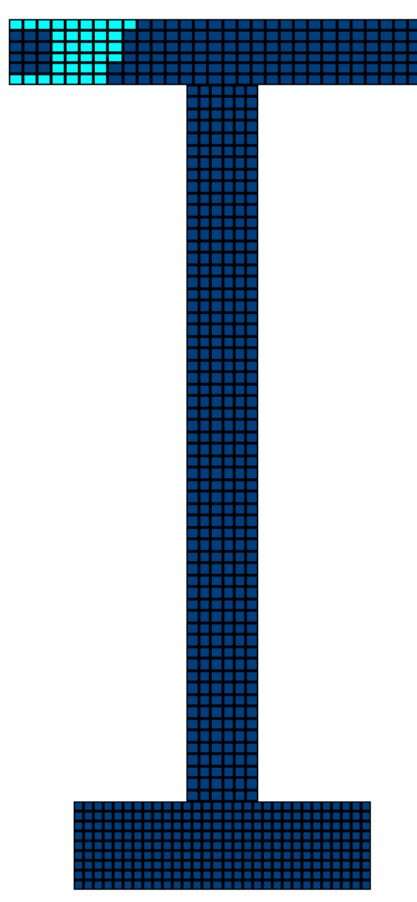

(a) $10^{\circ}$

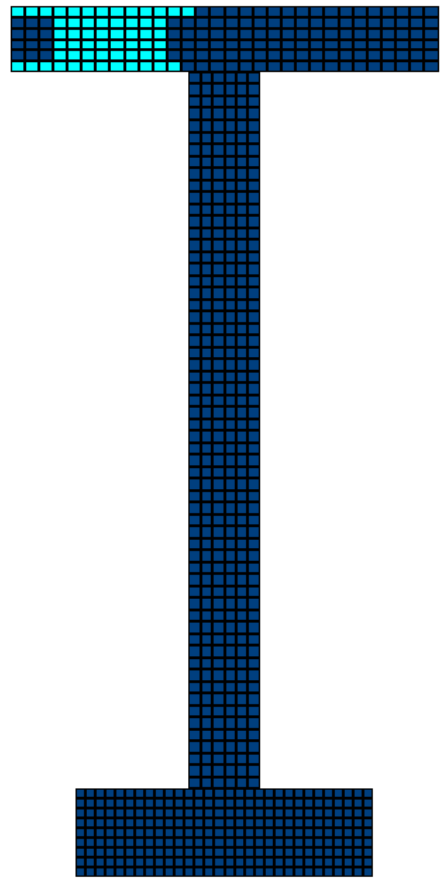

(b) $15^{\circ}$

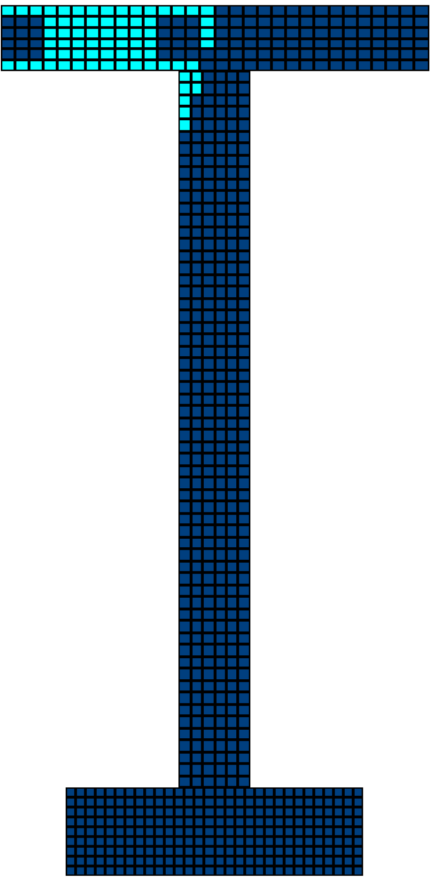

(c) $20^{\circ}$ 


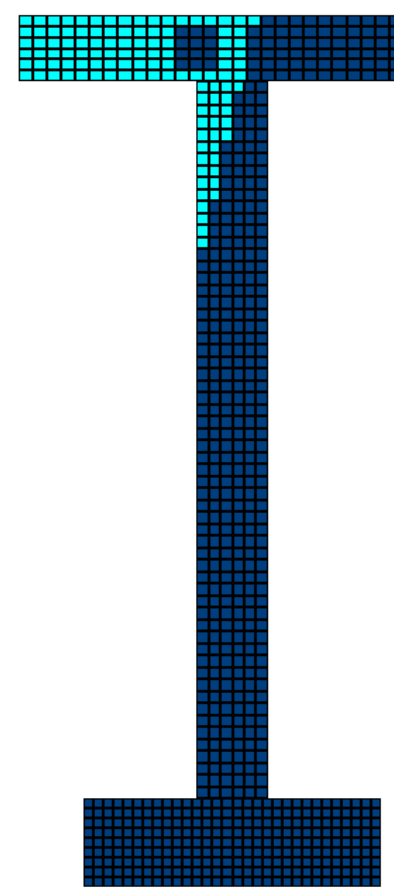

(d) $25^{\circ}$

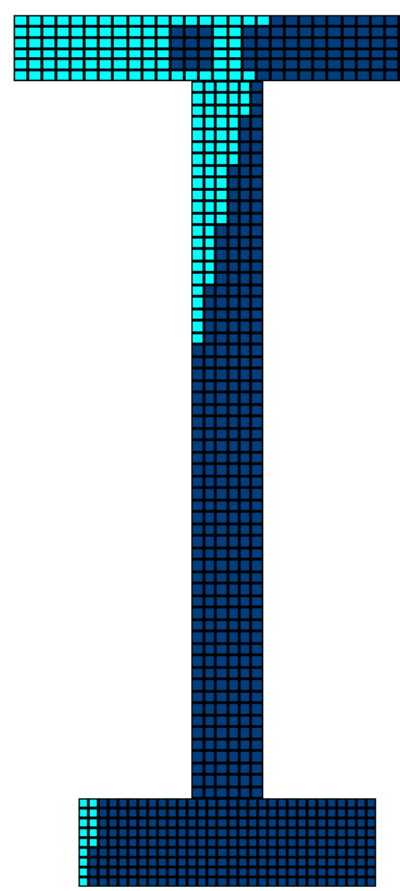

(e) $30^{\circ}$

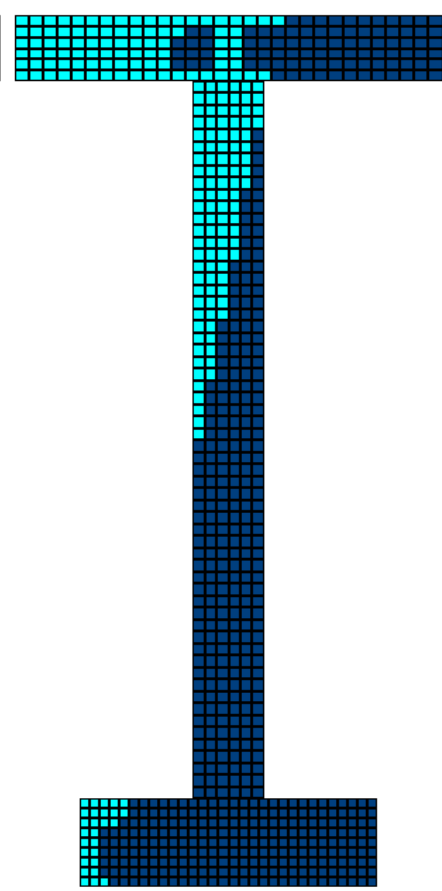

(f) $35^{\circ}$

Elemento fissurado

Elemento não fissurado

Figura 7.31 - Quadro de fissuração obtido numericamente com $e_{\mathrm{p}}=50 \mathrm{~cm}$ para etapas de giro imposto de (a) $10^{\circ}$, (b) $15^{\circ}$, (c) $20^{\circ}$, (d) $25^{\circ}$, (e) $30^{\circ}$ e (f) $35^{\circ}$.

Nas etapas de giro imposto que apresentam elementos fissurados de concreto, pode-se observar a zona de envolvimento da armadura considerada.

\subsubsection{Simulação NumÉRICA da FASE de IÇAMENTO COM APOIOS DEFORMáveIS}

A fim de desenvolver uma análise da fase de içamento com cabos verticais, a viga ensaiada por Mast (1994) será modelada numericamente com apoios deformáveis à torção.

A constante de mola foi estimada considerando o equilíbrio entre a reação no cabo e o giro permitido pela mola, conforme ilustra a Figura 7.32. A rigidez da mola $\mathrm{K}_{\theta_{\mathrm{x}}}$ é dada por:

$$
\begin{gathered}
\frac{\mathrm{P}}{2} \mathrm{e}_{\mathrm{i}}=\mathrm{K}_{\theta_{\mathrm{x}}} \cdot \theta_{\mathrm{x}} \\
\mathrm{K}_{\theta_{\mathrm{x}}}=\frac{\mathrm{P}}{2} \cdot \mathrm{y}_{\text {sup }} \cdot \frac{\operatorname{sen}\left(\theta_{\mathrm{x}}\right)}{\theta_{\mathrm{x}}}=28161 * 90,232 * \frac{\operatorname{sen}\left(\theta_{\mathrm{x}}\right)}{\theta_{\mathrm{x}}}
\end{gathered}
$$

O carregamento aplicado se resume ao peso-próprio e à protensão, tendo sido aplicado em 10 etapas de carga.

A seguir, serão analisadas a segurança da fase de içamento considerando o posicionamento dos cabos de suspensão sem balanços e com balanços. 


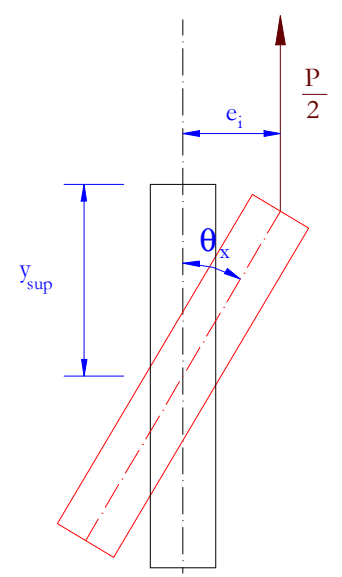

Figura 7.32 - Estimativa da constante de mola.

\subsubsection{SUSPENSÃO SEM BALANÇOS}

Considerando o efeito da variação da excentricidade lateral inicial $\mathrm{e}_{\mathrm{i}}$ como fator indutor da instabilidade lateral, pode-se observar na Figura 7.33, a resposta numérica obtida para os deslocamentos vertical e lateral da seção central, com e $\mathrm{i}_{\mathrm{i}}$ igual a 4, 5, 6, 6,2 e 6,5cm.

Conforme ilustra a Figura 7.33 e 7.34, esta última referente ao giro máximo por torção na seção central, a situação crítica ocorreu para excentricidade inicial lateral $\mathrm{e}_{\mathrm{i}}$ igual a $6,2 \mathrm{~cm}$. Na análise admitindo $\mathrm{e}_{\mathrm{i}}=6,5 \mathrm{~cm}$ ocorreu convergência até o nono passo de carga, no qual a seção central girou de $3,34^{\circ}$. A partir deste ângulo de inclinação lateral não verificou-se mais convergência, ou seja, não foi encontrada uma posição de equilíbrio.

Nesta posição, a viga perde estabilidade lateral praticamente sem apresentar um estado razoável de fissuração, como pode-se observar na Figura 7.35.

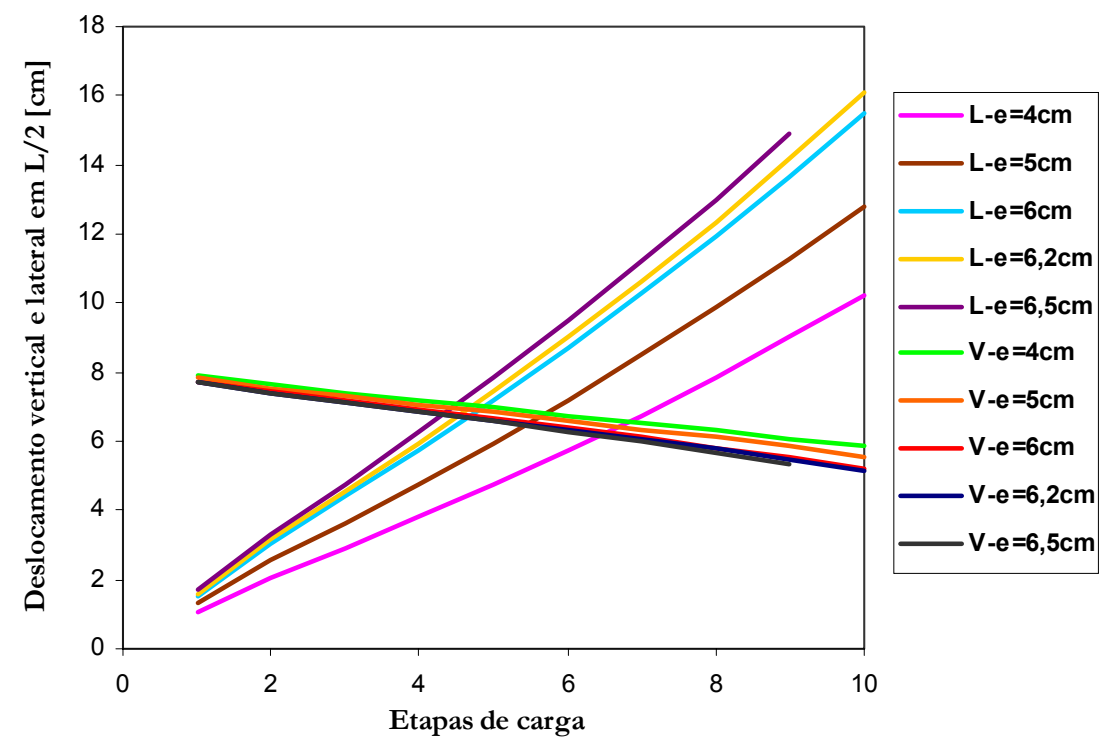

Figura 7.33 - Deslocamentos vertical e lateral na seção do meio do vão.

A análise da segurança nas fases transitórias também pode ser feita considerando o efeito do vento associado ou não à possibilidade de excentricidade lateral inicial por 
imperfeições construtivas. A modelagem numérica considerando apoios deformáveis à torção permite simular outras situações práticas, como a fase de transporte em caminhão, considerando a deformabilidade do sistema hidráulico do mesmo, sendo possível inclusive considerar um giro imposto devido à superelevação da via de tráfego.

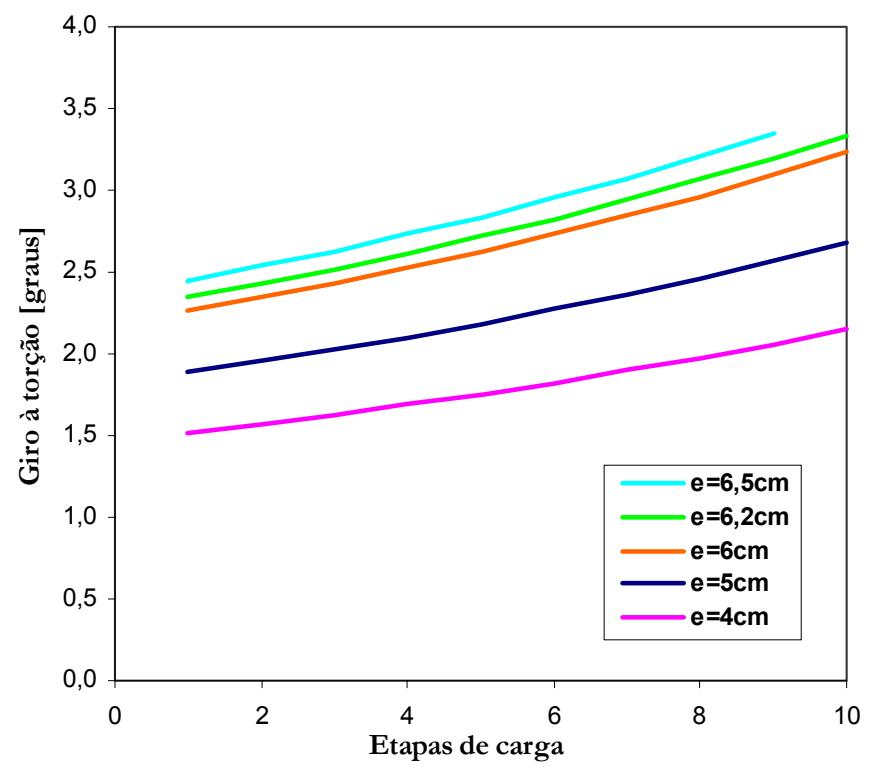

Figura 7.34 - Giro à torção na seção do meio do vão.

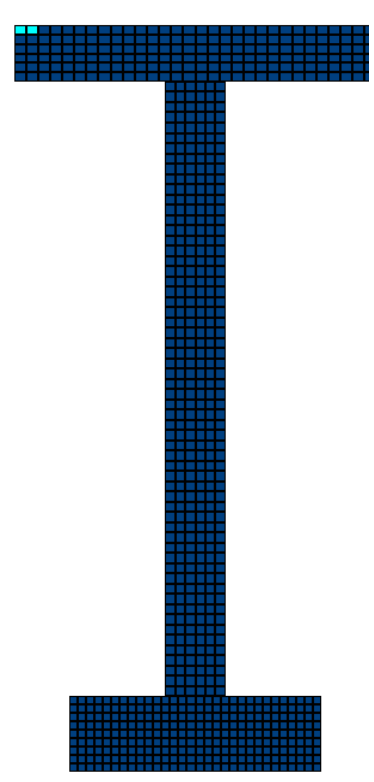

Figura 7.35 - Quadro de fissuração.

A NBR-9062/85 recomenda considerar uma tolerância de linearidade da peça prémoldada decorrente de sua execução igual a $\ell / 1000$, ou seja, para a viga em estudo cujo comprimento longitudinal é 45,45m, uma excentricidade lateral inicial de aproximadamente $4,5 \mathrm{~cm}$. Levando-se em conta uma tolerância de $6 \mathrm{~mm}$ no posicionamento dos cabos de suspensão, tem-se uma excentricidade lateral inicial total $\mathrm{e}_{\text {if }}$ igual a $5,1 \mathrm{~cm}$.

Assim, tem-se para a suspensão sem balanços um fator de segurança igual a 1,22, conforme estimado pela equação (7.3).

$$
\mathrm{FS}=\frac{\mathrm{e}_{\mathrm{i}_{\text {_máx }}}}{\mathrm{e}_{\mathrm{if}}}=\frac{6,2}{5,1}=1,22
$$

Tem-se portanto, um fator de segurança pequeno e que pode não permitir cobrir eventuais carregamentos laterais devido ao vento.

\subsubsection{SUSPENSÃO COM BALANÇOS}

Analisou-se neste trabalho seis comprimentos de balanços, desde o içamento pelo nó 2 , com 45,45cm de balanço, depois pelos nós 3, 4, 6, e finalmente pelo nó 7, com $272,7 \mathrm{~cm}$ de balanço.

A Figura 7.36 mostra a variação do ângulo de giro da seção central em função da excentricidade lateral inicial admitida para a mesma. No içamento pelos nós 3 e 4, numericamente, a seção transversal do meio do vão começa a apresentar fissuração, 
embora inexpressiva, conforme mostra a Figura 7.37.

Observa-se que a partir da suspensão pelo nó 4, o giro por torção já passa a ser negativo, ou seja, os balanços têm efeito instabilizante. O efeito estabilizante ou não dos balanços pode ser visualizado nas Figuras 7.38 (a) e (b).

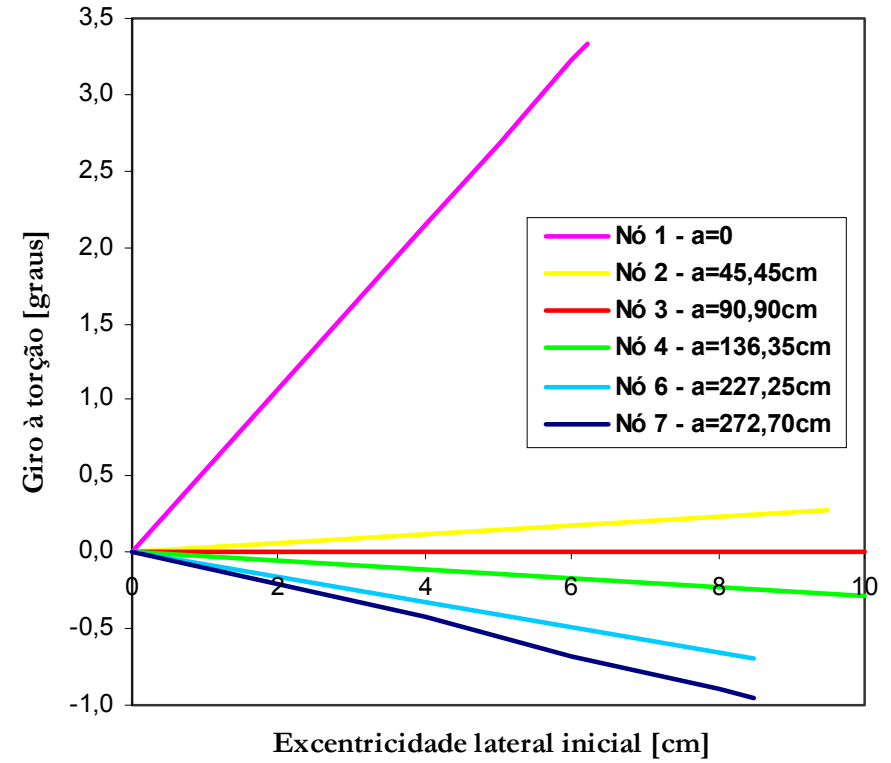

Figura 7.36 - Giro à torção na seção do meio do vão versus Excentricidade lateral inicial.

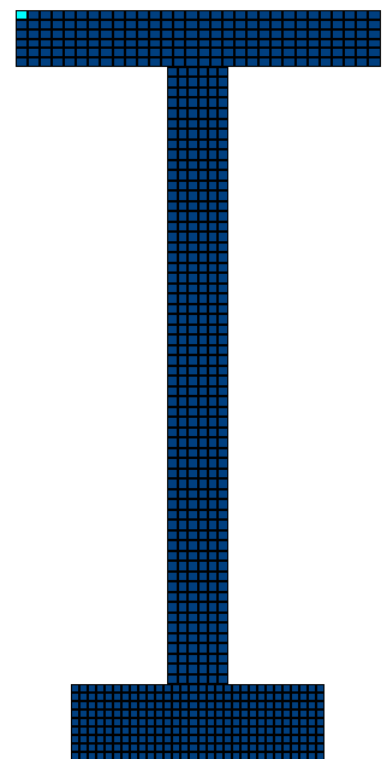

Figura 7.37 - Quadro de fissuração da seção crítica: Içamento pelo nó 3 ou nó 4 .

O fator de segurança obtido para a suspensão pelo nó 2 é igual a 1,86, conforme calculado pela Equação 7.4, com giro na seção central igual a $0,279^{\circ}$, sem apresentar fissuração.

$$
\text { Nó 2: } \quad F S=\frac{9,5}{5,1}=1,86
$$

O içamento pelos nós 3 e 4 resulta em FS=1,96 conforme mostra a equação (7.5), com um quadro de fissuração insignificante. $O$ giro máximo na seção central foi de $-0,003^{\circ} \mathrm{e}$ $-0,289^{\circ}$, respectivamente.

$$
\text { Nó } 3 \text { e Nó 4: } F S=\frac{10}{5,1}=1,96
$$

A suspensão pelos nós 6 e 7 têm $F S=1,67$, não apresentam fissuração, sendo o giro da seção do meio do vão igual a $-0,698^{\circ}$ e $-0,950^{\circ}$, respectivamente.

$$
\text { Nó } 6 \text { e Nó 7: FS = } \frac{8,5}{5,1}=1,67
$$




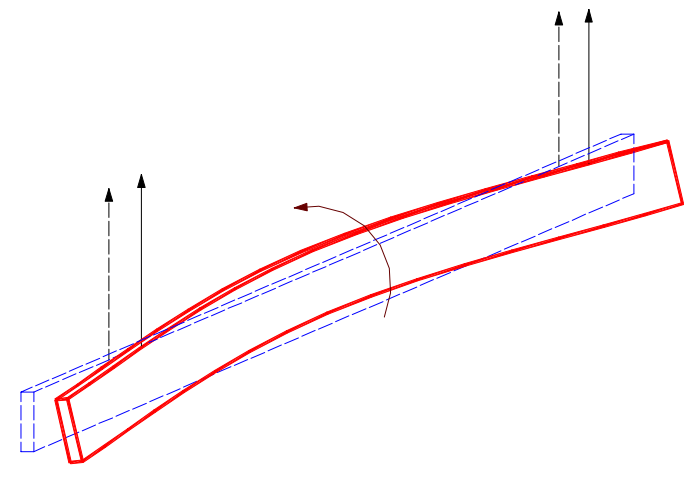

(a) Balanço com efeito estabilizante

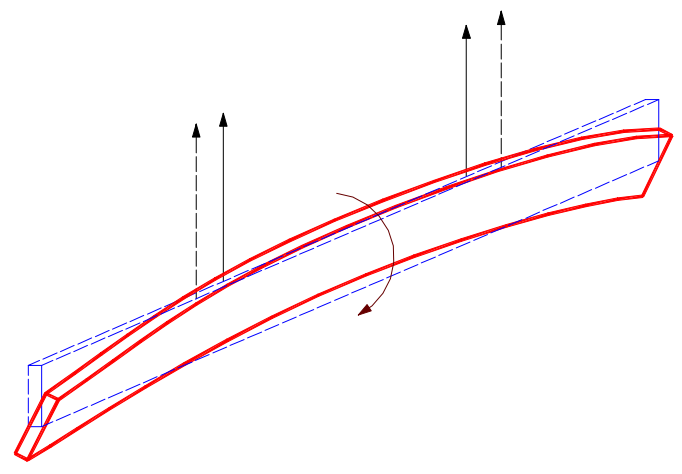

(b) Balanço com efeito instabilizante

Figura 7.38 - Influência do comprimento dos balanços no comportamento da viga.

\subsubsection{FATORES De SeGuranÇA SEgUndo MAST (1993)}

Mast (1993) apresenta alguns procedimentos simplificados para a determinação do fator de segurança da fase de içamento, em termos de limite fissuração e de ruptura, considerando as excentricidades geradas na fase de fabricação dos elementos estruturais.

Segundo Mast (1993), uma vez que a existência de imperfeições construtivas e de montagem são inevitáveis é razoável assumir uma excentricidade inicial $\mathrm{e}_{\mathrm{i}}$ do eixo de giro da viga em relação ao centro de gravidade do elemento. $\mathrm{O}$ eixo de giro, no caso do içamento por cabos, consiste na linha que une os pontos de fixação dos cabos, geralmente na face superior da viga.

A existência da excentricidade causa uma rotação inicial na viga, resultando em giro de corpo rígido e deslocamentos laterais que afasta o centro de massa da viga. Encontrar ou não uma posição de equilíbrio, depende da rigidez lateral da viga, podendo equilibrar-se para uma rotação pouco maior que a rotação resultante da não-linearidade do elemento, ou aumentar até o colapso da viga.

Mast (1993) propõe duas expressões para estimar a segurança da viga contra fissuração e contra ruptura, durante a fase de içamento. Estas fórmulas levam em conta, embora simplificadamente, a perda de rigidez lateral em função da fissuração da viga. Assim, o fator de segurança contra fissuração e contra ruptura podem ser calculados segundo as Equações (7.7) e (7.8) propostas pelo citado autor.

$$
\begin{gathered}
\mathrm{FS}_{\text {fiss }}=\frac{1}{\frac{z_{\mathrm{o}}}{\mathrm{y}_{\mathrm{r}}}+\frac{\phi_{\mathrm{i}}}{\phi_{\text {máx }}}} \\
\mathrm{FS}_{\text {rupt }}=\frac{\mathrm{y}_{\mathrm{r}} \phi_{\text {máx }}^{\prime}}{z_{\mathrm{o}}^{\prime} \phi_{\text {máx }}^{\prime}+\mathrm{e}_{\mathrm{i}}}
\end{gathered}
$$

onde $z_{o}$ é o valor fictício relacionado à flecha no meio do vão caso todo o peso-próprio estivesse aplicado lateralmente, $y_{\mathrm{r}}$ é a distância do CG à face superior da viga, $\phi_{\mathrm{i}}$ é a rotação inicial como giro de corpo rígido devido às imperfeições construtivas, $\phi_{\text {máx }}$ é a 
rotação máxima relativa à fissuração, $z_{o}^{\prime}=z_{o}\left(1+2,5 \phi_{\text {máx }}^{\prime}\right)$ que por sua vez considera a inércia da seção fissurada ou inércia efetiva, $\phi_{\text {máx }}^{\prime}$ é a rotação máxima relativa à ruptura e $e_{i}$ é a excentricidade lateral inicial.

Mast (1993) recomenda utilizar $\mathrm{FS}_{\text {fiss }}>1$ e $\mathrm{FS}_{\text {rupt }}>1,5$, e caso $\mathrm{FS}_{\text {rupt }}$ seja inferior ao valor obtido para $\mathrm{FS}_{\text {fiss }}$, o referido autor sugere considerar $\mathrm{FS}_{\text {rupt }}=\mathrm{FS}_{\text {fiss }}$.

Calculando-se, portanto, os coeficientes de segurança contra fissuração e contra ruptura propostos por Mast (1993) para a viga em estudo, tem-se, para a situação de içamento pelas extremidades da viga:

$$
\begin{gathered}
\mathrm{FS}_{\text {fiss }}=\frac{1}{\frac{z_{0}}{y_{\mathrm{r}}}+\frac{\phi_{\mathrm{i}}}{\phi_{\text {máx }}}}=\frac{1}{\frac{64,4942 \mathrm{~cm}}{89,1661 \mathrm{~cm}}+\frac{0,0245 \mathrm{rad}}{0,0936 \mathrm{rad}}}=1,014>1 \\
\mathrm{FS}_{\text {rupt }}=\frac{\mathrm{y}_{\mathrm{r}} \phi_{\text {máx }}^{\prime}}{\mathrm{z}_{\mathrm{o}}^{\prime} \phi_{\text {máx }}^{\prime}+\mathrm{e}_{\mathrm{i}}}=\frac{89,1661 \mathrm{~cm} * 0,1164 \mathrm{rad}}{83,3911 \mathrm{~cm} * 0,1164 \mathrm{rad}+2,189 \mathrm{~cm}}=0,87<1,5
\end{gathered}
$$

Neste caso, segundo Mast (1993), deve-se ter então $\mathrm{FS}_{\text {rupt }}=\mathrm{FS}_{\text {fiss }}=1,014$ que ainda é menor que o recomendável equivalente à 1,5. Segundo a análise desenvolvida neste trabalho na equação (7.3), o fator de segurança é igual a 1,22.

O içamento com balanços iguais a $6 \%$ do vão total resulta em fatores de segurança mais altos e iguais a:

$$
\begin{gathered}
\mathrm{FS}_{\text {fiss }}=\frac{1}{\frac{z_{\mathrm{o}}}{\mathrm{y}_{\mathrm{r}}}+\frac{\phi_{\mathrm{i}}}{\phi_{\text {máx }}}}=\frac{1}{\frac{32,526 \mathrm{~cm}}{88,7670 \mathrm{~cm}}+\frac{0,018604 \mathrm{rad}}{0,107900 \mathrm{rad}}}=1,86>1 \\
\mathrm{FS}_{\text {rupt }}=\frac{\mathrm{y}_{\mathrm{r}} \phi_{\text {máx }}^{\prime}}{\mathrm{z}_{\mathrm{o}}^{\prime} \phi_{\text {máx }}^{\prime}+\mathrm{e}_{\mathrm{i}}}=\frac{88,787 \mathrm{~cm} * 0,1425 \mathrm{rad}}{44,1134 \mathrm{~cm} * 0,1425 \mathrm{rad}+1,6515 \mathrm{~cm}}=1,59<\mathrm{FS}_{\text {fiss }} \\
\therefore \mathrm{FS}_{\text {rupt }}=\mathrm{FS}_{\text {fiss }}=1,86>1,5
\end{gathered}
$$

A Tabela 7.1 (a) e (b) permite observar a variação dos fatores de segurança contra fissuração $\mathrm{FS}_{\text {fiss }}$ e contra ruptura $\mathrm{FS}_{\text {rupt }}$ para vários comprimentos de balanços.

Estão apresentados nas referidas tabelas todos os parâmetros necessários para o cálculos dos fatores de segurança recomendados por Mast (1993). São eles: $\mathrm{M}_{\mathrm{g}} \mathrm{o}$ momento fletor vertical no meio do vão devido à protensão e ao peso-próprio, $\sigma_{\text {sup }}$ é a tensão normal na mesa superior, $\sigma_{\text {inf }}$ a tensão normal na mesa inferior, $\sigma_{\mathrm{ci}}$ a máxima tensão de compressão atuante no concreto (majorada), $\Delta \mathrm{z}$ é a tolerância de deslocamento lateral relacionada ao comprimento da viga, $e_{i}$ é a excentricidade lateral inicial, $\mathrm{R}$ é a curvatura no meio do vão, $\Delta \mathrm{v}$ é o deslocamento vertical no meio do vão, $\mathrm{y}_{\mathrm{r}}$ é a altura do CG devido à curvatura vertical da viga, $z_{\mathrm{o}}$ relaciona-se à flecha no meio do vão caso todo o pesopróprio estivesse aplicado lateralmente, $\phi_{\mathrm{i}}$ é a rotação como corpo rígido, $\mathrm{M}_{\mathrm{lat}}$ é o momento lateral máximo admitindo tensão de tração limite na mesa superior, $\phi_{\operatorname{máx}}$ é a 
rotação máxima relativa à fissuração, $\phi_{\text {máx }_{\mathrm{r}}}$ é a rotação máxima de ruptura e $z_{\mathrm{o}_{\mathrm{r}}}$ é o valor máximo fictício considerando a redução da inércia lateral devido à fissuração.

A Figura 7.39 ilustra a comparação entre os resultados obtidos segundo procedimentos recomendados por Mast (1993) e os obtidos neste trabalho, através da simulação com elementos de molas nos nós de içamento.

Tabela 7.1(a) - Cálculo dos fatores de segurança segundo Mast (1993).

\begin{tabular}{|c|c|c|c|c|c|c|c|c|c|}
\hline $\begin{array}{c}\mathbf{a} \\
\mathbf{c m}]\end{array}$ & $\mathrm{M}_{\mathrm{g}}$ & $\sigma_{\text {sup }}$ & $\sigma_{\text {inf }}$ & $\sigma_{\mathrm{ci}}$ & $\Delta z$ & $\mathrm{e}_{\mathrm{i}}$ & $\mathrm{M}$ & $\mathrm{R}$ & $\Delta \mathrm{v}$ \\
\hline 0 & $3,199 \mathrm{E}+11$ & $-67,1684$ & $-125,868$ & $-209,779$ & 2,3843 & 2,1895 & $7,14 \mathrm{E}+06$ & $1,61 \mathrm{E}+06$ & 1,6001 \\
\hline 45,45 & $3,071 \mathrm{E}+07$ & $-62,0855$ & $-131,307$ & $-218,846$ & 2,3843 & 2,0951 & $8,42 \mathrm{E}+06$ & $1,37 \mathrm{E}+06$ & 1,8869 \\
\hline 90,9 & $2,943 \mathrm{E}+07$ & $-57,0026$ & $-136,747$ & $-227,912$ & 2,3843 & 2,0026 & $9,70 \mathrm{E}+06$ & $1,19 \mathrm{E}+06$ & 2,1737 \\
\hline 136,35 & $2,815 \mathrm{E}+07$ & $-51,9196$ & $-142,187$ & $-236,979$ & 2,3843 & 1,9120 & $1,10 \mathrm{E}+07$ & $1,05 \mathrm{E}+06$ & 2,4606 \\
\hline 227,25 & $2,559 \mathrm{E}+07$ & $-41,7538$ & $-153,067$ & $-255,111$ & 2,3843 & 1,7365 & $1,35 \mathrm{E}+07$ & $8,51 \mathrm{E}+05$ & 3,0343 \\
\hline 272,7 & $2,431 \mathrm{E}+07$ & $-36,6709$ & $-158,507$ & $-264,178$ & 2,3843 & 1,6515 & $1,48 \mathrm{E}+07$ & $7,77 \mathrm{E}+05$ & 3,3211 \\
\hline 454,5 & $1,920 \mathrm{E}+07$ & $-16,3392$ & $-180,266$ & $-300,443$ & 2,3843 & 1,3312 & $1,99 \mathrm{E}+07$ & $5,78 \mathrm{E}+05$ & 4,4685 \\
\hline 909 & $6,399 \mathrm{E}+06$ & 34,49 & $-234,664$ & $-391,107$ & 2,3843 & 0,6636 & $3,27 \mathrm{E}+07$ & $3,52 \mathrm{E}+05$ & 7,3368 \\
\hline
\end{tabular}

Tabela 7.1(b) - Cálculo dos fatores de segurança segundo Mast (1993).

\begin{tabular}{|c|c|c|c|c|c|c|c|c|c|}
\hline $\begin{array}{c}\mathbf{a} \\
{[\mathbf{c m}]}\end{array}$ & $\mathrm{y}_{\mathrm{r}}$ & $\mathrm{z}_{\mathrm{o}}$ & $\phi_{\mathrm{i}}$ & $\mathrm{M}_{\text {lat }}$ & $\phi_{\text {máx }}$ & $\mathrm{FS}_{\text {fiss }}$ & $\phi_{\text {máx }_{-} \mathrm{r}}$ & $\mathrm{z}_{\mathrm{o}_{-} \mathrm{r}}$ & $\mathrm{FS}_{\text {rupt }}$ \\
\hline 0 & 89,1653 & 64,5941 & 0,0246 & $3,52 \mathrm{E}+06$ & 0,1101 & $\mathbf{1 , 0 6}$ & 0,1164 & 83,3977 & $\mathbf{0 , 8 7}$ \\
\hline 45,45 & 89,0488 & 58,3272 & 0,0235 & $3,37 \mathrm{E}+06$ & 0,1098 & $\mathbf{1 , 1 5}$ & 0,1199 & 75,8059 & $\mathbf{0 , 9 5}$ \\
\hline 90,9 & 88,9533 & 52,4400 & 0,0225 & $3,22 \mathrm{E}+06$ & 0,1095 & $\mathbf{1 , 2 6}$ & 0,1236 & 68,6431 & $\mathbf{1 , 0 5}$ \\
\hline 136,35 & 88,8780 & 46,9246 & 0,0215 & $3,07 \mathrm{E}+06$ & 0,1091 & $\mathbf{1 , 3 8}$ & 0,1277 & 61,9011 & $\mathbf{1 , 1 6}$ \\
\hline 227,25 & 88,7857 & 36,9761 & 0,0196 & $2,77 \mathrm{E}+06$ & 0,1084 & $\mathbf{1 , 6 8}$ & 0,1371 & 49,6459 & $\mathbf{1 , 4 2}$ \\
\hline 272,7 & 88,7670 & 32,5260 & 0,0186 & $2,62 \mathrm{E}+06$ & 0,1079 & $\mathbf{1 , 8 6}$ & 0,1425 & 44,1134 & $\mathbf{1 , 5 9}$ \\
\hline 454,5 & 88,8617 & 18,0218 & 0,0150 & $2,03 \mathrm{E}+06$ & 0,1056 & $\mathbf{2 , 9 0}$ & 0,1719 & 25,7661 & $\mathbf{2 , 6 5}$ \\
\hline 909 & 90,0364 & 1,55030 & $7,37 \mathrm{E}-03$ & $1,55 \mathrm{E}+06$ & 0,2417 & $\mathbf{2 0 , 9 6}$ & $4,36 \mathrm{E}-02$ & 1,71930 & $\mathbf{1 8 , 9 2}$ \\
\hline
\end{tabular}

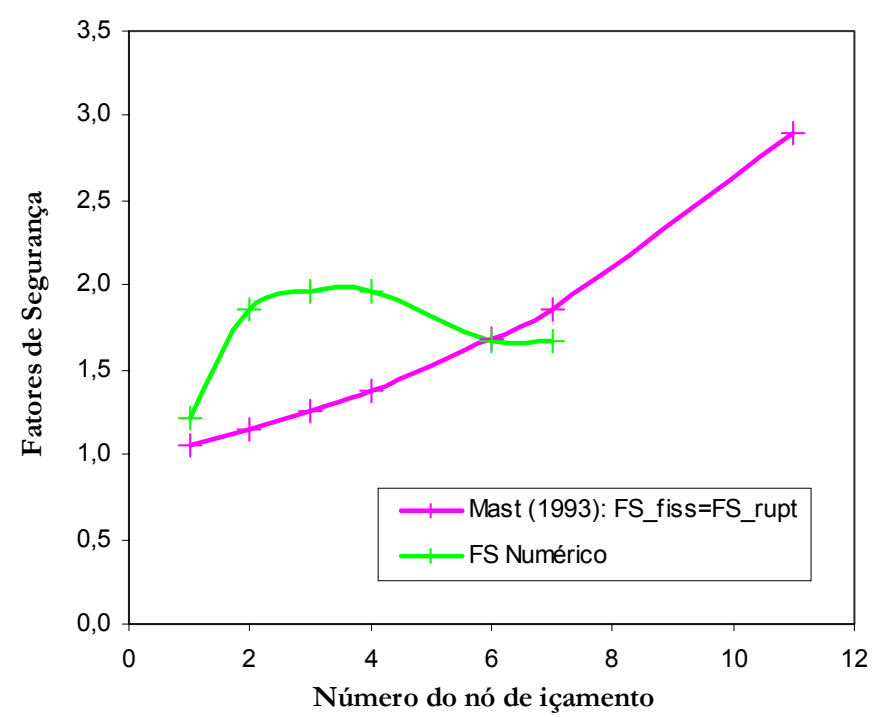

Figura 7.39 - Fatores de segurança obtidos segundo Mast (1993) e resposta numérica deste trabalho. 
Assim, as curvas apresentadas na Figura 7.39 mostram que as expressões propostas por Mast (1993) são válidas para pequenos comprimentos de balanços, e como pode-se observar na Tabela 7.1(b), para balanços iguais a $909 \mathrm{~cm}$, os fatores de segurança tornam suficientemente grandes e sem valor prático, uma vez que não se adequam mais ao problema do içamento de uma viga protendida.

Entende-se que para grandes comprimentos de balanços, a suspensão de vigas com protensão resultará em um problema com balanços instabilizantes, sendo ainda mais agravados pelo menor alívio do peso-próprio com relação à protensão, à medida em que aumenta-se o comprimento dos balanços.

Por outro lado, a resposta numérica descrita na Figura 7.39 recomenda cautela na suspensão com balanços, pois para o nível de protensão considerado deve-se proceder o içamento com pequenos balanços, sendo os nós 3 e 4 os mais indicados para tal tarefa.

\subsection{TESOURA PROTENDIDA}

A tesoura protendida produzida comercialmente pela empresa Marka Sistemas Construtivos em Concreto Estrutural será a seguir analisada numericamente com relação aos riscos de instabilidade lateral durante a fase transitória de suspensão. As dimensões e as características geométricas, bem como o detalhamento das armaduras encontram-se ilustrados nas Figuras 7.40 e 7.41.

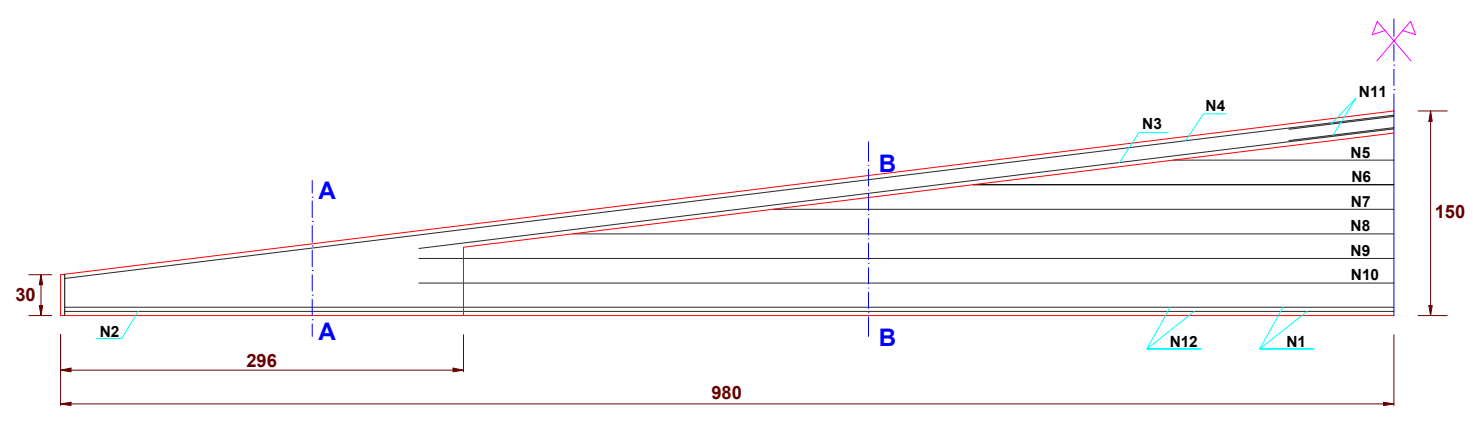

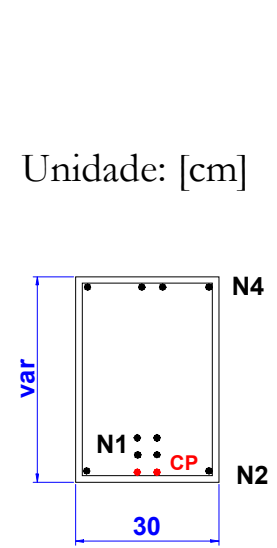

Corte AA

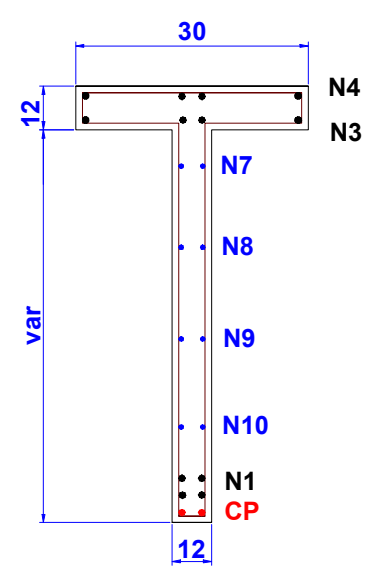

Corte BB

Figura 7.40 - Tesoura protendida: detalhamento da armadura longitudinal. 
As armaduras longitudinais indicadas na Figura 7.40 encontram-se identificadas na Tabela 7.2. Os estribos têm comprimento e altura variável, diâmetro de $6,3 \mathrm{~mm}$, espaçados a cada $16 \mathrm{~cm}$. A espessura do cobrimento utilizado foi de $2 \mathrm{~cm}$.

A viga tem 2 cabos de protensão CP 190-12,5mm com cordoalhas de 7 fios. A força de protensão em cada cabo foi de $140 \mathrm{kN}$. A excentricidade de protensão no nó do apoio é de $11,375 \mathrm{~cm}$.

A resistência característica do concreto à compressão foi considerada igual a $30 \mathrm{MPa}$ e o módulo de elasticidade do concreto igual à $30 \mathrm{GPa}$. O módulo de elasticidade das armaduras passivas foi adotado igual à $210 \mathrm{GPa}$ e das armaduras de protensão igual a $195 \mathrm{GPa}$.

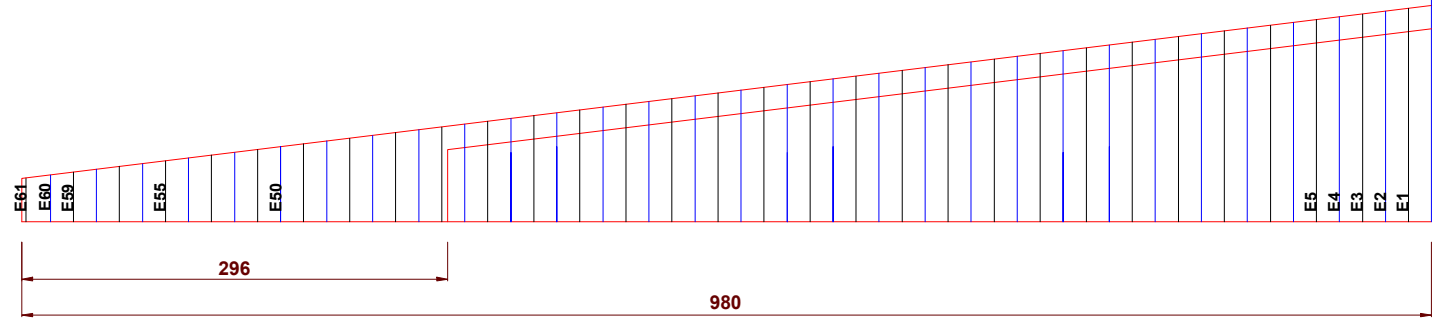

Figura 7.41 - Tesoura Protendida: detalhamento da armadura transversal.

Tabela 7.2 - Armaduras longitudinais.

\begin{tabular}{|c|c|c|}
\hline$\#$ & Quantidade - Diâmetro & Comprimento \\
\hline N1 & $4 \phi 16,0$ & 1200 \\
\hline N2 & $4 \phi 12,5$ & 298 \\
\hline N3 & $8 \phi 12,5$ & 710 \\
\hline N4 & $8 \phi 12,5$ & 980 \\
\hline N5 & $2 \phi 10,0$ & 324 \\
\hline N6 & $2 \phi 10,0$ & 650 \\
\hline N7 & $2 \phi 10,0$ & 975 \\
\hline N8 & $2 \phi 10,0$ & 1300 \\
\hline N9 & $2 \phi 10,0$ & 1200 \\
\hline N10 & $2 \phi 10,0$ & 1200 \\
\hline N11 & $8 \phi 12,5$ & 150 \\
\hline N12 & $4 \phi 16,0$ & 850 \\
\hline
\end{tabular}

\subsubsection{CONSIDERAÇÕES DA MODELAGEM NuMÉRICA}

A tesoura protendida foi modelada numericamente ao longo da linha que une o centro de gravidade das seções, tendo sido dividida em 31 elementos longitudinais de barra e 32 nós. Cada barra é identificada por seus nós, e cada nó está associado à seção transversal correspondente. A viga tem seção transversal variável ao longo do comprimento, sendo retangular do nó 1 ao nó 11 e de seção T entre o nó 11 e o nó 32, conforme pode-se observar na Figura 7.42.

O carregamento externo considerado na viga protendida resume-se ao peso-próprio. 


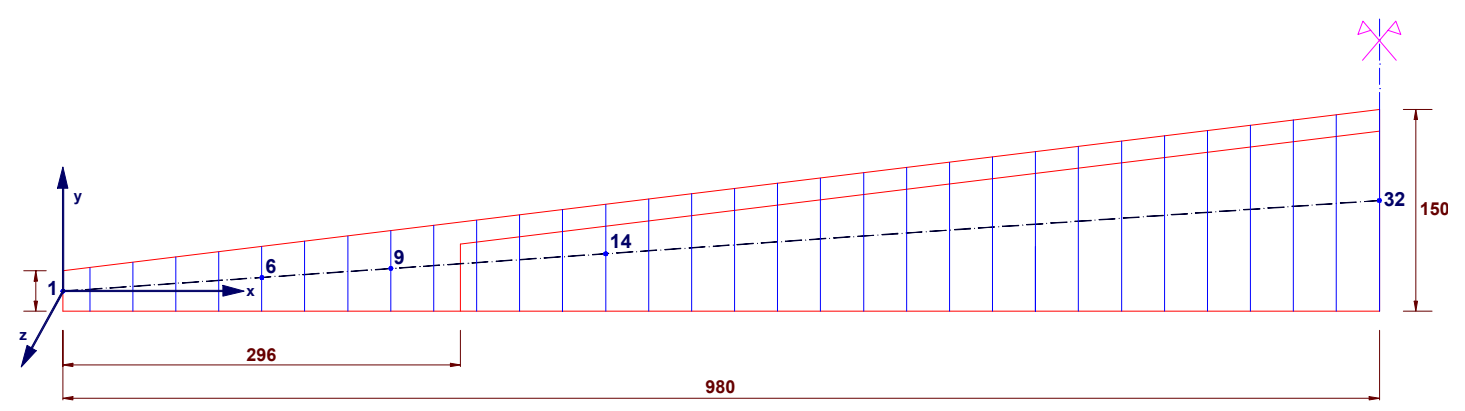

Figura 7.42 - Modelagem numérica através de elementos lineares ao longo da linha do CG.

\subsubsection{Simulação da Fase de IÇAMENTO COM ApOIOS DeformáVeIS}

A simulação numérica da fase de içamento da tesoura protendida foi analisada neste trabalho considerando apoios deformáveis à torção. Quatro comprimentos de balanços foram avaliados, entre eles, de $148 \mathrm{~cm}$ (apoio no nó 6), de $244 \mathrm{~cm}$ (apoio no nó 9), de $404 \mathrm{~cm}$ (apoio no nó 14) e situação sem balanços (apoio no nó 1). Vale observar que, na prática, o içamento sem balanços não ocorreria exatamente no nó extremo, como no caso o nó 1 , mas pelo menos a $25 \mathrm{~cm}$ da extremidade da viga.

Conforme calculado para a viga protendida do item 7.5, a tesoura em estudo foi também modelada numericamente com apoios deformáveis à torção, tendo sido da mesma forma estimada a constante de mola considerando o equilíbrio entre a reação no cabo e o giro permitido pela mola. Assim, para cada posição de içamento calculou-se a constante $\mathrm{K}_{\theta_{\mathrm{x}}}$, conforme mostram as equações (7.14), (7.15), (7.16) e (7.17).

Nó 1:

$$
\mathrm{K}_{\theta_{\mathrm{x}}}=\frac{\mathrm{P}}{2} \cdot \mathrm{y}_{\text {sup }} \cdot \frac{\operatorname{sen}\left(\theta_{\mathrm{x}}\right)}{\theta_{\mathrm{x}}}=3634.15 \cdot \frac{\operatorname{sen}\left(\theta_{\mathrm{x}}\right)}{\theta_{\mathrm{x}}}
$$

Nó 6:

$$
\mathrm{K}_{\theta_{\mathrm{x}}}=\frac{\mathrm{P}}{2} \cdot \mathrm{y}_{\text {sup }} \cdot \frac{\operatorname{sen}\left(\theta_{\mathrm{x}}\right)}{\theta_{\mathrm{x}}}=3634.23 \cdot \frac{\operatorname{sen}\left(\theta_{\mathrm{x}}\right)}{\theta_{\mathrm{x}}}
$$

Nó 9:

$$
\mathrm{K}_{\theta_{\mathrm{x}}}=\frac{\mathrm{P}}{2} \cdot \mathrm{y}_{\text {sup }} \cdot \frac{\operatorname{sen}\left(\theta_{\mathrm{x}}\right)}{\theta_{\mathrm{x}}}=3634.29 \cdot \frac{\operatorname{sen}\left(\theta_{\mathrm{x}}\right)}{\theta_{\mathrm{x}}}
$$

$[\mathrm{kgf.cm} / \mathrm{rad}]$

Nó 14: $\quad K_{\theta_{x}}=\frac{P}{2} \cdot y_{\text {sup }} \cdot \frac{\operatorname{sen}\left(\theta_{x}\right)}{\theta_{x}}=3634.32,81 \cdot \frac{\operatorname{sen}\left(\theta_{x}\right)}{\theta_{x}}$

Assim, a tesoura protendida foi analisada com apoios deformáveis nos nós 1, 6, 9 e 14, variando-se a excentricidade lateral inicial. A Figura 7.43 mostra o quanto a viga gira por torção em função da excentricidade inicial adotada, sob o carregamento devido ao pesopróprio, na simulação das quatro situações de içamento.

Pode-se observar na Figura 7.43 que o içamento com balanços de uma viga protendida deve ser cuidadosamente analisado. Nota-se que a tendência de giro por deformação e corpo-rígido é oposta da situação sem balanços e com balanços pequenos, com relação à situação com balanços em torno dos quartos de vão. Na primeira, o giro por torção é positivo e tem efeito estabilizante, e na segunda, negativo e com efeito instabilizante, conforme ilustrado anteriormente nas Figuras 7.38 (a) e (b), respectivamente. 


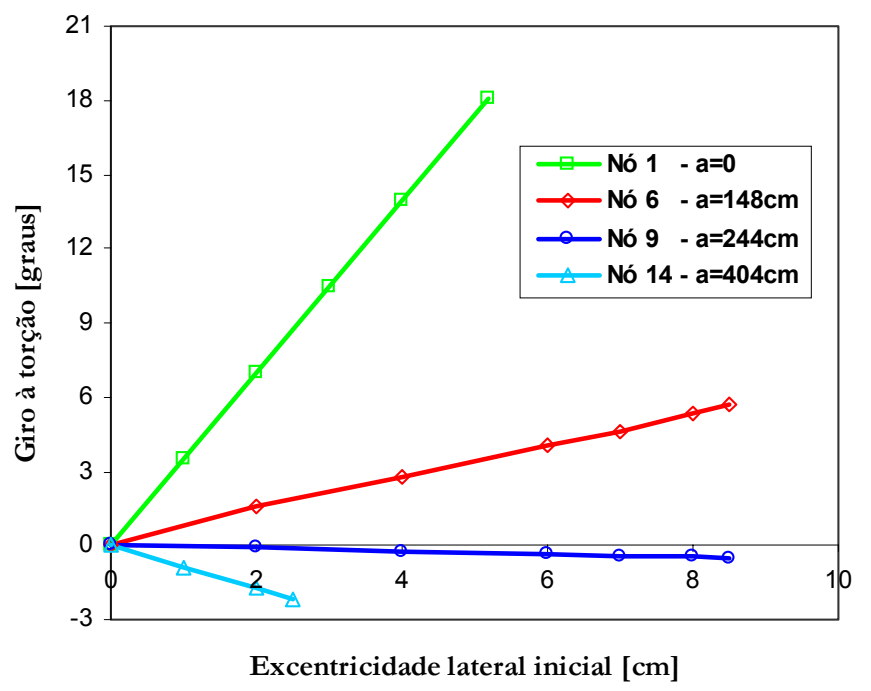

Figura 7.43 - Giro à torção versus Excentricidade lateral inicial da viga.

Assim, conforme o gráfico da Figura 7.43, a situação ideal de içamento da viga em estudo ocorre para comprimentos de balanços em torno de $1,5 \mathrm{~m}$. Nesta simulação a máxima excentricidade lateral para a qual existe equilíbrio é de $8,5 \mathrm{~cm}$, apresentando giro lateral de $5,69^{\circ}$. $\mathrm{Na}$ resposta numérica para estes valores, a viga não apresentou fissuração.

Para balanços de aproximadamente 2,5m, a excentricidade máxima alcançada foi também de $8,5 \mathrm{~cm}$, com ângulo de giro igual a $-0,51^{\circ}$, iniciando-se nesta fase um quadro inexpressivo de fissuração.

Já com balanços de $4 \mathrm{~m}$, a situação foi a mais crítica, verificando-se o equilíbrio para excentricidade inicial igual a $2,5 \mathrm{~cm}$, com giro de $-2,22^{\circ}$, também com fissuração.

$\mathrm{Na}$ simulação sem balanços, a excentricidade máxima inicial foi de $5,2 \mathrm{~cm}$, com giro de $18,07^{\circ}$, sem apresentar fissuração.

A Figura 7.44 mostra o quadro de fissuração da seção transversal do meio do vão no içamento com balanços de aproximadamente $2,5 \mathrm{~m}$ e $4 \mathrm{~m}$, na situação crítica e última de equilíbrio. Vale lembrar que, numericamente, a fissuração foi considerada levando-se em conta a zona de envolvimento da armadura e, por este motivo, alguns elementos discretizados atingem tensão nula à tração antes de outros mais solicitados.

Os deslocamentos laterais e verticais da seção do meio do vão para as excentricidades laterais iniciais analisadas podem ser observados na Figura 7.45, para cada uma das quatro situações de içamento em estudo. Observa-se que a suspensão é crítica com balanços de aproximadamente $4 \mathrm{~m}$, onde ocorre perda de equilíbrio ainda para pequena curvatura lateral inicial. 


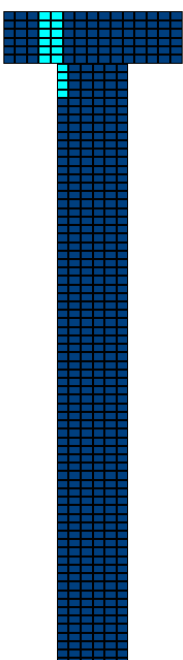

(a) Apoio no nó $9-\mathrm{e}_{\mathrm{i}-\mathrm{máx}}=8,5 \mathrm{~cm}$

Elemento fissurado

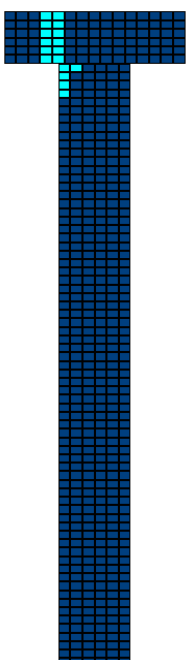

(b) Apoio no nó $14-\mathrm{e}_{\mathrm{i}-\mathrm{máx}}=2,5 \mathrm{~cm}$

Elemento não fissurado

Figura 7.44 - Quadro de fissuração com apoio no nó 9 e 14.

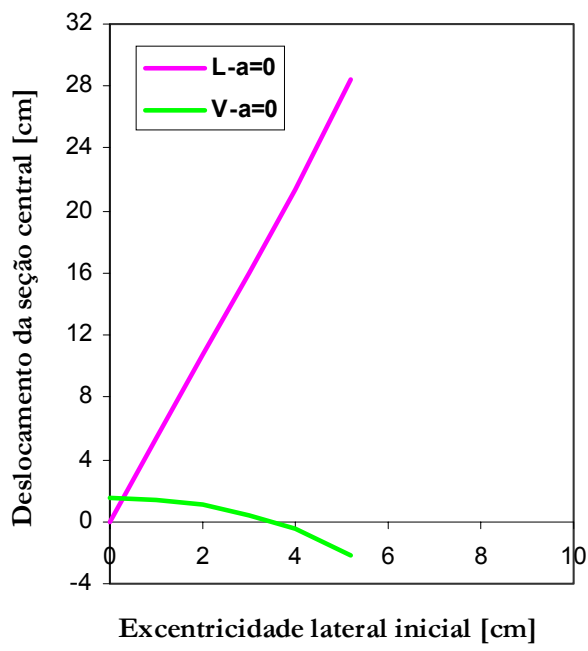

(a) Sem balanços

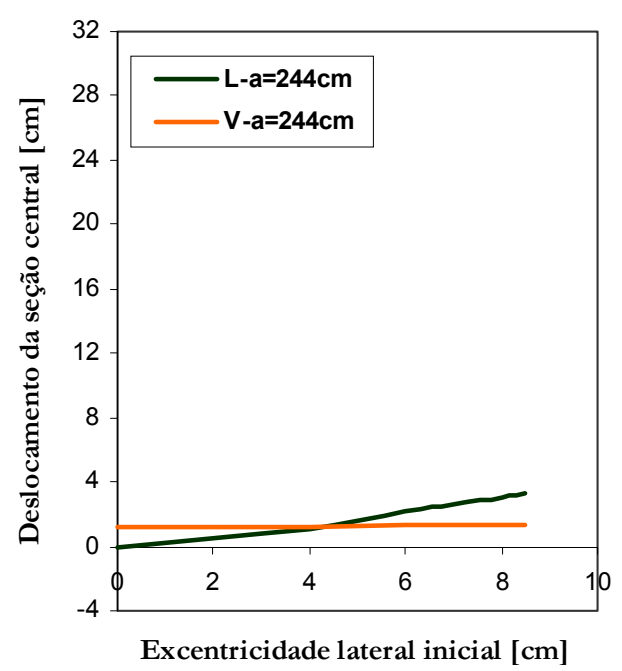

(c) Balanços de $244 \mathrm{~cm}$

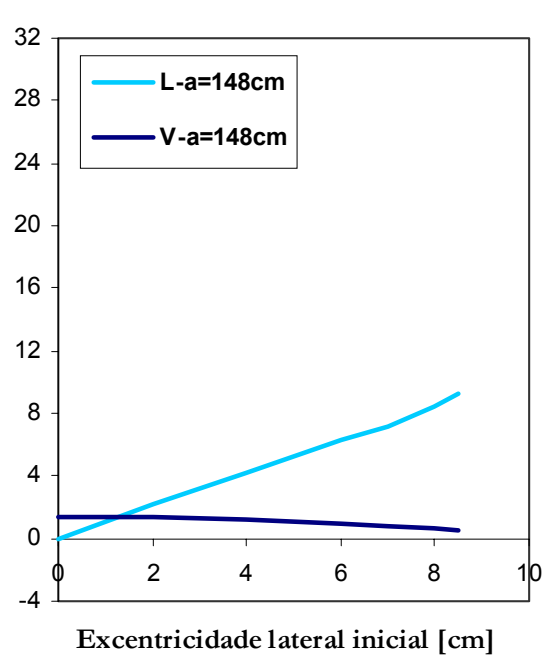

(b) Balanços de $148 \mathrm{~cm}$.

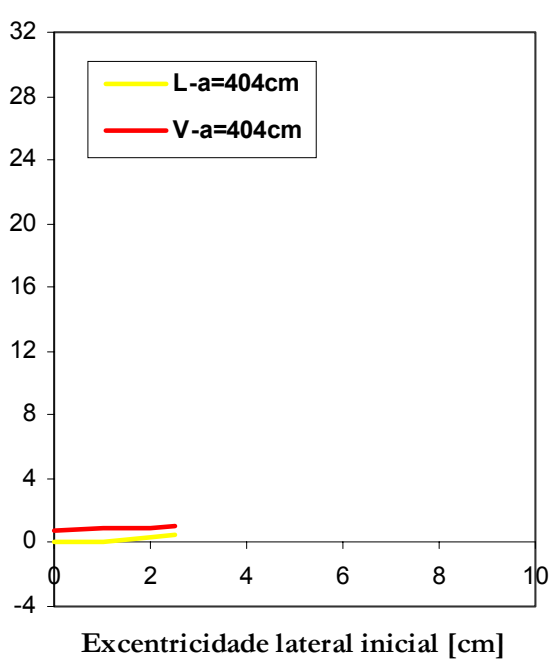

(d) Balanços de $404 \mathrm{~cm}$

Figura 7.45 - Deslocamentos vertical e lateral da seção do meio do vão. 
Conforme observado para a viga analisada no item 7.5, a NBR-9062/85 recomenda considerar uma tolerância de linearidade da peça pré-moldada decorrente de sua execução igual a $\ell / 1000$, ou seja, para a viga em estudo cujo comprimento longitudinal é 19,6m, uma excentricidade lateral inicial de aproximadamente $2 \mathrm{~cm}$. Levando-se em conta uma tolerância de $6 \mathrm{~mm}$ no posicionamento dos cabos de suspensão, tem-se uma excentricidade lateral inicial total $\mathrm{e}_{\text {if }}$ igual a $2,6 \mathrm{~cm}$. Portanto, pode-se estimar um fator de segurança FS baseado nesta excentricidade para os quatro casos analisados de comprimentos de balanços.

Assim, tem-se para a suspensão sem balanços, um fator de segurança igual a 2, conforme apresentado na Equação 7.18.

$$
\mathrm{FS}=\frac{\mathrm{e}_{\mathrm{i}_{\_} \text {máx }}}{\mathrm{e}_{\mathrm{if}}}=\frac{5,2}{2,6}=2
$$

Tanto a suspensão pelo nó 6 , com balanços de $1,5 \mathrm{~m}$ ou 7,6\% do vão, como a pelo nó 9 , com $2,5 \mathrm{~m}$ de balanços ou $12,8 \%$ do comprimento da viga, o fator de segurança estimado é de:

$$
\mathrm{FS}=\frac{8,5}{2,6}=3,3
$$

porém, a suspensão com 2,5m de balanço já começa a apresentar fissuração.

Para a suspensão com balanços de $20,6 \%$ do vão, ou balanços de $4 \mathrm{~m}$, o fator de segurança é menor que 1 , e portanto crítico.

$$
\mathrm{FS}=\frac{2,5}{2,6}=0,96
$$

Embora as análises desenvolvidas não levem em conta o efeito desfavorável do vento, a situação de içamento com balanços de $1,5 \mathrm{~m}$ resultou em um fator de segurança igual a 3,3 , valor este que pode cobrir eventuais carregamentos laterais, dentro de condições normais.

\subsubsection{CONSIDERAÇões FinaIs do IÇAMENTo DA TESOURA PROTENDIDA POR CABOS RETOS}

Lima et al. (2002) desenvolve um estudo da fase de içamento da tesoura protendida apresentada neste item. Segundo Lima et al. (2002), a análise da tesoura protendida sob tombamento lateral gradual por meio de giros impostos nos apoios permite observar o comportamento global da viga, levando-se em conta o aumento das deformações, desde a fissuração até o escoamento e a ruptura das armaduras. Observou-se que para a situação crítica com balanços de aproximadamente $4 \mathrm{~m}$ ou $20,6 \%$ do vão, a viga começa a fissurar-se com $5^{\circ}$ de inclinação lateral e ocorreu ruptura de armaduras longitudinais $\operatorname{com} 30^{\circ}$ de giro imposto.

Nesse trabalho, Lima et al. (2002) observa que a variação da rigidez à torção em função do nível de fissuração por flexão obtida da implementação do modelo de Hannachi \& 
Fouré (1996), apresentou-se de forma satisfatória e dentro do comportamento esperado. A resposta numérica obtida para tombamento lateral com balanços de aproximadamente $4 \mathrm{~m}$ chegou a $20 \%$ de redução da rigidez à torção devido à fissuração por flexão.

A simulação numérica através de apoios deformáveis permitiu desenvolver uma análise mais realista da fase de içamento. A definição do comprimento dos balanços é muito importante uma vez que o mesmo cria um efeito estabilizante ou instabilizante no comportamento geral. Isto é fundamental uma vez que o exemplo em questão é o de uma viga protendida. No caso de uma viga de concreto armado sem protensão e com altura constante, a situação mais favorável para a suspensão é a de balanços nos quartos do vão.

O efeito do peso próprio sobre a protensão quando se tem balanços é favorável dentro de um certo limite, pois para maiores comprimentos de balanços, o alívio do pesopróprio sobre a protensão na seção do meio do vão pode ser insuficiente para manter as tensões nesta seção dentro dos limites de fissuração e de estabilidade.

Conclui-se portanto que, para o içamento da tesoura protendida em análise, o comprimento ótimo para os balanços é em torno de 7,5\% do comprimento total da viga, podendo-se chegar à 12,8\%. Porém, com 7,5\%, não iniciou-se um quadro de fissuração na seção transversal mais solicitada e o comportamento geral ocorreu com balanços estabilizantes. O fator de segurança é em torno de 3,3 e o fato de não apresentar fissuração na seção crítica é ideal, uma vez que não é desejável que ocorra fissuração no elemento estrutural antes mesmo de ser posicionado no local para o qual foi projetado.

\subsubsection{IÇAMENTO COM CABOS INCLINADOS}

Dependendo do equipamento disponível e do comprimento da viga pré-moldada, o içamento pode ser realizado através de cabos inclinados, conforme ilustra a Figura 7.46.

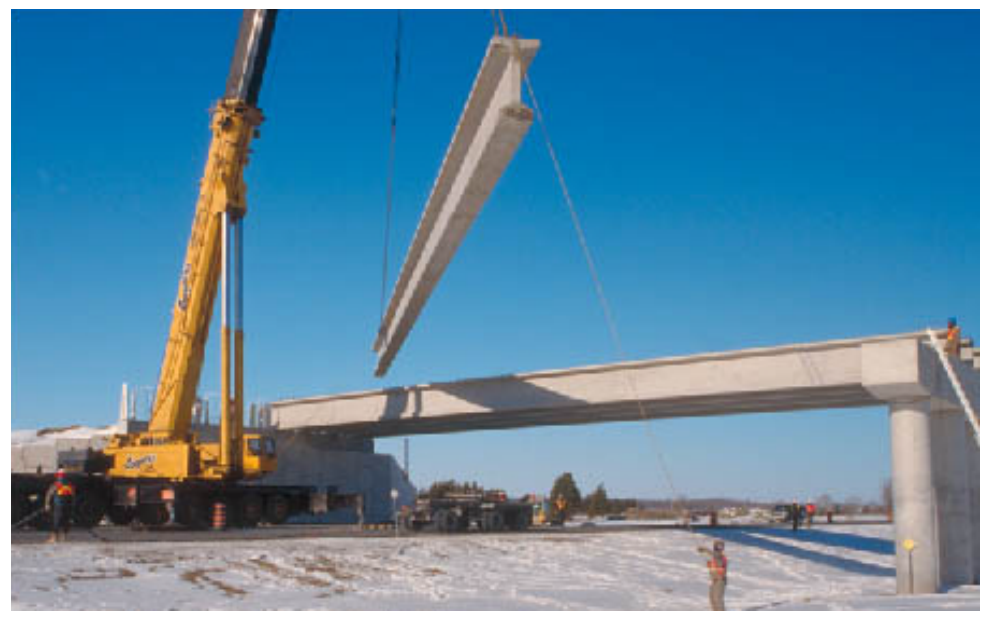

Figura 7.46 - Exemplo de içamento com cabos inclinados de uma viga pré-moldada.

Neste tipo de suspensão, surge uma componente de força horizontal de compressão $\mathrm{N}_{c}$ 
no ponto do apoio e um momento fletor $\mathrm{M}_{\mathrm{c}}$ de sentido contrário ao devido à protensão, no caso de vigas com armadura ativa, conforme ilustra a Figura 7.47. No caso de vigas não protendidas, o momento fletor resultante da inclinação do cabo tem o mesmo sentido do momento fletor devido ao peso-próprio.

Analisou-se numericamente a tesoura protendida suspensa por cabos inclinados com ângulos de inclinação $\alpha_{c}$ iguais a $45,6^{\circ}$ e $63,9^{\circ}$ com relação à horizontal.

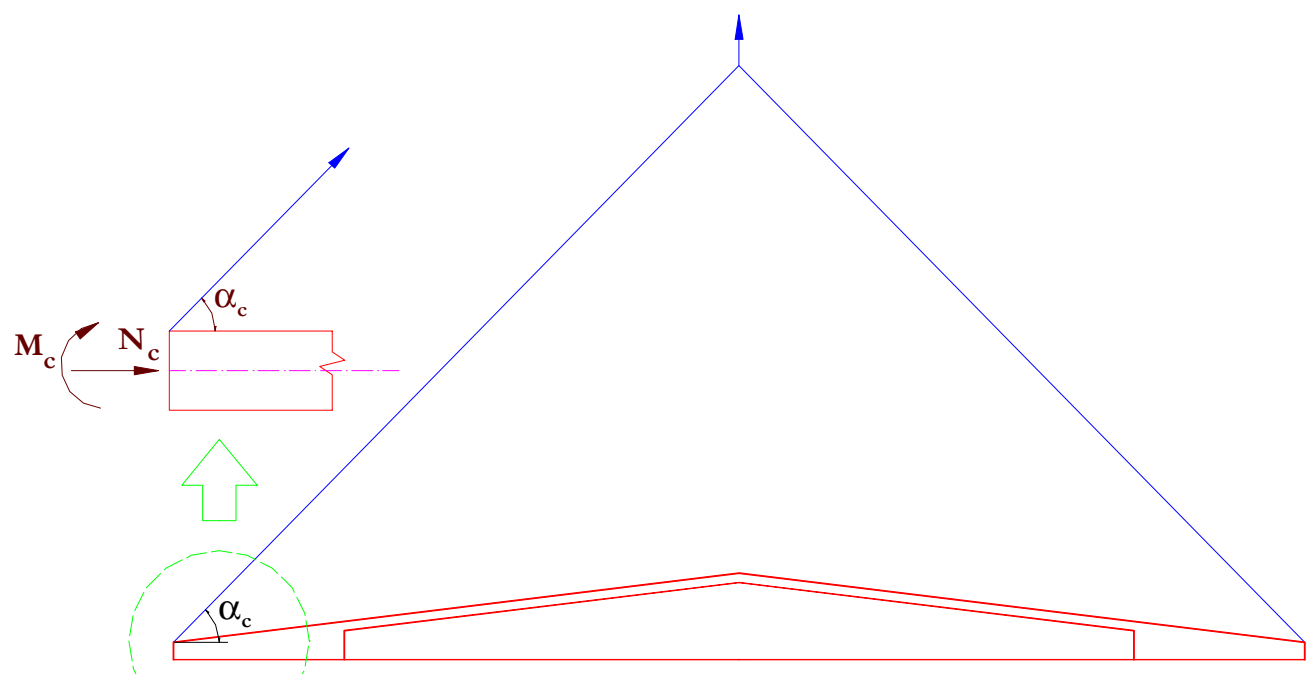

Figura 7.47 - Içamento com cabos inclinados de $\alpha_{c}$ e solicitações $N_{c}$ e $M_{c}$.

A Figura 7.48 mostra os resultados numéricos obtidos para as duas situações de inclinação dos cabos de içamento, ambas pela seção de extremidade, variando-se a excentricidade lateral da viga.

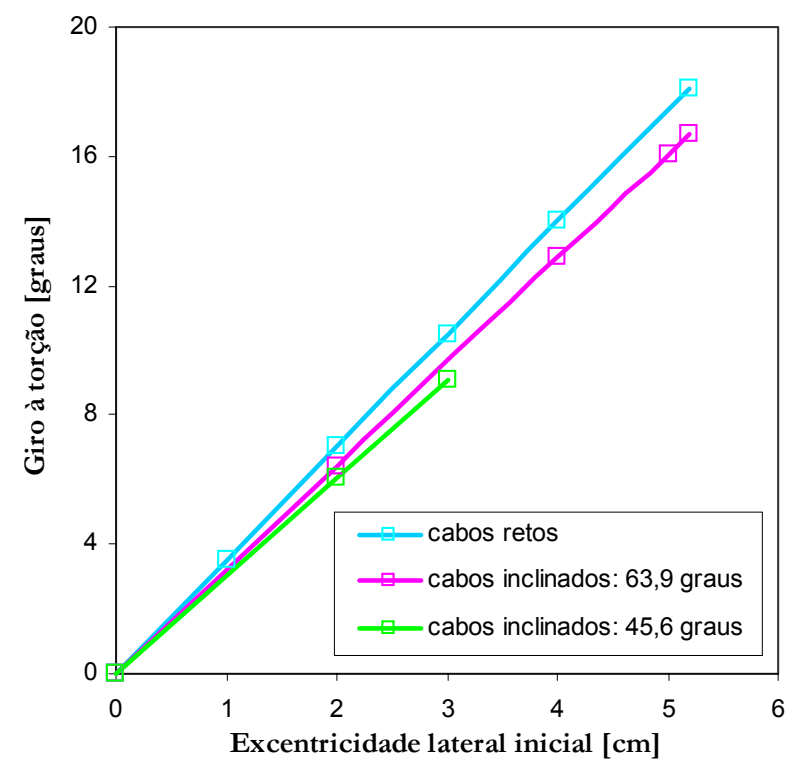

Figura 7.48 - Resposta numérica do içamento com cabos retos e inclinados de $\alpha_{c}$. 
Observou-se que no içamento com cabos verticais ou com cabos inclinados de $63,9^{\circ}$ com relação à horizontal resultam respostas numéricas próximas, com relação à segurança da fase de suspensão, pois:

$$
\mathrm{FS}=\frac{\mathrm{e}_{\mathrm{i}_{\_} \text {máx }}}{\mathrm{e}_{\mathrm{if}}}=\frac{5,2}{2,6}=2
$$

Entretanto, com $45,6^{\circ}$ aumentam-se os riscos de instabilidade lateral, uma vez que obteve-se convergência numérica apenas até excentricidade lateral igual a $3 \mathrm{~cm}$. Neste caso o fator de segurança passa a ser:

$$
\mathrm{FS}=\frac{\mathrm{e}_{\mathrm{i}_{\text {-máx }}}}{\mathrm{e}_{\mathrm{if}_{\mathrm{f}}}}=\frac{3}{2,6}=1,15
$$

Pode-se dizer, em linhas gerais, que caso o içamento tenha que ser realizado através de cabos inclinados, deve-se preferir trabalhar na situação mais próxima possível à da suspensão com cabos retos. 


\section{Capítulo}

\section{8 \\ CONSIDERAÇÕES FinAIS E CONCLUSÕES}

\subsection{SÍNTESE DO TRABALHO E CONCluSÕES}

O estudo da estabilidade das fases transitórias de vigas de grandes vãos é muito importante tanto para garantir a integridade estrutural do elemento como a segurança durante o manuseio.

O programa computacional desenvolvido nesta tese permite utilizar o modelo de solicitações combinadas de Cocchi \& Volpi (1996), caso o mecanismo estrutural que represente o comportamento do elemento aproxime-se bem da analogia de treliça espacial. Caso a solicitação predominante seja a flexão com pequeno momento de torção, deve-se preferir a resposta numérica obtida com a aplicação da proposta de Hannachi \& Fouré (1996). Uma análise ainda mais simplificada pode ser realizada utilizando-se as expressões propostas para torção pura por Lampert (1973) e Hsu (1968), para o cálculo do momento de torção pós-fissuração.

Assumindo comportamento bi-linear para a relação momento de torção $\mathrm{x}$ taxa de giro, sendo o limite entre a fase não-fissurada e a fase fissurada definido por Hsu (1968) para uma seção equivalente de concreto simples sob torção pura, pôde-se observar que, quanto menor a relação entre a torção e a flexão, melhor é a resposta numérica obtida da aplicação das expressões simplificadas de Lampert (1973).

Observou-se neste trabalho que, em casos onde a torção é uma solicitação predominante sobre a flexão, deve-se recorrer a modelos tridimensionais para análise de tensões. O modelo utilizado por Cocchi \& Volpi (1996) e implementando neste trabalho conduz a respostas satisfatórias do comportamento de elementos estruturais sob ações combinadas de flexão, torção e força axial. A resposta à flexão obtida utilizando o modelo de analogia de treliça, segundo Cocchi \& Volpi (1996), é melhor representada quando se considera a parcela resistente do núcleo central, o qual é desprezado na versão original do modelo.

Outro fator importante pôde ser observado na resposta à torção de peças sob solicitação conjunta com flexão, com relação ao início do ponto de fissuração por torção. Dependendo da resistência à tração do concreto admitida, o início da fissuração pode ajustar-se melhor à curva experimental momento torçor versus taxa de giro por torção.

A convergência do procedimento iterativo proposto por Cocchi \& Volpi (1996), composto por um sistema não-linear de equações de equilíbrio, de compatibilidade de deformações e das leis constitutivas dos materiais, é lenta devido ao grande número de iterações necessárias. Vale observar que, a discretização longitudinal de uma peça 
estrutural, somada à discretização na seção transversal, que contém um sistema de equações as quais não podem ser expressas explicitamente em termos de suas incógnitas, e que são calculadas por um procedimento iterativo de tentativa e erro, resulta em um algoritmo com sensibilidade numérica, da forma em que foi proposto.

Enfim, os exemplos analisados com a aplicação do modelo de Cocchi \& Volpi (1996) mostram que os resultados numéricos obtidos se aproximam satisfatoriamente dos resultados experimentais. O modelo constitui, portanto, em uma valiosa ferramenta para cálculo de esforços em seções sob ação conjunta de torção, flexão bilateral e força axial, devendo ser a torção solicitação predominante, uma vez que o modelo é aplicável quando se tem um quadro mínimo de fissuração em espiral.

Em casos onde a torção não é solicitação predominante sobre a flexão, o modelo de Hannachi \& Fouré (1996) permite calcular a rigidez à torção de vigas fissuradas por flexão. O citado modelo considera a influência de parâmetros como a forma da seção transversal, o estado de fissuração da viga e a contribuição da armadura longitudinal. A proposta de Hannachi \& Fouré (1996) adequa-se favoravelmente ao problema da instabilidade lateral de vigas, uma vez que suas hipóteses baseiam-se em problemas de estabilidade de forma, onde a flexão é solicitação predominante, e a rigidez à torção varia em função do grau de fissuração devido à flexão.

Embora não existam resultados experimentais sobre a variação da rigidez à torção em peças fissuradas por flexão, a resposta numérica obtida da aplicação do modelo de Hannachi \& Fouré (1996) é razoável em termos de comportamento. O cálculo da contribuição da armadura por meio do efeito de pino pode ser melhor representado por expressões como as obtidas do estudo de chumbadores sujeitos à força transversal, ao invés da analogia ao comportamento de estacas cravada em solo sob ação de força transversal, segundo a Mecânica dos Solos, analogia esta que foi utilizada pelos citados autores.

A realização do programa experimental serviu, neste trabalho, para calibrar o programa computacional Tritor desenvolvido, incluindo os modelos numéricos implementados. Observou-se que a zona de envolvimento da armadura considerada influencia na resposta numérica de forma mais acentuada nas vigas não protendidas. Pôde-se observar, experimentalmente, que a torção é de fato muito pequena no comportamento geral e que a flexão lateral é predominante em virtude da baixa rigidez lateral das vigas esbeltas. O comportamento não-linear dos materiais considerados apresentou-se com resposta numérica satisfatória, como foi possível observar a partir das leituras obtidas com os extensômetros elétricos no concreto e nas armaduras. A utilização das Estações Totais para medição de deslocamentos mostrou ser uma boa alternativa especialmente para o ensaio em questão, que apresenta deslocamentos consideráveis nas 3 direções. A leitura das coordenadas de pontos no espaço foi realizada através da emissão de um raio laser visível para a medição da distância. Uma das principais vantagens do uso desse tipo de equipamento é a visibilidade do raio laser e a capacidade de medir a distância sem o uso de refletores, e portanto, sem a necessidade da inclusão de acessórios especiais e sem o contato com a viga. Também para os deslocamentos, a resposta numérica aproximou-se bem da resposta experimental.

A simulação numérica da fase de içamento através de apoios deformáveis mostrou ser uma ferramenta importante que permite o giro das seções por torção, de forma que a 
pequena inércia lateral gera grandes deslocamentos, podendo levar a uma situação onde não se verifica mais o equilíbrio.

A definição do comprimento dos balanços é muito importante uma vez que o mesmo pode criar um efeito estabilizante ou instabilizante no comportamento geral. Isto é fundamental em vigas protendidas. No caso de uma viga de concreto armado sem protensão e com altura constante, a situação mais favorável para a suspensão é a de balanços nos quartos do vão.

No caso de vigas protendidas, a suspensão com balanços é uma alternativa que pode gerar menores esforços solicitantes, dependendo do nível de protensão. Deve-se observar cuidadosamente o comprimento dos balanços de forma a aumentar a segurança da fase de içamento, em virtude do efeito do peso-próprio com relação à protensão, à medida em que o comprimento dos balanços aumenta. Além disto, as tensões na seção mais solicitada devem estar dentro dos limites de fissuração e de estabilidade.

Os fatores de segurança propostos por Mast (1993) dão uma idéia geral da influência dos balanços na fase de içamento, porém perdem o significado físico para grandes comprimentos de balanços.

Análises sob tombamento lateral gradual através de giros impostos nos apoios permitem observar o comportamento global da viga, levando-se em conta o aumento das deformações, desde a fissuração até o escoamento e a ruptura das armaduras. Observouse numericamente que a variação da rigidez à torção em função do nível de fissuração por flexão obtida através da implementação do modelo de Hannachi \& Fouré (1996), apresentou-se de forma satisfatória e dentro do comportamento esperado, chegando a apresentar $20 \%$ de redução desta rigidez devido à fissuração por flexão, no caso analisado da tesoura protendida.

Das análises numéricas com apoios deformáveis à torção, variando-se a excentricidade lateral inicial da viga, pôde-se obter a excentricidade limite para a qual encontrou-se numericamente uma posição de equilíbrio. Comparando-se este valor à excentricidade máxima permitida pela NBR9062/85 para execução do elemento pré-moldado, considerando ainda a tolerância devido ao posicionamento dos cabos de suspensão, pode-se ter uma medida da segurança durante o içamento.

No içamento com cabos inclinados, o ângulo de inclinação dos mesmos deve ser observado de forma a introduzir o mínimo possível de solicitações instabilizantes.

Enfim, deve-se procurar realizar o içamento pelos pontos mais favoráveis à estabilidade desta fase transitória, de forma a cobrir eventuais efeitos não incluidos no fator de segurança estimado, como por exemplo o vento e os efeitos dinâmicos naturais da fase de suspensão. 


\subsection{SUGESTÕES PARA TRABALHOS Futuros}

Do ponto de vista do comportamento geral, entende-se que a consideração da nãolinearidade geométrica torna a análise do problema da instabilidade lateral mais realista. Para ser implementada de forma consistente com relação à matriz de rigidez, além da parcela elástica, deve-se considerar a parcela devido à atualização das coordenadas e a parcela da rigidez geométrica, que é função do nível de solicitação axial das barras. Os esforços devem ser obtidos empregando-se as equações de equilíbrio na posição deslocada.

O modelo de Hannachi \& Fouré (1996) exige ainda alguns ajustes a fim de aumentar sua generalidade, uma vez que depende de parâmetros semi-empíricos. Além disto, o cálculo do centro de torção de uma seção fissurada por flexão é ainda um tópico que merece estudos e pesquisas.

Com relação a problemas de instabilidade lateral em fases transitórias, um exemplo interessante para a aplicação do modelo numérico de Cocchi \& Volpi (1996) é o de vigas balcão em fase pré-serviço, com chumbadores nas ligações de extremidade, levando-se em conta a deformabilidade dos mesmos. Porém, a escolha de algoritmos numéricos que viabilizem a convergência, bem como melhorem a sensibilidade do mesmo, deve ser considerada.

Com relação às fases transitórias, o estudo da segurança durante a fase de transporte em caminhões requer o cálculo da rigidez do conjunto da carroceria do caminhão e do sistema de travamento, bem como a consideração da superelevação da via de tráfego. $\mathrm{Na}$ análise numérica, a rigidez do sistema pode ser simulada por meio de elementos de mola ou apoios deformáveis, e a segunda, através de deslocamentos impostos nos apoios.

Finalmente, talvez de maior interesse, sugere-se o desenvolvimento de um programa experimental em laboratório para ensaio de vigas de concreto protendido, simulando um problema de instabilidade, com o objetivo de aprimorar os modelos numéricos e observar o comportamento geral do processo de perda de estabilidade. 


\title{
Capítulo
}

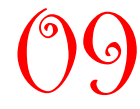

\author{
REFERÊNCIAS BIBLIOGRÁFICAS E \\ BIBLIOGRAFIA CONSULTADA
}

ASSOCIAÇÃO BRASILEIRA DA CONSTRUÇÃO INDUSTRIALIZADA (1986). Manual técnico de pré-fabricados de concreto. São Paulo, ABCI.

ASSOCIAÇÃO BRASILEIRA DE NORMAS TÉCNICAS (1985). NBR 9062 - Projeto e execução de estruturas de concreto pré-moldado. Rio de Janeiro, ABNT.

ASSOCIAÇÃO BRASILEIRA DE NORMAS TÉCNICAS (2001). NBR 6118 - Projeto de estruturas de concreto -Procedimento (projeto de revisão). Rio de Janeiro, ABNT.

ASSOCIAÇÃO BRASILEIRA DE NORMAS TÉCNICAS (2001). NBR 14724 Informação e documentação - Trabalhos acadêmicos - Apresentação. Rio de Janeiro, ABNT.

AYDIN, R.; KIRAÇ, N. (1998). Lateral buckling of reinforced concrete beams without lateral support. Structural Engineering and Mechanics, v.6, n.2, p.161-172.

BATHE, K. J., CIMENTO, A. P. (1980). Some practical procedures for the solution of nonlinear finite element equations. Computer Methods in Applied Mechanics and Engineering, v.22, p.59-85.

BHATT, P. (1999). Structures. Ed. Longman. Malásia. 597p.

BHATTI, M. A., ALMUGHRABI, A. (1996). Refined model to estimate torsional strength of reinforced concrete beams. ACI Structural Journal, v.93, n.5, p.614-622.

BISHARA, A. G.; LONDOT, L.; AU, P.; SASTRY, M. V. (1979). Flexural rotational capacity of spandrel beams. Journal of the Structural Division, ASCE, ST1, p.147-161. January.

BOER, A.; SCHAAFSMA, D. G. (1998). Rotation capacity of a reinforced prestressed concrete slender girder during lifting the girder. In: de Borst, Bićanić, Mang \& Meshke. Computational modeling of concrete structures, Galkema, Rotterdam, 1998. p.931937.

CANADIAN STANDARDS ASSOCIATION (1994). CAN3 A23.3-94 - Design of concrete structures. Toronto, ON, Canada, Rexdale. 199p.

CATANIA, M.; COCCHI, G. M. (1976). La stabilità dell'equilibrio di travi prefabbricate durante le fasi transitorie ed in presenza di imperfezioni ed errori costruttivi. In: 
CONGRESSO C.T.E. 1976 SULLA INDUSTRIALIZZAZIONE EDILIZIA, Siena, 12-14 novembre, 1976. Atti. Milano, ITEC/La Preffabbricazione. p.209-224.

CATANIA, M.; COCCHI, G. M. (1985). La stabilità nelle travi prefabbricate in regime transitorio e di esercizio. Milano, ITEC. 185p.

CHEN, W. F. (1982). Plasticity in reinforced concrete. Englewood Cliffs, EUA, McGraw-Hill. $474 \mathrm{p}$.

CLARKE, J. L.; GARAS, F. K.; ARMER, G. S. T. (1985). Design of concrete structures - The use of model analysis. London, Elsevier Applied Science. 379p.

COCCHI, G. M.; CAPPELLO, F. (1987). Sul calcolo delle ossature spaziali in regime non lineare. Giornale del Genio Civile 7, 8, 9.

COCCHI, G. M.; CAPPELLO, F. (1993). Inelastic analysis of reinforced concrete space frames influenced by axial, torsional and bending interaction. Computers \& Structures, v.46, n.1, p.83-87.

COCCHI, G. M.; VOLPI, M. (1996). Inelastic analysis of reinforced concrete beams subjected to combined torsion, flexural and axial loads. Computers \& Structures, v.61, n.3, p.470-494.

COLLINS, M. P.; LAMPERT, P. (1973). Redistribution of moments at cracking - the key to simpler torsion design. In: ANALYSIS OF STRUCTURAL SYSTEMS FOR TORSION. Detroit. ACI SP35-11. p.343-383.

COLLINS, M. P.; MITCHELL, D. (1980). Shear and Torsion Design of Prestressed and Non-Prestressed Concrete Beams. PCI Journal, p.32-100. Sept.-Oct.

COLLINS, M. P.; MITCHELL, D. (1997). Prestressed concrete structures. Canada, Response Publications, 766p.

CUNHA, J. C. (1994). Estabilidade de vigas protendidas e esbeltas durante o içamento e o transporte. In: REUNIÃO DO IBRACON, 36, Porto Alegre. Anais. v.1, p.299311.

EL-METWALLY, S. E.; EL-SHAHHAT, A. M.; CHEN, W. F. (1990). 3-D Nonlinear Analysis of R/C slender columns. Computers \& Structures. v.37, n.5, p.863-872.

ELLIOTT, K. (1997). Course on design of precast concrete structures. 108p. 26-27 Agosto, São Carlos, Departamento de Estruturas, Escola de Engenharia de São Carlos - USP.

FERNANDES, G. B. (1972). Torção em vigas de concreto. São Carlos. Dissertação (Mestrado). Escola de Engenharia de São Carlos - USP.

FERREIRA, M. A. (1993). Estudo de deformabilidades de ligações para análise linear em pórticos planos de elementos pré-moldados de concreto. São Carlos. Dissertação (Mestrado). Escola de Engenharia de São Carlos - USP.

FERREIRA, M. A. (1999). Deformabilidade de ligações viga-pilar de concreto pré-moldado. São 
Carlos. Tese (Doutorado). Escola de Engenharia de São Carlos - USP.

FIP PRACTICAL DESIGN OF STRUCTURAL CONCRETE (1999). Sept., 113p.

FOURÉ, B.; HANNACHI, N. E. (1999). Rigidité de torsion des poutres en béton armé fissurées en flexion. Revue Française de Génie Civil, v.3, n.2, p.115-154.

HANNACHI, N. E.; FOURÉ, B. (1996). Calcul de la rigidité de torsion des poutres en béton armé fissurées en flexion. Canadian Journal of Civil Engineering, v.23, n.6, p.11901198.

HSU, T. T. C. (1968). Torsion of Structural Concrete - Behavior of Reinforced Concrete Rectangular Members. ACI Journal, SP 18, p.261-306.

HSU, T. T. C. (1968a). Ultimate Torque of Reinforced Rectangular Beams. Journal of Structural Division - Proceedings of ASCE, p.485-510. February.

HSU, T. T. C. (1973). Post-cracking torsional rigidity of reinforced concrete sections. ACI Journal Proceedings, v.70, n.5, p.352-350. May.

HSU, T. T. C. (1984). Torsion of Reinforced Concrete. Von Nostrand Reinhold, 516p.

HSU, T. T. C.; MO, Y. L. (1985a). Softening of Concrete in Torsional Members Theory and Tests. ACI Journal, p.290-303, May-Jun.

HSU, T. T. C.; MO, Y. L. (1985b). Softening of Concrete in Torsional Members Design Recommendations. ACI Journal, p.443-452, Jul.-Ago.

HSU, T. T. C.; MO, Y. L. (1985c). Softening of Concrete in Torsional Members Prestressed Concrete. ACI Journal, p.603-615, Sept.-Oct.

HSU, T. T. C. (1988). Softened Truss Model Theory for Shear and Torsion. ACI Structural Journal, p.624-635, Nov.-Dec.

HSU, T. T. C. (1991). Nonlinear Analysis of Concrete Torsional Members. ACI Structural Journal, v.88, n.6, p.674-682.

HSU, T. T. C. (1996). Toward a unified nomenclature for reinforced-concrete theory. Journal of Structural Engineering, v.122, n.3, p.275-283, March.

HSU, T. T. C. (1998). Unified approach to shear analysis and design. Cement and Concrete Composites, v. 20, p.419-435.

IMPER, R. R.; LASZLO, G. (1987). Handling and shipping of long span bridge beams. PCI Journal, p.86-101, Nov.-Dec.

KARAYANNIS, C. G. (2000). Smeared crack analysis for plain concrete in torsion. Journal of Structural Engineering, ASCE, 126 (6), 638-645.

KARAYANNIS, C. G.; CHALIORIS, C. E. (2000). Experimental validation of smeared analysis for plain concrete in torsion. Journal of Structural Engineering, ASCE, 126 (6), 646-653. 
KONCZ, T. (1978). Manual de la construcción prefabricada. Tomo 2. H. Blume Ediciones. Rosario, 17. Madrid-5. 2 ed. p.56-62.

KOTSOVOS, M. D.; PAVLOVIC, M. N. (1995). Structural concrete - Finite-element analysis for limit-state design. Thomas Telford. 550p.

KRAUS, D.; EHRET K. -H. (1990). Lateral buckling and second order theory of reinforced and prestressed concrete girders. In: BICANIC, N.; MANG, H. eds. Computer aided analysis and design of concrete structures: Proc. 2nd Int. Conf., Austria, 1990. p.249-261.

LA NORMATIVA SUI PREFABBRICATI (1984). CNR-10025/84, ITEC - LA PREFABBRICAZIONE a cura della redazione e el C.T.E.

LAMPERT, P. (1973). Post-cracking stiffness of reinforced concrete beams in torsion and bending. In: ANALYSIS OF STRUCTURAL SYSTEMS FOR TORSION. Detroit. ACI SP35-12. p.385-433.

LEUNG, M. B. (1982). Inelastic Analysis of reinforced Concrete Beams Subjected to Combined Axial Force, Bending and Torsion. Thesis (Ph.D.), University of Illinois, Urbana, Ill., 205p.

LEUNG, M. B.; SCHNOBRICH, W. C. (1987). Reinforced concrete beams subjected to bending and torsion. ASCE Journal of Structural Engineering, v. 113, n.2, p. 307-321.

LIMA, J. S.; GUARDA, M. C.; PINHEIRO, L. M. (2000). Análise de torção em vigas de acordo com a nova NBR 6118. In: CONGRESSO BRASILEIRO DE CONCRETO - IBRACON, 2000. Fortaleza. Anais [CD ROM]. 16p.

LIMA, M. C. V. (1995). Instabilidade lateral das vigas pré-moldadas em serviço e durante a fase transitória. Dissertação (Mestrado). Escola de Engenharia de São Carlos - USP. 146p.

LIMA, M. C. V.; EL DEBS, M. K. (2000). Análise não-linear de um elemento de concreto armado sob ação conjunta de torção, flexão e força axial. In: IBERIAN LATIN AMERICAN CONGRESS ON COMPUTATIONAL METHODS IN ENGINEERING, 21 ${ }^{\text {st }}$, Rio de Janeiro. Anais [CD ROM]. 20p.

LIMA, M. C. V.; EL DEBS, M. K.; NETO, N. M. (2002). Instabilidade lateral em viga protendida - estudo de caso. In: XXX JORNADAS SULAMERICANAS DE ENGENHARIA ESTRUTURAL,2002. Brasília (Em fase de publicação). 15p.

MATILDI, P. et al. (1978). Problemi di statica delle strutture prefabbricate. Quaderni dei corsi di aggiornamento,. Milano, n.5, p.359-387.

MAST, R. F. (1989). Lateral stability of long prestressed concrete beams, Part 1. PCI Journal, p.34-53, Jan.-Feb.

MAST, R. F. (1993). Lateral stability of long prestressed concrete beams, Part 2. PCI Journal, p.70-88, Jan.-Feb.

MAST, R. F. (1994). Lateral bending test to destruction of a $149 \mathrm{ft}$ prestressed concrete 
I-beam. PCI Journal, v. 39, n. 4, p.54-62, Jul.-Aug.

MCGUIRE, W.; GALLAGHER, R. H.; ZIEMIAN R. D. (2000). Matrix Structural Analysis. John Wiley \& Sons. 460p.

MITCHELL, D. (1974). The behavior of structural concrete beams in pure torsion. Thesis (Ph.D.), University of Toronto, Toronto, ON, Canada. 140p.

MORI, D. D. (1988). Flexo-torção: Barras com seção transversal aberta e paredes delgadas. São Carlos, EESC-USP. 133p.

NARAYANAN, R. (1986). Concrete framed structures - Stability and strength. Elsevier Applied Science. 283p.

OJHA, S. K. (1974). Deformations of reinforced concrete rectangular beams under combined torsion, bending, and shear. ACI Journal Proceedings, v.71, n.8, p.383-391.

ONSONGO, W. M. (1978). The diagonal compression field theory for reinforced concrete beams subjected to combined torsion, flexure and axial load. Thesis (Ph.D.), University of Toronto, Toronto, ON, Canada. 246p.

PARK, R.; PAULAY, T. (1975). Reinforced concrete structures. Ed. John Wiley \& Sons. EUA. 769p.

PAULA, C. F. (2001). Contribuição ao estudo das respostas numéricas não-lineares estática e dinâmica de estruturas reticuladas planas. Tese (Doutorado). Escola de Engenharia de São Carlos - USP. 128p.

PEART, W.; RHOMBERG, E. J.; JAMES, R. W. (1992). Buckling of suspended cambered girders. Journal of Structural Engineering, ASCE, v.118, n.2, p.505-528.

PRESTRESSED CONCRETE INSTITUTE (1992). PCI design handbook. 4.ed.

RESHEIDAT, M.; GHANNA, M.; SUTTOON, C.; WAI-FAH CHEN. (1995). Flexural rigidity of biaxially loaded reinforced concrete rectangular column sections. Computers \& Structures, v.55, n.4, p.601-614.

RACHID, M. (1983). Instabilidade de barras de secção delgada. São Carlos, EESC-USP. 119p.

RACHID, M.; MORI, D. D. (1989). Instabilidade: conceitos - aplicação na flambagem por flexão. São Carlos, EESC-USP. 130p.

RACHID, M.; MORI, D. D. (1993). Instabilidade: flambagem de barras de seçãa delgada por torção e flexão. São Carlos, Escola de Engenharia de São Carlos - USP. 166p.

RAHAL, K. N (1993). The behavior of reinforced concrete beams subjected to combined shear and torsion. Thesis (Ph.D.), University of Toronto, Toronto, ON, Canada. 175p.

RAHAL, K. N.; COLLINS, M. P. (1995). Effect of thickness of concrete cover on shear-torsion interaction - an experimental investigation. ACI Structural Journal, v.92, n.3, p.334-342. 
RAHAL, K. N.; COLLINS, M. P. (1996). Simple model for predicting torsional strength of reinforced and prestressed concrete sections. ACI Structural Journal, v.93, n.6, p.658-666.

STRATFORD, T. J.; BURGOYNE, C. J.; TAYLOR, H. P. J. (1999). Stability design of long precast concrete beams. Proceedings of the Institution of Civil Engineers - Structures and Bridges, v.134, p.159-168.

STRATFORD, T. J.; BURGOYNE, C. J. (1999). Lateral stability of long precast concrete beams. Proceedings of the Institution of Civil Engineers - Structures and Bridges, v.134, p.169-180.

STRATFORD, T. J.; BURGOYNE, C. J. (2000). The toppling of hanging beams. International Journal of Solids and Structures, v.37, p.3569-3589.

STUCCHI, F. R. (1991). Torção composta em peças delgadas abertas de concreto armado. Tese (Doutorado). Escola Politécnica da Universidade de São Paulo. São Paulo, 2 vol., 913p.

SWANN, R. A.; GODDEN, W. G. (1966). The lateral buckling of concrete beams lifted by cables. The Structural Engineer, v.44, n.1, p.21-33.

SEXSMITH, R. G. (1998). Reliability during temporary erection phases. Engineering Structures, v.20, n.11, p.999-1003.

TWELMEIER, H.; BRANDMANN, D. (1984). Experimental investigations on the problem of lateral buckling of reinforced concrete beams. Design of concrete structures The use of model analysis. Elsevier Applied Science Publishers. p.208-217.

VECCHIO, F. J.; COLLINS, M. P. (1986). The modified compression-field theory for reinforced concrete elements subjected to shear. ACI Journal, p.219-231, Mar.-Apr.

VECCHIO, F. J.; COLLINS, M. P. (1988). Predicting the Response of Reinforced Concrete Beams Subjected to Shear Using Modified Compression Field Theory. ACI Structural Journal, p.258-268, May-Jun.

VECCHIO, F. J. (1989). Nonlinear finite element analysis of reinforced concrete membranes. ACI Structural Journal, p.26-35, Jan.-Feb.

YAMAMOTO, T. (1999). Nonlinear finite element analysis of transverse shear and torsional problems in reinforced concrete shells. Thesis (Master), University of Toronto, Toronto, ON, Canada. 112p.

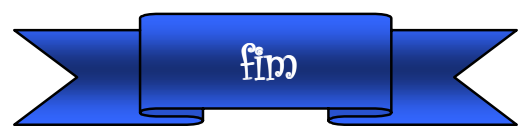

